University of Louisville

ThinkIR: The University of Louisville's Institutional Repository

Electronic Theses and Dissertations

8-2017

\title{
Engineering applications of organic surfactant modified bentonite in sorptive soil barriers.
}

Sadra Javadi

University of Louisville

Follow this and additional works at: https://ir.library.louisville.edu/etd

Part of the Environmental Engineering Commons, and the Geotechnical Engineering Commons

\section{Recommended Citation}

Javadi, Sadra, "Engineering applications of organic surfactant modified bentonite in sorptive soil barriers." (2017). Electronic Theses and Dissertations. Paper 2784.

https://doi.org/10.18297/etd/2784

This Doctoral Dissertation is brought to you for free and open access by ThinkIR: The University of Louisville's Institutional Repository. It has been accepted for inclusion in Electronic Theses and Dissertations by an authorized administrator of ThinkIR: The University of Louisville's Institutional Repository. This title appears here courtesy of the author, who has retained all other copyrights. For more information, please contact thinkir@louisville.edu. 


\title{
ENGINEERING APPLICATIONS OF ORGANIC SURFACTANT MODIFIED
} BENTONITE IN SORPTIVE SOIL BARRIERS

\author{
By \\ Sadra Javadi \\ B.S., University of Tabriz, 2009 \\ M.S., K. N. Toosi University of Technology, 2012
}

\begin{abstract}
A Dissertation
Submitted to the faculty of the

J. B. Speed School of Engineering of the University of Louisville

In Partial Fulfillment of the Requirements

for the Degree of

Doctor of Philosophy

In Civil and Environmental Engineering

Department of Civil and Environmental Engineering

University of Louisville

Louisville, Kentucky
\end{abstract}

August 2017 
Copyright 2017 by Sadra Javadi

All rights reserved 



\title{
ENGINEERING APPLICATIONS OF ORGANIC SURFACTANT MODIFIED
} BENTONITE IN SORPTIVE SOIL BARRIERS

\author{
By
}

\author{
Sadra Javadi \\ B.S., University of Tabriz, 2009 \\ M.S., K. N. Toosi University of Technology, 2012
}

A Dissertation Approved on

April 26, 2017

by the Following Committee:

Dr. Qian Zhao, Dissertation Director

Dr. J.P Mohsen

Dr. Thomas D. Rockaway

Dr. Xiao-An Fu 
To my beloved parents, Gholamreza Javadi and Nasrin Javadi For their unconditional love and relentless support 


\section{ACKNOWLEDGEMENTS}

I would like to extend my most sincere gratitude to all the people that contributed to this work and challenged me to accomplish the best through this path of knowledge. My first thanks go to my adviser Dr. Qian Zhao for his invaluable feedback and support during the completion of this dissertation. With his unwavering commitment and insightful guidance, he instigated in me his excitement for research and knowledge in the area of geotechnical engineering.

I am also very grateful to the head of the Department of Civil and Environmental Engineering, Dr. J. P. Mohsen for giving me this amazing opportunity and for always being there with kind and insatiable generosity.

I want to thank all my committee members, Dr. J. P. Mohsen, Dr. T. D. Rockaway, and Dr. X. A. Fu, for your advice and support during this project. I have great respect and admiration for each one of you and truly appreciate your participation in this project.

To my friends and colleagues Mohammad Ghavami, Hong Shang, Hamidreza Shabanzad, Nina Saraei and Milad Ebrahimi, I thank you for your friendship, help and moral support. Your presence was a great source of encouragement during this time. And I would like to thank my supportive, encouraging, and patient fiancée Asal. I would never come this far without you. 
Most importantly, I will always be eternally grateful to my family for their incessant support, love and encouragement throughout my academic career. I would not be the man I am without them and for that I will always be indebted.

Sadra Javadi

University of Louisville April 2017 


\begin{abstract}
ENGINEERING APPLICATIONS OF ORGANIC SURFACTANT MODIFIED BENTONITE IN SORPTIVE SOIL BARRIERS
\end{abstract}

\author{
Sadra Javadi
}

April 26, 2017

Earthen barriers such as CCLs and GCLs have been employed in geotechnical practices to provide a low permeability hydraulic barrier since long time ago. These types of barriers exhibited satisfactory performance for many applications such as landfills. The performance of low permeability barriers is based on the swelling potential of their component, which is mostly Na-bentonite, in contact with polar fluids such as water. However, the acceptable range of conductivity cannot be achieved by traditional earthen barriers when they are permeated by non-polar fluids such as gasoline. This phenomenon occurs due to the incompatibility of earthen barrier constituent with non-polar compounds. Also, the traditional earthen barriers are not able to retard the contaminant transport due to their negligible reactivity with organic compounds. As a result, the application of low permeability barriers was limited to polar and non-contaminated flows. In this study, the performance of traditional earthen barriers as a hydraulic and chemical 
barrier was enhanced by introducing an organically modified amendment (HDTMAbentonite) to traditional earthen barrier's components.

This study was undertaken to examine the sorption characteristics of partitioning organoclays and to evaluate their performances in soil-based barriers. The main goal of this study was to quantify the physicochemical properties of organobentonites for their applications in waste containment and site remediation.

It was observed that the intercalation of organic carbon on the surface of unmodified bentonites increased the organophilicity of sorbents. As a result, organic contaminants exhibited higher affinity toward modified bentonite. It was found that the organophilicity of organoclays increased either by increasing the chain length or number of chains. Consequently, PM-199 exhibited higher sorptivity compared to HDTMA-bentonite because it was synthesized by a double chain surfactant. The effect of grain size on the sorption capacity of organobentonites was also studied. The obtained results suggested no significant difference in sorption capacity of powder PM-199 and granular PM-199.

In addition, the effect of chlorination, and aromatic ring on sorptivity of sorbent was studied. It was observed that the solubility of organic compounds decreased by increasing the chlorinated positions on the aromatic ring. As a result, organophilicity of the organic contaminants increased as chlorination and the number of aromatic rings increased. The affinity of organic contaminants toward the organic phase of sorbents increased which resulted in higher partitioning toward HDTMA-bentonite.

When the effects of co-solvent on the sorptivity of sorbents was examined, it was observed that the Cosolvency of non-polar solvents resulted in higher solubility of 
organic contaminants in the solution which reduced their affinity toward HDTMAbentonite. Also, the effect of temperature on the sorption capacity of HDTMA-bentonite was studied. The obtained results indicated that the increase in temperature resulted in higher level of kinetic energy in the solution which facilitate the partitioning of benzene toward HDTMA-bentonite.

The feasibility of using the HDTMA-bentonite as an amendment in compacted clay liners was evaluated by conducting a soil column experiment. The obtained results from swelling experiment suggested that unmodified bentonites have higher swelling tendency in polar liquids while modified bentonites have higher swelling capacity in non-polar liquids. As a result, the permeability of the silty clay column was enhanced with unmodified bentonite when it was permeated by polar solution. On the other hand, the permeability of silty clay column was enhanced with modified bentonite when it was permeated by non-polar solutions. Additionally, it was observed that only 5\% HDTMAbentonite amendment enhanced the retardation capacity of the system while it had no significant effect on the permeability of the compacted silty clay. The obtained results suggested that a small percentage of HDTMA-bentonite can reduce the mass flux of contaminant by $90 \%$ which suggested that HDTMA-bentonite has a promising performance as reactive material for Compacted liner barrier for organic and/or low polarity fluids.

Additionally, the feasibility of using HDTMA-bentonite as a reactive amendment for GCL liners were investigated. The swelling behavior of unmodified and modified bentonites were studied as a function of: polarity, ion strength, acidic/basic environment. It was observed that unmodified bentonites had higher swelling tendency in polar liquids 
while modified bentonites swelled significantly in non-polar liquids. $\mathrm{pH}$ and low ionic strength $(<0.01 \mathrm{M})$ did not affect the swelling behavior of studied sorbents. However, the swelling of unmodified bentonites decreased drastically in solutions with higher ionic strength.

The permeability of GCL specimens with different percentage of HDTMA-bentonite permeated by polar and low polarity solutions were studied. It was observed that the permeability of GCL specimens to polar solutions increased by increasing the percentage of HDMA-bentonite in GCL soil. However, the permeability of GCL specimens to low polarity solutions decreased by increasing the percentage of HDMA-bentonite in GCL soil. Also, it was found that a small percentage of PM-199 amendment can provide the minimum permeability for GCL specimens permeated by both polar and non-polar liquids. It was observed that the permeability of GCL specimens increases by increasing the confining stress.

In addition, the breakthrough test was carried out to study the transport mechanism of benzene solution through the GCL specimens. The results suggested that $20 \%$ of HDTMA-bentonite enhanced the sorptivity and retardation of the GCL barriers significantly; however, it did not affect the permeability of the liner system. The numerical and analytical approaches were used to estimate the transport parameters of benzene by using experimental results.

Finally, the potential application of HDTMA-bentonite as a reactive component of fast flow rate barriers were evaluated. The acquired results suggested that the retardation capacity of HDTMA-bentonite increased by decreasing the seepage velocity of the column. In addition, the kinetic study and analytical approaches were employed to obtain 
the retardation factor of the soil columns at non-equilibrium condition. It was noticed that both methods resulted in a similar value within an acceptable range of error. This result suggested that the non-equilibrium partitioning coefficient measured from kinetic study can be employed to calculate a reliable retardation factor in non-equilibrium condition. The overall results suggested that HDTMA-bentonite can serve as an efficient reactive material in PRBs which not only increased the retardation capacity of the fast flow rate columns, but also did not affect the seepage velocity of the system with fast seepage velocity. 


\section{TABLE OF CONTENTS}

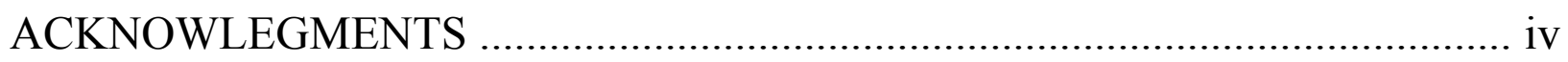

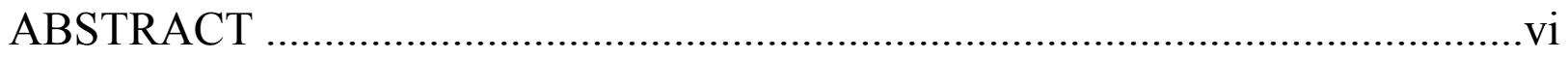

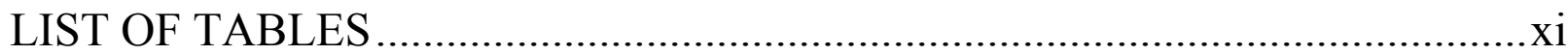

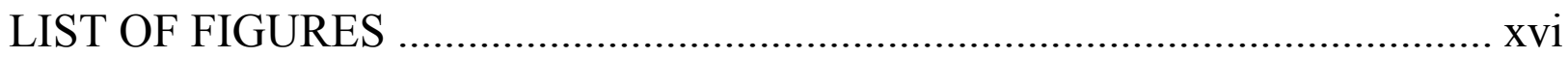

1. Chapter One. Introduction ...................................................................... 1

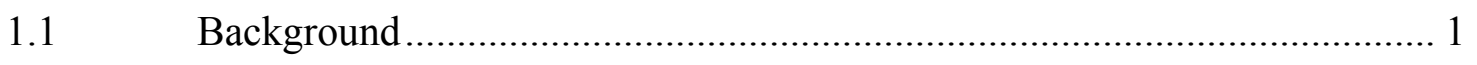

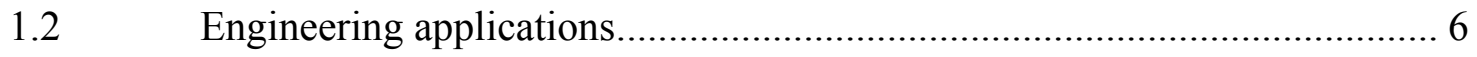

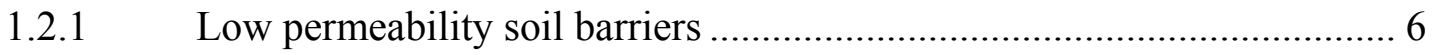

1.2.2 Fast flow rate barrier systems ………………................................... 10

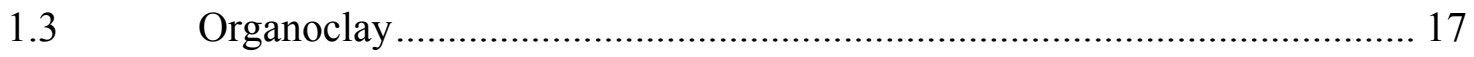

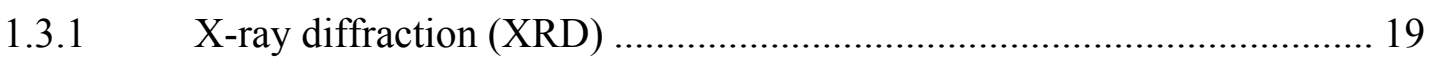

1.3.2 Scanning electron microscope (SEM) ................................................. 20

1.3.3 Total organic carbon analyzer (TOC) ……………………………...... 20

$1.4 \quad$ Geotechnical testing and engineering properties of soils .......................... 21

$1.5 \quad$ Current application of organoclays .......................................................... 21

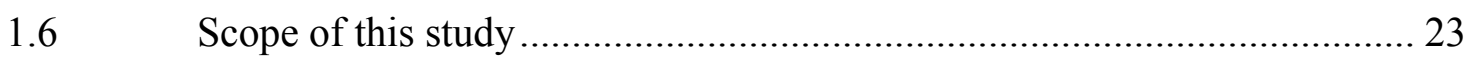

2. Chapter two. Sorption of organic contaminants onto organoclays ............25

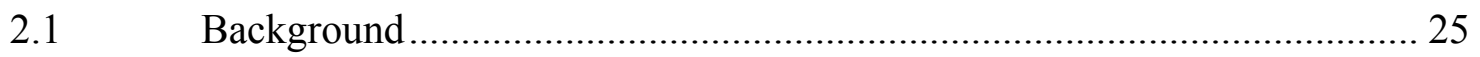

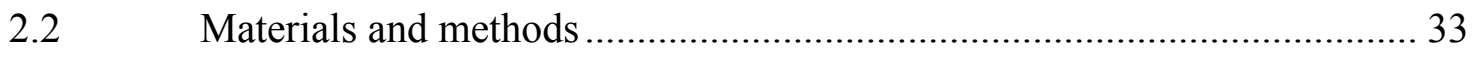

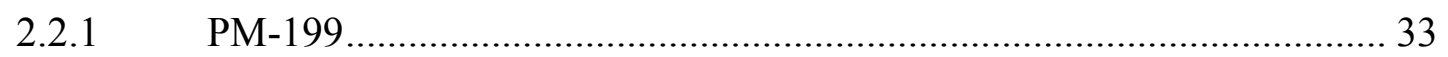

2.2.2 HDTMA modified bentonite ............................................................. 34

2.2.3 Organic sorbates ......................................................................... 38

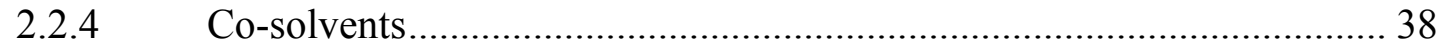

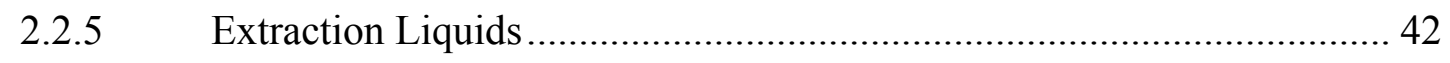

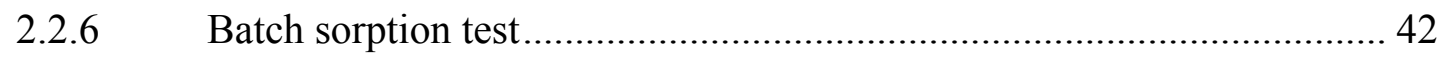

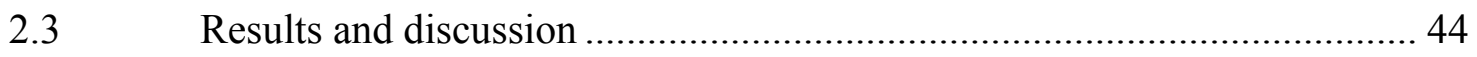




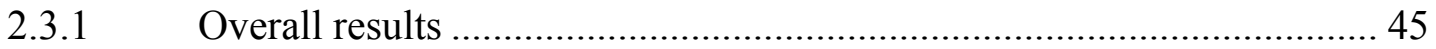

2.3.2 Effect of molecular characteristics of sorbents on sorption capacity...... 46

2.3.3 Effect of the characteristics of sorbates on sorption capacity ................. 50

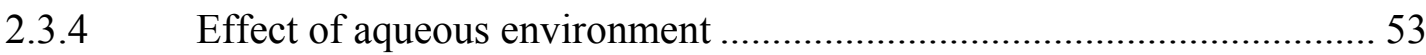

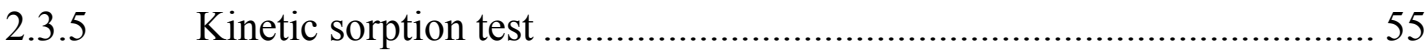

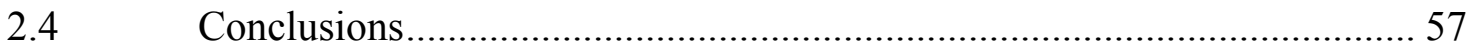

3. Chapter three. Engineering behaviors of compacted clay amended with Organoclays

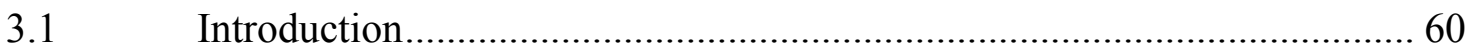

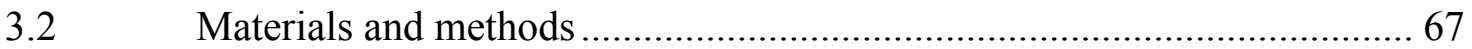

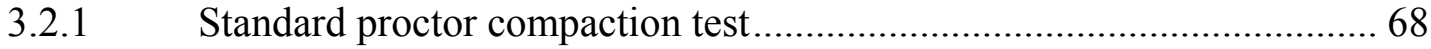

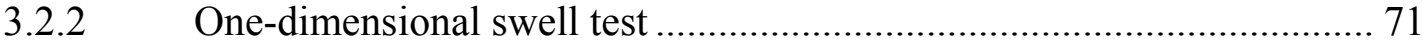

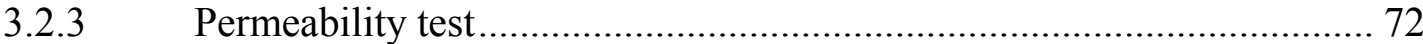

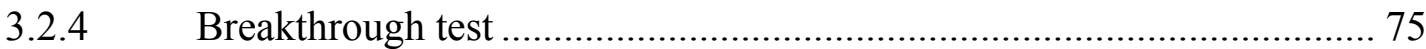

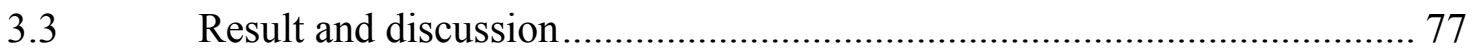

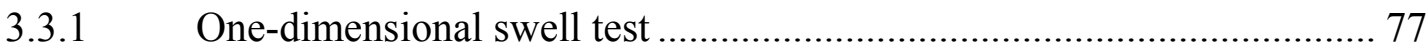

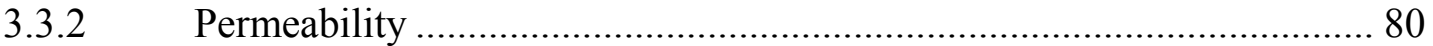

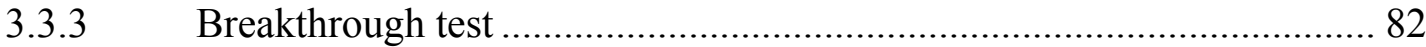

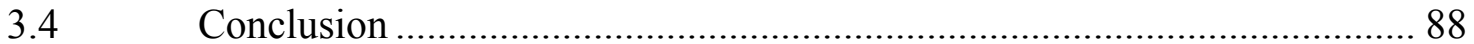

4. Chapter four. Engineering behaviors of geosynthetic clay liners (GCLs) amended with organoclays ................................................................ 90

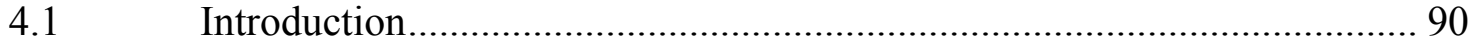

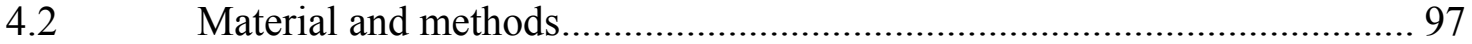

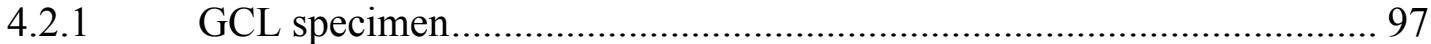

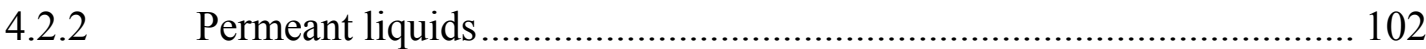

4.2.3 Swell index test of GCL soil components ........................................ 102

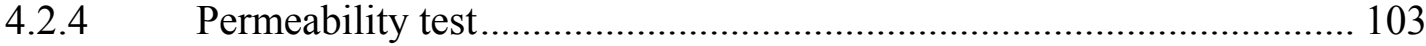

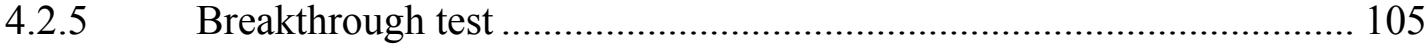

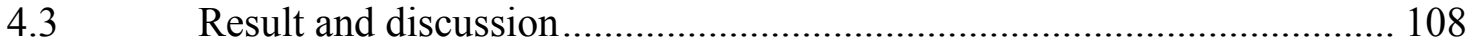

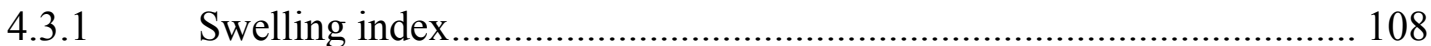

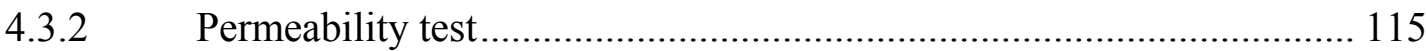

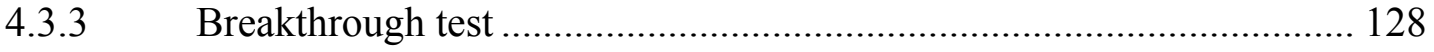


4.4 Conclusion 136

5. Chapter Five. Non-equilibrium sorption and retardation of organic contaminants in permeable reactive barriers (PRBs) amended with organoclays .

5.1

Introduction..... 141

5.2

Materials and methods 147

5.2.1 Column preparation..... 149

5.2.2 Hydraulic conductivity test 150

5.2.3 Breakthrough test 151

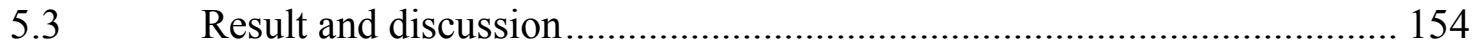

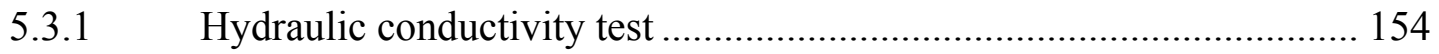

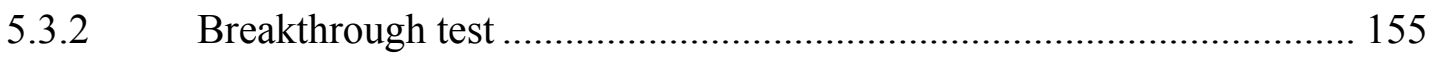

5.3.3 Effect of seepage velocity on the retrieved percentage of benzene mass in effluent 163

5.4 Conclusion 164

6. CHAPTER SIX Summary, Conclusions, and Recommendations 166 REFERENCES 174

CURRICULUM VITAE. 187 


\section{LIST OF TABLES}

Table 1-1. Summary of hydraulic conductivity for different amendments ...................... 5

Table 1-2. Conducted laboratory tests to evaluate the engineering properties of soils .... 21

Table 2-1. Linear models of Langmuir sorption isotherm............................................. 28

Table 2-2. Mineralogy of PM-199 (Lee et al. 2012) .................................................... 34

Table 2-3. The engineering properties of Ca-bentonite, Na-bentonite, and HDTMA

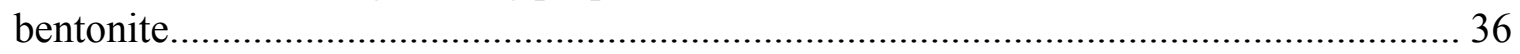

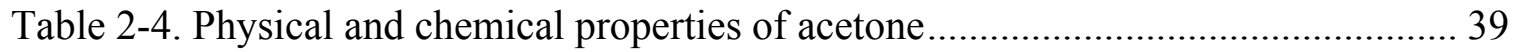

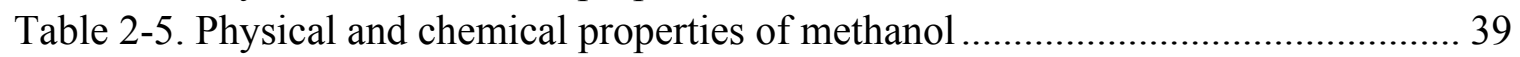

Table 2-6. Physical and chemical properties of the studied contaminants ...................... 40

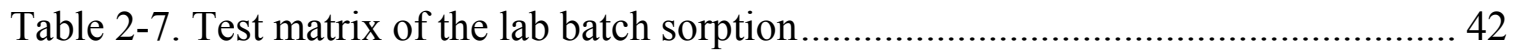

Table 2-8. Sorption kinetics and equilibrium sorption parameters ............................... 57

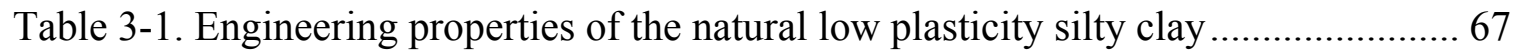

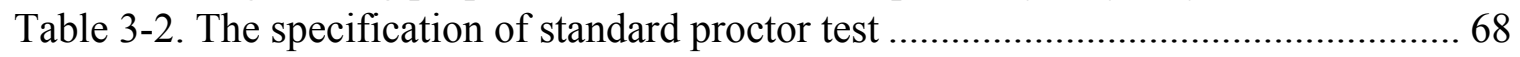

Table 3-3. Compaction test results ............................................................................. 71

Table 3-4. Physicochemical properties of the permeant fluids..................................... 74

Table 3-5. Specification of compacted soil column ..................................................... 75

Table 3-6. Average fluid conductivities of three compacted soils with varying permeants

Table 3-7. Summary of contaminant transport parameters for fast and slow flow rate

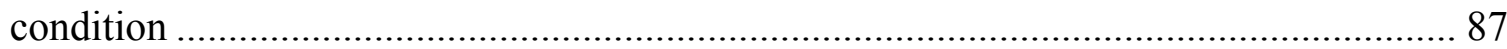

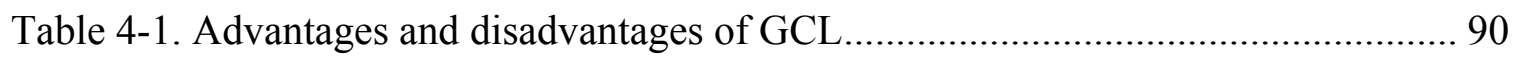

Table 4-2. Properties of Bentomat 200R ....................................................................... 98

Table 4-3. The physical parameters of calcium based GCL specimens ........................ 101

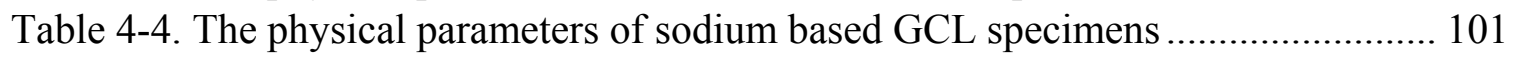

Table 4-5. Physical properties of GCL specimens for permeability study ..................... 103

Table 4-6. Swelling ratio of studied GCL specimens ................................................ 114

Table 4-7. Average conductivity of studied GCL specimens permeated by different

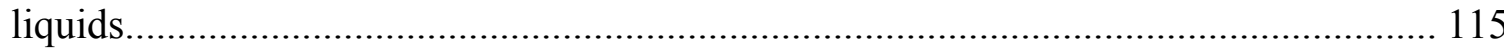

Table 4-8. The average permittivity of GCL specimens ......................................... 121

Table 4-9. Retardation factor and diffusion coefficients for six GCL specimens obtained from analytical and numerical methods and the first-moment equation ...................... 134

Table 5-1. Common treatment medium and targeted contaminants in PRBs................ 142

Table 5-2. Advantages and disadvantages of PRB system (Obiri-Nyarko et al. 2014).. 144

Table 5-3. physical properties of the coarse and fine sand ........................................... 148

Table 5-4. Properties of packed columns............................................................... 149 
Table 5-5. The measured hydraulic conductivity ................................................... 154

Table 5-6. Required time for seepage of benzene solution through the soil columns .... 158 Table 5-7. Non-equilibrium partitioning coefficient of HDTMA-bentonite for benzene 160

Table 5-8. Retardation factor and diffusion coefficients for seven soil columns obtained from analytical and numerical methods and the first-moment equation ....................... 162 Table 6-1. Results for equilibrium batch sorption study ........................................ 167 


\section{LIST OF FIGURES}

Figure 1-1. Schematic figure of bottom barrier system (a) single composite liner (b)

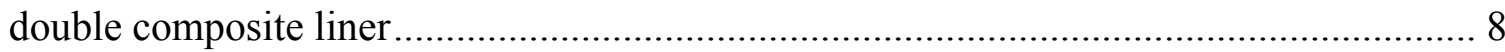

Figure 1-2. Schematic figure of cover system for buried waste ................................... 8

Figure 1-3. Schematic setup of USTs with barrier systems (Musy 2008)....................... 9

Figure 1-4. Schematic permeable reactive barrier system (Australia. 2012)................... 10

Figure 1-5. Low flow rate breakthrough curve for different type of solute injection....... 14

Figure 1-6. The effect of partitioning coefficient on the retardation of contaminant transport (Freeze and Cherry 1979) ............................................................................. 16

Figure 1-7. (a) the relative concentration of contaminant versus time (b) contaminant

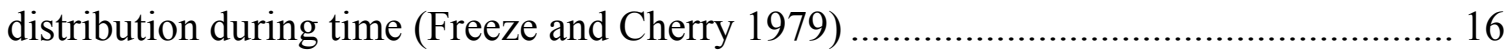
Figure 1-8. microstructure of (a) calcium bentonite (b) HDTMA-bentonite .................. 18 Figure 1-9. Different microstructure morphology of organoclays (Giannelis et al. 1999)19

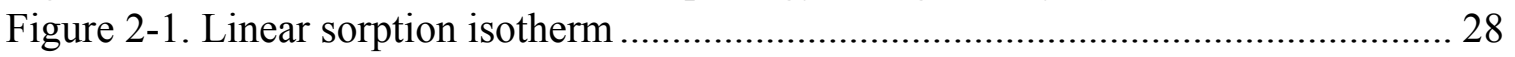

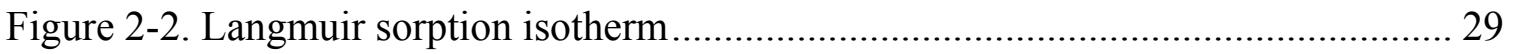

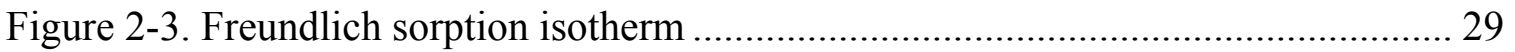

Figure 2-4. Effective factors in the sorption process of sorbates by sorbent................... 30

Figure 2-5. XRD result for Ca-bentonite and HDTMA-bentonite ................................ 37

Figure 2-6. (a) Scanning Electron Microscope (SEM) and Transmission electron microscopy (TEM) test of Ca-bentonite (b) Scanning Electron Microscope (SEM) and Transmission electron microscopy (TEM) test of calcium bentonite HDTMA-bentonite 38 Figure 2-7. Schematic figure of the sorption procedure ........................................... 44

Figure 2-8. Effect of TOC on the partitioning coefficient ........................................... 47 Figure 2-9. Sorption capacity of PM-199 and HDTMA-bentonite as a function of organic cation types for (a) benzene in aqueous solution, and (b) HCB in $30 \%$ acetone $+70 \%$ DI

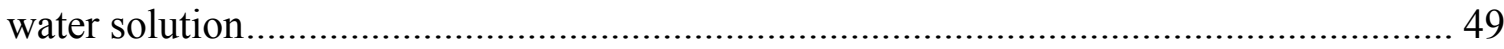

Figure 2-10. Effect of particle size on the sorption capacity of PM-199....................... 50

Figure 2-11. Chlorination effect on the sorption capacity of HDTMA-bentonite............ 51 Figure 2-12. Aromatic benzene ring effect on the sorption capacity of HDTMA-bentonite

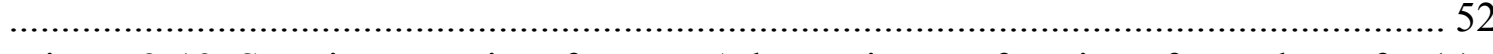

Figure 2-13. Sorption capacity of HDTMA-bentonite as a function of co-solvent for (a) benzene, and (b) naphthalene. 54

Figure 2-14. Effect of temperature variation on the sorption capacity of HDTMA-

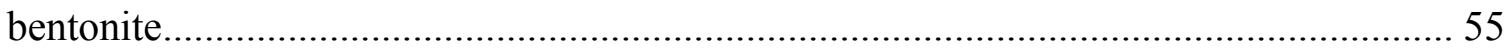

Figure 2-15. Sorption kinetic of (a) naphthalene (b) benzene on HDTMA-bentonite ..... 56 
Figure 3-1. Recommended design criteria for the compaction of CCLs (Sharma and

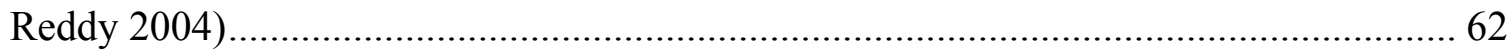

Figure 3-2. Acceptable range of water content and dry unit weight for CCLs (Sharma and

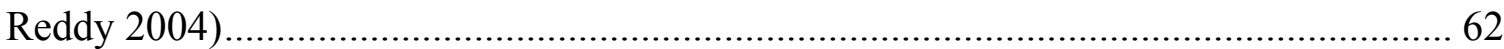

Figure 3-3. Contaminant transport through (a) conventional CCL (b) reactive geo-

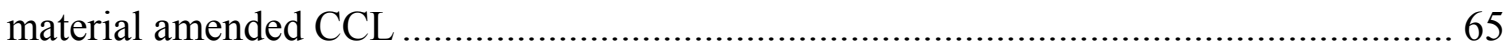
Figure 3-4. (a) Compaction of soil layer (b) Extruded soil from compaction mold......... 69 Figure 3-5. Compaction curve for the studied soil admixtures........................................ 71

Figure 3-6. (a) Soil column arrangement for hydraulic conductivity (b) Sealed soil

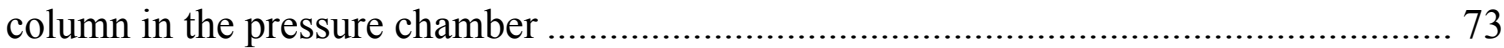

Figure 3-7. Experimental setup for breakthrough test .................................................. 77

Figure 3-8. Free swelling results for the three studied soil admixture in (a) water (b) gasoline 78

Figure 3-9. equilibrium sorption isotherms of naphthalene onto HDTMA-bentonite/silty clay.....

Figure 3-10. Average seepage velocity of naphthalene solution during the breakthrough study.....

Figure 3-11. Breakthrough curve of naphthalene transport in $95 \%$ silty clay $+5 \%$ HDTMA-bentonite compacted soil column 84

Figure 4-1. Variation of hydraulic conductivity with different confining stress (Bouazza 2002) 92

Figure 4-2. effect of hydraulic gradient on the conductivity of a GCL permeated with

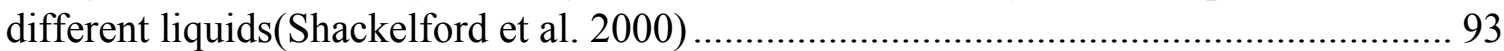

Figure 4-3. The base GCL, Bentomat 200R ………….............................................. 98

Figure 4-4. Carved GCL specimen from the base GCL …………………………....... 99

Figure 4-5. Filling the soil mixture in the GCL specimen............................................... 99

Figure 4-6. Assembled GCL specimen for column test................................................. 100

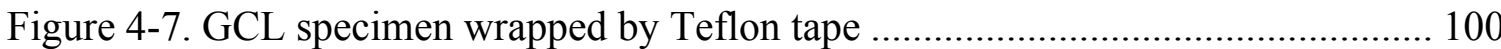

Figure 4-8. Swell index result for studied soil matrixes ................................................. 109

Figure 4-9. Swell index experiment for three studied soil specimens in gasoline........... 111

Figure 4-10. The effect of ionic concentration on the swelling tendency of the proposed

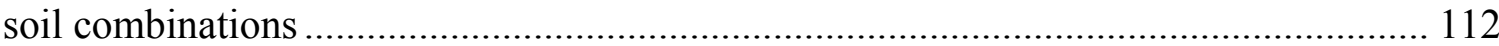

Figure 4-11. Effect of $\mathrm{pH}$ on the swelling of studied sorbents .................................... 113 Figure 4-12. Effect of $\mathrm{pH}$ on the swelling volume of the Na-bentonite mixture with PM199 and HDTMA-bentonite

Figure 4-13. Permeability of Na-bentonite GCL specimens with different percentages of

(a) PM-199 (b) HDTMA-bentonite permeated by water and gasoline 119

Figure 4-14. Effect of confining stress on the hydraulic conductivity of Na-amended GCLs

Figure 4-15. Measured hydraulic conductivity during breakthrough test for GCL with (a)

Ca-bentonite (b) 10\% HDTMA-bentonite $+90 \%$ Ca-bentonite (c) 20\% HDTMAbentonite $+80 \%$ Ca-bentonite (d) Na-bentonite (e) 10\% HDTMA-bentonite $+90 \% \mathrm{Na}$ bentonite (f) $20 \%$ HDTMA-bentonite $+80 \%$ Na-bentonite 
Figure 4-16. Average seepage velocity of GCLs with (a) Ca-bentonite (b) 10\% HDTMAbentonite $+90 \%$ Ca-bentonite (c) 20\% HDTMA-bentonite $+80 \%$ Ca-bentonite (d) Nabentonite amended GCL (e) 10\% HDTMA-bentonite $+90 \%$ Na-bentonite (f) $20 \%$ HDTMA-bentonite $+80 \%$ Na-bentonite 128

Figure 4-17. Benzene breakthrough curves through (a) Ca-bentonite based (b) Nabentonite based GCL specimens without/with HDTMA-bentonite 130 Figure 4-18. Fitted curve applying numerical and analytical solution for (a) Ca-bentonite GCL (b) Ca-bentonite GCL with 10\% HDTMA-bentonite amendment (c) Ca-bentonite GCL with 20\% HDTMA-bentonite amendment (d) Na-bentonite GCL (e) Na-bentonite

GCL with 10\% HDTMA-bentonite amendment (f) Na-bentonite GCL with $20 \%$

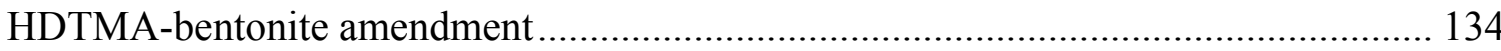

Figure 5-1. Schematic figure of PRB system (DOE-sites 1999) ………….................... 142

Figure 5-2. grain size distribution curve for coarse and fine sand................................. 148

Figure 5-3. Hydraulic conductivity test setup with constant head.................................. 151

Figure 5-4. Schematic setup of breakthrough test .................................................... 153

Figure 5-5. Breakthrough curve of benzene transport in column with (a) 10\% HDTMAbentonite amendment (b) 10\% PM-199 amendment .............................................. 157

Figure 5-6. partitioning coefficient of HDTMA-bentonite for benzene as a function of time 159

Figure 5-7. Fitted curve applying analytical solution for column (a) 1 (b) 2 (c) 3 (d) 4162 Figure 5-8. Rmass versus seepage velocity 163 


\section{CHAPTER ONE INTRODUCTION}

\subsection{Background}

The increasing growth of population in all over the world (near to 70 million growth of population is expected for United States by 2045 (USDOT 2015)) increases the demand of waste containment, contaminated site remediation and sustainable development (Sharma and Reddy 2004). Inappropriate waste disposal practices in the past has caused the contamination of subsurface and groundwater with a variety of environmental pollutants (Gates et al. 2009). These contaminants are detrimental to public health and the environment and lead to costly remediation actions. At the same time, although the land disposal technologies have been developed significant, new materials and improved containment systems still merit examination.

Up until the early 1970s, chemicals used in industrial and municipal activities and their byproducts were disposed without much consideration of their transport and fate in the subsurface, as well as their impact on the human health and the ecosystem. At the time, the collected solid waste was piled up in an open area on the ground surface or they were disposed in the open ditches or pits. Due to the absence of legislation and environmental laws to control this practice, these areas lacked appropriate liner systems, which led to contamination of the surrounding soil. 
Records indicated that in the past many coal mining piled up coarse tailing and the wastewater in an impoundment for a long period of time. The contaminants infiltrated into the subsurface and reached to the groundwater table. There are also several reports from army bases that have stored toxic chemical waste in unlined pits which led to the contamination of surrounding groundwater (Lo and Yang 2001). In early 1970s, impermeable caps were constructed over the pits or impoundments to minimize the percolation. However, it was until 1980's that the engineers started to build bottom barriers for landfills and surface impoundments (Sharma and Reddy 2004). Many old underground storage tanks (USTs) have been used to store chemicals and fuels. USEPA estimated that up until 1995 , over 400000 sites had been polluted by leakage from underground storage tanks. This led to a remedial operation that cost over $\$ 4$ million dollars.

There are many other examples in addition to the mentioned case studies, which confirm the necessity of using barrier systems in containment facilities. Additionally, for the remediation of the existing soil/groundwater contaminations, a short-term in-situ barrier system is often required to prevent the spreading of contaminants and also to facilitate the following remediation (Lee et al. 2012). Other long-term in-situ or ex-situ environmental geotechnics may apply in conjunction with short-term containment technologies (Sharma and Reddy 2004).

A waste containment facility can be categorized as either a passive system or an active system. Passive system includes the installation of physical low permeable barriers around the contaminated site. The purpose of passive system is to isolate the potential sources of contamination or contaminated site and minimize the possibility of 
contaminant spreading to the surrounding environment. Passive system can be used in vadose or saturated zone and includes one or combination of the following barrier types: (1) vertical barriers to limit the lateral spread of contaminants; (2) bottom barriers to prevent the vertical spread of contaminants such as bottom liner for storage tanks and landfills; or (3) cover barrier to isolate the stored waste and minimize the infiltration of surface water to the system such as landfills. An active containment system includes the installation of either pumping well or subsurface drain systems to adjust the hydraulic gradient with the purpose of containing groundwater contaminants. In some scenarios, a combination of active and passive system may be used in order to contain the contaminant plume carried by groundwater flow. Although a passive containment system can be incorporated into an active remediation system, this dissertation is focused on the in-situ containment practices and the performances of soil-based barriers as a part of a passive containment system.

\section{Vertical barriers}

Vertical barriers are also known as vertical cutoff barriers or vertical cutoff walls. The function of vertical barriers is to contain the contaminated soils/groundwater or block the lateral contaminant flow in subsurface. They can build on the top of a bottom barrier system or extend to a low permeability barrier systems. Most commonly, vertical barriers are used in combination with pump and treat method. The vertical barriers are constructed in different types such as: (1) compacted clay barriers; (2) slurry trench barriers; (3) grouted barriers; (4) mixed-in -place barriers, and (5) steel sheet pile barriers.

One of the most common type of vertical barriers is compacted clay barriers. Compacted clay barriers are constructed by compacting silty or clayey materials on subgrade soil or 
in a trench to construct a liner with a high dry unit weight. The moisture content and the type of compaction effort should be controlled to provide a soil barrier with the lowest permeability $\left(\mathrm{k} \leq 10^{-7} \mathrm{~cm} / \mathrm{s}\right)$. The most suitable application of compacted clay barriers is in aquitard layer with shallow depth.

\section{Bottom barriers}

Typically, bottom barriers are used to contain the waste site when there is no natural stratum with low permeability available at a reasonable depth. Their function is to minimize the diffusive and advective transport of contaminants into the subsurface layers as much as possible. Different techniques can be applied to construct a bottom barriers including grouting or a combination of different methods like tunneling and geomembrane installment, and a mixture of grout with slurry.

\section{Covers or caps}

Cover barriers are commonly constructed over a buried waste such as landfills to prevent the infiltration of liquid or gases and minimize the leachate generation. Cover barriers are consisted of six major components: (1) surface layer; (2) protection layer; (3) drainage layer; (4) hydraulic barrier layer; (5) gas collection layer; and (6) foundation layer, a detailed sketch of typical landfill cover system can be found in part 1.2.1 (Figure 1-2).

The conclusion of different studies in many cases has confirmed that the compaction of local soils does not provide the sufficient permeability requirements for low permeability barrier systems (Bagchi 2004). For instance, a layer of silty soil from Chaco - Pampean plain in the center and north- east of Argentina could reach to the average hydraulic conductivity of $10^{-8} \mathrm{~m} / \mathrm{s}$ after the heavy compaction effort (Francisca and Glatstein 2010). 
Thus, it is necessary to use amendments combined with local soils to make them useful for liner system.

During the past decade, many researches have been done to evaluate the feasibility of using various amendments to meet the required permeability for low permeability barrier systems. A list of different amendments used in liner system is summarized in Table 1-1 (Widomski et al. 2015). Among the tested geo-materials, bentonite demonstrated a promising performance regarding the permeability for the liner application. Bentonite is defined as a natural clay with high swelling tendency, high ion exchange capacity and very low water permeability. Other significant characteristics of bentonite are high percentage of montmorillonite (60-90\%), high water absorption capacity (200-700\% weight), high swelling potential(7-30 mL), high range of plasticity (140-380\%), and cation exchange capacity of $(0.60-0.90 \mathrm{~mol} / \mathrm{kg})$ (Egloffstein 2001). Consequently, bentonite-clay barriers have served as the containment systems for a long time.

Table 1-1. Summary of hydraulic conductivity for different amendments

\begin{tabular}{ccc}
\hline Material & $\begin{array}{c}\text { Minimum hydraulic } \\
\text { conductivity }(\mathrm{m} / \mathrm{s})\end{array}$ & Sources \\
\hline Fly ash & $3.1 \times 10^{-10}$ & $\begin{array}{c}\text { Palmer et al. (2000) } \\
\text { Wiśniewska and Stępniewski }\end{array}$ \\
Quicklime & $1.0 \times 10^{-10}$ & (2007) \\
Silica fume & $9.03 \times 10^{-10}$ & Kalkan and Akbulut (2004) \\
Cement & $8.53 \times 10^{-10}$ & Kalkan (2006) \\
Claystone & $5.34 \times 10^{-12}$ & Musso et al. (2010) \\
Red mud & $3.73 \times 10^{-10}$ & Kalkan (2006) \\
Bentonite & $1.0 \times 10^{-11}$ to $5.4 \times 10^{-12}$ & Komine (2010)\&Ahn and Jo \\
\hline
\end{tabular}

Although different types of barriers can be used individually as the bottom barrier systems, compacted clay liners are frequently used in combination with other geosynthetic materials; such as geomembrane; as a composite liner system. In addition, 
recent developments in geosynthetics area make it possible to use geosynthetic clay liners (GCLs) as a substitution for compacted clay liners due to their low permeability and cost efficiency.

\subsection{Engineering applications}

Most commonly, the barrier systems in waste containment facilities are employed to serve as low permeability barrier systems, or fast flow rate barrier systems.

\subsubsection{Low permeability soil barriers}

Many waste containment systems are required to have one or several low permeability hydraulic barriers. The liner system is typically a combination of engineered soils and geosynthetic materials and these composite liners must provide a hydraulic conductivity less than $10^{-7} \mathrm{~cm} / \mathrm{s}$ as bottom barriers and $10^{-5} \mathrm{~cm} / \mathrm{s}$ as cover barrier. They are frequently used for landfills and underground storage tanks (USTs). the typically layout of the composite barrier or soil barriers are briefly introduced next:

1. Landfill:

Landfill is the primary containment practice in the United States to dispose the municipal solid waste (MSW). Landfills are categorized to sanitary and secure landfills. Sanitary landfills are employed for disposal of non-hazardous waste while secure landfills are used to dispose the hazardous waste. Hazardous waste is buried in excavated holes or trenches which are lined with barrier systems to minimize the leakage of hazardous substances into the soil and water bodies. The Resource Conservation and Recovery Act (RCRA) in 1976 provided guidelines regarding the management of hazardous, non-hazardous wastes 
and underground storage tanks. In conclusion, a comprehensive regulation has been developed by USEPA under two major subtitles: subtitle C, and Subtitle D.

Subtitle $\mathrm{C}$ provides the minimum requirements for proper management and disposal practices of hazardous wastes. Based on subtitle $\mathrm{C}$, a landfill used for disposal of hazardous wastes should have a leachate collection system, a top flexible membrane liner, a system to collect, detect, and remove the leachate, and a composite liner system. Also, it is required to cover the landfills that are used for hazardous waste disposal with a final cover which minimize the long-term diffusion of liquids through the landfill. The cover system should have a permeability value equal or less than the permeability of bottom liners. A schematic arrangement of bottom liner legislated by subtitle $\mathrm{C}$ is presented in Figure 1-1 (b), and Figure 1-2.

Subtitle D provides the guidelines to manage the municipal solid wastes. It is required by subtitle D to employ a leachate collection system and a composite liner system which consisted of a compacted clay liner and flexible membrane liner for a landfill used for non-hazardous wastes. A schematic arrangement of bottom liner legislated by subtitle D is presented in Figure 1-1 (a).

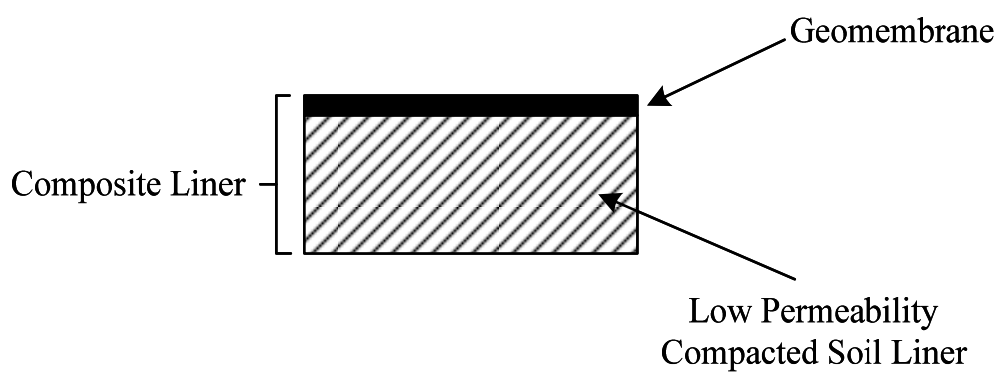

(a) 


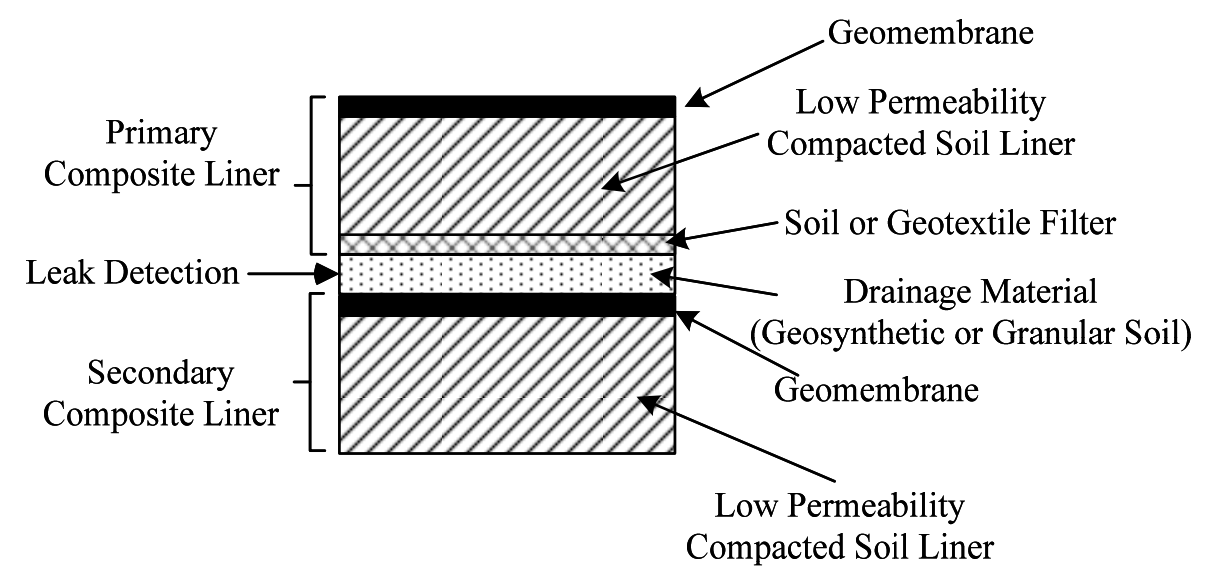

(b)

Figure 1-1. Schematic figure of bottom barrier system (a) single composite liner (b) double composite liner

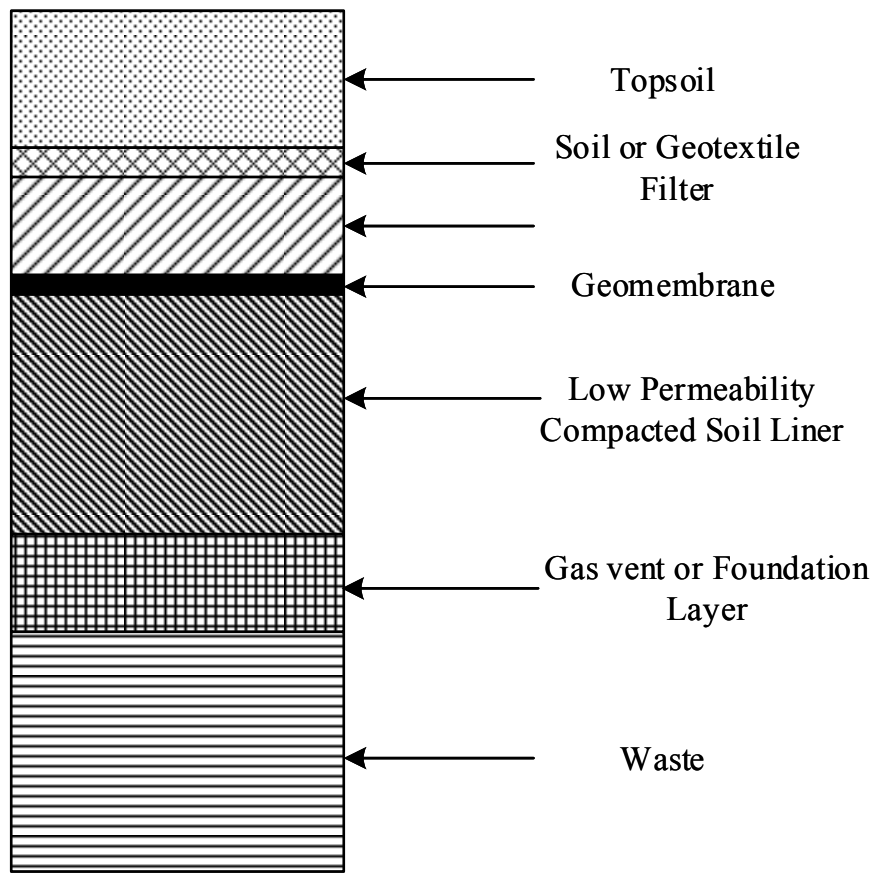

Figure 1-2. Schematic figure of cover system for buried waste

2. Underground storage tanks (USTs): 
USTs are referred to a tank and the pipe lines connected to the tank that has at least $10 \%$ of their entire system underground. Topically, USTs are used to store the pure phase chemical or petroleum related products as well as other hazardous substances. In 1984, subtitle I of the Solid Waste Disposal Act (SWDA) required the closure of near to 1.7 million active USTs in United States.

- Subtitle I:

Subtitle I encompasses the federal requirement for closure and corrective actions regarding the existing and new underground storage tanks (USTs) used to store the petroleum and other hazardous compounds. This subtitle has been addressed in 40 CFR 264.190 through 264.200. Subtitle I aims to provide guidelines for owners and operators of USTs regarding the maintenance and closure of the USTs. Under this subtitle, different requirements have to be addressed including:

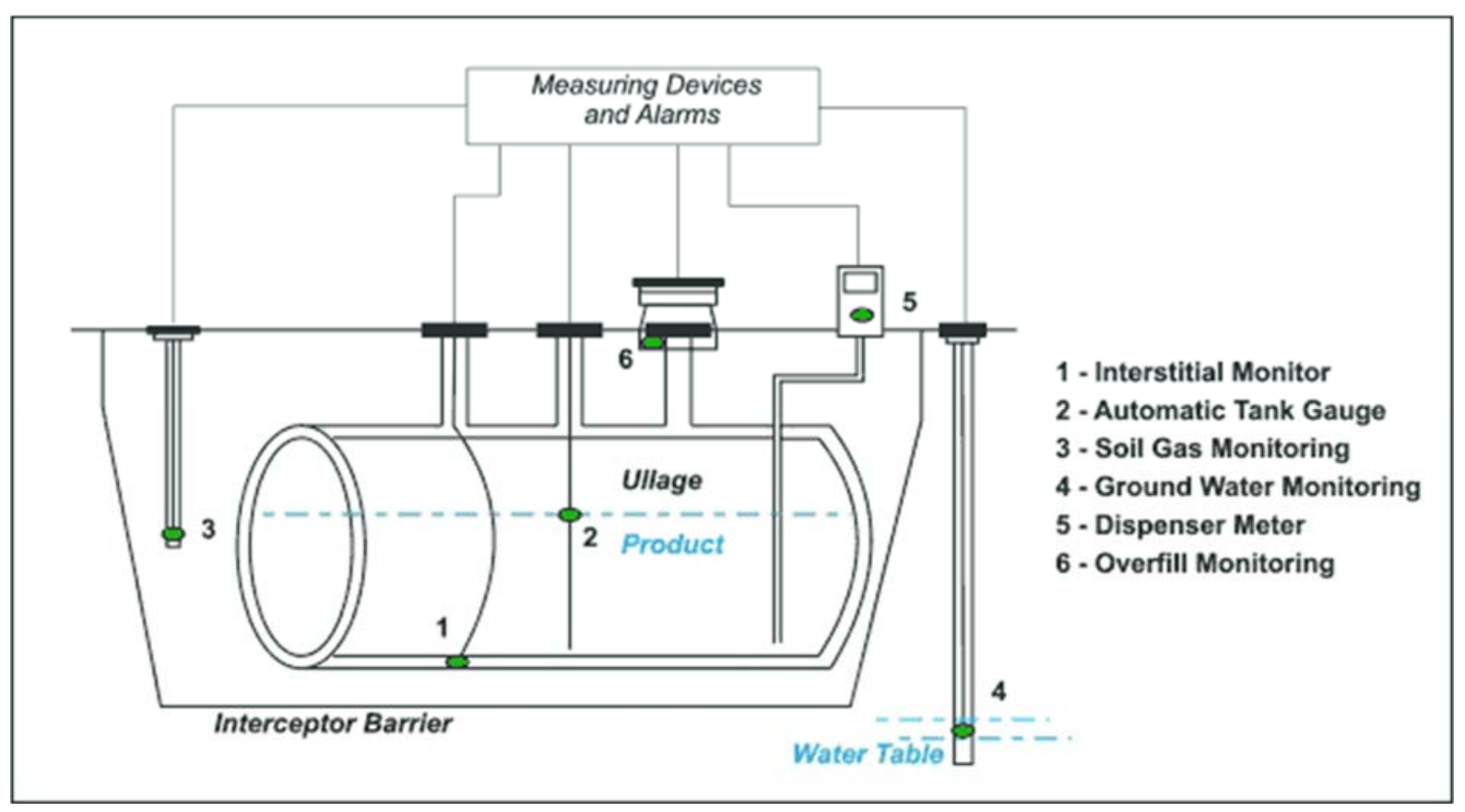

Figure 1-3. Schematic setup of USTs with barrier systems (Musy 2008) 


\subsubsection{Fast flow rate barrier systems}

In addition to low permeability barriers, vertical barriers can be used as fast flow rate barriers in groundwater remediation practices such as permeable reactive barriers (PRBs). PRBs are permeable chemical barriers that designed to degrade or immobilize the constituent contaminant in the groundwater flow while passing through them. Permeable reactive barriers have received significant attention during the past decade due to their considerable capacity for attenuating or removal of a wide range of contaminants. To construct the PBRs, a trench with reactive components will be built perpendicular to the contaminant flow (Figure 1-4). The pollutants carried by the flow will be immobilized or transformed into nontoxic constituents (Vidic and Pohland 1996)

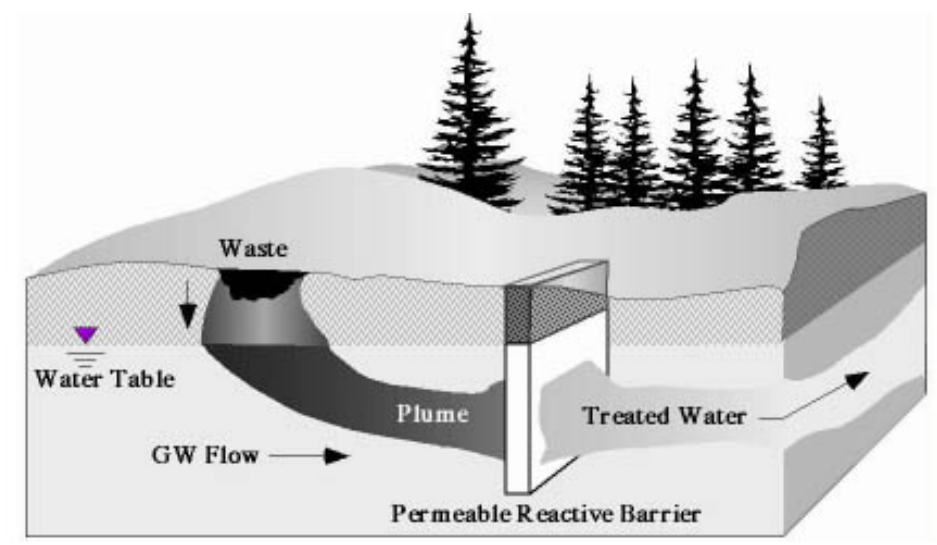

Figure 1-4. Schematic permeable reactive barrier system (Australia. 2012)

The reactive components of PRBs include reactive material to degrade the volatile contaminants, chelators to immobilize the heavy metals, or nutrients and oxygen to enhance the bioremediation (Bowman 1999). To facilitate the groundwater flow through PRBs, the reactive components are often mixed with porous materials such as sand.

Reactive components in the PRB system attenuate the transport of variety of groundwater contaminants including organic and inorganic contaminants. Organic contaminants such 
as BTEX, TCE, PCBs, PAHs, and TCA can be treated by employing a barrier with reactive material that degrade or sorb the pollutants. Most common reactive materials for organic contaminant degradation are zero-valent iron (ZVI), iron (II) porphyrin, restingstate microorganisms, and dithionite. Other materials to sorb the contaminants include zeolite, organobentonites, and activated carbon. The reactive permeable barriers are suitable to use in sites with permeable soil, with relatively high speed groundwater flow which the contamination zone locates no deeper than $50 \mathrm{ft}$ below ground.

If designed and installed appropriately, the conventional soil barriers exhibited desirable performance and reliability for water with low solute concentrations. However, chemical incompatibility was also observed in conventional soil barriers when they were permeated by organic liquids and fuels. Previous studies indicated that the permeability of natural clay soils increased up to four order of magnitudes when they were permeated with pure hydrocarbons liquids (Brown et al. 1983; Brown et al. 1984). Bowders and Daniel (1987) investigated the permeability of compacted kaolinite and illite when permeated by methanol, acetic acid, heptane, trichloroethylene (TCE), and water. They concluded that the permeability of clay increased when the concentration of methanol exceeded $80 \%$. They also suggested that the increased permeability was due to the shrinkage of the diffuse double layer of the clays in methanol. They also observed that pure heptane and TCE would cause the increased flow in the clay liner.

In addition to significantly increased permeability due to chemical incompatibility, the conventional soil barriers also have limited contaminant retention capacity. Although it would take longer time for the contaminant flow to go through the common soil barriers, the dissolved organic contaminants might migrate through them at a faster pace. From a 
perspective of barrier performance, they are not very capable of impeding the mass transport of contaminants even if they can minimize the flow. In these situations, an effective "chemical barrier" is also required in addition to the existing hydraulic barrier. Consequently, novel soil barriers with higher chemical compatibility and enhanced the sorption capacity for organic compounds merits examination.

It was suggested that the chemical incompatibility between the organic liquids and clay minerals is due to the differences in polarity of the two (Chiou 1998; Lo and Yang 2001; Smith et al. 1988). Typically, inorganic soils like clays are hydrophilic as their constituents are mainly aluminosilicate sheets, however, most of the organic compounds are non-polar, hydrophobic substances that have lowest affinity to the minerals. Consequently, organic-matter enhancement of liner materials has been suggested to improve the compatibility of soil and organic compounds as they can be compatible with both. The improvement due to the additives could be the stable permeability and increased contaminant retention capacity of soil barriers. The increased contaminant retention capacity is explained in next few paragraphs.

There are three major processes that control the transport of contaminant in porous media: (1) advection, diffusion and dispersion; (2) chemical mass transfer process such as sorption; and (3) biological process. Advection refers to the contaminant transport under a hydraulic gradient while diffusion refers to the contaminant transport under a chemical gradient. The relative importance of advection and diffusion can be quantified by the Peclet number, equation 1-1:

$P_{L}=\frac{v_{s} L}{D}$ 
where $P_{L}$ is the Peclet number, $v_{s}$ is the seepage velocity $(\mathrm{m} / \mathrm{s}), L$ is the travel distance for contaminant (m), and $D$ is the diffusion coefficient $\left(\mathrm{m}^{2} / \mathrm{s}\right)$. The advection process is dominant in contaminant transportation at high flow rate systems (e.i., $P_{L} \geq 50$ ) whereas the diffusion controls the contaminant transportation mechanism in low flow rate systems (e.i., $\left.P_{L} \leq 1\right)$.

The transport of solute through homogeneous soil is typically described by the onedimensional advection-dispersion equation, equation 1-2.

$R \frac{\partial C_{r}}{\partial t}=D\left(\frac{\partial^{2} C_{r}}{\partial x^{2}}\right)-v\left(\frac{\partial C_{r}}{\partial x}\right)$

where $\mathrm{D}$ is the hydrodynamic dispersion coefficient $\left(\mathrm{m}^{2} / \mathrm{s}\right), \mathrm{v}$ is seepage velocity $(\mathrm{m} / \mathrm{s}), \mathrm{x}$ is microscopic distance in the direction of transport (m), $\mathrm{t}$ is time (s), and $\mathrm{Cr}$ is the concentration of solute in the pore water of the soil $(\mu \mathrm{g} / \mathrm{mL})$.

The chemical mass transfer is negligible if the solutes have limited reactions with soils. However, if certain chemical reactions (e.g. acid-base reaction; reduction-oxidation reaction; dissolution-precipitation; sorption-desorption) can reduce the aqueous concentration of the solute, the mass of the solute (or contaminant) will be retarded. If sorption of solute molecules by the porous media is the dominant mechanism, the retardation can be described by a retardation factor that is related to the sorptivity of the soil. Assuming the distribution of solute (or contaminant sorbate) in solvent and in soil sorbent is proportional, the retardation factor $\mathrm{R}$ can be determined as equation 1-3 (Freeze and Cherry 1979):

$R=1+\frac{\rho_{b}}{n} K_{d}$ 
where $\rho_{b}$ is dry density of porous media $\left(\mathrm{g} / \mathrm{cm}^{3}\right), n$ is the porosity of the porous media, and $K_{d}$ is the distribution coefficient $(\mathrm{mL} / \mathrm{g})$. More details of the equations and parameters can be found in chapter 3 .

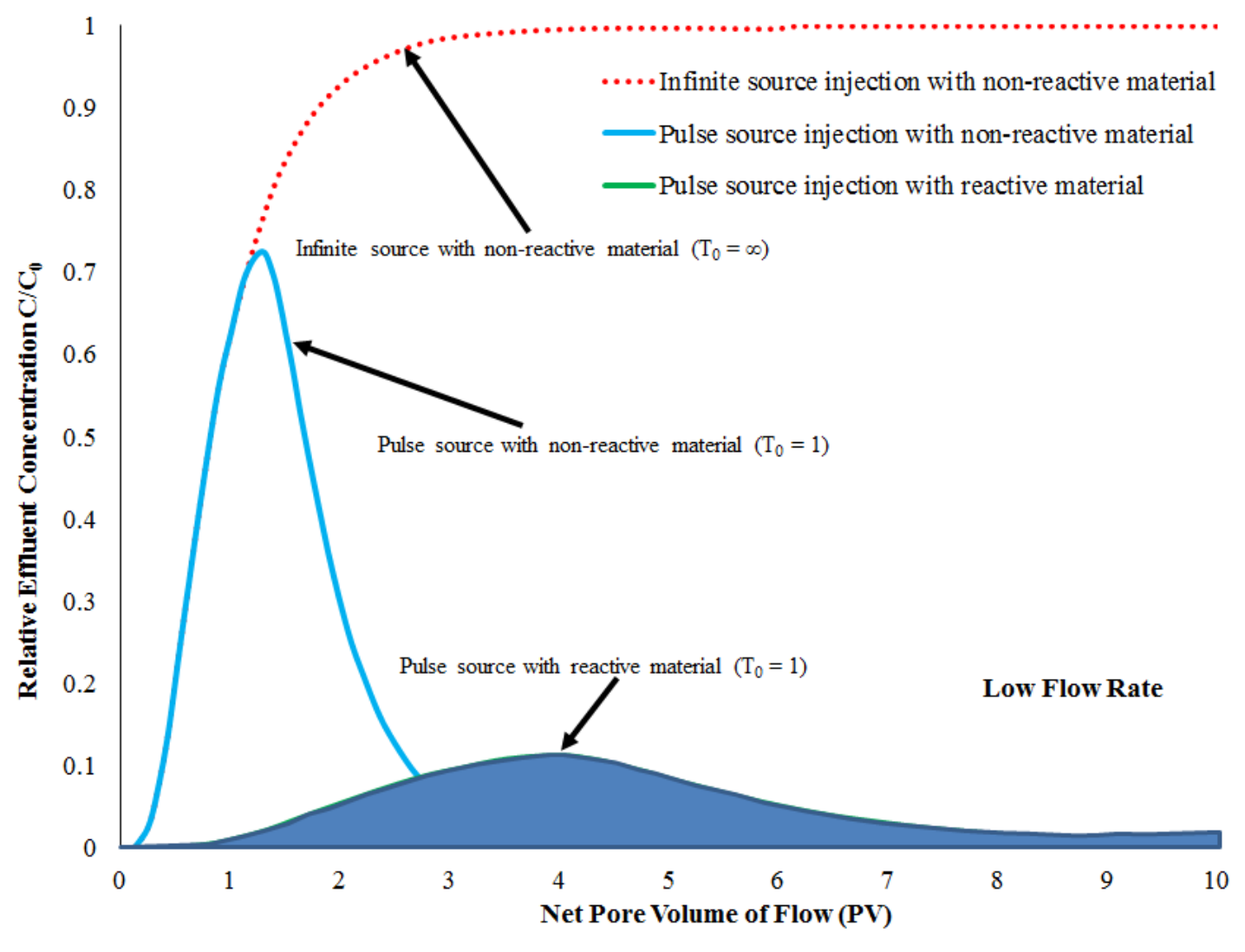

Figure 1-5. Low flow rate breakthrough curve for different type of solute injection

At the laboratory scale, the retardation factor can be estimated from soil column study. the studied contaminants can be introduced to the soil columns through two different injection method. The first one is infinite source injection which the contaminated solution will be injected to the column continuously until the relative concentration (concentration of contaminant in effluent/initial concentration of contaminant) is equal to 1. It results to a s shape breakthrough curve (red curve). Also, the solution can be introduced to the soil column for one pore volume and then it be flushed by water. In this case, pulse source injection results in a bell shape breakthrough curve (blue curve). If the 
component of soil column consists of sorptive material, the pulse signal injection method results in a flatten belled shape breakthrough curve with considerably low relative concentration at peak followed by a long tail. This phenomenon occurs due to the higher sorption capacity of sorptive materials which sorb the contaminants and release them with a much-attenuated concentration in a long period of time. This mechanism is called retardation.

At the field scale, the retardation of contaminants by the soil barriers would lead to a slower spreading of the contaminants in the subsurface, or a much smaller plume of contaminants within certain time. Pickens and Lennox (1976) demonstrated a solution for contaminant transport considering retardation term. They concluded that the contaminant transport through a large area as a result of advection and dispersion and they simulated the situations when the soil was non-sorptive, slightly sorptive and very sorptive $\left(K_{d}\right.$ was 0, 1 and 10, correspondingly). The concluded result is illustrated in Figure 1-6.

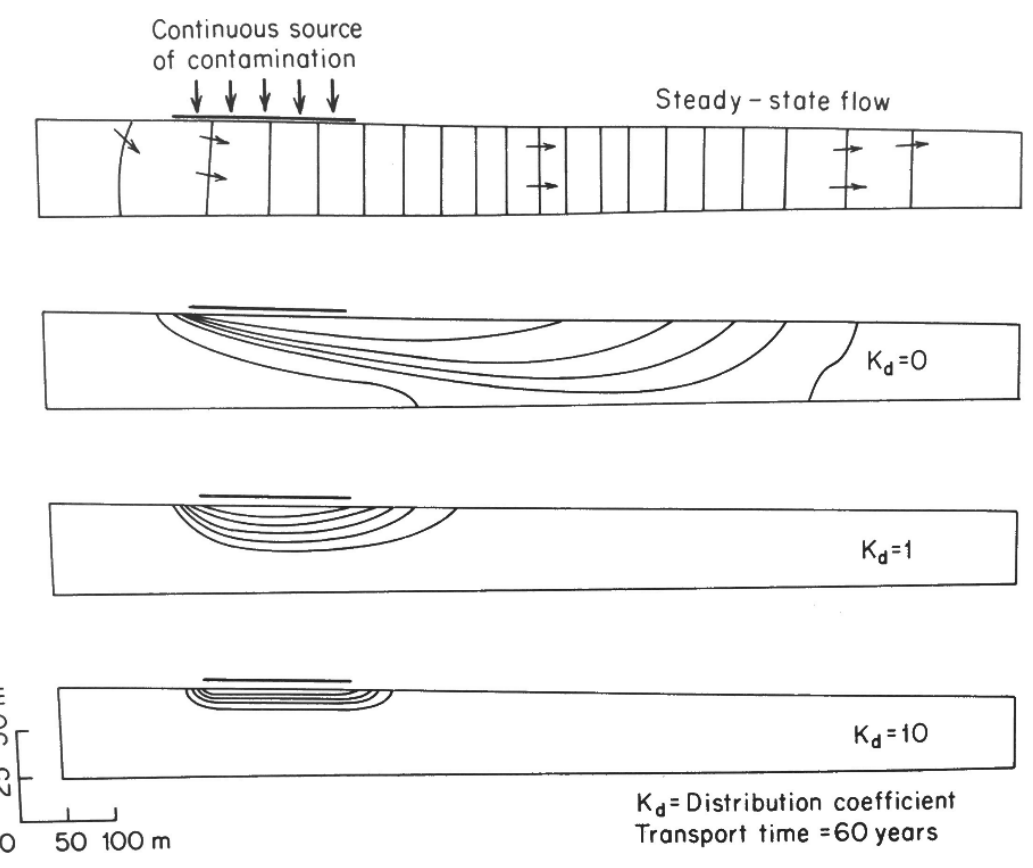


Figure 1-6. The effect of partitioning coefficient on the retardation of contaminant transport (Freeze and Cherry 1979)

For either constant (Figure 1-6) or limited source (Figure 1-7) of contaminants, the sorptive soil would decrease the size of the contamination plume or reduce the contaminant concentration in the subsurface.

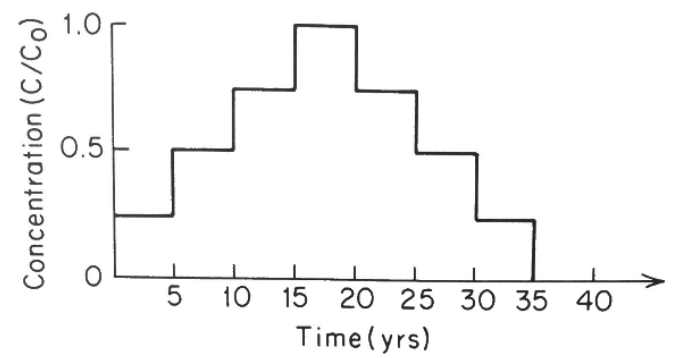

(a)

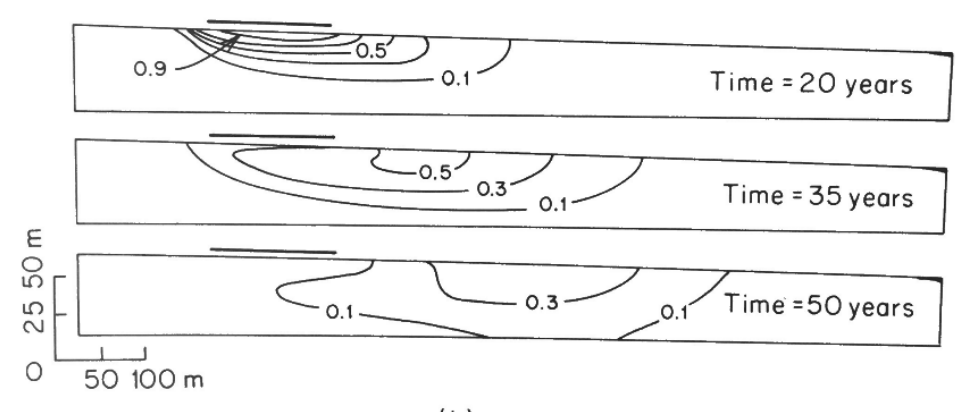

(b)

\section{Figure 1-7. (a) the relative concentration of contaminant versus time (b) contaminant distribution during time (Freeze and Cherry 1979)}

Most naturally occurring soils have low sorptivity of nonpolar organic compounds (NOCs) due to their low organic content (Park et al. 2011). Various types of reactive materials have been proposed as amendments to enhance the sorption/retardation and compatibility of liner materials. The proposed materials are: mixture of bentonite and fly ash, surfactant modified soils, activated carbon, paper industry sludge, organo-sand, zeolite, organo-zeolite, and many other commercial additives. Recently, the surface modification of clay minerals has received a great attention because it can produce a 
strong and stable sorbent media with favorable sorption of common environmental pollutants (Redding et al. 2002; Richards and Bouazza 2007; Zhao and Burns 2012). Among the surfactant modified soils, organoclays have demonstrated superior performances as a fine-grained soil sorption. This effectiveness of organoclay is due to its considerable characteristics including higher organic carbon, higher thermal stability, organophilicity, hydrophobicity, and higher sorption/retardation capacity (Benson et al. 2015; de Paiva et al. 2008; Gates et al. 2004; Soule and Burns 2001). Consequently, organoclay was chosen as the studied material in this dissertation.

\subsection{Organoclay}

Organoclays are typically synthesized from naturally occurring aluminum silicates under controlled laboratory conditions. The synthesis of organoclay enriches the base aluminum silicate with organic carbons which often leads to their expanded interlayer spacing and hydrophobicity. In general, organoclays are synthesized from sodium or calcium montmorillonites as they have high cation exchange capacity and desirable interlayer spacing for intercalation. Some other clay minerals such as hectorite, mica, sepiolite, illite, muscovite, clinoptilolite, kaolinite and vermiculite are also possible base clays for the synthesis of organoclays (de Paiva et al. 2008; Soule and Burns 2001).

Several types of organic matters including quaternary ammonium cations (QACs), polymeric quaternary alkylammonium cations and copolymers, alcohols, aldehydes, and biomolecules are often used for the organoclay synthesis (Bate et al. 2014; de Paiva et al. 2008; Lee and Tiwari 2012). Among the available organic surfactants, QAC is the most 
common cationic surfactant type due to its availability, ease of preparation and stable physicochemical behaviors (Sarkar et al. 2012).

The synthesis of organoclay can be achieved by the cation exchange process in the aqueous phase, which is also known as the "slurry method". Most of the naturally occurring inorganic cations in montmorillonite (e.g., calcium cation, Figure 1-8) reside in the interlayer spacing of montmorillonite and they tend to hydrate when the soil is soaked in water. The inorganic cations will be substituted by the organic cationic surfactant in they present in the same aqueous phase. This is typically referred as the cation exchange process or primary sorption of organic phase by the clays. After cation exchange, the interlayer calcium/sodium cations and water molecules are replaced by the intercalated organic cations.

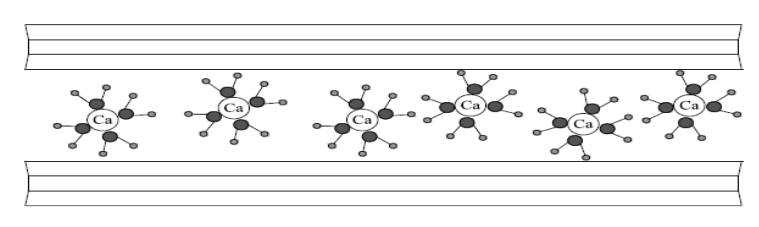

(a)

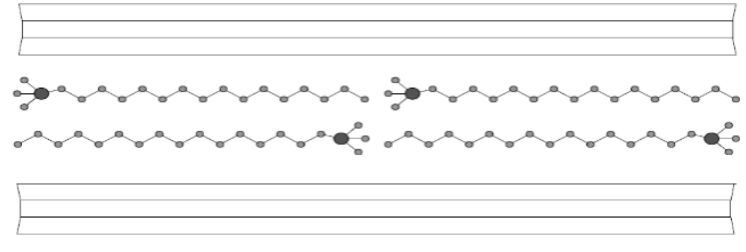

(b)

Figure 1-8. microstructure of (a) calcium bentonite (b) HDTMA-bentonite

The structure of polymer/clay composite is categorized based on the microstructure of particle-aggregates of the synthesized clays. Most commonly, the polymer/surfactant modification of clays will lead to separated or exfoliated silica sheets. Based on previous studies, possible patterns of organoclays microstructures are: conventional, intercalated, and exfoliated composites (Alexandre and Dubois 2000; Esfandiari et al. 2008; Giannelis et al. 1999; Lan et al. 1995), Figure 1-9.The method of synthesizing, structure of clay and 
polymer, and organic modifiers are the controlling factors in determining the morphology of polymer or surfactant/clay composites (Giannelis et al. 1999).

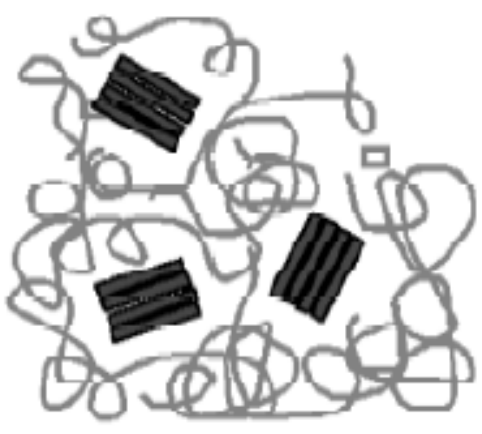

Conventional

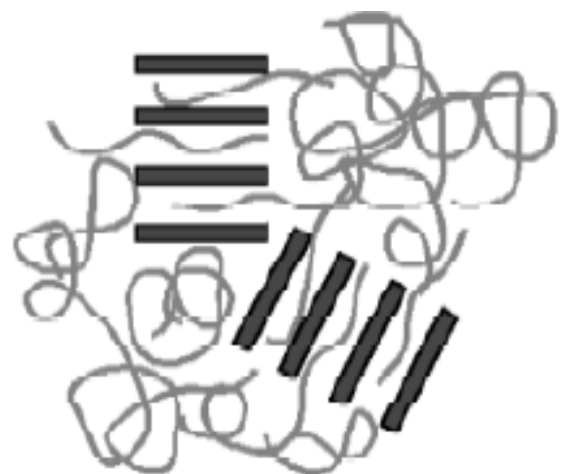

Intercalated

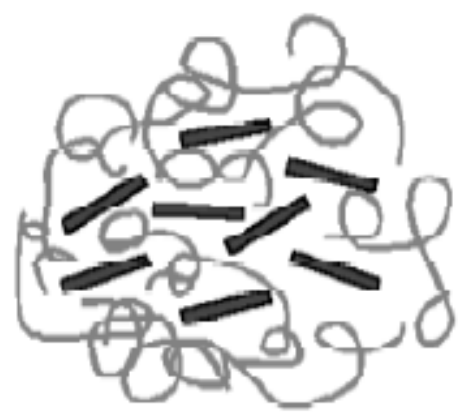

Exfoliated

\section{Figure 1-9. Different microstructure morphology of organoclays (Giannelis et al.} 1999)

To optimize the structural stability of the surfactant/clay composites, the modifier polymers or surfactants with long carbon chains is often preferred as they can be intercalated in interlayer and interact with both clay platelets (Esfandiari et al. 2008).

Several laboratory characterization techniques can be used to study the microstructure of organoclays at the micro-scale level (Nanos to microns). Most commonly, the basal spacing of intercalated clays is the most important parameter and it can be related to the microstructure of the intercalated surfactants and ultimately, the physicochemical properties of organoclays. The most common techniques that are used to study the microstructures of clays are: X-ray diffraction (XRD) and scanning electron microscope (SEM).

\subsubsection{X-ray diffraction (XRD)}


The small angle XRD is able to measure the basal spacing of the clay particles. The emitted X-rays diffract in different directions after reflecting from the crystalline atoms of clay minerals. The intensity of the reflected rays can be measured as the function of the reflection angles. The basal spacing of the clay minerals can be measured by plotting the intensity versus the reflection angles of the beams (He et al. 2005). The basal spacing of organoclays usually are detected in the scanning angles $(2 \theta)$ ranging from 3 to $6^{\circ}$ (approximately 14.7 to $44.1 \AA$ ) (Zhao et al. 2016). Lagaly (1986) proposed an arrangement patterns which can be used to measure the number of organic carbon layers by using the XRD results. The expansion of the interlayer of the unmodified clays after the intercalation of cationic surfactant can be detected by XRD measurement (Xue et al. 2007).

\subsubsection{Scanning electron microscope (SEM)}

SEM is a non-destructive method to create the surface topography and composition of the particles in microscale by using the electron beams instead of light beams. SEM demagnifies an electron beams generated from a source to scan the surface of the soil in a parallel fashion. The reflected beam from the surface of the soil sample produces

different types of emission and captured by multi detectors. The topographical and compositional information can be assessed by analysis of specific type of collected electron(Suga et al. 2014).

\subsubsection{Total organic carbon analyzer (TOC)}

TOC analyzer measures the quantity of the total organic carbon presents in the soil sample. In this method, the soil sample is combusted at a $680^{\circ} \mathrm{C}$ in an environment 
enriched with oxygen. As a result, the existing carbons in the soil structure will be decomposed and converted to carbon dioxide $\left(\mathrm{CO}_{2}\right)$ in gaseous phase. The $\mathrm{CO}_{2}$ emission from the combustion procedure will be cooled down and collected by an infrared gas analyzer (Schumacher 2002). The fraction of organic carbon would be determined by analysis of the emission and comparison with the calibration curves.

\subsection{Geotechnical testing and engineering properties of soils}

The engineering properties of the geo-materials can be evaluated through well-known laboratory soil experiments. For this reason, a series of laboratory experiments were conducted during this study to quantify the physical and chemical properties of geomaterials. The test methods used to evaluate the engineering properties of soils are summarized in Table 1-2.

Table 1-2. Conducted laboratory tests to evaluate the engineering properties of soils

\begin{tabular}{ccc}
\hline Type of test & Standard & Target engineering properties \\
\hline Atterberg limit test & ASTM D 4318-05 & Liquid limit (LL), Plastic \\
specific gravity test & ASTM D 854-B & Specific gravity (Gs) \\
specific surface area & Santamarina et al. (2002) and & Specific surface area (SSA) \\
test & Kandhal and Parker (1998) & \\
\hline
\end{tabular}

\subsection{Current application of organoclays}


Currently, organoclays have been used in various engineering applications such as: drilling, site remediation and waste disposal (de Paiva et al. 2008). Although the field applications of organoclays in conventional earthen barriers is still limited, several studies indicated that they could be very promising amendments in earthen barriers to enhance both the hydraulic and chemical performances. Lo (2001) investigated the potential use of organoclay-bentonite admixture as a barrier for waste containment. He suggested that a small percentage of organoclay $(20 \%)$ can be mixed with bentonite and used as the material of a soil-based liner. He explained that organoclay enhanced the removal efficiency of the soil liner and maintain the hydraulic conductivity of the barrier at the acceptable range which is required by U.S. Environmental Protection Agency (i.e. $1 \times 10^{-7} \mathrm{~cm} / \mathrm{s}$ ). Lo and Yang (2001) studied the hydraulic barrier performance of a organoclay as the secondary containment for the underground storage tanks. They concluded that organoclays can be efficient barriers for advective transport of gasoline. they stated that organoclays have a fair resistance to desiccation, weathering, and selfhealing because of their notable swelling tendency in contact with gasoline. Lo and Mak (1998) studied the feasibility of employing organoclay in compacted liner systems to retard the transport of phenolic compounds. They proposed that using the organoclay in compacted clay liners increased the retardation factor of barrier system to phenolic compounds, significantly.

In addition, organoclays have been used as rheological agent in oil-based drilling fluids. Caenn et al. (2011)clarified that the oil-based drilling fluids have higher lubricity, significant thermal stability, and higher rate of penetration compared to the water-based drilling fluids. Organoclay can be dispersed easily in the organic hydrocarbon liquids like 
diesel and mineral oils due to their organophilic properties. As a result, organoclay amendments can enhance the physical and chemical properties of oil-based drilling fluids under high pressure and high temperature.

\subsection{Scope of this study}

Although many studies have been carried out to investigate the geochemical properties of engineered organoclays, their geotechnical behaviors, especially the field performance as a sorptive amendment in earthen barrier still merits examination. The goal of this dissertation is to bridge the laboratory sorption test with the possible geotechnical engineering applications of organoclays in compacted clays, geosynthetic clay liners and permeable reactive barriers by investigating the hydraulic performance and contaminant retention of organoclays under controlled laboratory conditions. Specifically, this dissertation discusses the following topics:

1. The sorptivity of organoclays, especially partitioning clays as a function of: sorbate properties (organic carbon content, surfactant type, grain size); sorbate properties (chlorination, water solubility) and the aqueous environment (temperature, co-solvent). To obtain the results, several series of batch sorption tests were designed and carried out. The details were elaborated in Chapter 2.

2. The mass transport of representative organic contaminants through soil barriers including compacted clay, geosynthetic clay liner and permeable soil admixtures. We proposed a new concept of using the organoclays as the active components to aid the performance of these materials as chemical barriers. The effect of organoclay amendment on the mass flux of contaminants and enhanced retardation capacity of the amended barrier materials were investigated. 
Additionally, the "hydraulic" performance of the same materials was studied, with the emphasis being placed on the impact of organoclay additive ion the fluid flow of non-polar liquids. For these reason, flexible-wall permeability tests and column breakthrough tests were carried out and analyzed. The details of these investigations were elaborated in Chapter 3, 4 and 5. 


\section{CHAPTER TWO SORPTION OF ORGANIC CONTAMINANTS ONTO ORGANOCLAYS}

\subsection{Background}

Sorption process in an aqueous phase defines the distribution of the dissolved contaminants (sorbate) between the solution and sorbent (Sharma and Reddy 2004). For a variety of environmental pollutants (e.g., polychlorinated biphenyls, polycyclic aromatic hydrocarbons, etc.), natural soils typically have very limited sorption unless they are with high natural organic matter (NOC) content. In comparison, the engineered organic surfactant/clay hybrids, or organoclays, typically have their sorptivity hundreds of times greater than their unmodified counterparts (Chiou et al. 1983; Redding et al. 2002; Richards and Bouazza 2007; Upson and Burns 2006). They have significant amount of organic carbon content and are strong sorbents for chlorinated hydrocarbons and petroleum related hydrocarbons (with solubility no greater than a few $\mathrm{mg} / \mathrm{L}$ ). The physical/chemical properties of the synthesized organoclay is a function of the characteristics of the quaternary ammonium cations (QACs) including the molecular structure and quantity, or the morphology of the intercalated QACs. Based on the level of interaction, the sorption mechanism can be categorized into: (1) physical sorption which also is known as the van der Waals sorption (physisorption), and (2) chemical sorption (chemisorption) (Webb 2003). 
The physical sorption occurs when a relatively weak van der Waals interaction exists between solid and liquid phase. The level of energy generated during physical sorption is typically under $80 \mathrm{~kJ} / \mathrm{mole}$. In addition, it is possible that the sorbate molecules diffuse on the exterior surface of the solid phase and make a weak bond which can be reversed easily. However, the physically sorbed molecules do not have the potential to make a structural disturbance on the sorption site. Physical sorption can result in either a monolayer or a multilayer structure of sorbed molecules on the interaction surfaces which have favorable temperature and pressure condition for the physical bonding.

In contrast, the chemical adsorption is the result of strong chemical bond between sorbate and sorbent. The nature of chemical bonds can be either the covalent (electron sharing) or ionic (electron charge transferring). The released heat energy during the chemical adsorption ranges between $600 \mathrm{~kJ} / \mathrm{mole}$ to $800 \mathrm{~kJ} / \mathrm{mole}$. Because of a strong chemical bond in chemisorption, the nature of adsorbate change and form a new species. Moreover, the structure of top layers in adsorbent can be changed as well. These changes include the relaxation of interlayer spacing and/or the rearrangement of molecular structure in the adjacent top layers to the adsorption site. In this class of adsorption, typically the adsorption process lasts until the adsorbate can make a direct contact with the surface of adsorbent (Webb 2003).

Mostly, organoclays are produced by exchanging the QACs with the existing inorganic cations in interlayer of base clay. The intercalation of QACs into the interlayer space of base clay refers to the primary sorption. However, increasing the QAC loading will result in propping up the interlayer spacing which creates a favorable organophilic phase for sorption of non-polar molecules. This process refers to the secondary sorption. 
The relationship between the amount of sorbed contaminant by sorbent $(\mathrm{S})$ and the remained contaminant in the solution phase (C) at equilibrium is known as isotherm (Suzuki 1990). Concentrations in liquid and solid phase are described as a unit mass per volume, and absorbed mass of contaminant per unit mass of sorbent, respectively. The sorption isotherm models are categorized in three major groups: (1) Linear isotherm (2) Langmuir isotherm (3) Freundlich isotherm.

In the linear isotherm, there is a linear relationship between the absorbed amount of contaminant and the remaining concentration of contaminant in the solution defined by equation 2-1.

$S=K_{d} \mathrm{C}$

where $\mathrm{S}$ is the mass of adsorbed contaminant by the sorbent $(\mu \mathrm{g} / \mathrm{g}), \mathrm{K}_{\mathrm{d}}$ is the linear distribution (partitioning) coefficient $(\mathrm{mL} / \mathrm{g})$, and $\mathrm{C}$ is the concentration of contaminant in the solution at the equilibrium condition $(\mu \mathrm{g} / \mathrm{mL})$. To obtain the $\mathrm{K}_{\mathrm{d}}$ value, mass of adsorbed contaminant by the sorbent $(\mathrm{S})$ is plotted versus concentration of contaminant in the solution at the equilibrium condition (C) and the slope of linear fitted line to the data points is defined as distribution coefficient. An example of linear sorption isotherm is shown in Figure 2-1.

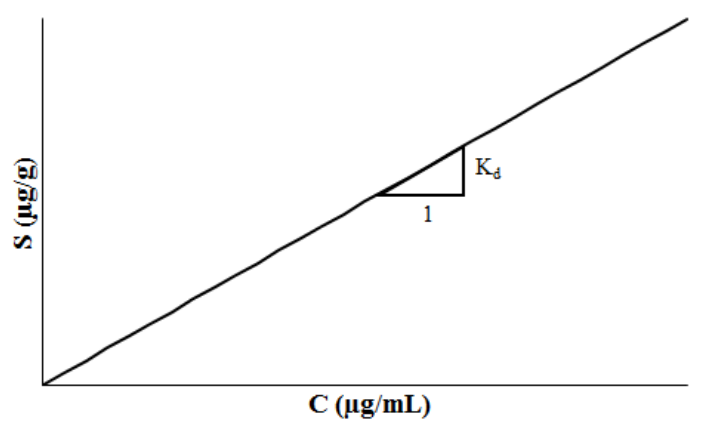




\section{Figure 2-1. Linear sorption isotherm}

In the Langmuir isotherm, a non-linear relationship between the absorbed amount of contaminant and the remaining concentration of contaminant in the solution is defined based on the concept that there are finite number of sorption sites available on the solid surface and sorption process depends on the availability of the sorption sites. Langmuir isotherm can be defined mathematically by equation $2-2$.

$S=\frac{\alpha \beta C}{1+\alpha C}$

where $\alpha$ is a sorption constant that defines the binding energy $(1 / \mathrm{mg})$, and $\beta$ is the maximum mass of contaminant that can be absorbed by sorbent $(\mu \mathrm{g} / \mathrm{g})$. To find the sorption constants, there are four different linear models that can be applied to the Langmuir sorption data, Table 2-1 (Ho 2006).

Table 2-1. Linear models of Langmuir sorption isotherm

\begin{tabular}{c|c}
\hline Linear model & Plot \\
\hline$\frac{\beta}{S}=\frac{1}{C} \beta+\frac{1}{\alpha} C$ & $\frac{\beta}{S}$ vs. $\beta$ \\
$\frac{1}{S}=\left(\frac{1}{\alpha C}\right) \frac{1}{\beta}+\frac{1}{C}$ & $\frac{1}{S}$ vs. $\frac{1}{\beta}$ \\
$S=C-\left(\frac{1}{\alpha}\right) \frac{S}{\beta}$ & $S$ vs. $\frac{S}{\beta}$ \\
$\frac{S}{\beta}=\alpha C-\alpha S$ & $\frac{S}{\beta}$ vs. $S$ \\
\hline
\end{tabular}

An example of Langmuir sorption isotherm is shown in Figure 2-2. 


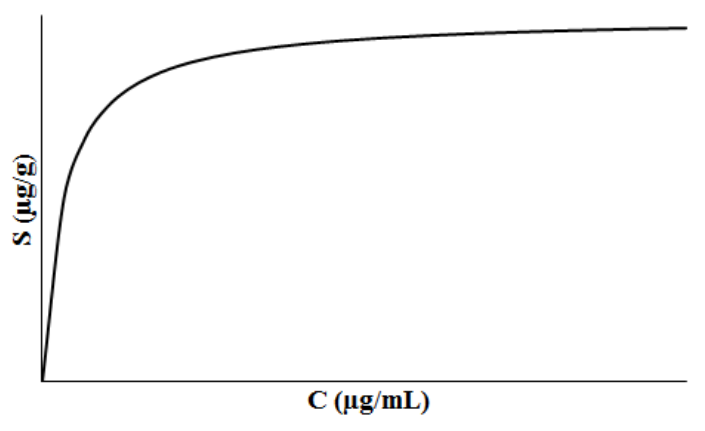

Figure 2-2. Langmuir sorption isotherm

The Freundlich isotherm is used for higher concentrations which represents highly favorable sorption. The Freundlich isotherm model is described mathematically as equation 2-3.

$S=K C^{N}$

where $\mathrm{K}$ is the constant of sorption capacity and $\mathrm{N}$ is the intensity constant which is always less than 1. An example of Freundlich sorption isotherm is shown in Figure 2-3.

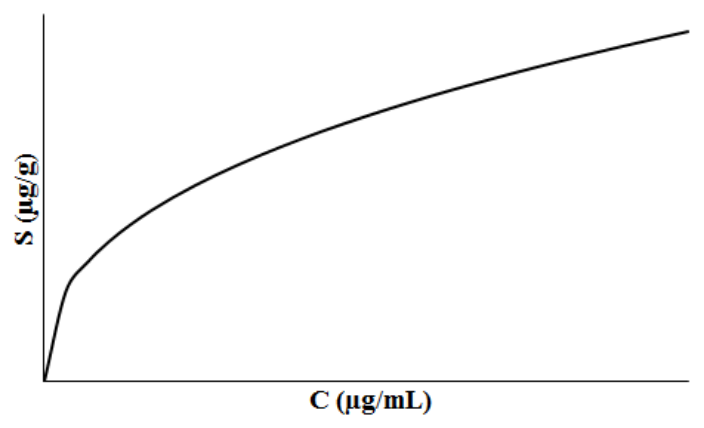

Figure 2-3. Freundlich sorption isotherm

There are many diverse factors which affect the sorption of a sorbate in soil media. The mentioned factors can be classified in three major groups: (1) sorbate characteristics such as water solubility, (2) soil characteristics such as TOC, and (3) fluid media characteristics such as temperature (Sharma and Reddy 2004). The classification of the 
effective factors on the sorption of organic contaminants by soil media is illustrated in Figure 2-4.

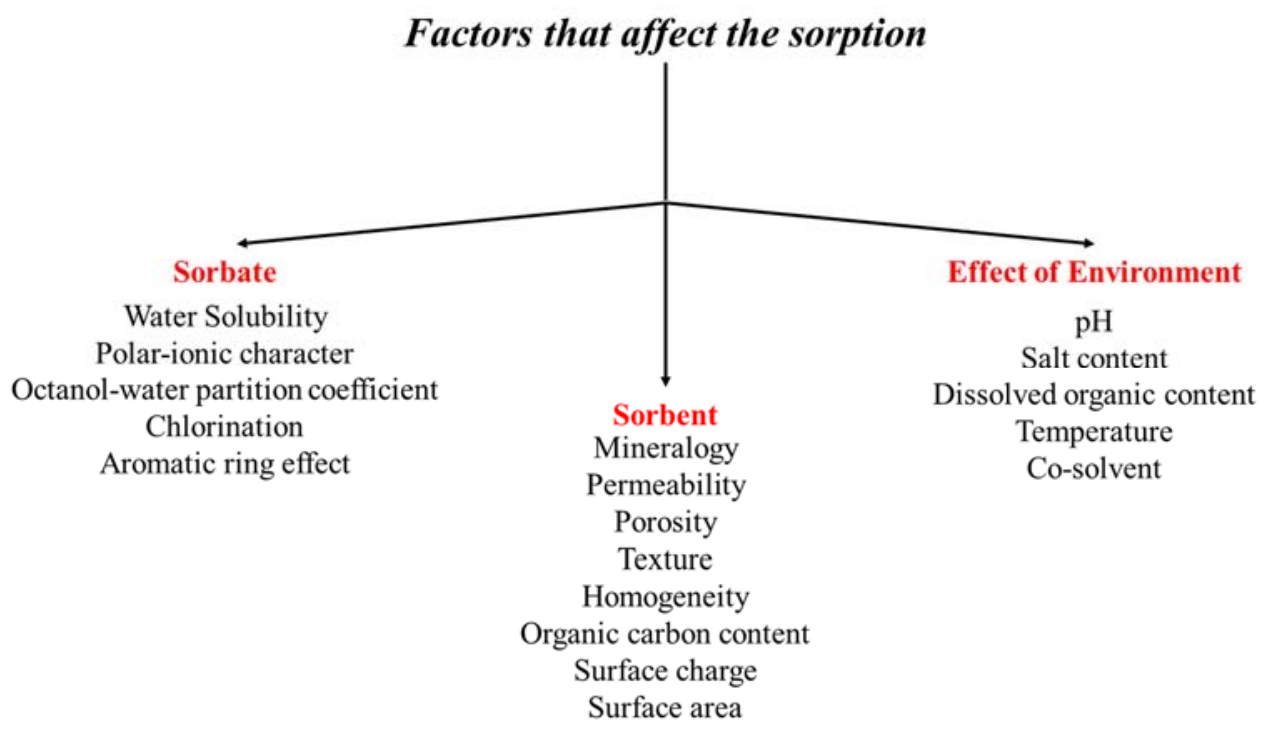

Figure 2-4. Effective factors in the sorption process of sorbates by sorbent

Previous studies indicated that the sorption capacity of partitioning organoclays can be affected by both sorbate and sorbent properties. Specifically, greater amount of intercalated cationic surfactants with larger size (or consequently, higher amount organic carbon loading) would increase the sorptivity of synthesized organoclays while the type, size and functional group could control the affinity of sorbates towards the organoclay sorbents., Additionally, the aqueous environmental including the co-solvent, $\mathrm{pH}$, temperature and ionic strength can also impact the sorption process. Previously, the most common approach to predict the affinity of organic sorbates to the partitioning clays was based on their solubility in octanol-water distribution coefficient (Kow) (Chiou et al. 1998; Di Cesare and Smith 1994; Smith et al. 1988). Chiou et al. (1982) suggested that the water solubility of the organic compounds could be one of the primary indicator of the affinity of organic compounds toward the organically modified clays. It was 
suggested that the water solubility of sorbate molecule would decrease if the number of aromatic ring and degree of chlorination of the molecule increases and consequently, an increased Kow is often observed (Mortland et al. 1986; Zhao et al. 2016).

The quantity of aliphatic carbon will increase on the surface of organoclays by increasing the total organic carbon (TOC). In a QAC modified clay, typically the entangled bulk aliphatic chains of the QAC play the role of partitioning medium in the sorption process. Many studies have indicated that the sorption capacity of organoclays is directly related to their TOC content, especially the organic carbons that was intercalated into the interlayer of the clays. Lee et al. (1989) used three organic cations: hexadecyltrimethylammonium (HDTMA), dodecyltrimethylammonium (DDTMA), nonyltrimethylammonium (NTMA) to modified soils. They observed that organic cation with longer aliphatic carbon chain demonstrated higher sorption capacity of nonionic organic contaminants (NOCs). Redding et al. (2002) studied the sorption of benzene onto two organoclays as a function of TOC and demonstrated that benzene has higher binding tendency to partitioning organoclays when the TOC increases. For organoclays modified by cationic surfactant with branched carbon chains, Bartelt-Hunt et al. (2003) indicated BTEA-bentonite had higher sorption capacity for TCE, benzene, and 1,2-dichlorobenzene from aqueous phase.

The next few paragraphs discuss the effect of aqueous environment on the organoclay sorptivity. Previous studies indicated that the co-solvent may inhibit the sorption of organic sorbates onto organoclays (Nzengung et al. 1997). The study of Nzengung et al. (1996) evaluated the sorption of naphthalene dissolved in solution with different methanol fraction $\left(\mathrm{f}^{\mathrm{c}}\right)$ by organobentonites. They concluded that the sorption of 
naphthalene onto organoclays decreased as the fraction of methanol in solution matrix increased. Rao et al. (1985) presented a solvophobic model to quantify the effect of cosolvent on the sorption capacity of hydrophobic organic chemicals (HOCs) (equation 2-4):

$\ln \left(\frac{K^{m}}{K^{w}}\right)=-a \alpha \sigma^{c} f^{c}$

where $K^{w}$ is the sorption coefficient from water $(\mathrm{mL} / \mathrm{g}), K^{m}$ is the partitioning coefficient from mixed solvent $(\mathrm{mL} / \mathrm{g}),{ }^{a}$ is an empirical constant presenting the interactions between water and co-solvent, $\alpha$ is an empirical constant presenting the interactions between sorbent and solvent, and $\sigma^{c}$ is the cosolvency power of the solvent which presents the interaction between solvent and the solution. This model suggests the equilibrium partitioning coefficient $\left(K^{m}\right)$ of HOCs decreases exponentially as the fraction of co-solvent $\left(f^{\mathfrak{c}}\right)$ in the solution increases. Fu and Luthy (1986) investigated the effect of nonpolar solvents on the sorptivity of hydrophobic solutes onto the silt loam and sandy soil. They concluded that the sorption of hydrophobic solutes decreased semilogarithmically as the percentage of solvents increased in the aqueous solution.

Also, the effect of temperature on the sorption tendency of sorbents has been studied. Chiou et al. (1979) indicated that the sorption of 1, 1, 1- trichloroethane increases at higher temperature. In another study, Mirmohamadsadeghi et al. (2012) studied the effect of temperature in the range of 30 to $50^{\circ} \mathrm{C}$ on the sorption of phenol to HDTMAbentonite. They concluded that HDTMA-bentonite reached to its maximum sorption capacity at $50^{\circ}$ C. Also, Sadeghi Ghari and Shakouri (2016) studied the effect of temperature on the sorption of toluene on organoclay. The reported that the sorption of 
toluene by organoclay increases when the temperature increases from 25 to $55^{\circ} \mathrm{C}$. they stated that the observed increase in the sorption capacity of organoclay is due to the higher level of interaction between organoclay and solvent.

Although many studies were conducted to quantify the sorption capacity of different organoclay sorbents vs organic sorbates, the fundamental sorption process still merits examination. This was due to the complexity of understanding the natures of the sorbents and sorbates as well as the difficulty of taking the aqueous environmental conditions into consideration. In this chapter, a series of batch sorption studies were conducted to quantify the sorption capacity of the organoclay sorbents with known microstructures and physicochemical properties. The impact of sorbate, and aqueous environment were also examined. Two partitioning clays: HDTMA-bentonite and PM-199 were selected as the soil sorbents for the batch sorption tests and benzene, naphthalene, hexachlorobenzene, 1 , 2, 4 -trichlorobenzene, and phenanthrene were selected as the dissolved organic contaminants. The major factors involved in sorption study were: (1) sorbate (chlorination, water solubility), (2) sorbent (organic carbon content, surface charge, grain size), and (3) aqueous environment (temperature, co-solvent).

\subsection{Materials and methods}

\subsubsection{PM-199}

Organoclay PM-199 in powder format was obtained from CETCO Company (Hoffman Estates, Illinois). PM-199 is a sodium bentonite (Na-bentonite) that modified by bis(hydrogenated tallow alkyl) dimethyl ammonium chloride. The modification was achieved by exchanging the naturally occurring sodium cations in the Na-bentonite 
interlayer with the dimethylammonium cation (Lee et al. 2012). The physical properties of PM-199 are summarized in Table 2-3. The specific gravity of PM-199 was measured as $1.46 \pm 0.2$ while the specific gravity of Na-bentonite was around 2.75 (ASTM D854B). The diffrences between the specific gravity of PM-199 and Na-bentonite was attributed to intercalated organic cations (Burns et al. 2006; Lee et al. 2012; Soule and Burns 2001). The mineralogy of PM-199 is summarized in Table 2-2

Table 2-2. Mineralogy of PM-199 (Lee et al. 2012)

\begin{tabular}{cc}
\hline Mineral & $(\%)$ \\
\hline smectite & 62 \\
quartz & 14 \\
plagioclase feldspar & 12 \\
halite & 5 \\
potassium feldspar & 2 \\
\hline
\end{tabular}

\subsubsection{HDTMA modified bentonite}

Hexadecyltrimethylammonium (HDTMA) cation $\left(\left[\left(\mathrm{CH}_{3}\right)_{3} \mathrm{NC}_{16} \mathrm{H}_{33}{ }^{+}\right]\right)$was selected as the surfactant to synthesize HDTMA-bentonite because it yields surfactant/clay hybrid with higher structural stability under different environmental conditions. A calcium bentonite (Ca-bentonite) (Panther Creek 200, American Colloid Company) was used as based clay to synthesize the HDTMA-bentonite under a controlled laboratory condition. It was reported that the Ca-bentonite contained about $85 \%$ montmorillonite (American Colloid Company) and 2.58\% natural organic-carbon content (McCoy \& McCoy Laboratories, Incorporated), with a cation exchange capacity (CEC) of $103 \mathrm{meq} / 100 \mathrm{~g}$ (Hazen Research, Incorporated).

The amount of HDTMA cation for the synthesis of HDTMA-bentonite was estimated by: 
$f=\frac{M_{\text {cation }}}{C E C \cdot M_{\text {clay }} \cdot G M W_{\text {cation }} \cdot Z}$

where $\mathrm{f}$ is the desired percentage of CEC that will be satisfied by organic cation, $\mathrm{M}_{\text {cation }}$ is the mass of the organic cation that is needed to achieve the designed CEC, CEC is the cation exchange capacity of the base bentonite (meq/mol), Mclay is the mass of the bentonite that will be used to modify (g), GMW cation is the gram molecular weight of the HDTMA-Br $(\mathrm{g} / \mathrm{mol})$, and $\mathrm{Z}$ is the number of charge moles per each equivalent.

The weighted salt (Hexadecyltrimethylammonium (HDTMA) bromide $\left.\left(\left[\left(\mathrm{CH}_{3}\right)_{3} \mathrm{NC}_{16} \mathrm{H}_{33} \mathrm{Br}\right]\right)\right)$ was first dissolved in $500 \mathrm{ml}$ of deionized water at $60^{\circ} \mathrm{C}$. Next, $300 \mathrm{~g}$ of the calcium bentonite (sieved through \#200) was mixed with the prepared solution and the slurry was stirred for $30 \mathrm{~min}$. The slurry was covered and placed at room temperature for $24 \mathrm{hrs}$. The modified clay was filtered and rinsed with deionized water before it was oven-dried at $110^{\circ} \mathrm{C}$ for $72 \mathrm{hrs}$. Finally clay particles was ground and sieved by sieve number 40 .

In order to measure the surfactant intercalation, the basal spacing of Ca-bentonite and HDTMA-bentonite were measured using the XRD analysis. The spectra of XRD was recorded for angles between $2^{\circ}$ to $20^{\circ}(2 \theta)$ using CuKa radiation $(n=1.5406 \AA)$ at the scanning rate of $2 \% \mathrm{~min}$. The basal spacing of the Ca-bentonite and HDTMA-bentonite were measured as $15.06 \AA$ and $19.44 \AA$, respectively. The XRD results are shown in Figure 2-5. Due to the intercalation process, HDTMA cations penetrated into the interlayer of Ca-bentonite and consequently increased the basal spacing of the clay. In addition to Ca-bentonite, a commercially available Na-bentonite was purchased from CECTCO Company and used as a sorbent for comparison. The engineering properties of 
Ca-bentonite, HDTMA-bentonite, and Na-bentonite are summarized in Table 2-3. Additionally, SEM and TEM tests were conducted to examine the microstructures of Cabentonite and HDTMA-bentonite (Figure 2-6).

Table 2-3. The engineering properties of Ca-bentonite, Na-bentonite, and HDTMA bentonite

\begin{tabular}{|c|c|c|c|c|c|}
\hline Properties & References & Ca-bentonite & $\begin{array}{l}\text { HDTMA- } \\
\text { bentonite }\end{array}$ & $\begin{array}{c}\text { Na- } \\
\text { bentonite }\end{array}$ & PM-199 \\
\hline Liquid limit (\%) & ASTM D4318 & 88.3 & 74.9 & 282.5 & 50.7 \\
\hline Plasticity index (\%) & ASTM D4318 & 37.3 & 16.3 & 221.6 & 2 \\
\hline $\begin{array}{c}\text { Fraction pass } \\
\text { through } \# 200 \text { sieve } \\
(\%)\end{array}$ & ASTM D6913 & 85.5 & 100 & 100 & 100 \\
\hline Specific gravity & ASTM D854-14 & 2.58 & 1.75 & 2.75 & 1.46 \\
\hline $\begin{array}{c}\text { Specific surface area } \\
\qquad\left(\mathrm{m}^{2} / \mathrm{g}\right)\end{array}$ & $\begin{array}{l}\text { Santamarina } \\
\text { et al. (2002) }\end{array}$ & 276.28 & 162.21 & 628 & 60.7 \\
\hline $\begin{array}{c}\text { Total organic carbon } \\
(\%)\end{array}$ & ASTM D7348 & 2.58 & 21.44 & $<1$ & 21.7 \\
\hline Basal spacing $(\AA)$ & Ye et al. (2014) & 15.06 & 19.44 & 12.57 & 35.58 \\
\hline
\end{tabular}




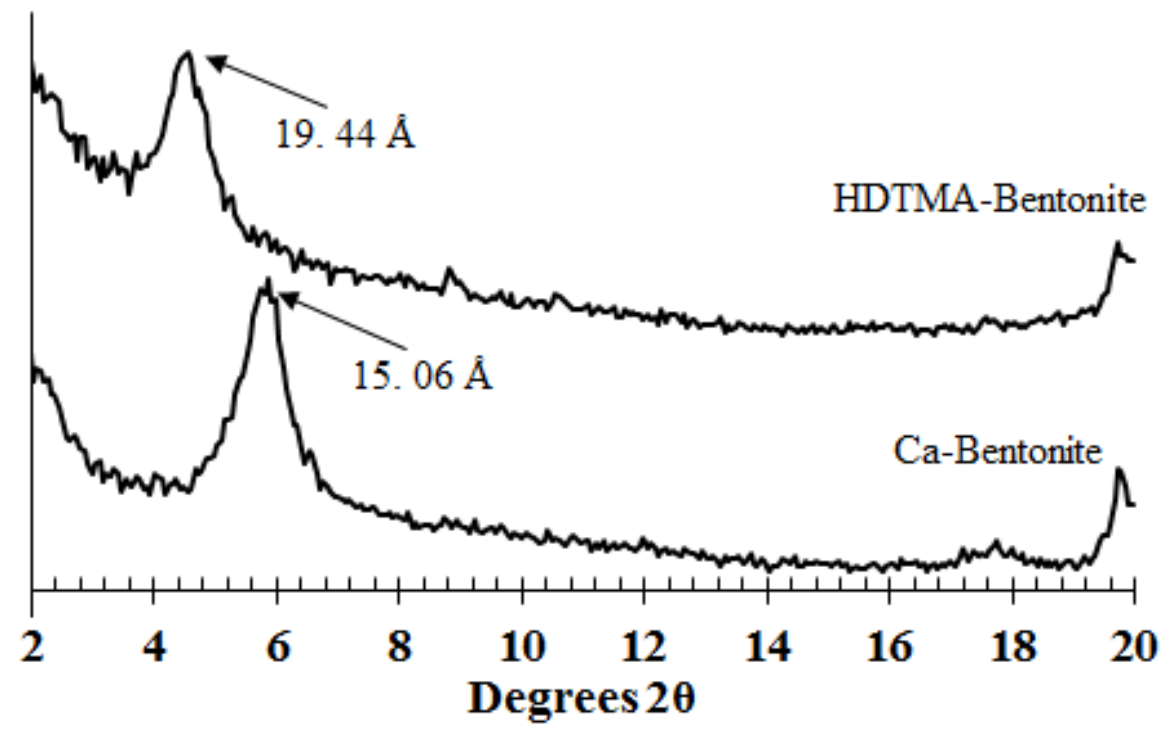

Figure 2-5. XRD result for Ca-bentonite and HDTMA-bentonite

Calcium bentonite

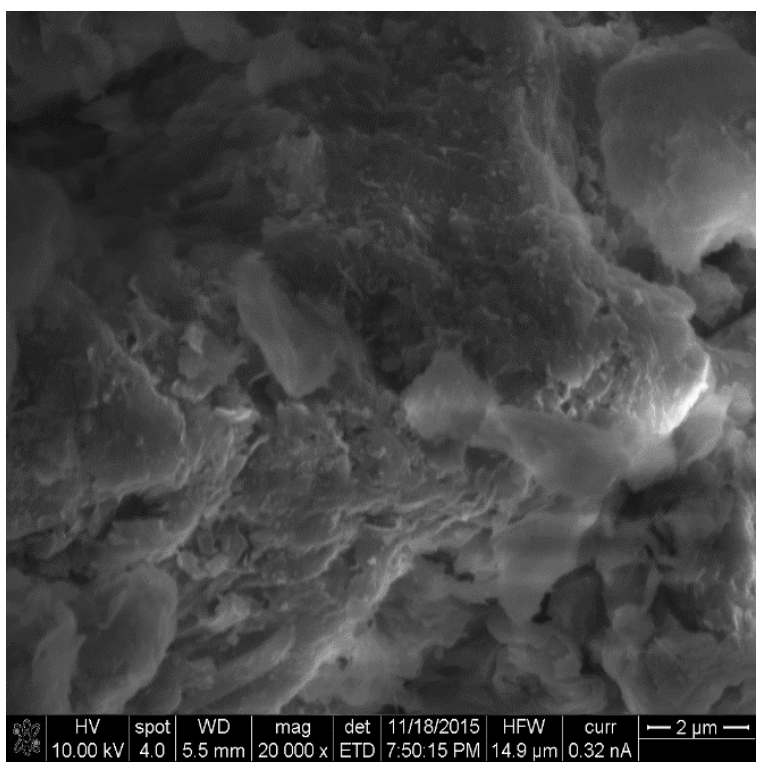

HDTMA-bentonite

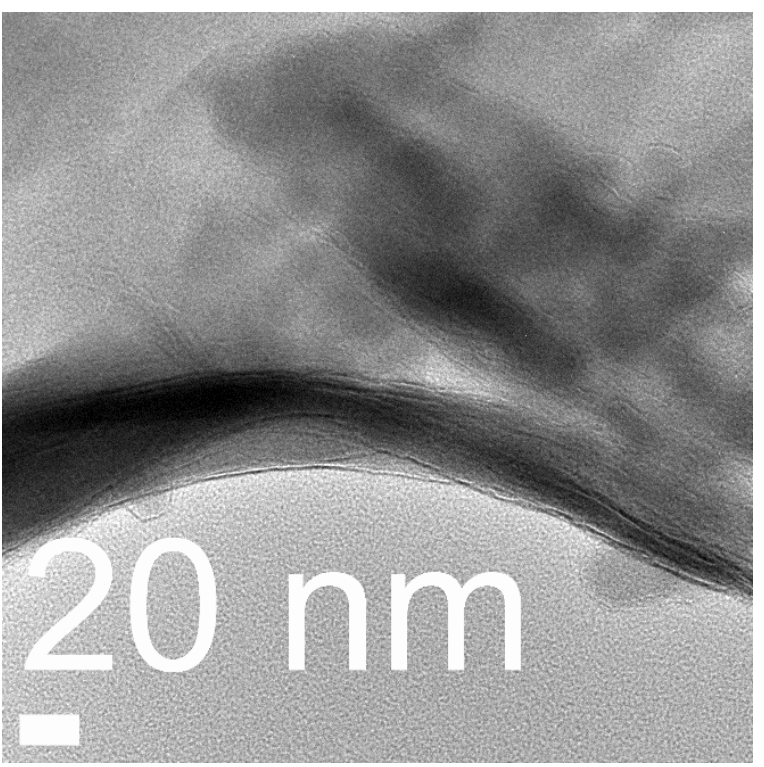

(a) 

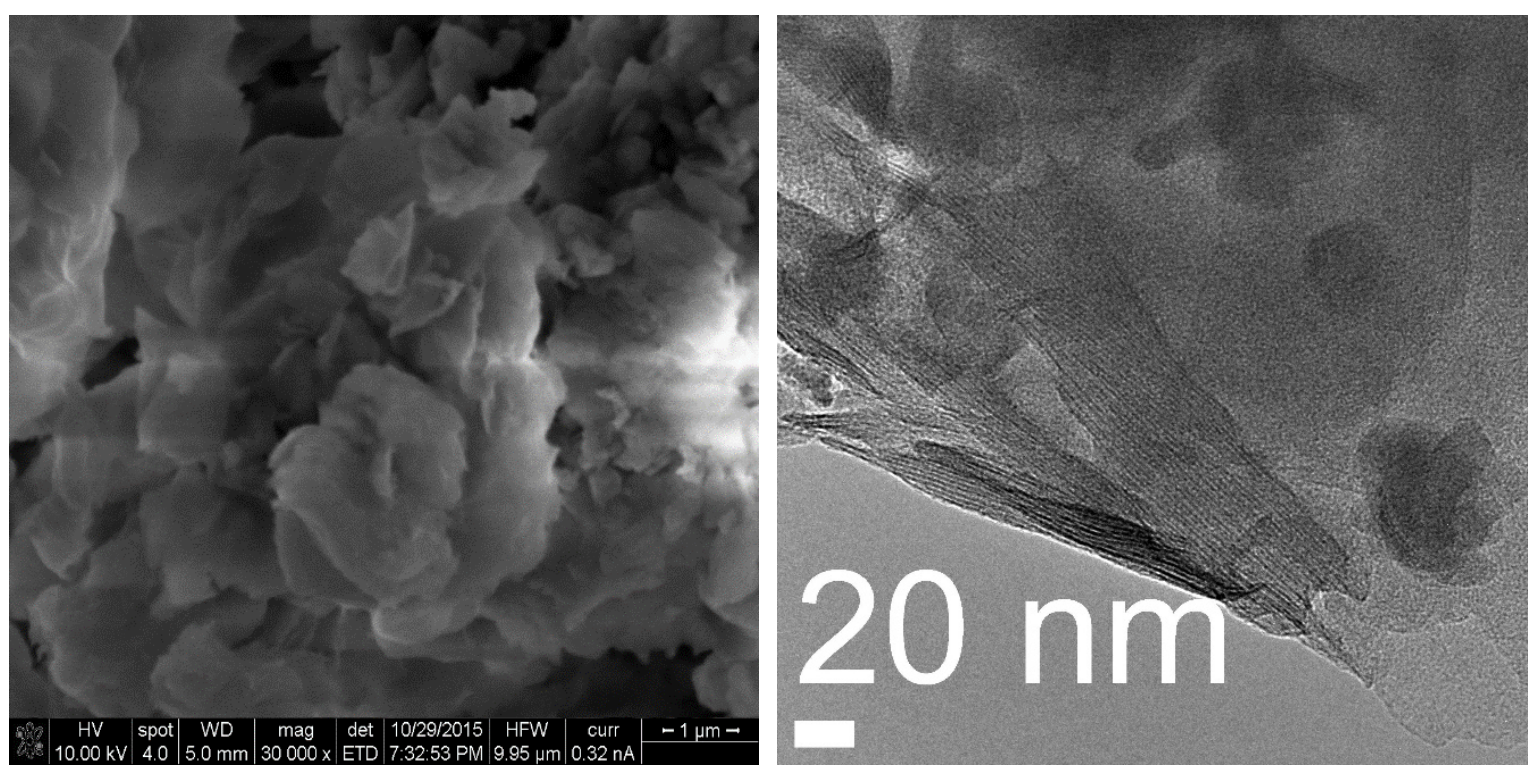

(b)

Figure 2-6. (a) Scanning Electron Microscope (SEM) and Transmission electron microscopy (TEM) test of Ca-bentonite (b) Scanning Electron Microscope (SEM) and Transmission electron microscopy (TEM) test of calcium bentonite HDTMAbentonite

\subsubsection{Organic sorbates}

Anhydrous benzene with purity of $99.8 \%$, hexachlorobenzene with purity of $99.1 \%$ in acetone solution, and anhydrous 1,2,4-trichlorobenzene with purity of $99 \%$ were purchased (Sigma-Aldrich). Also, Phenanthrene and naphthalene in crystal form with purity of $97 \%$ were purchased (Fisher Scientific Company). The physical and chemical properties of the studied contaminants are summarized in Table 2-6.

\subsubsection{Co-solvents}

Acetone (W.M.Barr Co.)and methanol (Carolina Co.) were used as the organic solvent. The physical and chemical properties of the solvents are summarized in Table 2-4 and Table 2-5. 


\section{Table 2-4. Physical and chemical properties of acetone}

\begin{tabular}{cc} 
Physical States: & Liquid \\
\hline Boiling Point: & $>133^{\circ} \mathrm{F}$ \\
\hline Auto-ignition Point: & $869^{\circ} \mathrm{F}$ \\
\hline Flash Point (according to TAG Closed & $0{ }^{\circ} \mathrm{F}$ \\
Cup method): & \\
\hline Explosive Limits: & LEL: $2.5 \%$ at $77^{\circ} \mathrm{F}$, and UEL: $13 \%$ at $77^{\circ} \mathrm{F}$ \\
\hline Density: & $0.7845 \mathrm{~g} / \mathrm{cm}^{3}$ at $77^{\circ} \mathrm{F}$ \\
\hline Vapor Pressure (vs. Air or $\mathrm{mm} \mathrm{Hg}$ ): & $30.6 \mathrm{kPa}$ at $77^{\circ} \mathrm{F}$ \\
\hline Solubility in Water: & Complete
\end{tabular}

Table 2-5. Physical and chemical properties of methanol

\begin{tabular}{cc} 
Physical States: & Liquid \\
\hline Boiling Point: & $>148.5^{\circ} \mathrm{F}$ \\
\hline Auto-ignition Point: & $878^{\circ} \mathrm{F}$ \\
\hline Flash Point (according to TAG Closed & $52^{\circ}$ to $54^{\circ} \mathrm{F}$ \\
Cup method): & \\
\hline Explosive Limits: & LEL: $6 \%$ at $77^{\circ} \mathrm{F}$, and UEL: $36 \%$ at $77^{\circ} \mathrm{F}$ \\
\hline Density: & $0.792 \mathrm{~g} / \mathrm{cm}^{3}$ \\
\hline Vapor Pressure (vs. Air or $\mathrm{mm} \mathrm{Hg}):$ & $13.02 \mathrm{kPa}$ at $68^{\circ} \mathrm{F}$ \\
\hline Solubility in Water: & Complete
\end{tabular}




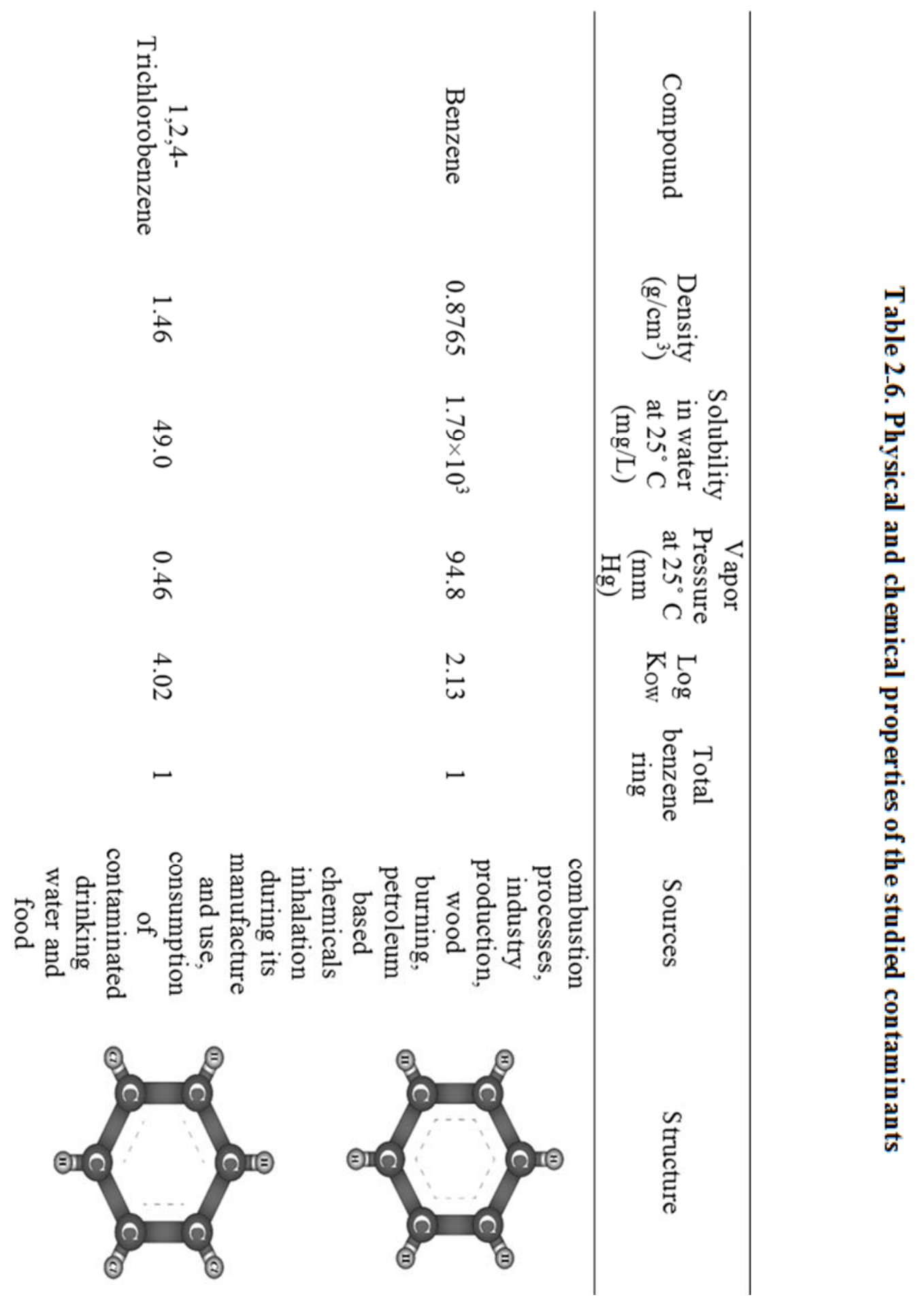




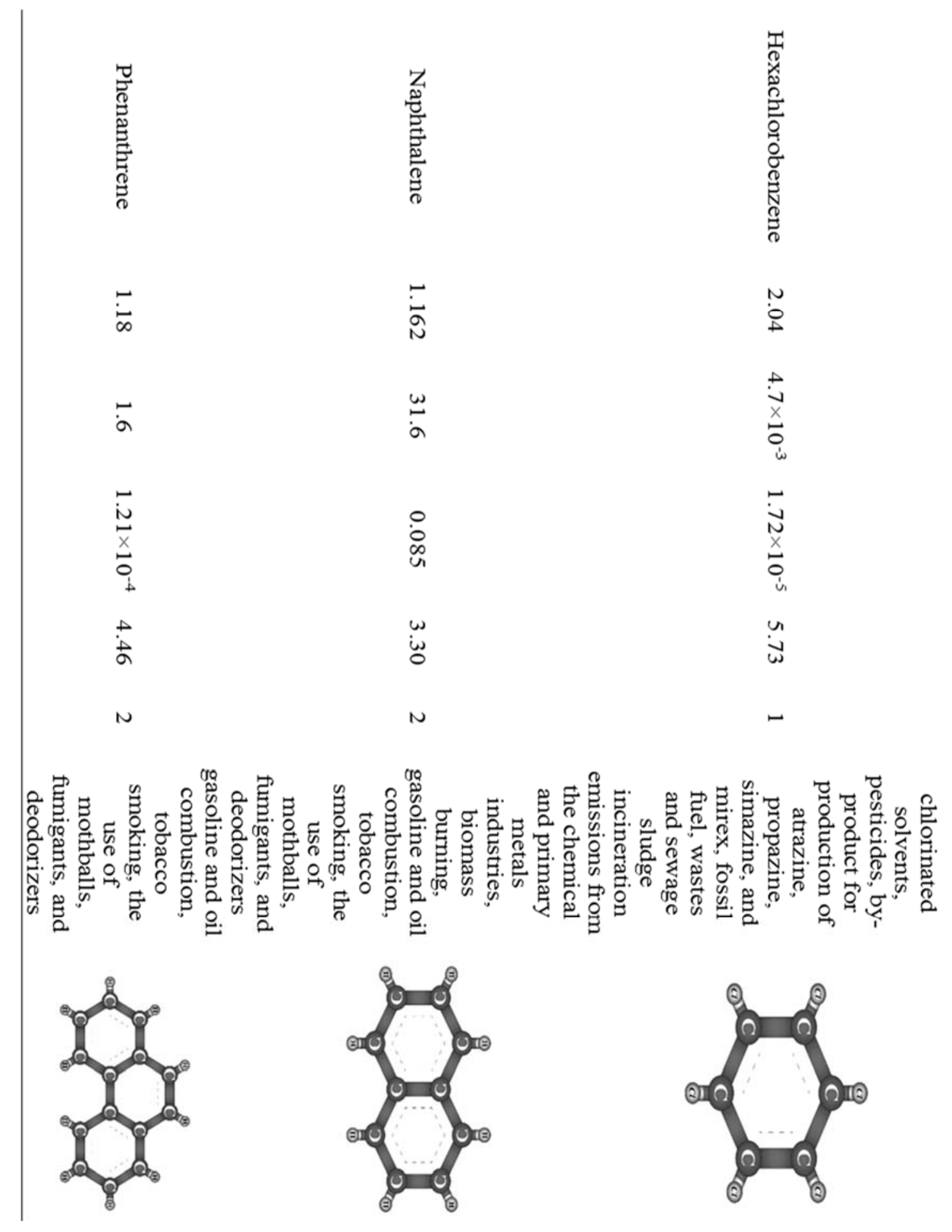




\subsubsection{Extraction Liquids}

American Chemical Society (ACS) grade hexanes (Carolina Co.) and anhydrous dichloromethane (DCM) with purity of $99.8 \%$ (Sigma-Aldrich Co.) were used to extract sorbates from the aqueous phase.

\subsubsection{Batch sorption test}

\subsubsection{Sample preparation}

The sorption capacity of soils sorbents and the effects of sorbents properties (including the grain size, TOC, specific gravity, and specific surface area); sorbates properties (including the water solubility and chlorination of the sorbate molecules), and aqueous environment (co-solvent fraction and temperature) were investigated. The testing matrix of conducted sorption tests is summarized in Table 2-7.

Table 2-7. Test matrix of the lab batch sorption

\begin{tabular}{|c|c|c|c|c|c|}
\hline Test NO. & Sorbate & Co-Solvent & Water & Temperature & Sorbent \\
\hline 1 & HCB & Acetone $(100 \%)$ & $0 \%$ & $25^{\circ} \mathrm{C}$ & HDTMA-bentonite \\
\hline 2 & $\mathrm{HCB}$ & Acetone $(100 \%)$ & $0 \%$ & $25^{\circ} \mathrm{C}$ & PM - 199 (Powder) \\
\hline 3 & $\begin{array}{c}1,2,4 \text { - } \\
\text { Trichlorobenzene }\end{array}$ & Acetone $(100 \%)$ & $0 \%$ & $25^{\circ} \mathrm{C}$ & HDTMA-bentonite \\
\hline 4 & Phenanthrene & Acetone $(100 \%)$ & $0 \%$ & $25^{\circ} \mathrm{C}$ & HDTMA-bentonite \\
\hline 5 & Naphthalene & Methanol (30\%) & $70 \%$ & $25^{\circ} \mathrm{C}$ & HDTMA-bentonite \\
\hline 6 & Naphthalene & Methanol (30\%) & $70 \%$ & $25^{\circ} \mathrm{C}$ & Low plasticity silty clay \\
\hline 7 & Naphthalene & Acetone $(100 \%)$ & $0 \%$ & $25^{\circ} \mathrm{C}$ & HDTMA-bentonite \\
\hline 8 & Benzene & Methanol (30\%) & $70 \%$ & $25^{\circ} \mathrm{C}$ & HDTMA-bentonite \\
\hline 9 & Benzene & $0 \%$ & $100 \%$ & $60^{\circ} \mathrm{C}$ & HDTMA-bentonite \\
\hline 10 & Benzene & $0 \%$ & $100 \%$ & $40^{\circ} \mathrm{C}$ & HDTMA-bentonite \\
\hline 11 & Benzene & $0 \%$ & $100 \%$ & $25^{\circ} \mathrm{C}$ & HDTMA-bentonite \\
\hline 12 & Benzene & $0 \%$ & $100 \%$ & $10^{\circ} \mathrm{C}$ & HDTMA-bentonite \\
\hline 13 & Benzene & $0 \%$ & $100 \%$ & $25^{\circ} \mathrm{C}$ & $\mathrm{Ca}$ - bentonite \\
\hline 14 & Benzene & $0 \%$ & $100 \%$ & $25^{\circ} \mathrm{C}$ & $\mathrm{Na}$ - bentonite \\
\hline 15 & Benzene & $0 \%$ & $100 \%$ & $25^{\circ} \mathrm{C}$ & PM - 199 (Powder) \\
\hline 16 & Benzene & $0 \%$ & $100 \%$ & $25^{\circ} \mathrm{C}$ & PM - 199 (Granular) \\
\hline 17 & Benzene & Acetone $(100 \%)$ & $0 \%$ & $25^{\circ} \mathrm{C}$ & HDTMA-bentonite \\
\hline
\end{tabular}


As an example, the solution preparation procedure for $\mathrm{HCB}$ is described in follow. The HCB stock solution with an initial concentration of $1000 \mu \mathrm{g} / \mathrm{mL}$ was used to generate the HCB solutions with the desired concentrations to investigate the impact of chlorination and water solubility of the sorbate molecules, and also the effect of modifier surfactant on the sorption capacity of the sorbents. For this purpose, acetone was used as the solvent to prepare the HCB solutions with final concentrations of 1, 5, 10, 20,30, 40, 60, 80, and $100 \mu \mathrm{g} / \mathrm{mL}$.

Next, a sets of conical centrifuge tubes with teflon coded lid (CORING Co.) with capacity of $15 \mathrm{~mL}$ were filled with prepared stock solutions. Next, $0.2 \mathrm{~g}$ of sorbent was added to the second set of batch reactors. Then, the batch reactors were agitated for 24 hours before centrifuged at $1500 \mathrm{rpm}$ for $30 \mathrm{~min}$. Next, $8 \mathrm{~mL}$ of supernatant in batch reactor was filtered through a $0.2 \mu \mathrm{m}$ syringe filters (Acrodisc Co.). The filtered samples were extracted with hexane (used for naphthalene) or dichloromethane (used for benzene) at a ratio of 10:1 (v/v) to prepare the samples for analysis. The filtered samples were analyzed with Gas Chromatography equipped with flame ionization detector and electron capture detector (GC-FID/ECD) (Clarus 480, Perkin Elmer Co.). A schematic illustration of the batch sorption procedure is shown in Figure 2-7.

The concentration of the absorbed sorbate by sorbent was measured as:

$S=\frac{V_{m}\left(C_{0}-C\right)}{M_{s}}$

Where $\mathrm{S}(\mu \mathrm{g} / \mathrm{g})$ is the concentration of sorbate sorbed by sorbent, $\mathrm{C}_{0}(\mu \mathrm{g} / \mathrm{mL})$ and $\mathrm{C}$ $(\mu \mathrm{g} / \mathrm{mL})$ are the initial and equilibrium concentrations of sorbate in the solution, respectively. $V_{M}(\mathrm{~mL})$ is the volume of the batch reactor, and $\mathrm{MS}_{\mathrm{S}}(\mathrm{g})$ is the total weight of the sorbent. $\mathrm{S}$ was plotted versus $\mathrm{C}$ and the slope of the linear fit was determined as the 
partitioning coefficient, $\mathrm{K}_{\mathrm{d}}$.

In addition, the sorption kinetics of naphthalene and benzene onto HDTMA-bentonite were quantified by a series of non-equilibrium sorption tests. For kinetic study of naphthalene, 16 stock solutions consisted of $200 \mu \mathrm{g} / \mathrm{mL}$ naphthalene in $70 \%$ deionized water and $30 \%$ methanol were prepared in the batch reactors. For benzene, 32 stock solutions with concentration of $200 \mu \mathrm{g} / \mathrm{mL}$ in deionized water were prepared in the batch reactors. Then $0.2 \mathrm{~g}$ of HDTMA-bentonite were added to batch reactor. At 16 preset time periods (starting from 15 secs to $48 \mathrm{~h}$ ), the supernatant was tested for the naphthalene and benzene concentration.

\section{Benzene solution}
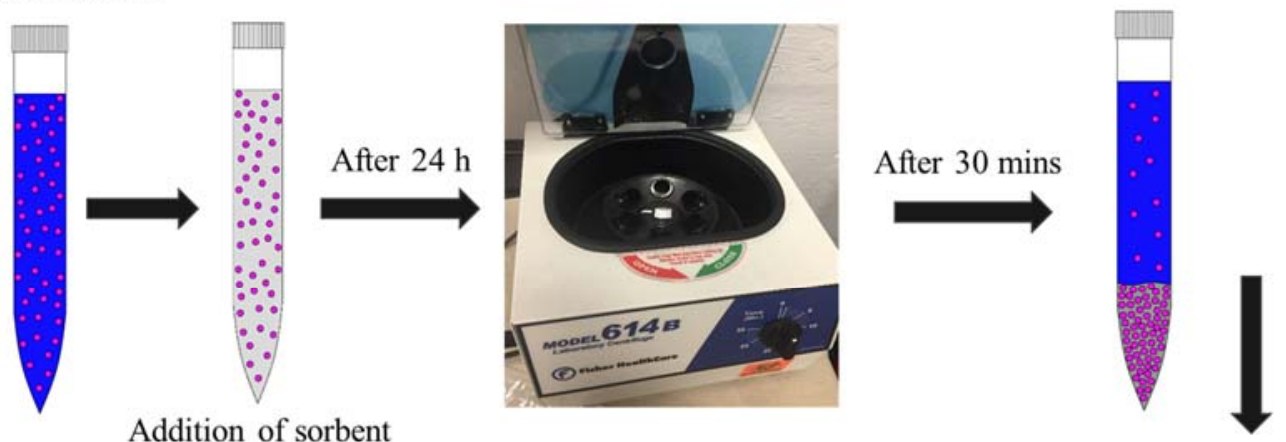

Addition of sorbent

Extraction

Isotherm

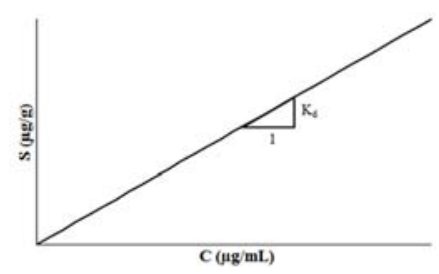

GC Analysis
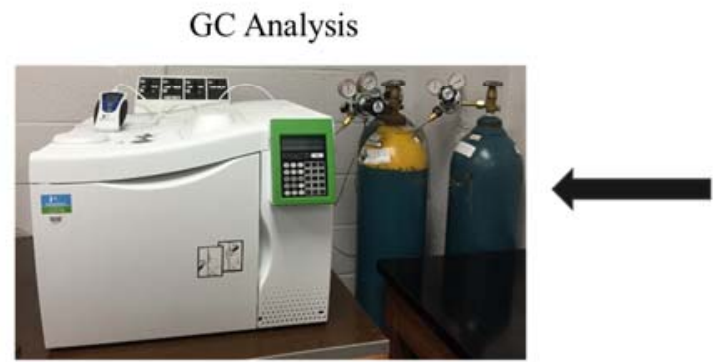

Figure 2-7. Schematic figure of the sorption procedure

\subsection{Results and discussion}




\subsubsection{Overall results}

The effect of major factors including (1) sorbate (chlorination, water solubility), (2) sorbent (organic carbon content, surface charge, surface area, grain size), and (3) aqueous environment (temperature, co-solvent) on the sorption characteristics of studied sorbents were studied.

The acquired results suggested that the affinity of dissolved organic contaminants to organobentonites increased when the number of aromatic rings and chlorination increased in organic contaminants. It was observed that the solubility of molecules decreased in the order of (phenanthrene $>$ naphthalene $>$ benzene) as the aromatic ring increased. Likewise, the solubility of molecules decreased in the order of (hexachlorobenzene $>1,2,4$ trichlorobenzene >benzene) as the chlorinated position on the ring increased. This happened because of the increased hydrophobicity of organic contaminants which resulted in decreased solubility.

The surface modification resulted in expansion of interlayer in the base clay followed by increasing the organic matter loading within the clay interlayer. Consequently, a favorable organophilic phase was created in organobentonite which attributed to higher affinity of dissolved organic contaminants toward organobentonites compared to unmodified sorbents. Also, it was observed that PM-199 showed higher sorption capacity to organic contaminants compared to HDTMA-bentonite. The reason was that PM-199 was synthesized by a double chain surfactant modifier while a single chain surfactant

modifier was used to synthesize HDTMA-bentonite. As a result, the percentage of aliphatic carbon in PM-199 was higher than HDTMA-bentonite which resulted in higher 
sorption capacity of PM-199. In addition, the obtained results suggested that grain size has a negligible impact on the sorption capacity of the sorbents.

Additionally, it was found that the affinity of organic contaminants to organobentonite was decreased by increasing the percentage of solvent in the aqueous solution due to the cosolvency of the co-solvent which increased the solubility and decreased the sorption capacity of hydrophobic organic contaminants. Also, it was observed that the sorption capacity of the organobentonites increased by increasing the temperature due to a higher level of kinetic energy that was induced to the solution and increased the interaction between organobentonite and organic contaminants.

\subsubsection{Effect of molecular characteristics of sorbents on sorption capacity}

In this section, the effect of molecular characteristics of sorbents on the sorption behavior of organically modified and unmodified sorbents is discussed.

The obtained results from the batch sorption study of dissolved benzene in aqueous solution indicated that the sorption capacity of organobentonites to organic contaminants were significantly higher than unmodified bentonites. The partitioning coefficient of PM199 and HDTMA-bentonite for benzene solution were measured as 251.4, and 82.97 $\mathrm{mL} / \mathrm{g}$ respectively. While, the partitioning coefficient of Ca-bentonite and Na-bentonite for benzene solution decreased drastically to 19.83 , and $9.75 \mathrm{~mL} / \mathrm{g}$ respectively. As it mentioned previously, the intercalation of QACs with base clays increases the organic matter loading within the clay interlayer. Many studies have been done on the effect of

organic carbon loading on the sorption capacity of sorbents (Bartelt-Hunt et al. 2003; 
Boyd et al. 1988; Redding et al. 2002). The natural organic carbons existing on the surface of sorbents has higher affinity to interact with organic compounds. As a result, unmodified bentonites and silty clay presented a negligible sorption capacity to organic contaminants because they have limited percentage of natural occurring carbon in their structure (Redding et al. 2002). However, organobentonites exhibited significant sorption capacity to organic contaminants because the intercalated modifier cations increase the carbon loading on the surface of organobentonites (Boyd et al. 1988; Smith and Jaffe 1994).The effect of TOC on the partitioning coefficient of studied sorbents has been shown in Figure 2-8.

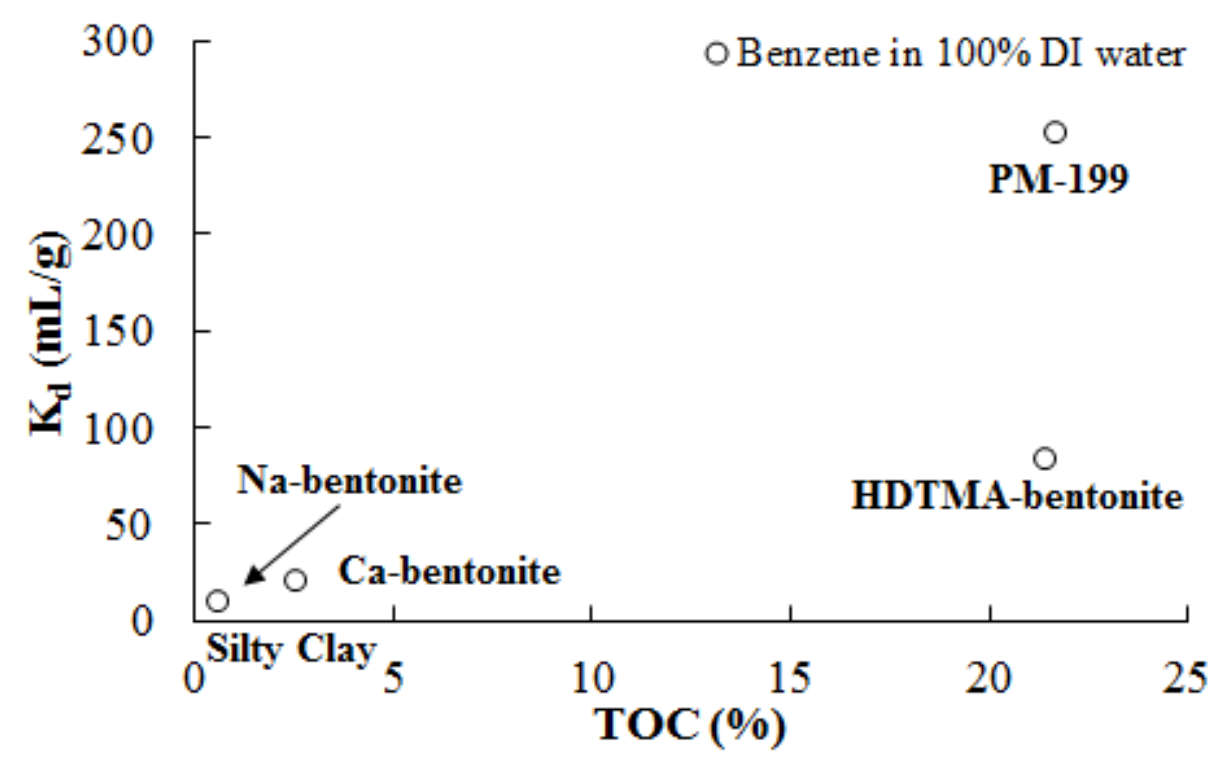

Figure 2-8. Effect of TOC on the partitioning coefficient

In addition, it was noticed that PM-199 exhibited much higher sorption capacity for organic contaminant compared to HDTMA-bentonite. This result was validated using two sets of sorption study including the sorption of benzene from aqueous solution and HCB from 30\% acetone $+70 \%$ DI water solution to PM-199 and HDTMA-bentonite. The partitioning coefficient of PM-199 and HDTMA-bentonite for HCB were measured 
as 240.67 , and $133.83 \mathrm{~mL} / \mathrm{g}$ respectively. It was found that the higher sorption capacity of PM-199 compared to HDTMA-bentonite was due to the higher number of aliphatic carbons in PM-199 compared to HDTMA-bentonite. The number of intercalated aliphatic carbons can be increased either by increasing the length of carbon chain or the number of organic chains, which results in higher sorption of organic compounds (Burns et al. 2006). Due to the mentioned reason, it was anticipated that PM-199 exhibits higher sorptivity compared to the HDTMA-bentonite because PM-199 was synthesized by a double chain surfactant compared to HDTMA-bentonite that was synthesized by a single chain surfactant. The obtained results are demonstrated Figure 2-9.

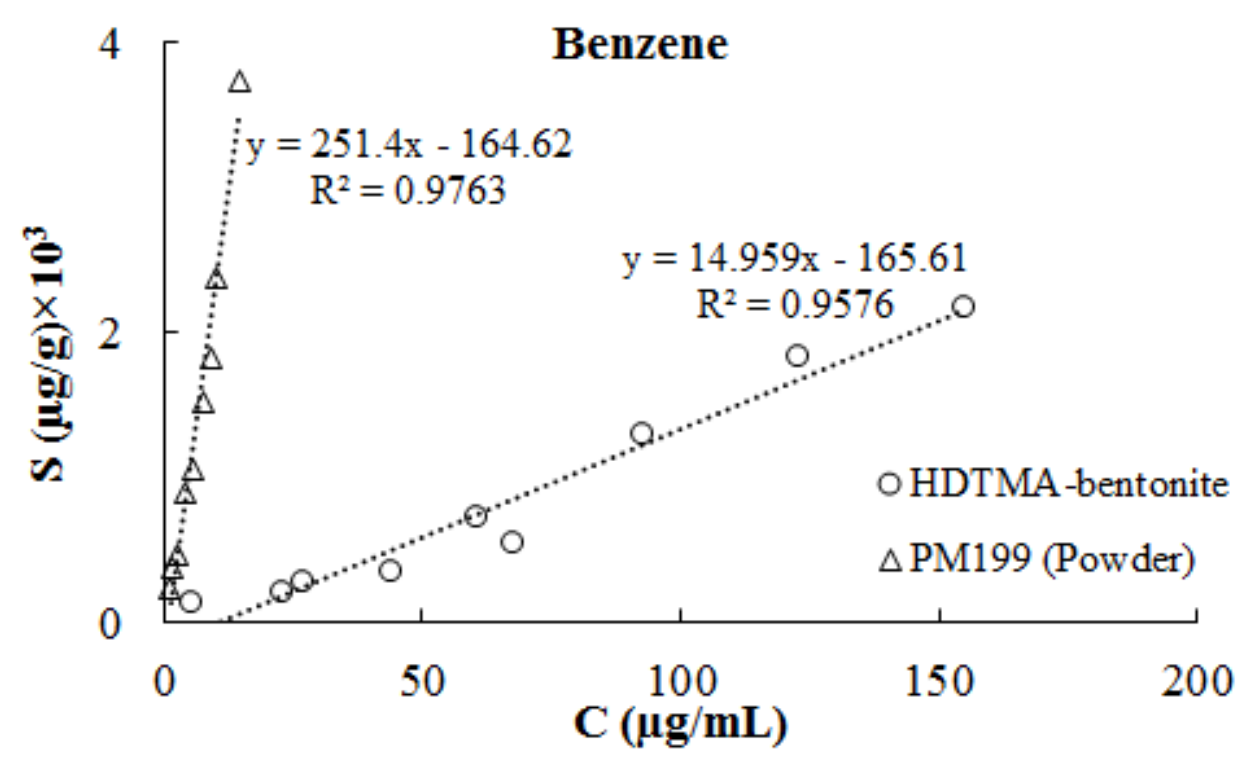

(a) 


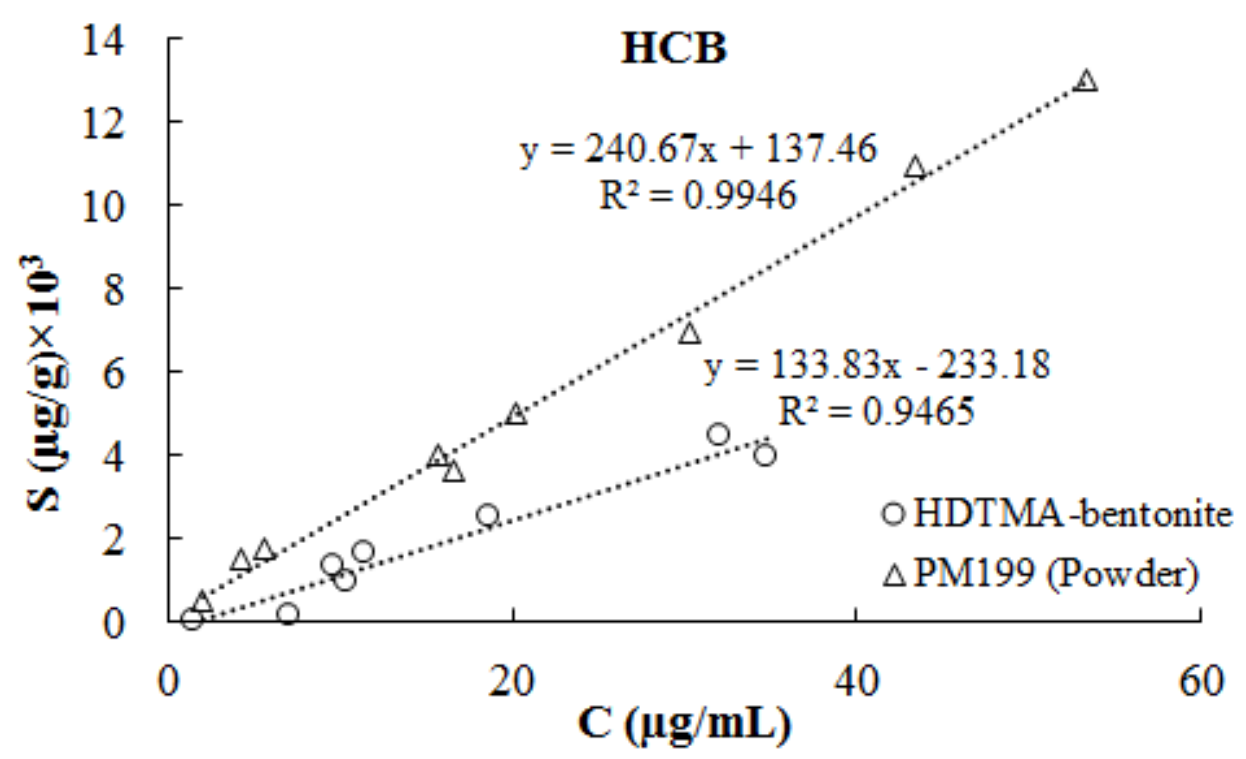

(b)

Figure 2-9. Sorption capacity of PM-199 and HDTMA-bentonite as a function of organic cation types for (a) benzene in aqueous solution', and (b) HCB in $\mathbf{3 0 \%}$ acetone $+\mathbf{7 0} \%$ DI water solution

Also, the sorption capacity of PM-199 in the form of powder and granular for dissolved benzene in aqueous solution was investigated to study the effect of particle size as a physical property of sorbent on the sorption capacity of sorbent. The results are presented in Figure 2-10. The partitioning coefficient of powder PM-199 and granular PM-199 for benzene were measured as 251.4, and $231.37 \mathrm{~mL} / \mathrm{g}$ respectively. As a result, no significant differences between the partitioning coefficient of powder and granular PM199 was observed. It can be concluded that the particle size has a negligible impact on the sorptivity of sorbents.

\footnotetext{
${ }^{1}$ The isotherm for benzene sorption by HDTMA is scaled down by 10 .
} 


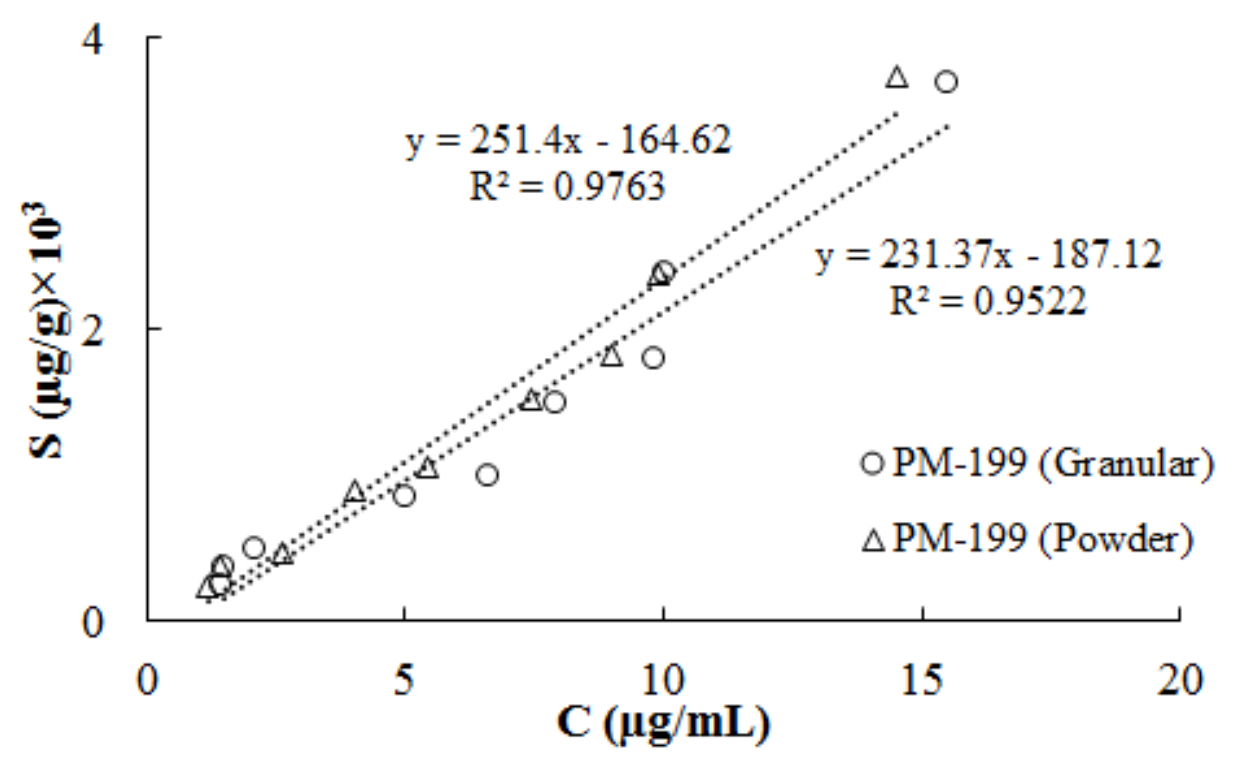

Figure 2-10. Effect of particle size on the sorption capacity of PM-199

\subsubsection{Effect of the characteristics of sorbates on sorption capacity}

Although the molecular characteristics of sorbents has significant impact on their sorption capacity, the molecular structure of sorbates can directly affect the sorption capacity of geo-material. In this section, the effect of sorbate structure on the sorption capacity organic compounds onto HDTMA-bentonite has been investigated. The sorption capacity of HDTMA-bentonite as a function of two variable factors including the chlorination and the number of aromatic rings has been quantified by conducting a series of batch sorption tests.

Benzene, 1,2,4-Trichlorobenzene, and $\mathrm{HCB}$ were selected as the organic contaminants to study the impact of chlorination on the sorption capacity of HDTMA-bentonite. For this reason, a set of batch sorption test for each organic compound was conducted using acetone as co-solvent. The sorption data for each component was fitted with a linear isotherm which confirmed that the sorption of studied organic contaminants onto the 
HDTMA-bentonite occurred due to the partitioning mechanism. The obtained isotherms are illustrated in Figure 2-11.

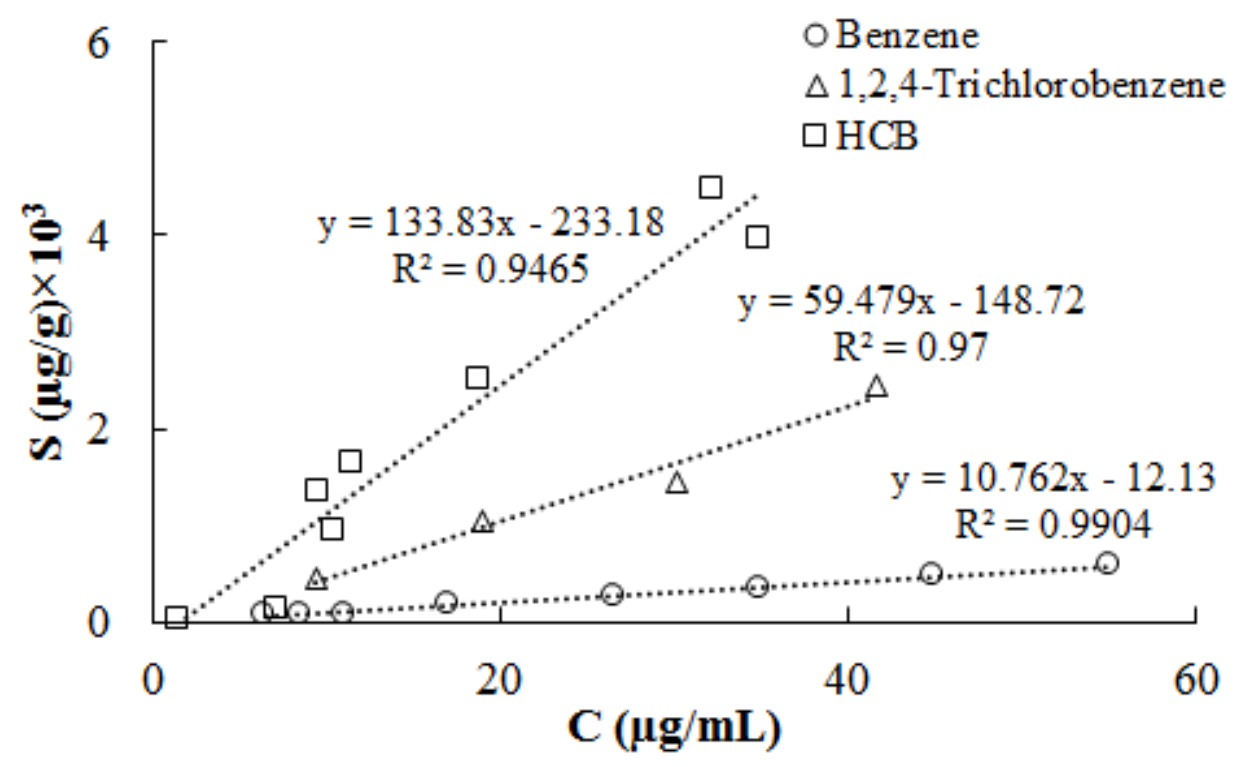

Figure 2-11. Chlorination effect on the sorption capacity of HDTMA-bentonite ${ }^{2}$

The partitioning coefficient of HDTMA-bentonite for benzene, 1,2,4-Trichlorobenzene, and $\mathrm{HCB}$ were measured as $10.76,59.47$, and $133.83 \mathrm{~mL} / \mathrm{g}$, respectively. For the sorption of three studied compounds to HDTMA-bentonite, the sorption capacity increased as the compound chlorinated. It can be said that the chlorination decreases the solubility of compounds. In benzene, hydrogen atoms facilitate the hydrogen bonding of benzene with acetone which demonstrates a weak partitioning to the HDTMA-bentonite compared to the $\mathrm{HCB}$ with relatively lower solubility in acetone. As a result, the partitioning coefficient of studied compounds decreases in the order of $\mathrm{HCB}>1,2,4-$ trichlorobenzene $>$ benzene, respectively.

Additionally, benzene, naphthalene, and phenanthrene were selected to study the effect of aromatic rings on the sorption capacity of HDTMA-bentonite. Therefore, a set of batch

2 The isotherm for 1,2,4-Trichlorobenzene is scaled down by 10 
sorption test for each organic compound was carried out using acetone as co-solvent. The sorption data for each component was fitted with a linear isotherm. The isotherm parameters are illustrated in Figure 2-12.

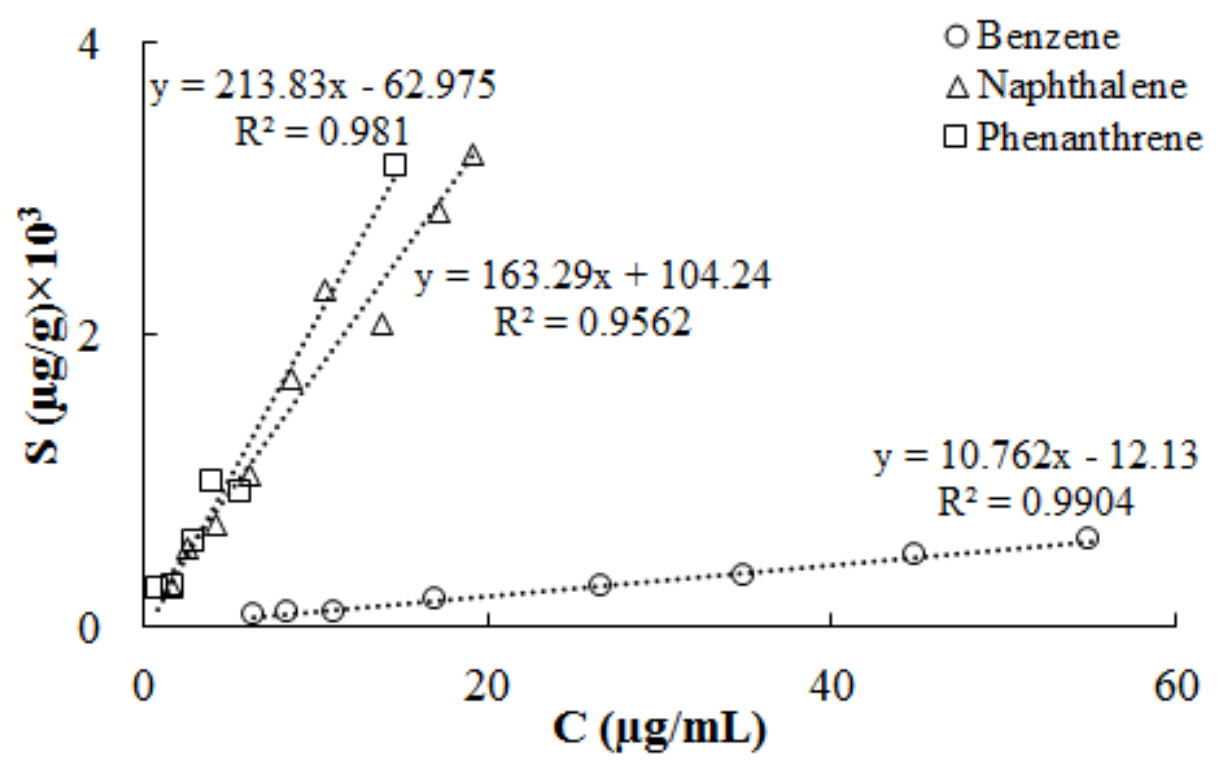

Figure 2-12. Aromatic benzene ring effect on the sorption capacity of HDTMAbentonite $^{3}$

The partitioning coefficient of HDTMA-bentonite for benzene, naphthalene, and phenanthrene were measured as $10.76,163.29$, and $213.83 \mathrm{~mL} / \mathrm{g}$, respectively. It was observed that the sorption capacity of HDTMA-bentonite increased when the number of aromatic rings increased in the compound structure. The partitioning coefficient of benzene is much lower than naphthalene and phenanthrene. It can be attributed to higher solubility of benzene in acetone compared to naphthalene and phenanthrene. It suggests that organic compounds with higher solubility have lower sorption into sorbent due to the partitioning mechanism compared to the organic compounds with lower solubility

\footnotetext{
${ }^{3}$ The isotherm for Naphthalene is scaled down by $10 \&$ the isotherm for Phenanthrene is scaled down by 100
} 
(Changchaivong and Khaodhiar 2009). In conclusion, the $K_{d}$ values decrease in the order of phenanthrene>naphthalene>benzene, respectively.

\subsubsection{Effect of aqueous environment}

Additionally, the effect of co-solvent on the sorption behavior of organobentonite (HDTMA-bentonite) was studied. The stock solutions were prepared by using acetone as the non-polar co-solvent and DI water as polar solvent. Benzene and naphthalene were selected as organic sorbates. It was observed that the partitioning coefficient of benzene in water is $149.59 \mathrm{~mL} / \mathrm{g}$ and decreased to $75.51 \mathrm{~mL} / \mathrm{g}$ and $10.76 \mathrm{~mL} / \mathrm{g}$ by increasing the percentage of acetone from $30 \%$ to $100 \%$, respectively. it was concluded that the dissolved benzene in water has 13 times higher affinity to HDTMA-bentonite compared to dissolved benzene in acetone. The acquired results are shown in Figure 2-13 (a). Likewise, it was observed that the sorption capacity of HDTMA-bentonite to naphthalene dissolved in a aqueous solution consisted of $30 \%$ acetone was $1253.4 \mathrm{~mL} / \mathrm{g}$ and decreased to $163.29 \mathrm{~mL} / \mathrm{g}$ when the naphthalene dissolved in $100 \%$ acetone. The acquired results are shown in Figure 2-13 (b). This result showed that the capacity of HDTMA-bentonite to sorb naphthalene decreased drastically (by 86\%) when the solvent for naphthalene changed from aqueous solution with $30 \%$ acetone to $100 \%$ acetone. As a result, the partitioning coefficient increases when the co-solvent fraction in the solution decreases. Increasing the co-solvent percentages in the solution will be accompanied by higher water solubility of organic components which results in lower affinity to the sorbents (Nzengung et al. 1996). Rao et al. (1990) concluded a similar result. They explained that the cosolvency of the co-solvent increased the solubility and decreased the sorption capacity of hydrophobic organic chemicals. 


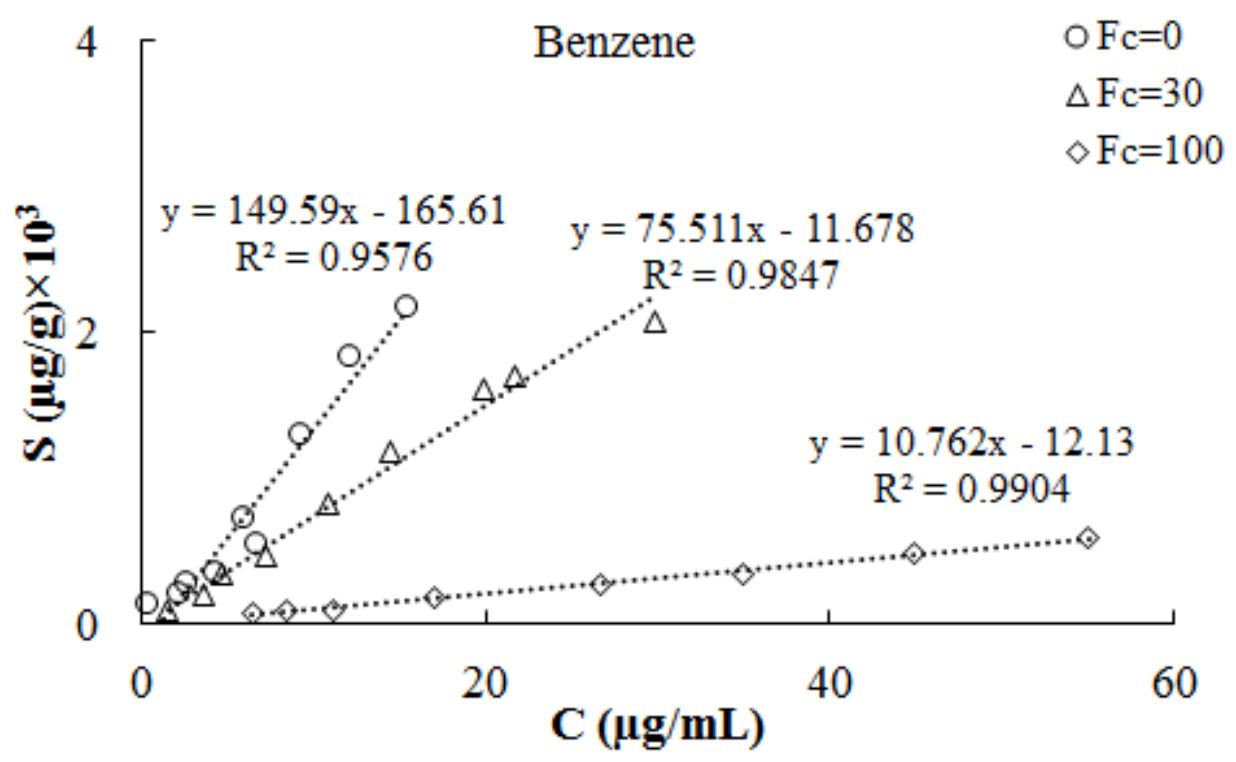

(a)

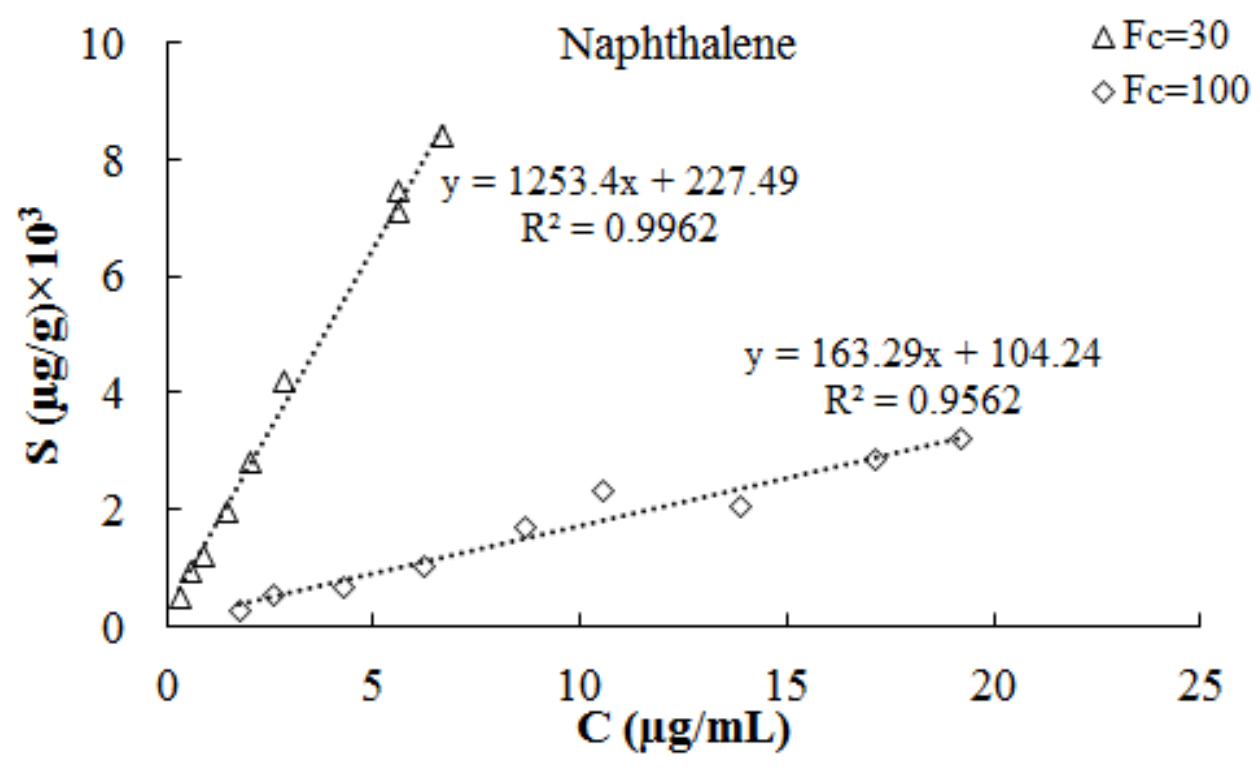

(b)

Figure 2-13. Sorption capacity of HDTMA-bentonite as a function of co-solvent for (a) benzene $e^{4}$, and (b) naphthalene ${ }^{5}$

Moreover, the sorption of benzene onto HDTMA-bentonite was characterized as a function of temperature variation. The obtained results are presented in Figure 2-14.

\footnotetext{
${ }^{4}$ The isotherms for benzene sorption $\left(\mathrm{F}^{\mathrm{c}}=0\right.$ \& 30$)$ are scaled down by 10 .

${ }^{5}$ The isotherm for naphthalene sorption $\left(\mathrm{F}^{\mathrm{c}}=100\right)$ is scaled down by 10 .
} 


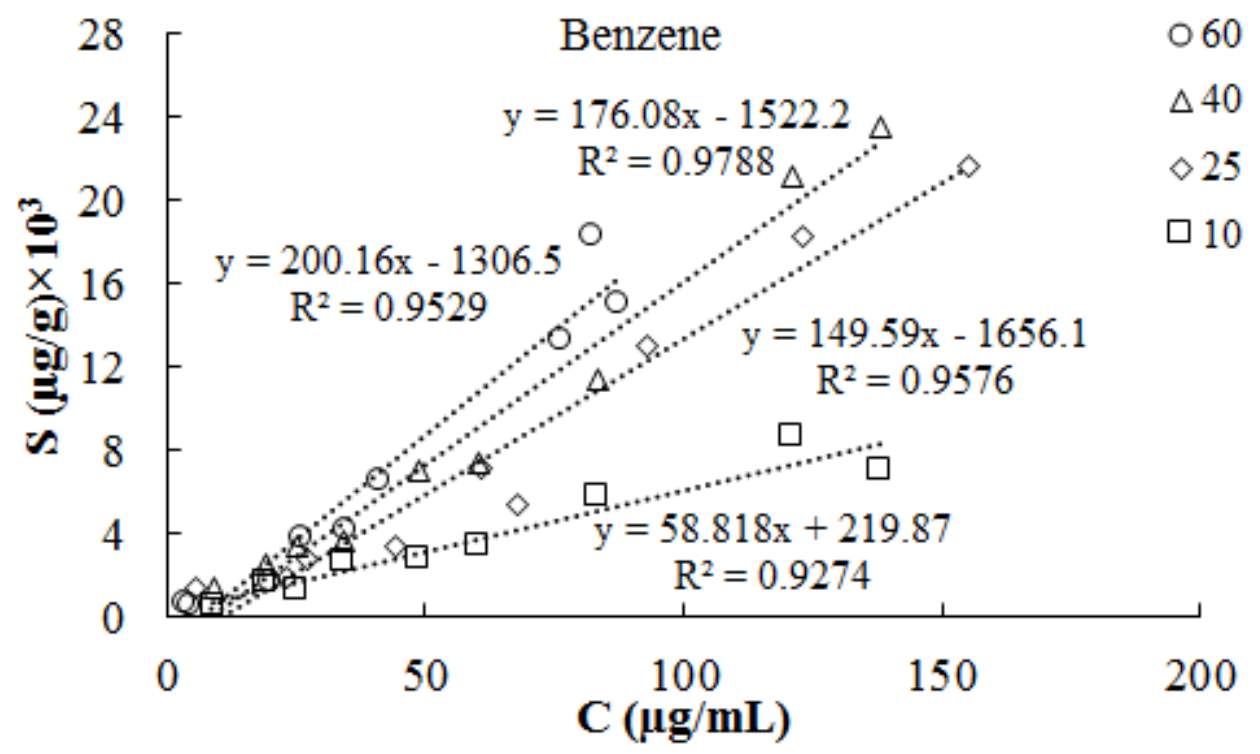

Figure 2-14. Effect of temperature variation on the sorption capacity of HDTMAbentonite

The sorption isotherm displayed a linear behavior for the entire range of studied temperature. This indicated that the governing reaction process between benzene and HDTMA-bentonite in various temperatures was partitioning. The partitioning coefficient of HDTMA-bentonite at $60^{\circ} \mathrm{C}$ was measured as $200.16 \mathrm{~mL} / \mathrm{g}$ and decreased to 176.08 , 149.59 , and $58.81 \mathrm{~mL} / \mathrm{g}$ by lowering the temperature from $40^{\circ} \mathrm{C}$ to $25^{\circ} \mathrm{C}$ and $10^{\circ} \mathrm{C}$, respectively. the results suggested that the sorptivity of benzene in aqueous solution to HDTMA-bentonite increases by increasing the temperature. The reason may attribute in the higher kinetics energy that will be induced to the solution by increasing the temperature. As a result, the kinematic energy of dissolved contaminant compounds increases which increases the level of interaction between sorbent and sorbate. Rowe et al. (2005) derived the same conclusion for the sorption of benzene to Na-bentonite.

\subsubsection{Kinetic sorption test}


The results of sorption kinetic are shown in Figure 2-15. The kinetic study revealed that the uptaking of naphthalene by HDTMA-bentonite occurred quicker (20 s) when compared with the uptaking benzene (20 min). It was observed that approximately $85 \%$ of sorbed concentration of naphthalene at equilibrium were uptaken by the HDTMAbentonite within first 20 seconds while only $5 \%$ of benzene was sorbed to the HDTMAbentonite in first 20 seconds. These results suggested that the rate of sorption for benzene is 17 times lower than naphthalene. After the initial rapid sorption stage, the rest of ultimate sorption for both sorbents were attained in a slow sorption stage that was completed in 12 hours.

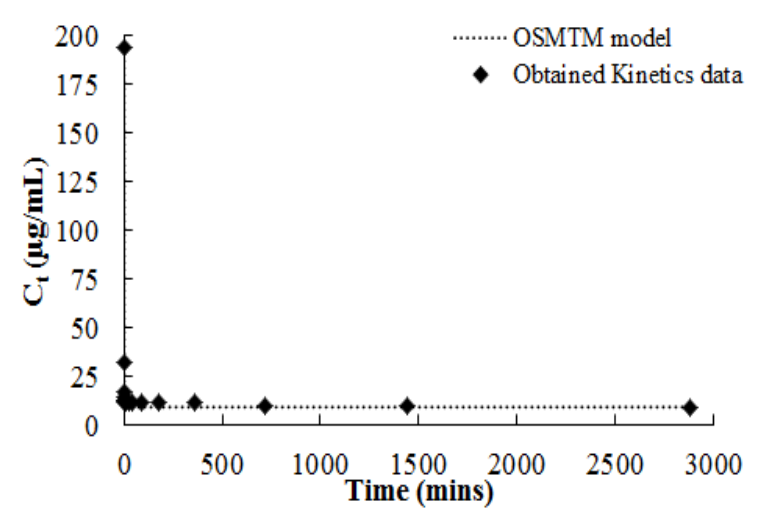

(a)

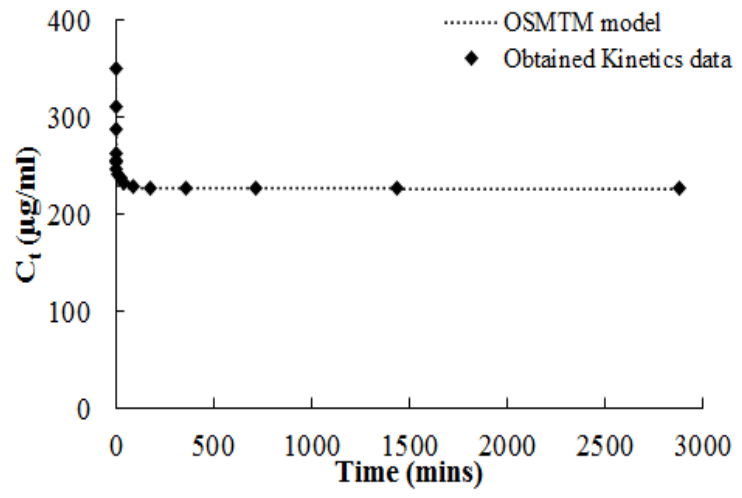

(b)

\section{Figure 2-15. Sorption kinetic of (a) naphthalene (b) benzene on HDTMA-bentonite}

The kinetic parameters for both studies were estimated by applying the on-site transfer model described by the following equation (Nzengung et al. 1997):

$C_{t}=C_{e}+\left[C_{0}-C_{e}\right] \exp \left[-\left(\frac{\varepsilon C_{0}}{C_{e}}\right) t\right]$

where $C_{t}$ is the solution concentration at time $(t)(\mu g / m L), C_{e}$ is the solution concentration at equilibrium $(\mu \mathrm{g} / \mathrm{mL}), \mathrm{C}_{0}$ is the initial solution concentration $(\mu \mathrm{g} / \mathrm{mL}), \mathrm{t}$ is time $(\mathrm{min})$, 
and $\varepsilon$ is mass transfer coefficient $(1 / \mathrm{min})$. As a result, the mass transfer coefficient $(\varepsilon)$ was optimized using the partitioning coefficient constant $\left(\mathrm{K}_{\mathrm{P}}\right)$ obtained from batch sorption study for studied sorbates, naphthalene and benzene. The measured kinetic parameters are summarized in Table 2-8.

Table 2-8. Sorption kinetics and equilibrium sorption parameters

\begin{tabular}{ccccc}
\hline Sorbate-Sorbent & $\begin{array}{c}\mathrm{K}_{\mathrm{P}}\left(\mathrm{K}_{\mathrm{d}}\right) \\
(\mathrm{mL} / \mathrm{g})\end{array}$ & $\mathrm{R}^{2}$ & $\varepsilon(1 / \mathrm{min})$ & $\begin{array}{c}\text { Equilibrium time } \\
(\mathrm{h})\end{array}$ \\
\hline Naphthalene/HDTMA-bentonite & 1355.50 & 0.98 & 0.45 & 12 \\
Naphthalene/Silty clay & 4.53 & 0.95 & N. A. & N. A. \\
Benzene/HDTMA-bentonite & 149.59 & 0.95 & 0.39 & 12 \\
Benzene/PM-199 & 251.4 & 0.97 & N. A. & N. A. \\
\hline
\end{tabular}

The obtained results are in good agreement with previous researches and indicated that the equilibrium sorption governed the transport of naphthalene and benzene in soils when given the low flow rate or long detention time. Also, it was assumed that the desorption of naphthalene and benzene occurs fast as well and the one-dimensional mass transport model is valid for the contaminant transport modeling in the next few chapters (Freeze and Cherry 1979).

\subsection{Conclusions}

In this chapter, the sorption characteristics of two representative organobentonites were studied by examining the effects of sorbate properties, sorbents properties and the aqueous conditions. It was observed that the surface modification increased the organic carbon content of Ca-bentonite from $2.58 \%$ to $21.44 \%$ for HDTMA-bentonite. The increasing of the organic carbon content crated a organophilic phase which increased the affinity of organic contaminants toward organobentonite. As a result, the sorption 
capacity of organobentonites to organic contaminants were considerably higher than unmodified bentonite. Also, the result from the sorption study of benzene solution confirmed that the partitioning coefficient of PM-199 and HDTMA-bentonite for benzene solution were much higher compared to the partitioning coefficient of Ca-bentonite and Na-bentonite. In addition, the results from sorption study suggested that PM-199 exhibited much higher sorption capacity for organic contaminant compared to HDTMAbentonite. In addition, the obtained results suggested that grain size has a negligible impact on the sorption capacity of the sorbents.

In addition, the effect of chlorination and water solubility of sorbates on the sorption characteristics of HDTMA-bentonite was investigated. The acquired results suggested that the affinity of dissolved organic contaminants to organobentonites increased when the number of aromatic rings and chlorination increased in organic contaminants. This happened because the chlorination and increased aromatic rings result in increased hydrophobicity of organic contaminants and result in decreased solubility. It was observed that the solubility of molecules decreased in the order of (phenanthrene $>$ naphthalene $>$ benzene) as the aromatic ring increased. Likewise, the solubility of molecules decreased in the order of (hexachlorobenzene>1, 2, 4 trichlorobenzene $>$ benzene) as the chlorinated position on the ring increased. The organic contaminants with lower solubility have higher organophilicity which results in higher affinity toward organobentonite.

Finally, the effect of aqueous condition on the sorption characteristics of HDTMAbentonite was investigated. The results of this study suggested that the sorption capacity of HDTMA-bentonite to the organic contaminants decreased when the fraction of co- 
solvent increased in the solution because the cosolvency of the co-solvent increased the solubility and decreased the sorption capacity of hydrophobic organic contaminants. Moreover, the effect of temperature on the sorptivity of HDTMA-bentonite was evaluated. It was found that the sorption capacity of sorbents to the organic contaminants increases when the environment temperature increases. The reason may attribute in the higher kinetics energy that will be induced to the solution by increasing the temperature. As a result, the kinematic energy of dissolved contaminant compounds increased which increases the level of interaction between sorbent and sorbate. 


\section{CHAPTER THREE ENGINEERING BEHAVIORS OF COMPACTED CLAY AMENDED WITH ORGANOCLAYS}

\subsection{Introduction}

Compacted clay liner (CCL) is the most common soil liner for landfills or underground storage tanks. CCLs are mechanically modified soils to reduce the fluid flow and mass transport in the subsurface (Broderick and Daniel 1990). Most commonly, CCLs are compacted to a thickness of $600 \mathrm{~mm}(2 \mathrm{ft})$ or $900 \mathrm{~mm}(3 \mathrm{ft})$. However, their thickness can reach to 1.2 to $3 \mathrm{~m}$ or higher, especially for the applications in vertical barriers (or vertical cutoff walls). There are several major types of CCL materials: natural soils, soilbentonite mixtures and others. Naturally occurring clays are the most common components in CCLs. This group of soil consists of significant amount of clay including lean clay $(\mathrm{CL})$, fat clay $(\mathrm{CH})$, or clayey sand $(\mathrm{SC})$. A mixture of natural soil and bentonite is typically used when the excavated soil from vicinity borrows does not contain significant percentages of clay content. Bentonites, mainly composed of sodium or calcium smectites are ideal amendments in CCLs to provide low permeability and to assure barriers performances (Boynton and Daniel 1985; Rowe et al. 2004).

The CCLs are typically designed to have a low hydraulic conductivity at the field. Daniel and Benson (1990) demonstrated that the hydraulic conductivity of a CCL would decrease if (1) the level of energy in compaction effort increased; (2) the water content 
slightly increased from the optimum water content (Figure 3-1). For the CCL application in a horizontal or a vertical barrier, two factors must be considered and it yields an acceptable zone on the compaction curve: (1) the CCL must have its hydraulic conductivity lower than $10^{-7} \mathrm{~cm} / \mathrm{s}$. A good example is illustrated in Figure 3-1: for the reduced proctor test, the compacted soil must have a water content between $\mathrm{W}_{1}$ and $\mathrm{W}_{2}$ such that the resultant hydraulic conductivity of the soil will be lower than $10^{-7} \mathrm{~cm} / \mathrm{s}(2)$ density. Typically, the soil must be compacted at a dry density $\gamma_{\mathrm{d}}$ greater than $90 \sim 95 \%$ of its maximum dry density $\gamma_{\max }$ such that the soil will be stronger and less compressible. Most commonly, the requirement of the hydraulic performance of the CCL defines the range of water content in which the soil should be compacted while the requirement of strength and deformation defines the lower bound of the dry density of the compacted CCL. To meet both requirements, the combination of water content and dry density is required to be situated in the acceptable zone, as illustrated in Figure 3-2. 


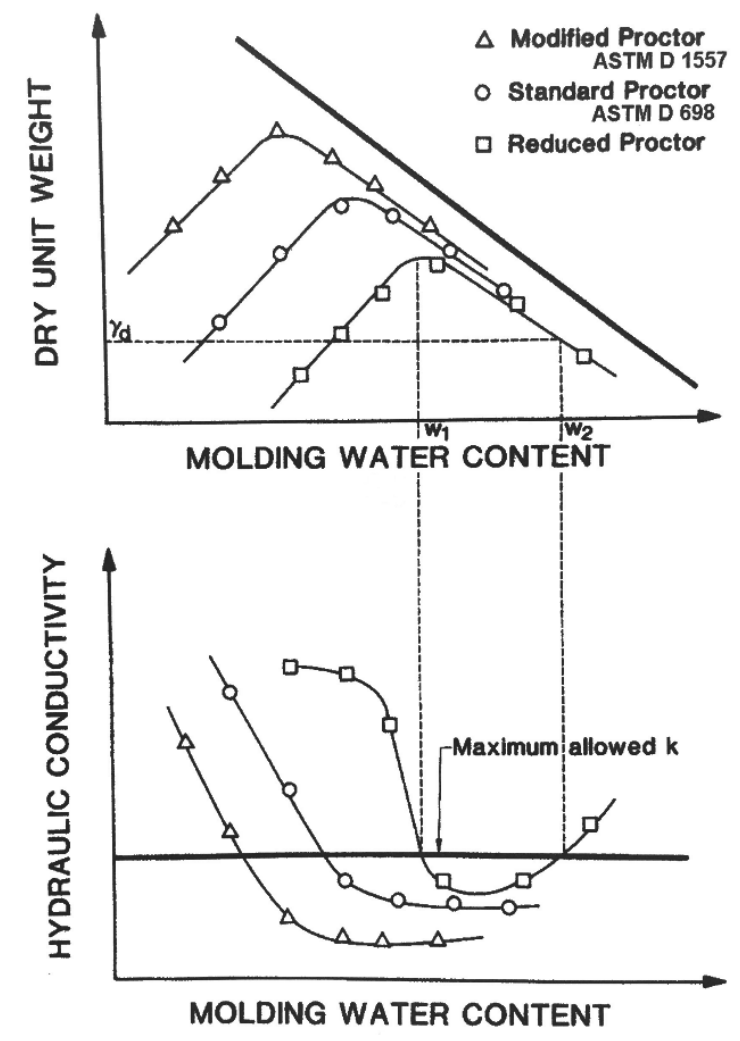

Figure 3-1. Recommended design criteria for the compaction of CCLs (Sharma and Reddy 2004)

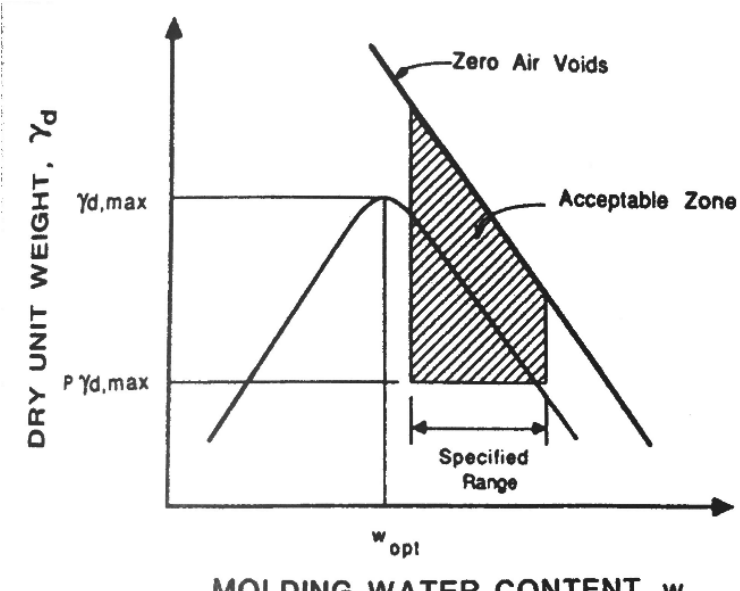

MOLDING WATER CONTENT, w

Figure 3-2. Acceptable range of water content and dry unit weight for CCLs (Sharma and Reddy 2004) 
Although the CCLs are designed to provide a low rate of permeability, the previous studies indicated that the permeability of CCLs to the certain organic contaminants could increase significantly due to the chemical incompatibility. For instance, it was observed that the CCL materials shrink in contact with pure phase organic compounds or petroleum-related products and cracks are developed in entire CCL profile which cause higher hydraulic conductivity (Bowders and Daniel 1987; Broderick and Daniel 1990; Fernandez and Quigley 1985).

Also, the mass flux of contaminant through CCLs can be significant even though the low flow rate regime governs the advection of contaminants through CCLs because the filling materials in conventional CCLs have non-interactive nature and low sorption capacity (Bright et al. 2000; Brown and Burris 1996). The advection-dispersion mechanism controls the contaminant mass transport through CCLs with non-interactive components because no chemical or biochemical reactions take place in the pore volumes of fillings that uptake or reduces the concentration of contaminants (Shackelford 1994).This indicates that a low level of pure organic or petroleum derivative contaminants can raise a great concern regarding the long term performance of CCL systems (Ma et al. 2015). Therefore, additional investigation on the behavior of CCLs in contact with certain chemical contaminants is required to enhance the long-term performance of CCL system.

The obtained results from the recent investigations have proposed the possibility of using the chemically reactive geo-materials as an additive in CCL soil to enhance the chemical compatibility and the contaminant attenuation capability of CCLs. Consequently, the concept of low permeability reactive barrier with reactive geo-material amendments has been proposed for the clay liner applications(Lo et al. 1997; Wiles et al. 2005). .The 
advantages of the proposed reactive barriers over the conventional CCLs is their ability to uptake, immobilize and/or degrade the contaminant transport (Figure 3-3) while maintaining the hydraulic conductivity of the barrier in a satisfactory range (Crocker et al. 1995; Lo and Yang 2001; Wagner et al. 1994). Many different studies have been conducted to identify suitable natural or engineered geo-material candidates as reactive amendment in CCLs (LaGrega et al. 1994). Other than bentonite, mixture of bentonite and fly ash, modified soils, activated carbon, paper industry sludge, and many other commercial additives can be used as a CCL component under certain circumstances. By all of the studied geo-materials, fly ash, zeolite, organo-zeolite, coated sand and organoclays have shown promising potential as reactive amendment in order to improve the soptivity of CCLs (Lo and Liljestrand 1996; Prasad et al. 2012; Varank et al. 2011; Younus and Sreedeep 2012).Among the proposed amendments, organoclays have demonstrated the most effective sorption capacity of organic contaminants (Benson et al. 2015; de Paiva et al. 2008; Gates et al. 2004; Soule and Burns 2001).

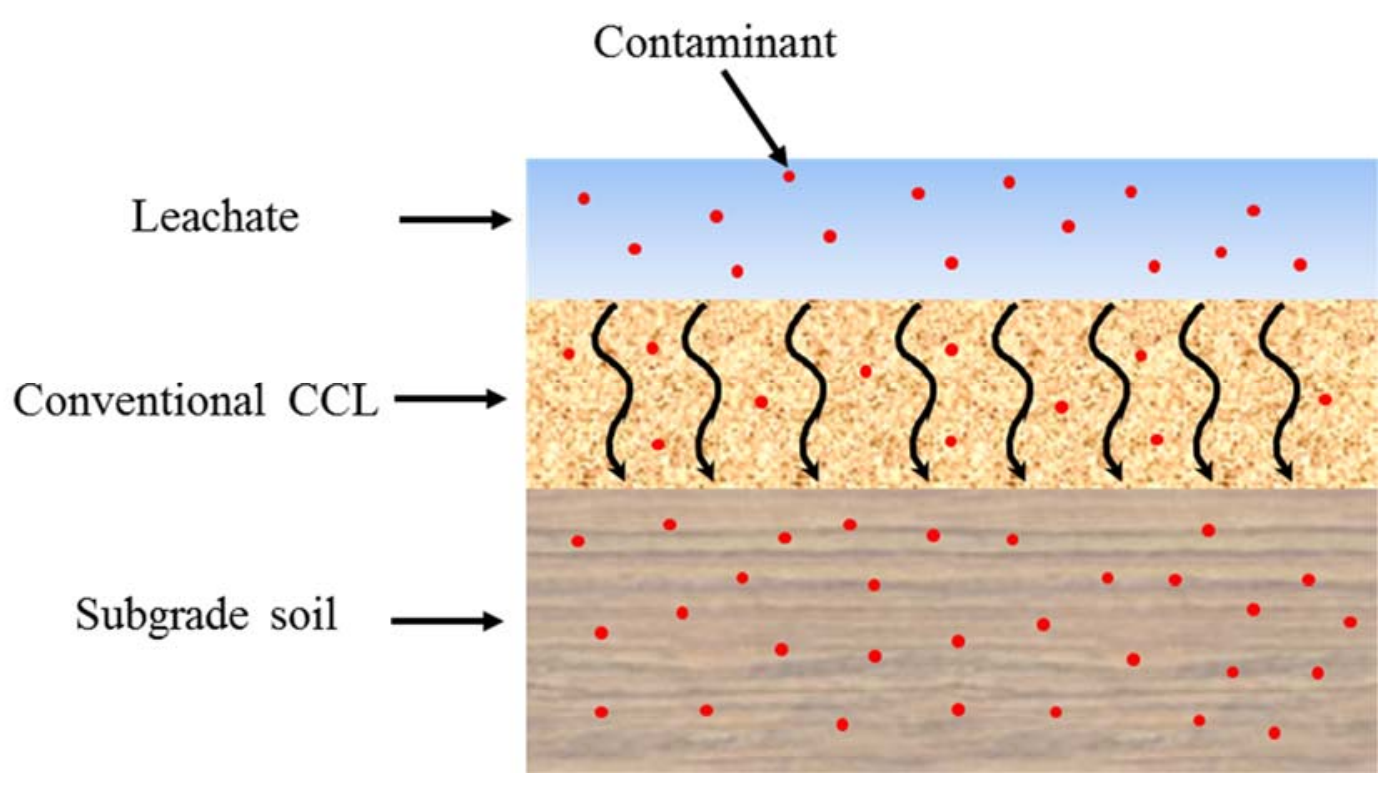


(a)

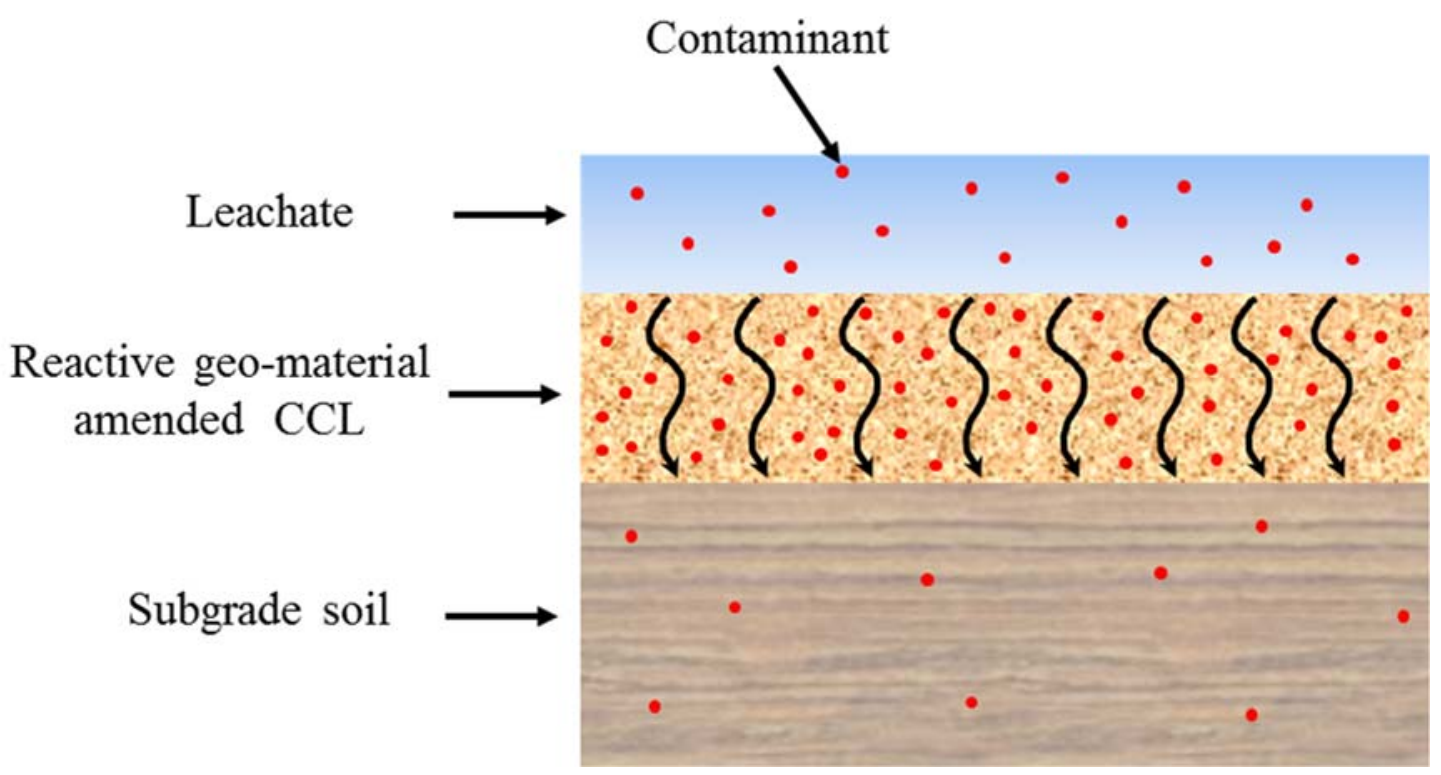

(b)

Figure 3-3. Contaminant transport through (a) conventional CCL (b) reactive geomaterial amended CCL

Organoclays are suitable sorbents to uptake nonpolar or low-polarity compounds from aqueous phase. The organic surfactant/clay hybrids also have increased swelling tendency and plasticity in organic liquids and decreased permeability for non-polar liquids.

Based on previous studies, organoclays are efficient to enhance the retention capacity of organic liquids or petroleum products by the CCLs (Lo and Yang 2001; Moon et al. 2007; Smith et al. 2003; Yang and Lo 2004). It was observed that the permeability of organoclays amended CCLs to gasoline decreased two to four orders of magnitude compared to the hydraulic conductivity of same system permeated by water (Smith et al. 2003). Although the organoclays increase the hydraulic conductivity of barrier system when permeated with water, a low dosage of organoclay in the CCL soil has limited 
impact the overall permeability of the CCLs (Yang and Lo 2004). However, a small fraction of organoclays in GCL soil increases significantly the attenuation capability of non-polar organics, chlorinated organics, polycyclic hydrocarbons and pesticides from aqueous phase (Boyd et al. 1988; Jaynes and Boyd 1990; Jaynes and Boyd 1991; Larsen et al. 1992; Montgomery et al. 1991; Owabor et al. 2010; Qu et al. 2008; Smith et al. 1990). Nzengung et al. (1996)proposed that the organic contaminants can be absorbed by organically modified clays through the partitioning process, which mostly the partitioning coefficient of organoclays may be hundreds of thousands of times greater than those of natural soils.

Many studies have been conducted to assess the barrier performance of low flow rate (CCLs) and the corresponding contaminant transport parameters (Acar and Haider 1990; Crooks and Quigley 1984; Lai and Lo 2006; Lai et al. 2006). However, relatively limited researches have been conducted to evaluate the feasibility of using organoclays as an amendment in CCLs for the purpose of attenuating the mass transport of waste contaminant (Lee et al. 2012; Lo and Mak 1998). This is because of difficulties in controlling the properties of flow and the contamination and long duration of breakthrough test in low flow rate systems. The scope of this study is to produce barrier systems with new reactive components. The objectives of studying low flow rate barrier (CCL) are to quantify the transport parameter when permeating by naphthalene and evaluate the attenuation capacity of the system consisting of $95 \%$ silty clay and $5 \%$ HDTMA-bentonite. HDTMA-bentonite was selected as a reactive component of CCL because it has relatively high percentage of organic carbon and high sorption capacity to absorb organic compounds (organophilicity). The barrier performance of silty clay with 
HDTMA-bentonite amendment permeating with gasoline (as a representative of petroleum product) and PAH (as a representative of NAPLs which are the most common pollution in groundwater) was assessed. Initially, the permeability of saturated CCLs specimens consisted of silty clay with HDTMA-bentonite amendment were evaluated in the flexible wall permeameter. Also, the free swelling experiment to measure the swelling index of the clay/HDTMA bentonite in water and gasoline were carried out. Finally, the retardation factor and diffusion coefficient of naphthalene in compacted clay/HDTMA bentonite soil were quantified using batch sorption study and soil column laboratory test.

\subsection{Materials and methods}

Three different soil media including natural low plasticity silty clay, HDTMA-bentonite, and Ca-bentonite were used in this study. The low plasticity silty clay (Nugent Sand Co.) consisted of $1 \%$ gravel, $12 \%$ sand, and $87 \%$ fine particles (ASTM D422). The physical properties of the low plasticity silty clay is summarized in Table 3-1.

Table 3-1. Engineering properties of the natural low plasticity silty clay

Properties Low plasticity silty clay

Liquid limit (\%)

Plasticity index (\%)

Fine content \% (<\#200 sieve $)$

Specific gravity

Specific surface area $\left(\mathrm{m}^{2} / \mathrm{g}\right)$

Total organic carbon (\%)
26

4.5

87

2.62

33.5

$<1$ 


\subsubsection{Standard proctor compaction test}

To determine the optimum water content and the maximum dry density, the standard proctor test was carried out for each soil specimen in accordance with ASTM D698, Method A. The specification of standard proctor testis summarized in Table 3-2.

Table 3-2. The specification of standard proctor test

\begin{tabular}{cccccc}
\hline Method & $\begin{array}{c}\text { Mold } \\
\text { diameter }\end{array}$ & $\begin{array}{c}\text { Rammer } \\
\text { weight }\end{array}$ & $\begin{array}{c}\text { Rammer } \\
\text { free-fall } \\
\text { height }\end{array}$ & $\begin{array}{c}\text { Number of } \\
\text { layers } \\
\text { (and } \\
\text { blows per } \\
\text { layer) }\end{array}$ & $\begin{array}{c}\text { Equivalent } \\
\text { compaction } \\
\text { energy }\end{array}$ \\
\hline $\begin{array}{c}\text { Standard } \\
\text { effort } \\
\text { (ASTM }\end{array}$ & $4 \mathrm{in}$ & $5.5 \mathrm{lbf}$ & $12 \mathrm{in}$ & 3 & $12400 \mathrm{ft}-\mathrm{lbf} / \mathrm{ft}^{3}$ \\
D698) & $(101.6 \mathrm{~mm})$ & $(24.4 \mathrm{~N})$ & $(305 \mathrm{~mm})$ & $(25)$ & $\left(600 \mathrm{kN}-\mathrm{m} / \mathrm{m}^{3}\right)$ \\
\hline
\end{tabular}

First, the synthesized HDTMA bentonite, calcium bentonite, and silty clay were oven dried for 24 hrs. The compaction test was conducted on 4 soil admixtures of: $100 \%$ silty clay; $90 \%$ silty clay $+10 \%$ Ca-bentonite; $90 \%$ silty clay $+10 \%$ HDTMA-bentonite; and $95 \%$ silty clay $+5 \%$ HDTMA-bentonite (by weight). Approximately $2 \mathrm{~kg}$ of the designed oven dried soil admixtures was weighted and spread out on the pan to cool down. For each soil admixture, six specimens with different water content ranging from $10 \%$ to $16 \%$ (with increment of 1\%) were prepared and standard proctor test was carried out on each specimen. Approximately $2 \mathrm{~kg}$ of prepared soil was placed into a compaction mold. Next, a $5.5 \mathrm{lbf}$ rammer was dropped from the height of 12 inches and transfer the total compaction energy $\left(12400 \mathrm{ft}-\mathrm{lbf} / \mathrm{ft}^{3}\right)$ to the soil (Figure 3-4(a)). After compaction, the collar was removed and the soil was trimmed. Next, the compacted soil was weighted and 
3 samples were taken from the top, middle, and bottom of the soil column $(\sim 100 \mathrm{~g})$ for a water content determination, Figure 3-4(b).

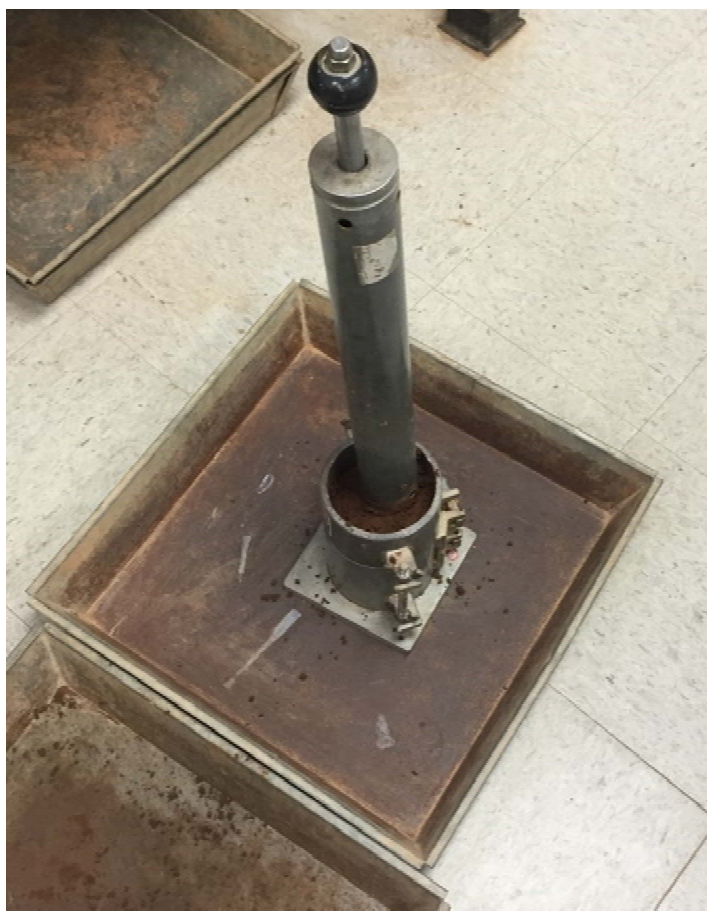

(a)

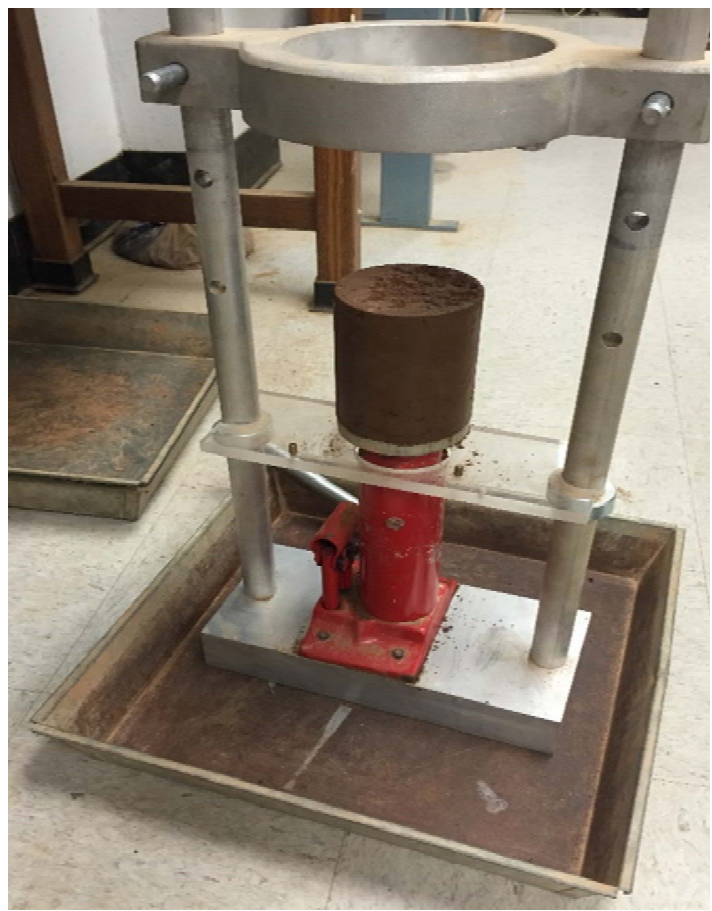

(b)

\section{Figure 3-4. (a) Compaction of soil layer (b) Extruded soil from compaction mold}

To measure the water content of moist samples, their weight was recorded right after sampling. Then, soil samples were oven-dried for 24 hours. Finally, the weight of dried samples was recorded. The water content of the samples was calculated by using equation $3-1$.

$$
w=\frac{w_{w}}{w_{s}} \times 100
$$


Where $w$ is the water content of the soil sample (\%), $w_{w}$ is the weight of water which is also the difference between the weight of moist soil $\left(w_{T}\right)$ and the weight of the ovendried soil $\left(w_{s}\right)$. Initially, the moist density of the compacted soil was determined using equation 3-2.

$$
\rho_{m}=\frac{\left(M_{t}-M_{m d}\right)}{1000 \mathrm{~V}}
$$

where $\rho_{m}$ is the moist density of the compacted soil, $M_{t}$ is the total weight of soil specimen and mold, $M_{m d}$ is the weight of mold, and $V$ is the volume of compaction mold ( $944 \mathrm{~cm}^{3}$ for the standard effort).

The dry density $\rho_{d}$ of the compacted soil specimen was by:

$$
\rho_{d}=\frac{\rho_{m}}{1+\frac{w}{100}}
$$

The dry unit weight $\left(\gamma_{d}\right)$ was calculated as:

$$
\gamma_{d}=9.807 \rho_{d}\left(\mathrm{kN} / \mathrm{m}^{3}\right)
$$

The relationship between water content and dry density of each compacted specimen was obtained with sufficient numbers of repeated tests. The maximum dry density and the optimum water content of each admixture were determined and shown in Figure 3-5 and Table 3-3. 


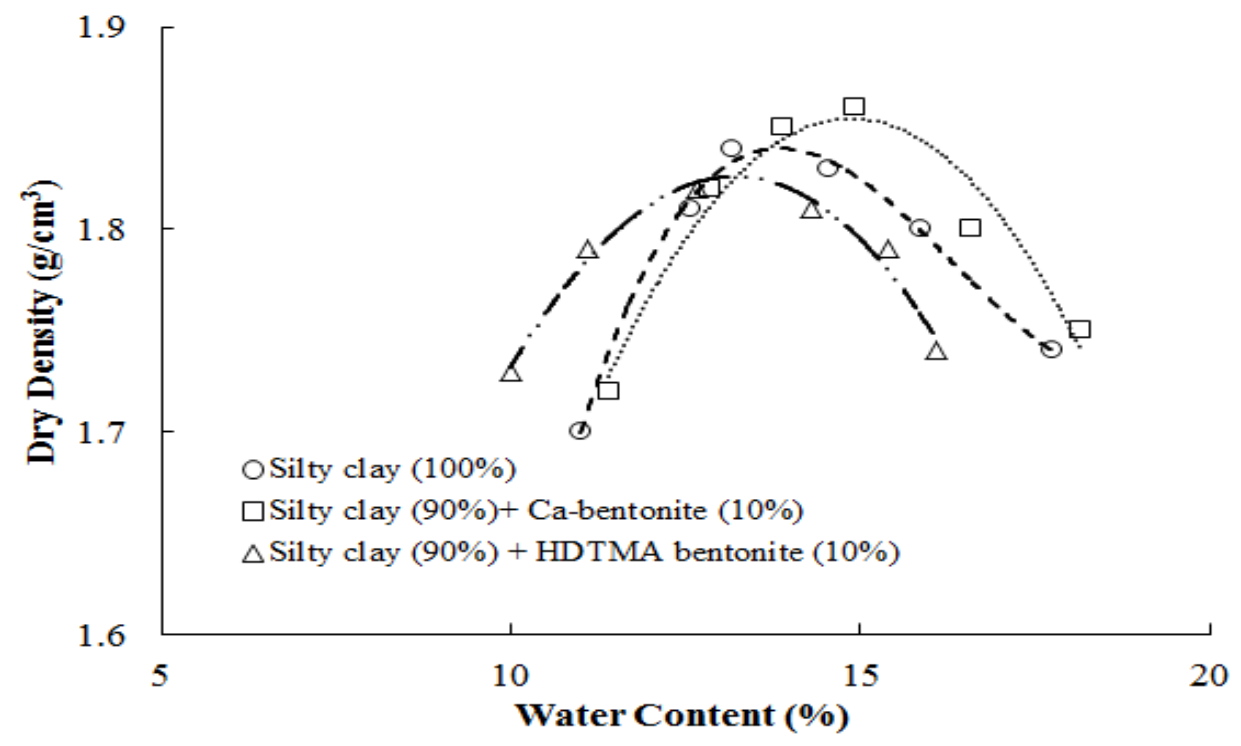

Figure 3-5. Compaction curve for the studied soil admixtures

Table 3-3. Compaction test results

\begin{tabular}{ccc}
\hline Soil admixture & $\mathrm{W}(\%)$ & $\mathrm{\gamma d}_{\mathrm{d}}\left(\mathrm{g} / \mathrm{cm}^{3}\right)$ \\
\hline Silty clay $(100 \%)$ & 13.6 & 1.85 \\
Silty clay $(90 \%)+$ Ca-bentonite $(10 \%)$ & 14.83 & 1.86 \\
Silty clay $(90 \%)+$ HDTMA-bentonite $(10 \%)$ & 13.04 & 1.82 \\
\hline
\end{tabular}

\subsubsection{One-dimensional swell test}

The one-dimensional swell test was carried out for the three soil admixtures including $100 \%$ silty clay, $90 \%$ silty clay $+10 \%$ Ca-bentonite, and $90 \%$ silty clay $+10 \%$ HDTMAbentonite according to ASTM D4546. First of all, the three soil admixtures were oven dried for $24 \mathrm{~h}$. Next, the water content of the oven dried specimens was adjusted to 13 to $14 \%$. The soil specimens were mixed and placed into a ring with diameter of $66 \mathrm{~mm}$ and height of $20 \mathrm{~mm}$, respectively. The surface of the filled soil into the ring was smoothened and the ring was placed into the oedometer apparatus. An overburden pressure of $1 \mathrm{kPa}$ was applied to each of the soil specimen. Then water or gasoline was added to the soil 
specimen in the ring. The vertical deformation of the soil specimen was recorded versus time. It was observed that the vertical deformation typically stabilized after 24 hours.

\subsubsection{Permeability test}

The hydraulic conductivity of three compacted soils: $100 \%$ silty clay, $90 \%$ silty clay + $10 \%$ Ca-bentonite, and 90\% silty clay $+10 \%$ HDTMA-bentonite were measured using flexible wall permeameter (Trautwein Soil Testing Equipment) following the ASTM standard D5084. First each soil specimen was compacted at the determined optimum water content following the compaction procedure explained in section 3.2.1. After extruding the compacted specimens from the compaction mold, a cylindrical trimming mold with $5.08 \mathrm{~cm}$ diameter and $10.16 \mathrm{~cm}$ in height was used to obtain a compacted soil sample with desirable dimensions for the permeability test. Two pairs of porous stone and filter paper were saturated before placed on top and below the trimmed soil specimen. Next, a membrane stretcher was used to stretch a latex membrane before it wrapped around the soil specimen. Next, a Finally, the inflow and outflow tubes were connected to the top cap and the chamber was mounted on the base of permeameter (Figure 3-6). 


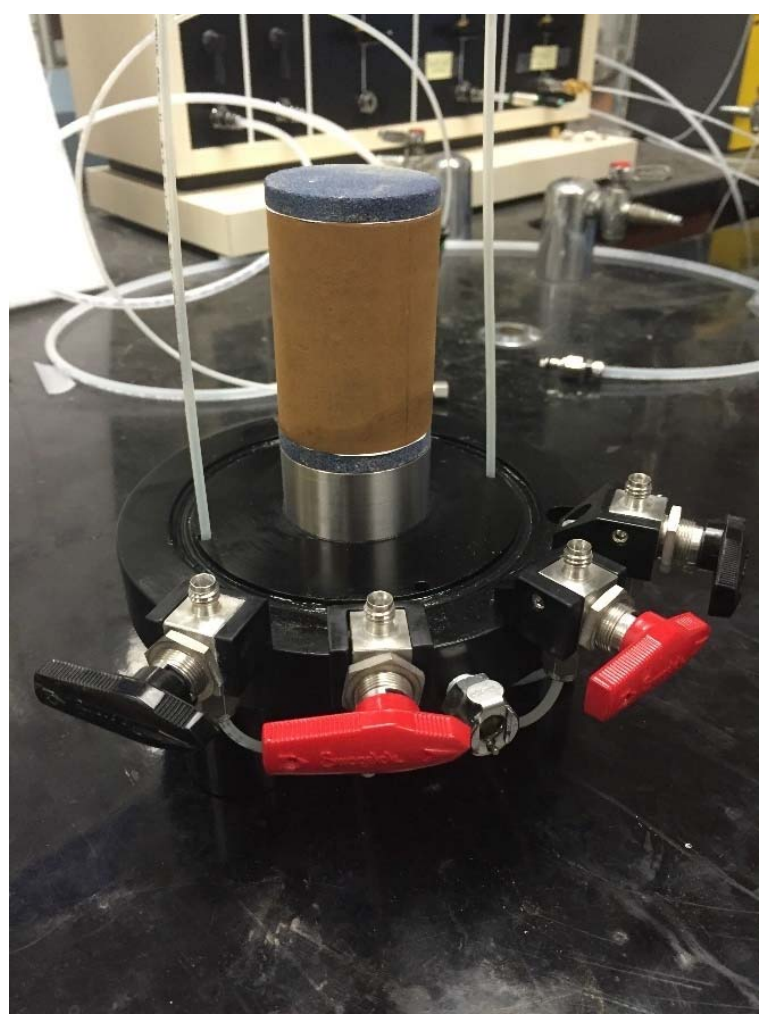

(a)

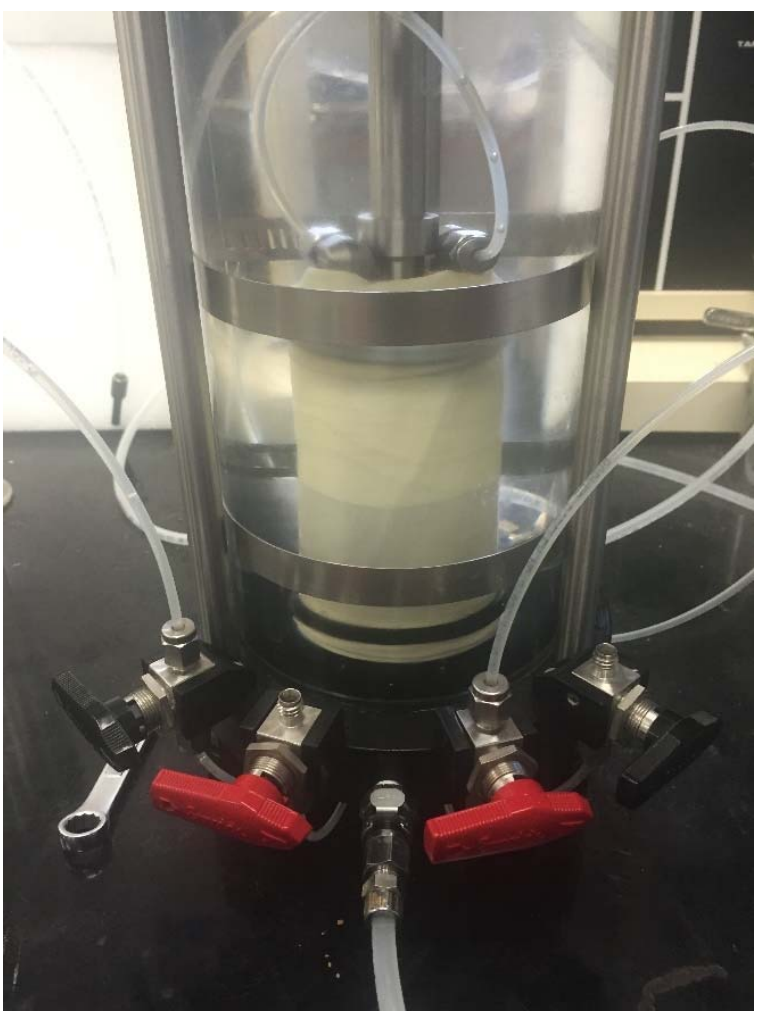

(b)

Figure 3-6. (a) Soil column arrangement for hydraulic conductivity (b) Sealed soil column in the pressure chamber

After the chamber was filled with de-aired water, the chamber pressure (cell pressure) was set at $13.7 \mathrm{kPa}$ and the water was fed into the soil column from the bottom to the top. To increase the saturation of the soil specimen, back pressure was applied to the specimen. The back pressure and cell pressure were increased simultaneously with same increment of13.7 kPa each time and the Skempton's B-value was examined. Typically, B-value greater than $95 \%$ was achieved for hydraulic conductivity test at the back pressure of $192 \mathrm{kPa}$ and the cell pressure of $206 \mathrm{kPa}$.

Initially, the hydraulic conductivity of three specimens was measured using the falling head, rising tailwater method (Method C). In addition, the permeability of soil specimen with of $90 \%$ silty clay and $10 \%$ HDTMA-bentonite to the gasoline was measured using 
the same method. The fluid conductivity of compacted soil sample to the permeant fluid $\mathrm{k}$ was determined by:

$k=\frac{a \cdot L}{2 A \cdot \Delta t} \ln \left(\frac{h_{1}}{h_{2}}\right)$

The falling head, constant tailwater pressure (Method B) was used to measure the hydraulic conductivity $\mathrm{k}$ of soil column comprised of $95 \%$ silty clay and 5\% HDTMAbentonite which permeated by benzene solution for the breakthrough test:

$k=\frac{a \cdot L}{A \cdot \Delta t} \ln \left(\frac{h_{1}}{h_{2}}\right)$

where $\mathrm{k}$ is the hydraulic conductivity $(\mathrm{m} / \mathrm{s})$, $\mathrm{a}$ is the cross-sectional area of the reservoir containing the influent liquid $\left(\mathrm{m}^{2}\right), \mathrm{L}$ is the length of specimen $(\mathrm{m}), \mathrm{A}$ is the crosssectional area of specimen $\left(\mathrm{m}^{2}\right), \Delta \mathrm{t}$ is the time interval between $\mathrm{h}_{1}$ and $\mathrm{h}_{2}(\mathrm{~s}), \mathrm{h}_{1}$ is the head loss across the specimen at $\mathrm{t}_{1}(\mathrm{~m})$, and $\mathrm{h}_{2}$ is the head loss across the specimen at $\mathrm{t}_{2}$ (m). The physicochemical properties of the permeant fluids are summarized in Table 3-4.

Table 3-4. Physicochemical properties of the permeant fluids

\begin{tabular}{ccccc}
\hline Fluids & Type & Polarity & $\begin{array}{c}\text { Density } \\
(\mathrm{kg} / \mathrm{L}) \text { at } 20^{\circ} \\
\mathrm{C}\end{array}$ & $\begin{array}{c}\text { Dynamic } \\
\text { viscosity }(\mathrm{cP})\end{array}$ \\
\hline Water & Deaired & 10.2 & 1 & 1 \\
Gasoline & $\begin{array}{c}\text { Unleaded \#87 } \\
\text { Crystal/reagent } \\
\text { graphthalene/methanol }\end{array}$ & 5.1 & 0.76 & 0.55 \\
& $\begin{array}{c}<3 \\
\text { grade }\end{array}$ & & 0.791 & 0.56 \\
\hline
\end{tabular}


The fluid conductivity of each soil specimen was measured when the steady state was reached. Typically, the results of three trials were recorded for each test and the average was chosen as the reported value.

\subsubsection{Breakthrough test}

A compacted soil column specimen consisted of 5\% of HDTMA-bentonite and $95 \%$ of silty clay was constructed to evaluate the efficiency of HDTMA-bentonite amended CCL in retention of organic contaminants. The compaction and sample preparation procedure were conducted as it was explained in section 3.2.1. The compaction test results confirmed that the optimum water content of silty clay remained the same after $10 \%$ HDTMA-bentonite was added. Consequently, the soil admixture for breakthrough test was compacted at the optimum water content of $13 \%$ to $14 \%$ following ASTM D698 (Method A). The standard proctor compaction effort resulted in compacted soil column with bulk density ranging between 1.78 to $1.85 \mathrm{~g} / \mathrm{cm}^{3}$. The soil specimen was wrapped with Teflon tape before wrapped with latex membrane to minimize the sorption of dissolved naphthalene by the latex membrane.

Table 3-5. Specification of compacted soil column

\begin{tabular}{cc}
\hline Column Component & 95\% Silty clay $+5 \%$ HDTMA bentonite \\
\hline Diameter $(\mathrm{mm})$ & 50 \\
Length $(\mathrm{mm})$ & 68 \\
$\mathrm{G}_{\mathrm{s}}$ & 2.57 \\
Unit weight $\left(\mathrm{g} / \mathrm{cm}^{3}\right)$ & 2.02 \\
Porosity & 0.3
\end{tabular}


Prior to the saturation stage, the soil column was flushed with de-aired water for approximately 4 pore volume. Then, the saturation stage started which took near to 2 pore volumes to complete till the steady state was attained at effluent. The flow rate of effluent at steady state stage was measured as approximately $1 \mathrm{~mL} / \mathrm{hr}$. To prepare the permeant solution, $0.13 \mathrm{~g}$ of naphthalene in solid phase was dissolved in $300 \mathrm{~mL}$ of methanol and diluted with $700 \mathrm{~mL}$ of deionized water to acquire a solution with naphthalene concentration of $130 \mu \mathrm{g} / \mathrm{mL}$. Naphthalene was selected as the organic contaminant because of its relatively simple structure (Chen et al. 2005) and the frequent presence in the wastewater of landfill (Javadi et al. 2016; Wolfe et al. 1986). A bladder accumulator with viton membrane was used to feed the solution into the soil column. The bladder accumulator was filled with the naphthalene solution and 1 pore volume of pulse-type contaminant solution $\left(\sim 42 \mathrm{~cm}^{3}\right)$ was injected to the soil column. Next, the inflow was switched back to the de-aired water right away. At the same time, samples were taken from effluent in vials with capacity of $8 \mathrm{~mL}$. The de-aired water was injected into the soil column for additional 12 pore volumes (approximately 30 more days) until the concentration of naphthalene in the effluent was below the detection limit. The collected effluent samples were extracted from aqueous phase by hexane and analyzed for naphthalene concentration by GC, as described in chapter 2. The experimental setup is illustrated in Figure 3-7. 


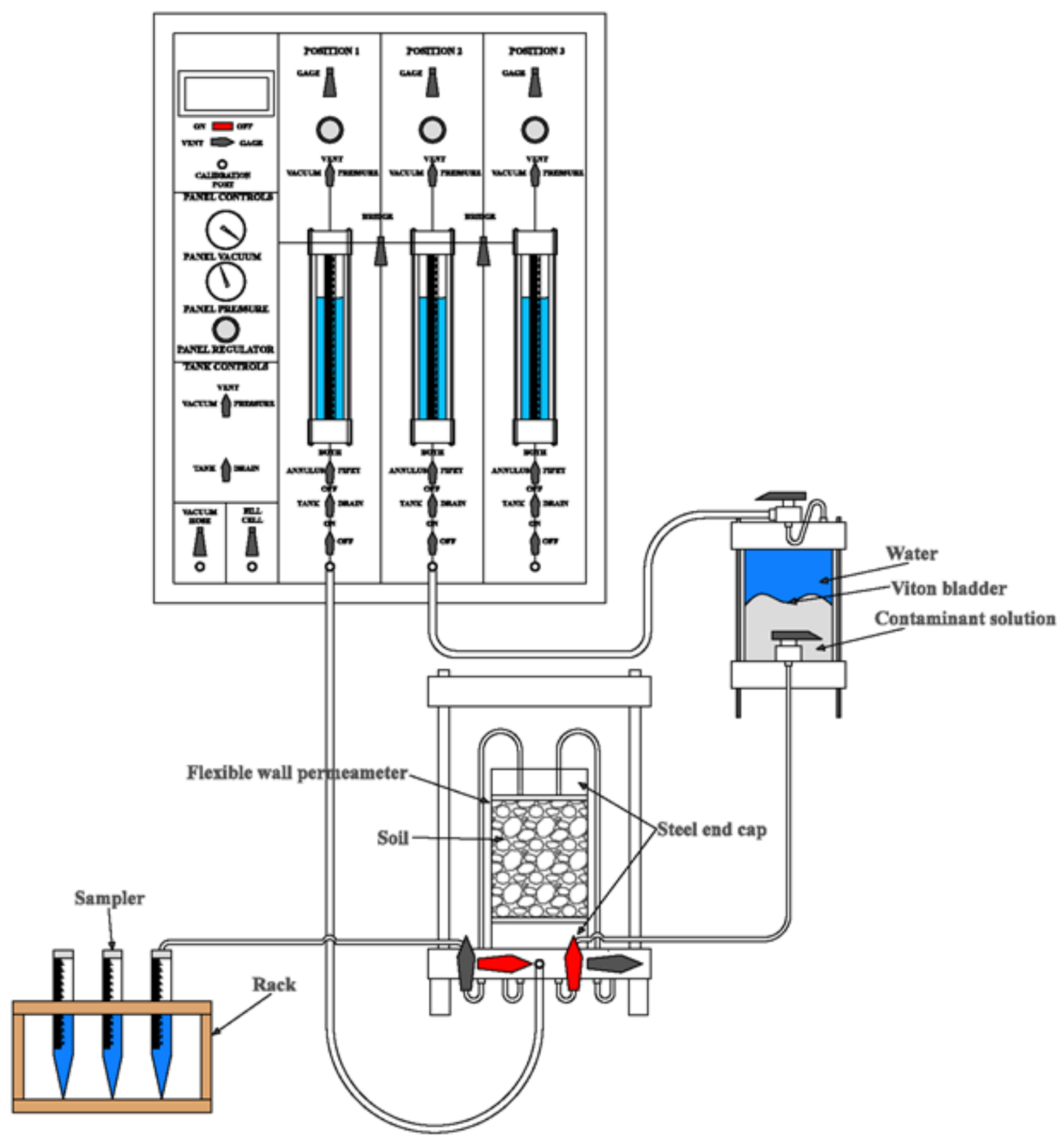

Figure 3-7. Experimental setup for breakthrough test

\subsection{Result and discussion}

\subsubsection{One-dimensional swell test}


The swelling tendency of three studied soil admixtures including silty clay, silty clay + $10 \%$ Ca-bentonite, silty clay $+10 \%$ HDTMA-bentonite in the water and gasoline are presented in Figure 3-8.

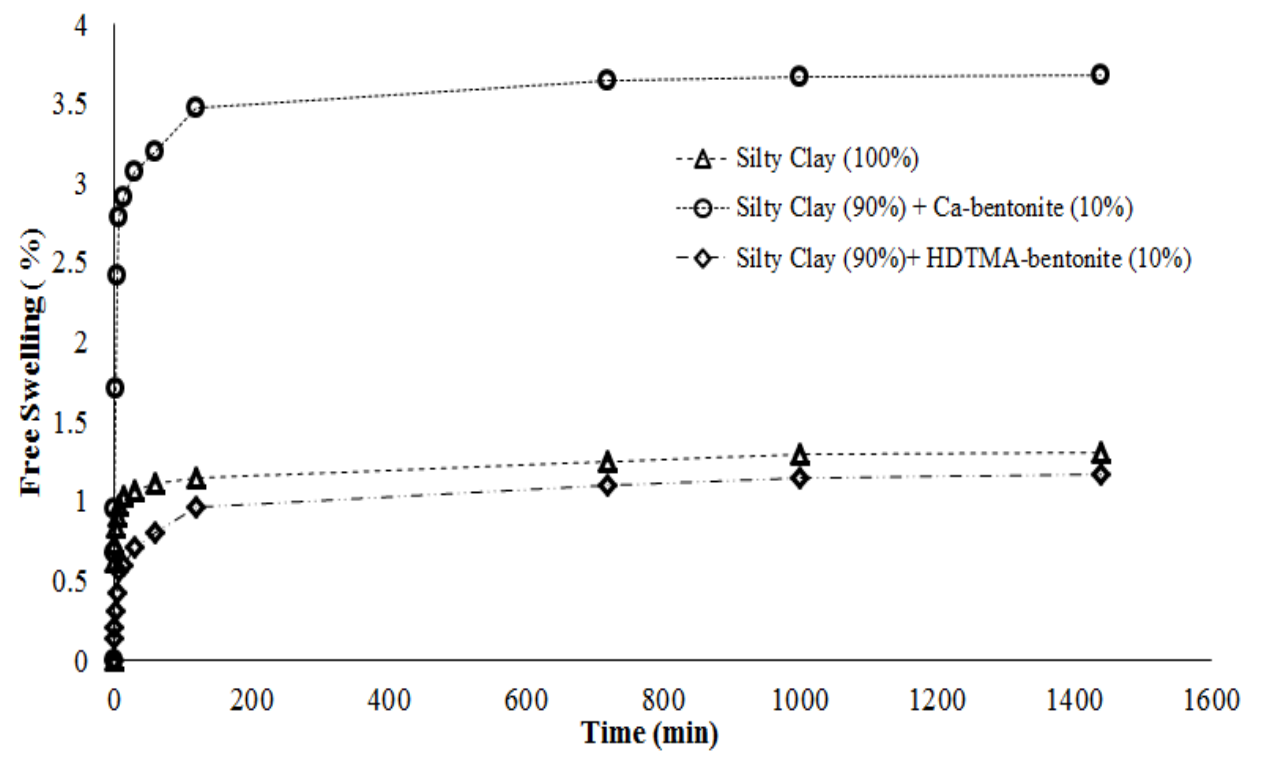

(a)

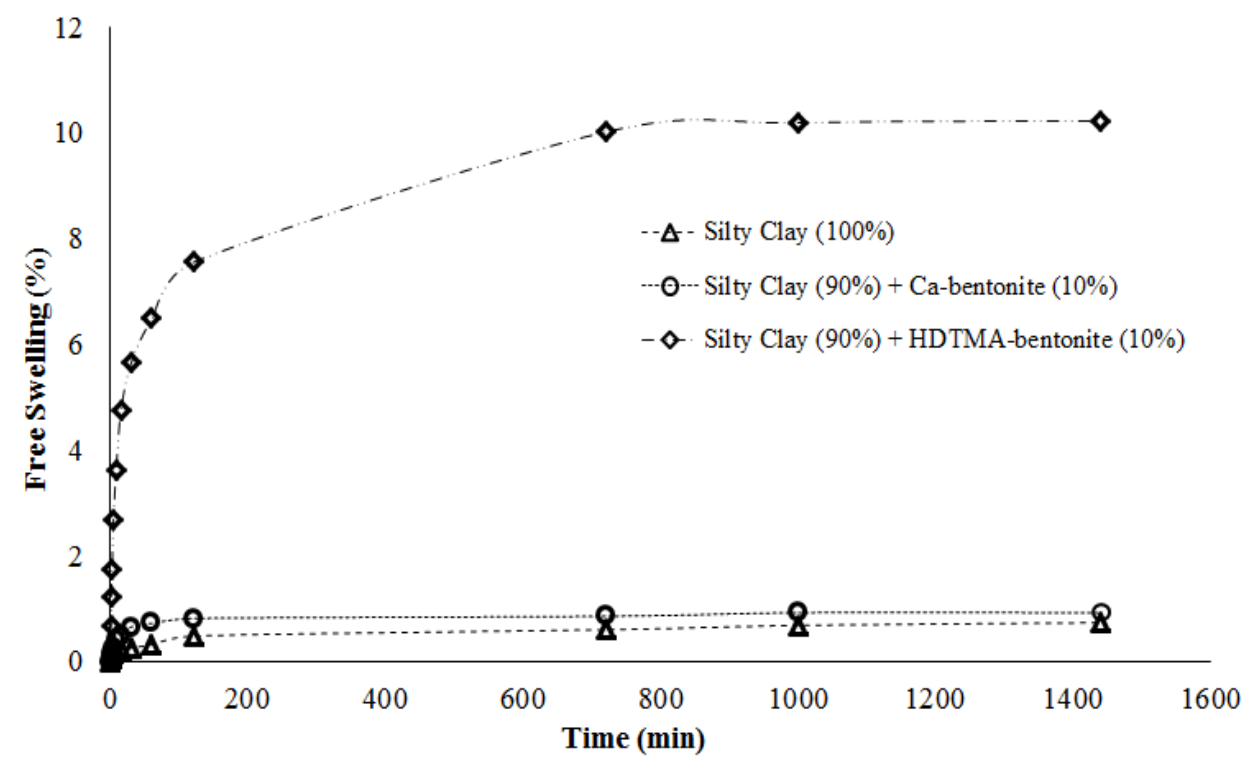

(b)

Figure 3-8. Free swelling results for the three studied soil admixture in (a) water (b) gasoline 
It was observed that adding $10 \%$ of Ca-bentonite to the silty clay soil increased the free swelling of the admixture significantly and the hydration of Ca-bentonite is the main reason of the notable swelling tendency of the admixture (Chapuis 1990; Sun et al. 2009). In comparison, silty clay with $10 \%$ of HDTMA bentonite exhibited very limited swelling in water as both components had very low hydration in water and also low plasticity. (Benson et al. 2015; Sreedharan and Sivapullaiah 2014). However, the admixture of silty clay and HDTMA-bentonite demonstrates a considerable swelling tendency in nonpolar organic liquids such as gasoline. Tests results (Figure 3-8 (b)) suggested that $10 \%$ of HDTMA-bentonite $+90 \%$ of silty clay had 10 times of swelling in gasoline when compared to the $100 \%$ silty clay. The above observations can be explained by the hydrophobic interactions between non-polar species and intercalated aliphatic carbon chains in HDTMA bentonite (Slade and Gates 2004).As naturally occurring clay minerals, the pure silty clay or Ca-bentonite had demonstrated a little or negligible swelling in gasoline because the mineral hydration and cation hydration were predominant interactions between the two and water. However, the HDTMA bentonite, with modified and hydrophobic characteristics were able to interact with aliphatic aromatic hydrocarbons. Consequently, it appeared that organoclays could be superior materials for the containment of petroleum related products or other non-polar fluids when compared to natural clays. It is important to note most of the earthen barrier materials are under certain overburden stresses other than $1 \mathrm{kPa}$. The effect of confining stress on the swelling tendency of the studied soil admixtures was not investigated here. It was expected that the higher swelling potential could lower the permeability the 
admixtures in the same liquid but the overburden stress would also lower the permeability as well.

\subsubsection{Permeability}

The hydraulic conductivity of three soils including silty clay, $90 \%$ silty clay $+10 \% \mathrm{Ca}-$ bentonite admixture, and 90\% silty clay $+10 \%$ HDTMA-bentonite admixture were measured. In addition, the permeability of $90 \%$ silty clay $+10 \%$ HDTMA-bentonite to gasoline was measured and the obtained results are summarized in Table 3-6.

Table 3-6. Average fluid conductivities of three compacted soils with varying permeants

\begin{tabular}{|c|c|c|c|c|c|c|c|}
\hline Materials & Soil preparation & $\begin{array}{l}\text { Void } \\
\text { ratio }\end{array}$ & Permeant liquid & Liquid limit & $\begin{array}{l}\text { Plasticity } \\
\text { index }\end{array}$ & $\begin{array}{c}\text { Fluid } \\
\text { conductivity } \\
(\mathrm{m} / \mathrm{s})\end{array}$ & $\begin{array}{c}\text { Intrinsic } \\
\text { permeability } \\
\left(\mathrm{m}^{2}\right)\end{array}$ \\
\hline Silty clay $(100 \%)$ & $\begin{array}{c}\text { Compacted } \\
\left(\rho_{\mathrm{d}}=1.85 \mathrm{~g} / \mathrm{cm}^{3}\right)\end{array}$ & 0.42 & Water & 26 & 4.4 & $5.04 \times 10^{-9}$ & $5.16 \times 10^{-16}$ \\
\hline $\begin{array}{l}\text { Silty clay }(90 \%)+\text { Ca- } \\
\text { bentonite }(10 \%)\end{array}$ & $\begin{array}{c}\text { Compacted } \\
\left(\rho_{\mathrm{d}}=1.82 \mathrm{~g} / \mathrm{cm}^{3}\right)\end{array}$ & 0.43 & water & 32 & 10 & $7.70 \times 10^{-10}$ & $7.78 \times 10^{-17}$ \\
\hline \multirow{2}{*}{$\begin{array}{c}\text { Silty clay }(90 \%)+ \\
\text { HDTMA-bentonite } \\
(10 \%)\end{array}$} & \multirow{2}{*}{$\begin{array}{c}\text { Compacted } \\
\left(\rho_{\mathrm{d}}=1.78 \mathrm{~g} / \mathrm{cm}^{3}\right)\end{array}$} & 0.42 & water & 30 & 6.6 & $1.57 \times 10^{-8}$ & $1.61 \times 10^{-15}$ \\
\hline & & 0.42 & Gasoline & - & - & $9.20 \times 10^{-10}$ & $6.7 \times 10^{-17}$ \\
\hline
\end{tabular}

The hydraulic conductivity of compacted silty clay was $5.04 \times 10^{-9} \mathrm{~m} / \mathrm{s}$ while adding $10 \%$ Ca-bentonite to the component of compacted soil specimen decreased the hydraulic conductivity of the compacted admixture to $7.70 \times 10^{-10} \mathrm{~m} / \mathrm{s}$. This was explained as the swelling of Ca-bentonite resulted in deceased pores volumes in the soil admixture and consequently, lower hydraulic conductivity. However, the hydraulic conductivity of compacted soil admixture consisted of silty clay and 10\% HDTMA-bentonite was $1.57 \times 10^{-8} \mathrm{~m} / \mathrm{s}$, approximately 1 order of magnitude higher than the hydraulic conductivity of the compacted silty soil. This can be explained by the increased hydraulic 
conductivity of the HDTMA-bentonite as a results of its hydrophobic surface characteristics(Li et al. 1996; Lorenzetti et al. 2005; Moon et al. 2007).

This occurred because the plasticity index of the soil admixture increased from 4.4 for the pure silty clay to 10 for $90 \%$ silty clay $+10 \%$ Ca-bentonite (Benson et al. 1994; Lo and Yang 2001). It was noted that the hydraulic conductivity of silty clay with $10 \%$ HDTMAbentonite to water increased by approximately 1 order of magnitude compared to $100 \%$ silty clay which is. HDTMA-bentonite increases the hydrophobicity of the soil specimen, and as expected the conductivity of the water through soil pores increases when the hydrophobicity of complex increases.

Previous studies confirmed that organoclays have the swelling potential in non-polar liquids similar to natural bentonites in water(Benson et al. 2015). Some other studies also suggested that organoclays had very low plasticity in water but could exhibit high consistency in non-polar liquids (Soule and Burns 2001). Lo and Yang (2001) explained that the soils with higher liquid limit and plasticity index in a certain liquid expressed higher swelling capacity which resulted in lower fluid permeability. The permeability of compacted soil specimen consisted of $90 \%$ silty clay with $10 \%$ HDTMA-bentonite to gasoline was measured as $9.20 \times 10^{-10} \mathrm{~m} / \mathrm{s}$ while the permeability of the same compacted soil specimen to water was as high as $1.57 \times 10^{-8} \mathrm{~m} / \mathrm{s}$. The same trend in permeability of different soil specimen to water and gasoline was reported by several previous studies (Lo and Yang 2001; Moon et al. 2007; Smith et al. 2003).Smith et al. (2003)investigated the permeability of compacted BTEA-bentonite and HDTMA-bentonite to water and unleaded gasoline. They observed that the permeability of compacted organoclays decreased approximately by an order of 2 in magnitude when permeated with unleaded 
gasoline instead of water. Yang and Lo (2004)noted that the permeability of compacted BB-40 to gasoline $\left(10^{-9} \mathrm{~cm} / \mathrm{s}\right)$ was four orders of magnitude lower than the permeability of Na-bentonite to gasoline $\left(10^{-5} \mathrm{~cm} / \mathrm{s}\right)$. All these studies indicated that compared to the naturally occurring bentonite, HDTMA-bentonite has a higher permeability to water, but much lower permeability to petroleum related products like unleaded gasoline. It was explained that the higher swelling tendency of HDTMA-bentonite in non-polar liquids and the increased drag force on the gasoline caused the decreased permeability of gasoline in organoclay. Consequently, the permeability of compacted soil specimen consisted of $90 \%$ silty clay with $10 \%$ HDTMA-bentoniteto gasoline was lower than its permeability to water.

It was concluded that small dosage oforganoclayhave a low impact on the overall hydraulic conductivity of soil admixtures when used as additives(Bate 2010; Ghavami et al. 2016). However, our results suggested that the permeability of compacted silty clay and only $10 \%$ of organobentonite to gasoline was decrease by half.For the unsaturated flow in the same compacted soil admixture, the permeability could be even lower for the low-polarity fluids. This suggests that organoclays, especially organobentonitesare promising amendment in compacted soils to reduce the advection rate of organic contaminant flow. Also, it was not investigated in this study but it was expected that combinations of Na-bentonite and organoclay could be effective amendments to reduce the advection of water and organic fluids in compacted soil barriers.

\subsubsection{Breakthrough test}

From the obtained results in chapter 2 , the equilibrium sorption isotherms of naphthalene onto HDTMA-bentonite/silty clay is presented in Figure 3-9. 


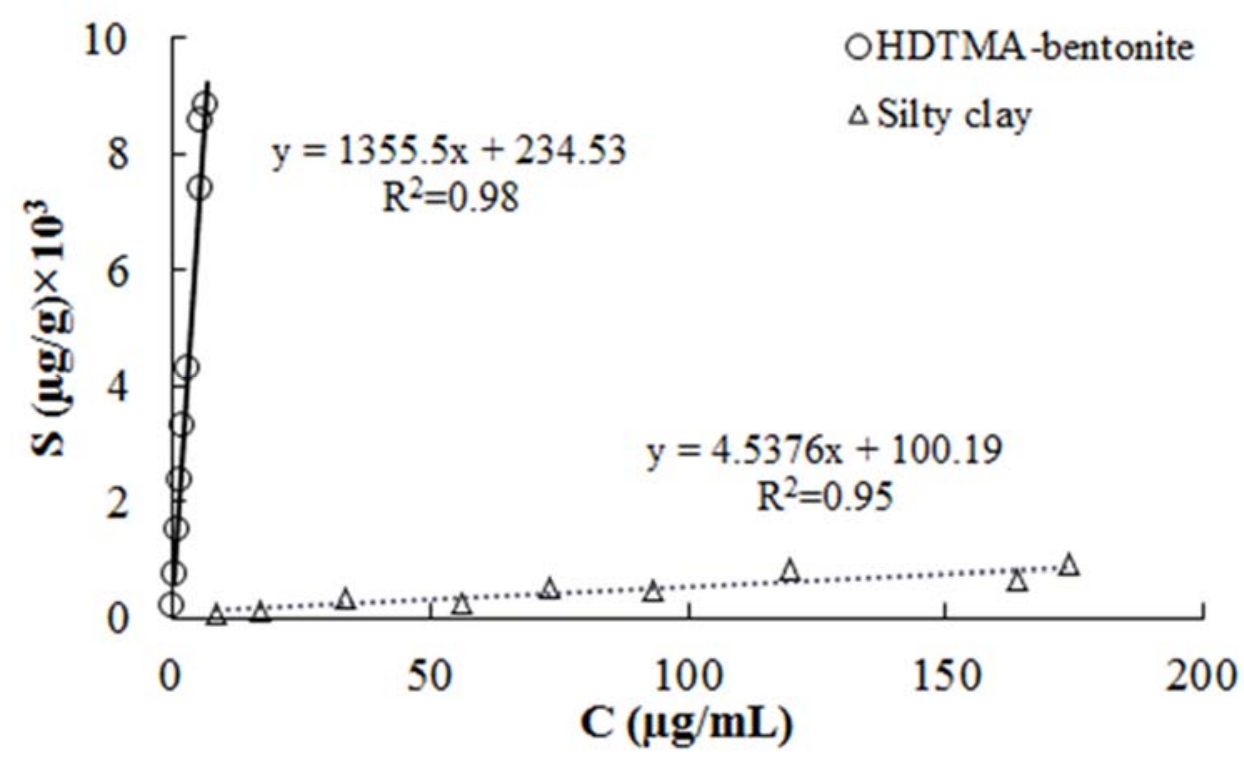

Figure 3-9. equilibrium sorption isotherms of naphthalene onto HDTMAbentonite/silty clay

Linear isotherms were observed for the sorption of naphthalene onto two studied soils. The measured partitioning coefficient $\left(\mathrm{K}_{\mathrm{d}}\right)$ of silty clay and HDTMA-bentonite for naphthalene were 4.53 and $1355.5 \mathrm{~mL} / \mathrm{g}$, respectively.

The transport of naphthalene through the compacted clay column was performed under the low flow rate condition to stimulate the mass transport of organic contaminants through the low permeability earthen barriers. The average seepage velocity of the effluent permeated solution was monitored during the breakthrough test to assure that the steady state condition was available during the experiment. The recorded average seepage velocity is presented in Figure 3-10. The average hydraulic conductivity of the naphthalene solution was also measured during the breakthrough test as $8.84 \times 10^{-9} \mathrm{~m} / \mathrm{s}$ following ASTM D5084, method B. 


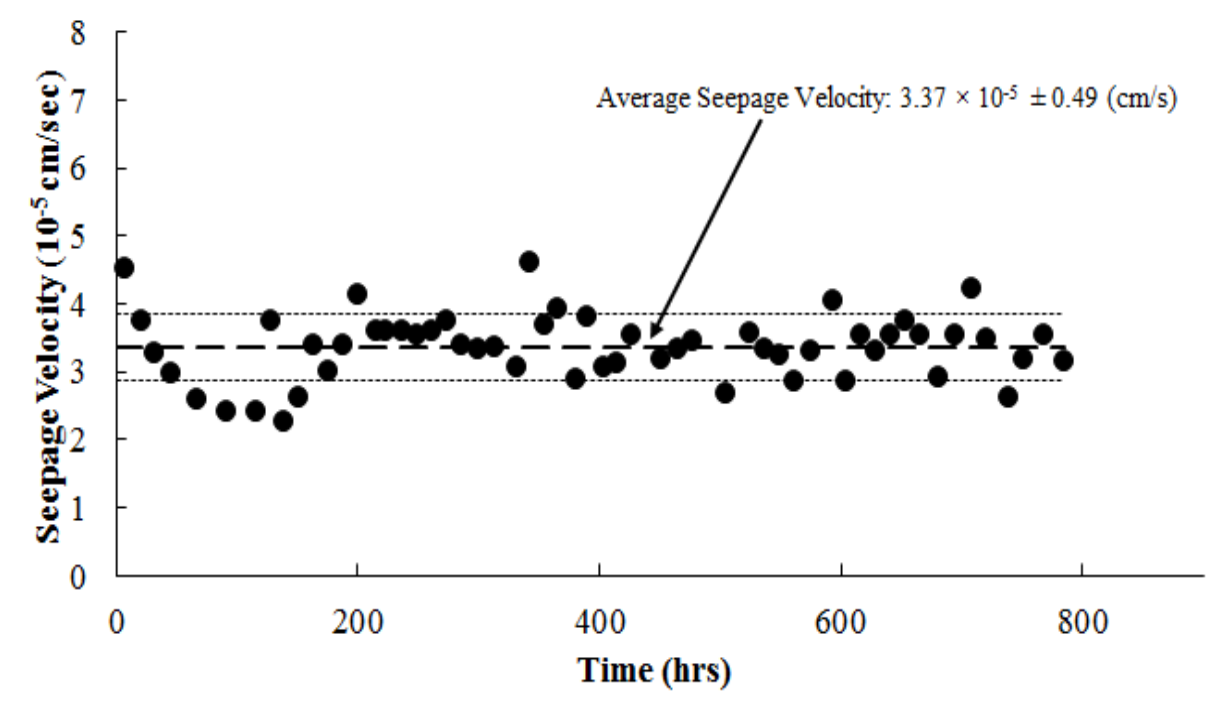

Figure 3-10. Average seepage velocity of naphthalene solution during the breakthrough study

The breakthrough of naphthalene solution in compacted soil column consisting of $95 \%$ silty clay and 5\% HDTMA-bentonite is shown in Figure 3-11.The maximum concentration of naphthalene breakthrough curve in compacted silty clay/HDTMAbentonite column appeared after 142 hours which was approximately 9 times lower than initial introduced concentration to the column. The high sorption capacity of HDTMAbentonite to adsorb naphthalene from aqueous phase resulted in significant low naphthalene concentration in effluent. Because a relatively low advection rate mechanism governed the mass transport of naphthalene through the compacted soil column, the retardation factor for the pulse-type injection was measured from the first moment analysis(Shackelford and Redmond 1995; Valocchi 1985). Using the first moment method analysis, the retardation factor of naphthalene solution passing through compacted silty clay/ HDTMA bentonite soil column was measured as 6.98. For the retardation calculation, the initial introduced naphthalene concentration into the column $\left(\mathrm{C}_{0}\right)$ was $130 \mu \mathrm{g} / \mathrm{mL}$ and the pore volume of introduced naphthalene solution into the 
column $\left(\mathrm{PV}_{0}\right)$ was 1 . The calculated retardation factor was compared with the retardation coefficient derived from the partitioning coefficient (Freeze and Cherry 1979), equation 3-7:

$R=1+\frac{\rho_{b}}{n} \cdot K_{d}=1+\frac{2.02}{0.3} \cdot(0.05 \times 1355.5+0.95 \times 4.5376) \cong 486$

The latter calculation disclosed a notable difference between the retardation factor calculated from first moment analysis and derived from partitioning coefficient. Shackelford (1994) explained that the retardation factor equation proposed by Freeze and Cherry may be applicable for the fast flow rate regimes which the advection is the dominant transport mechanism. However, the retardation factor should be calculated from the breakthrough curve for the cases of (1) an infinite constant contaminant source with continuous contaminant injection method, or (2) a finite constant contaminant source with pulse-signal type contaminant injection method. For the first scenario, the retardation factor is equal to the pore volume corresponds to the relative effluent concentration of 0.5 . For the second scenario, the first moment analysis should be applied to estimate the retardation factor (Daniel 1993). Although previous works including the research conducted by Shackelford and Redmond (1995) did not consider the organoclays as amendment in the compacted soil matrix, the obtained results suggest that the same conclusion can be drawn on the breakthrough experiment of naphthalene in HDTMA-bentonite amended soil column. 


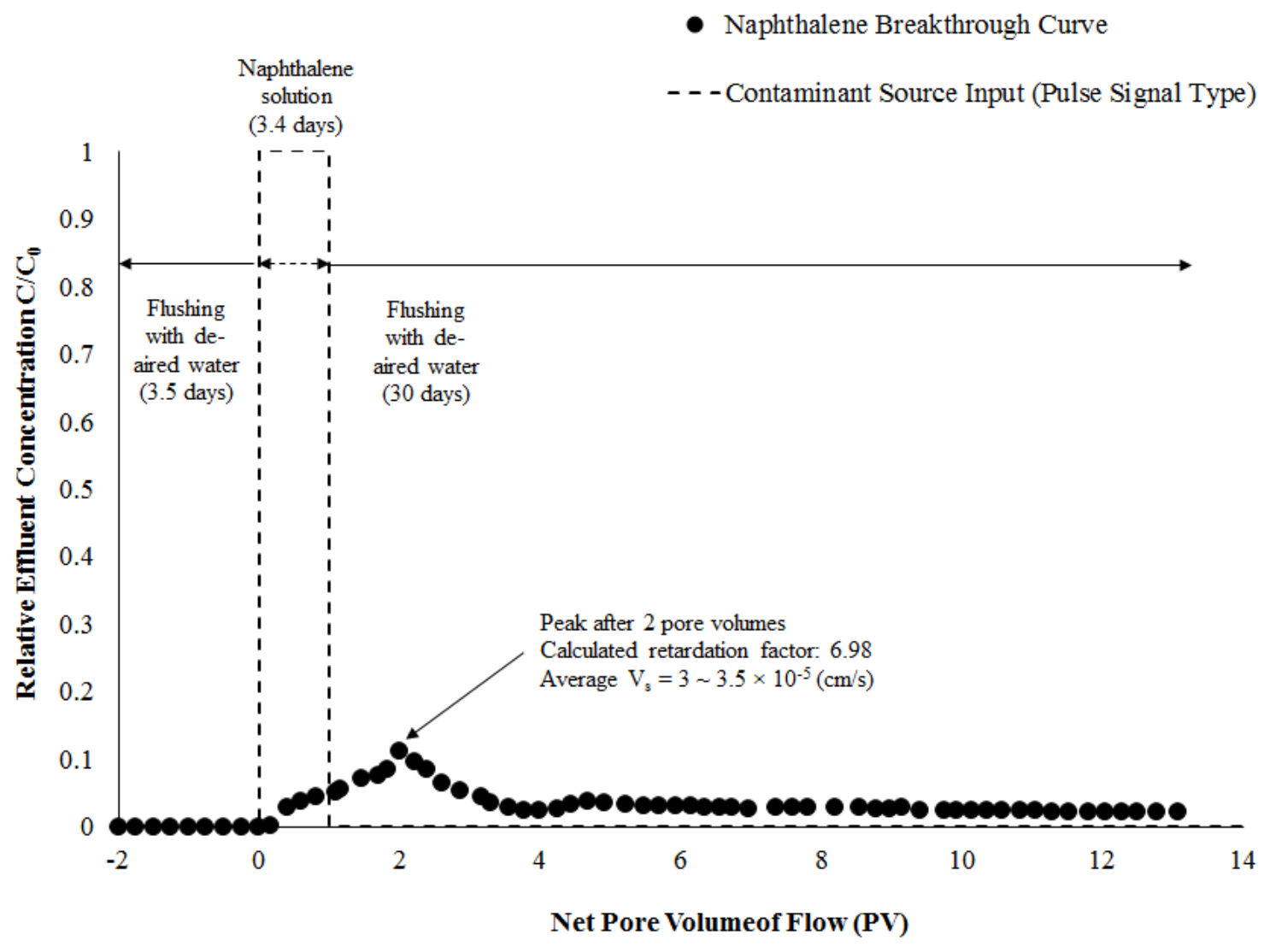

Figure 3-11. Breakthrough curve of naphthalene transport in $95 \%$ silty clay $+5 \%$ HDTMA-bentonite compacted soil column

Moreover, the breakthrough curve revealed that even a small fraction of HDTMAbentonite (only $5 \%$ by weight) as an amendment to silty clay decreases the mass flux of naphthalene in the effluent, significantly. Also, the reduction of mass flux in the effluent increases as the percentages of HDTMA-bentonite in soil matrix increases. The mass flux of introduced naphthalene solution into the compacted soil column was 0.113 $\mathrm{mg} / \mathrm{cm}^{2} \times$ day while the retardation process decreased the mass flux of naphthalene to $0.004 \mathrm{mg} / \mathrm{cm}^{2} \times$ day in the effluent (approximately reduced 29 times). In addition, the mass balance calculation indicated that only $5 \%$ of HDTMA-bentonite exhibited such a high sorption capacity that $54 \%$ of total introduced naphthalene to the soil column was still uptaken by the column after 33 days and was releasing gradually. Using numerical 
modeling, a transport model for equation 1-3 was developed to estimate the diffusion coefficient of naphthalene. By curve fitting of the developed model to the breakthrough curve, it was concluded that the diffusion coefficient of naphthalene was in the order of $10^{-6} \mathrm{~cm}^{2} / \mathrm{s}$ for the HDTMA-bentonite amended silty clay which was comparable with the results from previous researches on the retardation performance of soil barriers (Headley et al. 2001). A summary of previous studies on contaminant transport in fast/low flow rate systems is presented in Table 3-7.

Table 3-7. Summary of contaminant transport parameters for fast and slow flow rate condition

\begin{tabular}{|c|c|c|c|c|c|}
\hline Study & Contaminants & Soil Matrix & $\begin{array}{l}\text { Velocity } \\
(\mathrm{cm} / \mathrm{s})\end{array}$ & $\begin{array}{l}\text { Retardation } \\
\text { Factor }\end{array}$ & $\begin{array}{l}\text { Diffusion } \\
\text { Coefficient } \\
(\mathrm{cm} 2 / \mathrm{s})\end{array}$ \\
\hline & \multicolumn{5}{|c|}{ High Flow Rate } \\
\hline \multirow{2}{*}{$\begin{array}{l}\text { Liu et al. } \\
\text { (1991) }\end{array}$} & \multirow{2}{*}{ Naphthalene } & Lincoln - sand & \multirow{2}{*}{$2 \times 10^{-3}$} & 5 & \multirow{2}{*}{ N.A. } \\
\hline & & Eustis - sand & & 12 & \\
\hline \multirow{4}{*}{$\begin{array}{l}\text { Thierrin et al. } \\
\text { (1995) }\end{array}$} & Benzene & \multirow{4}{*}{ Sandy aquifer } & \multirow{4}{*}{$2.5 \times 10^{-2}$} & 1.02 & \multirow{4}{*}{ N.A. } \\
\hline & Toluene & & & 1.04 & \\
\hline & p-Xylene & & & 1.12 & \\
\hline & Naphthalene & & & 1.32 & \\
\hline $\begin{array}{c}\text { Owabor et al. } \\
\text { (2010) }\end{array}$ & Naphthalene & Sandy soil & $2 \times 10^{-3}$ & 25.77 & N.A. \\
\hline \multirow[t]{2}{*}{$\begin{array}{c}\text { Larsen et al. } \\
\text { (1992) }\end{array}$} & Naphthalene & Aquifer material & N.A. & 1.61 & N.A. \\
\hline & \multicolumn{5}{|c|}{ Low Flow Rate } \\
\hline Lo et al. (1997) & $\begin{array}{c}\text { benzene, } \\
\text { toluene, o- } \\
\text { xylene, ethyl- } \\
\text { benzene, } \\
\text { phenol, } 2- \\
\text { chlorophenol, } \\
2,4- \\
\text { dichlorophenol, } \\
\text { and 2,4,6- } \\
\text { trichlorophenol }\end{array}$ & BB-40 & $4.93 \times 10^{-6}$ & N.A. & N.A. \\
\hline Li et al. (2002) & Chromate & $\begin{array}{c}\text { HDTMA- } \\
\text { modified illite }\end{array}$ & $1 \times 10^{-4}$ & N.A. & N.A. \\
\hline \multirow{2}{*}{$\begin{array}{c}\text { Shackelford et } \\
\text { al. (1991) }\end{array}$} & Cl- & \multirow{2}{*}{$\begin{array}{l}\text { Kaolinite \& } \\
\text { Lufkin clay }\end{array}$} & \multirow[b]{2}{*}{ N.A. } & \multirow[b]{2}{*}{ N.A. } & 4.4 to $6 \times 10^{-6}$ \\
\hline & $\mathrm{Br}-$ & & & & 4.8 to $\underset{6}{6.5} \times 10$ \\
\hline
\end{tabular}




\begin{tabular}{|c|c|c|c|c|c|}
\hline \multirow{2}{*}{$\begin{array}{c}\text { Shackelford } \\
(1995)\end{array}$} & $\mathrm{Cl}-$ & \multirow{2}{*}{ Kaolin } & \multirow{2}{*}{$7 \times 10^{-7}$} & 1.4 & $3.75 \times 10-6$ \\
\hline & $\mathrm{Na}+$ & & & 2.4 & $5.8 \times 10^{-6}$ \\
\hline Lo (2003) & $\begin{array}{c}\text { Total organic } \\
\text { carbon of } \\
\text { landfill leachate }\end{array}$ & $\begin{array}{l}\text { Mixture of BB- } \\
\text { 40, bentonite, } \\
\text { and } \\
\text { decomposed } \\
\text { volcanic rock }\end{array}$ & N.A. & 8.92 & $2.3 \times 10^{-6}$ \\
\hline \multirow{2}{*}{$\begin{array}{c}\text { Shackelford } \\
\text { and Redmond } \\
\text { (1995) }\end{array}$} & $\mathrm{Cl}-$ & \multirow{2}{*}{ Kaolin } & \multirow{2}{*}{$7 \times 10^{-7}$} & 2.336 & $2.84 \times 10^{-6}$ \\
\hline & $\mathrm{Na}+$ & & & 9.53 & $8.78 \times 10^{-6}$ \\
\hline \multirow{3}{*}{$\begin{array}{l}\text { Rodriguez- } \\
\text { Cruz (2007) }\end{array}$} & Linuron & \multirow{3}{*}{$\begin{array}{l}\text { Modified sandy } \\
\text { loam with } \\
\text { ODTMA- } \\
\text { montmorillonite }\end{array}$} & \multirow{3}{*}{ N.A. } & 69.5 & \multirow{3}{*}{ N.A. } \\
\hline & Atrazine & & & 9 & \\
\hline & Metalaxyl & & & 10 & \\
\hline This Study & Naphthalene & $\begin{array}{l}\text { HDTMA- } \\
\text { bentonite }\end{array}$ & $3.4 \times 10^{-5}$ & 6.98 & $\sim 9 \times 10^{-6}$ \\
\hline
\end{tabular}

This study suggests that a small fraction of HDTMA-bentonite amendment $(5 \%$ by weight) in soil matrix have negligible impact on total hydraulic conductivity and diffusion coefficient of soil admixture. However, even a small fraction of HDTMAbentonite amendment can increase the sorption capacity and enhance the retardation of naphthalene in compacted soil and it may enhance the sorption characteristics of the compacted clay for other organic contaminants as well. As a result, organoclay amendments can enhance the sorption capacity of the barrier systems and decrease the mass flux of contaminant through the barriers while they do not impose a considerable change to the advection and diffusion rate of contaminants.

\subsection{Conclusion}

In this chapter, the permeability of compacted soil barrier consists of silty clay and HDTMA-bentonite. Obtained results suggested that $10 \%$ of HDTMA-bentonite additive has a negligible impact on the free swelling behavior of silty clay in water. However, the HDTMA-bentonite amended silty clay demonstrated a significant swelling tendency to gasoline because of the interaction between the organophilic surfactants in the HDTMA 
bentonite and non-polar liquid. Although the 10\% HDTMA-bentonite as an amendment to compacted silty clay increased the hydraulic conductivity of the system to water, slightly $\left(5.04 \times 10^{-9} \mathrm{~m} / \mathrm{s}\right.$ to $\left.1.57 \times 10^{-8} \mathrm{~m} / \mathrm{s}\right)$, but it decreased the permeability of the compacted clay system to gasoline approximately 1 order of magnitude $\left(9.20 \times 10^{-10} \mathrm{~m} / \mathrm{s}\right)$. the acquired results from this study in conjunction with previous studies suggest that a small fraction of organoclay amendments have a limited impact on the hydraulic conductivity of compacted silty clay while they enhance the capability of the barrier system to confine the transport of organic or low-polarity fluids. The breakthrough study revealed that a small percentage of HDTMA-bentonite additive $(\sim 5 \%)$ to the compacted silty clay enhances the retardation capacity (approximately 7 ) of the system to the mass transport of organic contaminant (naphthalene). Although the breakthrough rate of the naphthalene through compacted HDTMA-bentonite amended silty clay did not increase significantly, the absorbed mass of naphthalene by HDTMA-bentonite was released in a considerably low paste (average of $0.004 \mathrm{mg} / \mathrm{cm}^{2} \times$ day and peak of $0.011 \mathrm{mg} / \mathrm{cm}^{2} \times$ day compared to the source of $0.113 \mathrm{mg} / \mathrm{cm}^{2} \times$ day). The overall results in this study suggest that HDTMA bentonite or other organophilic clays hold the promise of being the amendment material in a CCL barrier for organic and/or low polarity fluids. 


\section{CHAPTER FOUR ENGINEERING BEHAVIORS OF GEOSYNTHETIC CLAY LINERS (GCLS) AMENDED WITH ORGANOCLAYS}

\subsection{Introduction}

Conventional Geosynthetic Clay Liners (GCLs) consists of a layer of sodium or calcium bentonite sandwiched between two layers of woven/nonwoven geotextiles (Bouazza 2002). GCLs have been used as low permeability components in composite hydraulic barriers in the United States since 1980, and their design and applications have gained increasing popularity due to their reliable performances. Most commonly, GCLs have been used in composite liner systems; capping of landfills; liquid waste ponds; barrier system for the hydrocarbon spills; liners of underground storage tanks; containment systems of gas and fluids in mining industry and transportation facilities (Lorenzetti 2005; Nathalie Touze-Foltz 2012; Touze-Foltz et al. 2012).Compared to the conventional low-permeability barriers (e.g. compacted clay), GCLs have significant advantages such as availability, consistent low hydraulic conductivity $\left(\mathrm{k}_{\mathrm{w}}<10^{-10} \mathrm{~m} / \mathrm{s}\right)$, low cost, limited thickness, and easy installation (Bouazza 2002).Detailed comparison of advantages and disadvantages of GCL is summarized in Table 4-1 (Bouazza 1997). These advantages were recognized and consequently, increased the interest of GCL application in environmental geotechnics

Table 4-1. Advantages and disadvantages of GCL 


\begin{tabular}{|c|c|}
\hline Advantages & Disadvantages \\
\hline Rapid installation/less skilled labor/low cost & $\begin{array}{l}\text { Low shear strength of hydrated bentonite (for } \\
\text { unreinforced GCLs) }\end{array}$ \\
\hline $\begin{array}{c}\text { Very low hydraulic conductivity to water if } \\
\text { properly installed }\end{array}$ & $\begin{array}{l}\text { GCLs can be punctured during or after } \\
\text { installation }\end{array}$ \\
\hline $\begin{array}{l}\text { Can withstand large differential settlement } \\
\text { Excellent self-healing characteristics }\end{array}$ & $\begin{array}{l}\text { Possible loss of bentonite during placement } \\
\text { Low moisture bentonite permeable to gas }\end{array}$ \\
\hline Not dependent on availability of local soils & $\begin{array}{c}\text { Potential strength problems at interfaces with } \\
\text { other materials }\end{array}$ \\
\hline Easy to repair & Smaller leachate attenuation capacity \\
\hline Resistance to the effects of freeze/thaw cycles & Possible post-peak shear strength loss \\
\hline $\begin{array}{l}\text { More airspace resulting from the smaller } \\
\text { thickness }\end{array}$ & $\begin{array}{l}\text { Possible higher long term flux due to a } \\
\text { reduction in bentonite thickness under an } \\
\text { applied normal stress }\end{array}$ \\
\hline $\begin{array}{l}\text { Field hydraulic conductivity testing not } \\
\text { required }\end{array}$ & $\begin{array}{c}\text { Possible increase of hydraulic conductivity due } \\
\text { to } \\
\text { compatibility problems with contaminant if not } \\
\text { prehydrated with compatible water source }\end{array}$ \\
\hline Hydrated GCL is an effective gas barrier & $\begin{array}{l}\text { Higher diffusive flux of contaminant in } \\
\text { comparison with compacted clay liners }\end{array}$ \\
\hline Reduce overburden stress on compressible & $\begin{array}{c}\text { Prone to ion exchange (for GCLs with sodium } \\
\text { bentonite) }\end{array}$ \\
\hline substratum (MSW) & $\begin{array}{l}\text { Prone to desiccation if not properly covered (at } \\
\text { least } 0.6 \mathrm{~m} \text { of soil) }\end{array}$ \\
\hline
\end{tabular}

Typically, the common range of hydraulic conductivity of GCLs under the different confining stresses is in the range of $2 \times 10^{-12}$ to $2 \times 10^{-10} \mathrm{~m} / \mathrm{s}$ (Figure 4-1).Petrov et al. (1997) suggested that the higher confining stress decreases the bulk void ratio of the GCL. Consequently, the hydraulic conductivity of the GCL tendto decrease asthe confining stress increases. 


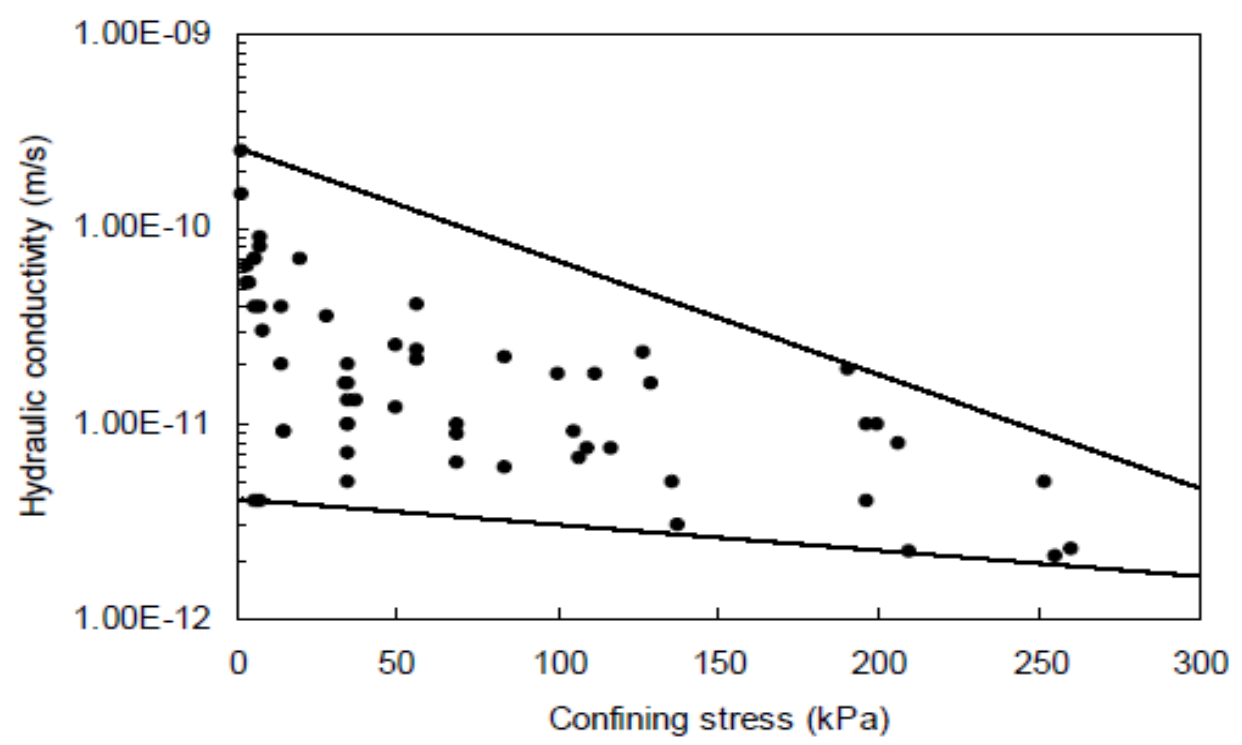

Figure 4-1. Variation of hydraulic conductivity with different confining stress (Bouazza 2002)

A higher hydraulic gradient is commonly used when examining the hydraulic performance of low flow rate systems because it would reduce the duration of the tests. However, exceeding a certain level of hydraulic gradient will cause the consolidation of the specimen due to seepage force and possibly result in a lower hydraulic conductivity (Shackelford et al. 2000).Typically, the acceptable range of hydraulic gradient for GCL layers lays is in the range of 50 and 500 (Daniel et al. 1993; Petrov et al. 1997; Shan and Daniel 1991). Petrov et al. (1997) investigated the effect of hydraulic gradient on the conductivity of a GCL permeated with deionized water, and $0.6 / 2 \mathrm{M} \mathrm{NaCl}$ solutions. The retrieved results are presented in Figure 4-2. 


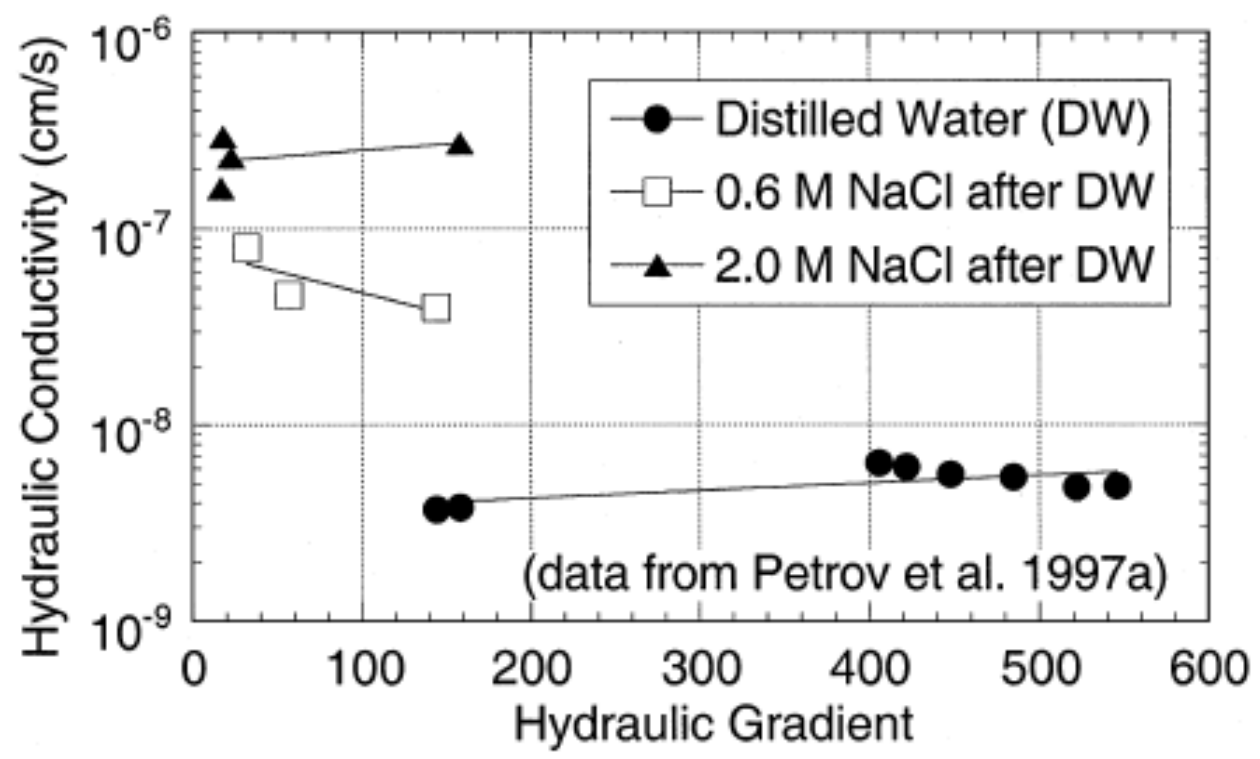

Figure 4-2. effect of hydraulic gradient on the conductivity of a GCL permeated with different liquids(Shackelford et al. 2000)

Petrov et al. (1997) proposed that the hydraulic gradient has a negligible effect on the hydraulic conductivity of GCLs (<factor of 2). Previously, Rad et al. (1994)suggested the same concept.

Although GCLs have a long history of successful engineering applications and have demonstrated reliable hydraulic performance to decrease the advective flow, the following limitations were observed in the field, including: (1) possible defects due to manufacture, transportation and installation (2) susceptibility and incompatibility (e.g. increased permeability, shrinkage) with certain chemicals, especially organic liquids (3) significant diffusive transport of contaminants even the advection is low. The abovementioned limitations, especially the chemical impartibility of conventional Na-bentonite GCL or Ca-bentonite GCL with organic fluid may directly impair their performance in soil barriers (e.g. liners of underground storage tank), which may raise short-term or long-term concerns. Specifically, it has been reported that the organic compounds with 
higher concentration or low-polarity organic fluids may dehydrate the clay minerals and consequently increase the hydraulic conductivity of the liner systems due to desiccation (Ruhl and Daniel 1997). In addition, the clay materials exposed to organic liquids tends to shrink considerably which results in different levels of cracks and increases the hydraulic conductivity of barrier system (Bowders and Daniel 1987; Lake and Rowe 2004). Ruhl and Daniel (1997) investigated the hydraulic performance of GCLs permeating with simulated municipal solid wastes. They discovered that the permeability of studied GCLs to the leachates of the solid wastes was about four orders of magnitude higher than the permeability of GCLs to the tap water. Additionally, Daniel et al. (1993) and Shan and Daniel (1991) evaluate the permeability of a GCL permeated with varying fluids. Their results suggested the GCL used to have a permeability for water as low as $10^{-9} \mathrm{~cm} / \mathrm{s}$, however, when permeated with organic liquid(s), the permeability of GCL increased drastically to $10^{-5} \mathrm{~cm} / \mathrm{s}$.

Other fluid properties, including ionic strength and $\mathrm{pH}$ could affect the hydraulic performance of GCL as well. Jo et al. (2001) studied the impact of ionic concentration on the swelling tendency and hydraulic conductivity of non-prehydrated GCLs. They noted that the GCLs permeated by solutions with higher ionic concentration or with highvalence cations exhibited higher hydraulic conductivity compared to solutions with monovalent cations or water. Shackelford et al. (2000) investigated the hydraulic performance of GCLs permeated by non-standard solutions and they draw similar conclusions. Bradshaw et al. (2016)conducted tests to evaluate the effect of $\mathrm{pH}$ on the saturated hydraulic conductivity of studied GCL. They suggested that the hydraulic conductivity decreased when the $\mathrm{pH}$ of the permeant solution increased.Ye et al. (2014) 
explored the effect of $\mathrm{pH}$ on the hydraulic conductivity of compacted bentonite and concluded that compacted bentonite has higher hydraulic conductivity in the basic solution.

Most commonly, the chemical incompatibility observed for the GCL field applications are due to the contact with petroleum-related products, landfill leachate, fuels, and industrial wastewater (Bradshaw et al. 2016). Typically, the organic compounds, or the organic liquids in the waste or wastewater are the components that are not compatible with inorganic soils like Na-bentonite or Ca-bentonite. Additionally, although the conventional Na-bentonite or Ca-bentonite based GCLs exhibited lower permeability for aqueous solutions, they also had a much lower contaminant retention capacity for dissolved organics(Broderick and Daniel 1990). Because of the above reasons, the performance of conventional GCL as both hydraulic barrier and chemical barrier can be fair or poor. Different sorptive/reactive geo-materials have been suggested as an amendment in compacted soil liners (Lo et al. 1997).. Similarly, certain amendments with enhanced reactivity with organic solute and/or organic fluid could enhance the chemical compatibility of the conventional GCLs Many studies have been carried out to investigate the feasibility of using fly ashes, zeolites, organo-zeolites, coated sands and organoclays as reactive amendments to the GCLs(Lo and Liljestrand 1996; Prasad et al. 2012; Varank et al. 2011; Younus and Sreedeep 2012).

Recent studies suggested that the permeability of organobentonites decreases by decreasing the polarity of the permeant fluid. For instance, the permeability of organoclays to non-polar liquid like fuels is much lower compared to polar or semi-polar liquids(Ghavami et al. 2016). Lorenzetti et al. (2005) studied the effect of different 
percentages of organoclays amendment on the hydraulic conductivity of GCLs. They indicated that the hydraulic conductivity of GCLs can be affected significantly by different fraction of organoclays, especially when the fraction of organoclay amendment is greater than $20 \%$ of total weight of filling material in GCLs. Their results showed that the hydraulic conductivity of GCL permeated by water increases as the percentages of organoclay amendment increases. However, it was observed that a small fraction of organoclays (less than $10 \%$ by weight) has limited impact on the hydraulic conductivity of GCLs while it can reduce the permeability of the GCL to organic liquids and may retard the mass transport of organic contaminants significantly. Although organoclays increase the hydraulic conductivity of the compacted clay systems, the bentonite component compensates the defect of hydraulic conductivity and maintains the conductivity of the system at a low rate. It was proposed that a combination of organoclay and bentonite could be used as earthen barrier materials because they can enhance the sorption and retardation capacity of the barrier systems to organic contaminants while they can provide a relatively low hydraulic conductivity for waste disposal practices.

Although previous studies yield great insights into the interactions between bentonites, permeant fluids and ions, the organic compounds retention of GCLs under a slow advective flow condition remained relatively unknown. This was due to: (1) the time required to perform the study of organic contaminant mass transport through a low flow rate GCL is too long (more than weeks); (2) the difficulty to control the organic contaminant source during the test; (3) the lack of analytical solution to interpret the 
observed retention or retardation of organic contaminants in GCLs; and also (4) the limited chemical interactions between conventional GCLs and the organic compounds. In this study, the permeability of conventional Ca-bentonite/Na-bentonite GCLs and Cabentonite/Na-bentonite GCLs amended with organobentonite were investigated. Water, benzene solution, methanol, and gasoline were chosen as the permeant liquids and the

effects of confining stress, $\mathrm{pH}$, and ionic strength on the permeability of GCLs were studied. Lab batch sorption test and contaminant breakthrough in the GCLs were carried out and benzene was selected (a representative of BTEX) as the organic contaminant. The retarded transport of benzene through Ca-bentonite/Na-bentonite GCL with different fraction of organobentonites was observed and analyzed.

\subsection{Material and methods}

\subsubsection{GCL specimen}

A roll of Bentomat 200R GCL was provided by CETCO Co. (Figure 4-3). The Bentomat 200R consists of a layer of granular bentonite sandwiched between a nonwoven and woven geotextile layers. The geotextile layers and granular bentonite as the middle layer are needle punched together. The properties of Bentomat $200 \mathrm{R}$ is summarized in Table 4-2 (CETCO 2014): 


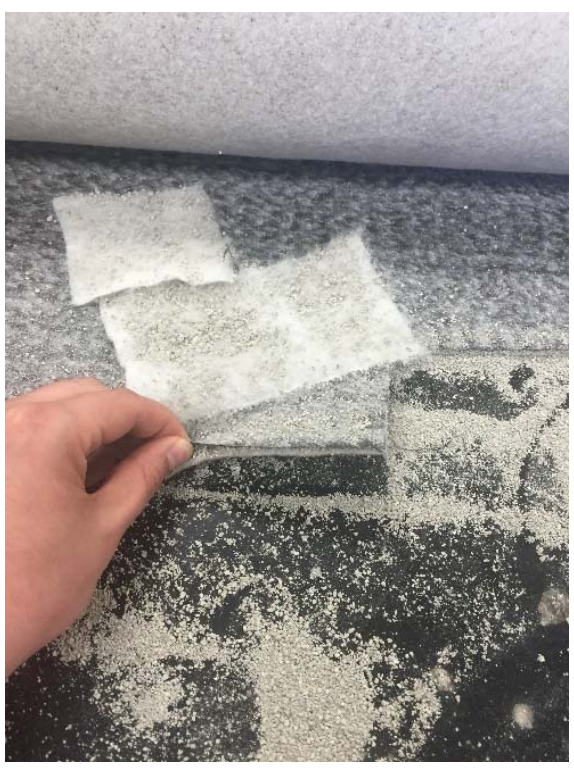

Figure 4-3. The base GCL, Bentomat 200R

Table 4-2. Properties of Bentomat 200R

\begin{tabular}{ccc} 
Material property & Test method & Required values \\
\hline Bentonite Swell Index & ASTM D 5890 & $24 \mathrm{~mL} / 2 \mathrm{~g} \mathrm{~min}$. \\
Bentonite Fluid Loss & ASTM D 5891 & $18 \mathrm{~mL} \mathrm{max.}$ \\
Bentonite Mass/Area & ASTM D 5993 & $0.75 \mathrm{lb} / \mathrm{ft}^{2}\left(3.6 \mathrm{~kg} / \mathrm{m}^{2}\right) \mathrm{min}$. \\
GCL Tensile Strength & ASTM D 6768 & $30 \mathrm{lb} / \mathrm{in}(53 \mathrm{~N} / \mathrm{cm}) \mathrm{MARV}$ \\
GCL Peel Strength & ASTM D 6496 & $1 \mathrm{lb} / \mathrm{in}(1.75 \mathrm{~N} / \mathrm{cm}) \mathrm{min}$. \\
GCL Index Flux & ASTM D 5887 & $1 \times 10^{-8} \mathrm{~m}^{3} / \mathrm{m}^{2} / \mathrm{sec} \mathrm{max.}$ \\
GCL Hydraulic Conductivity & ASTM D 5887 & $5 \times 10^{-9} \mathrm{~cm} / \mathrm{sec} \mathrm{max.}$ \\
GCL Hydrated Internal Shear & ASTM D 5321 & $150 \mathrm{psf}(7.2 \mathrm{kPa})$ typical \\
Strength & ASTM D 6243 & \\
\hline
\end{tabular}

The entire surface of GCL was inspected for any damages or defects. A porous stone was used as a base to cut a circular sample of GCL, which matches to the exact size of the base and cap used in the column study. In this study, GCL specimens were carved from the base GCL with the dimension of 4 inches $(101.6 \mathrm{~mm})$ in diameter, Figure 4-4. 


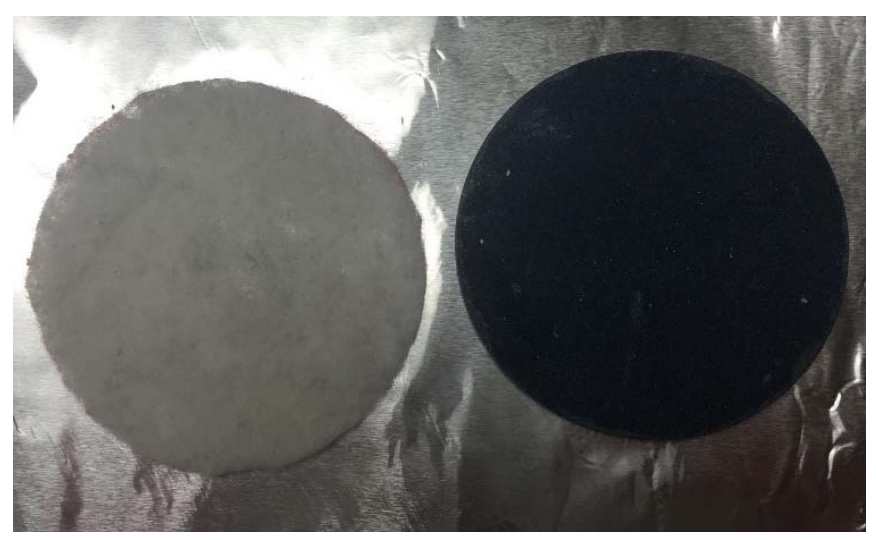

Figure 4-4. Carved GCL specimen from the base GCL

The original soil filling in the Bentomat 200R was replaced by a certain weight of desired soil filling. A mixture of calcium and sodium bentonite and desired percentages of HDTMA bentonite was used as the filling (D6766). The edges of the specimens were moisturized by a squirt bottle to prevent the filling lost at the edges (Rowe et al. 2000), Figure 4-5.

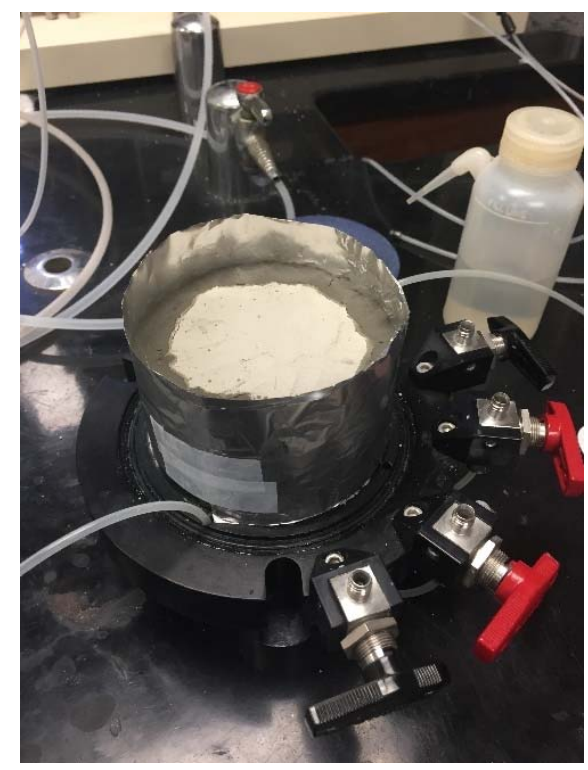

Figure 4-5. Filling the soil mixture in the GCL specimen

To have an even flow distribution through the sample, a pair of porous stone were placed at top and bottom of each specimen. The initial thickness of constructed GCL specimens were typically measured between 7 and $8 \mathrm{~mm}$, Figure 4-6. 


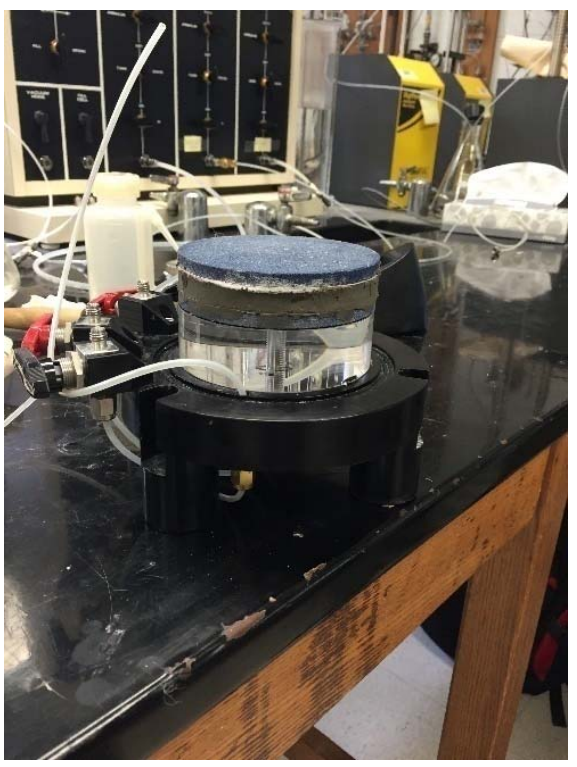

\section{Figure 4-6. Assembled GCL specimen for column test}

To ensure the compatibility with the permeant fluids, polytetrafluoroethylene (PTFE) tubes were used in the entire flow-through system. Also, the GCL specimens were wrapped finally by the Teflon tape to prevent the decay of initial concentration of benzene due to the sorption by the latex membrane, Figure 4-7.

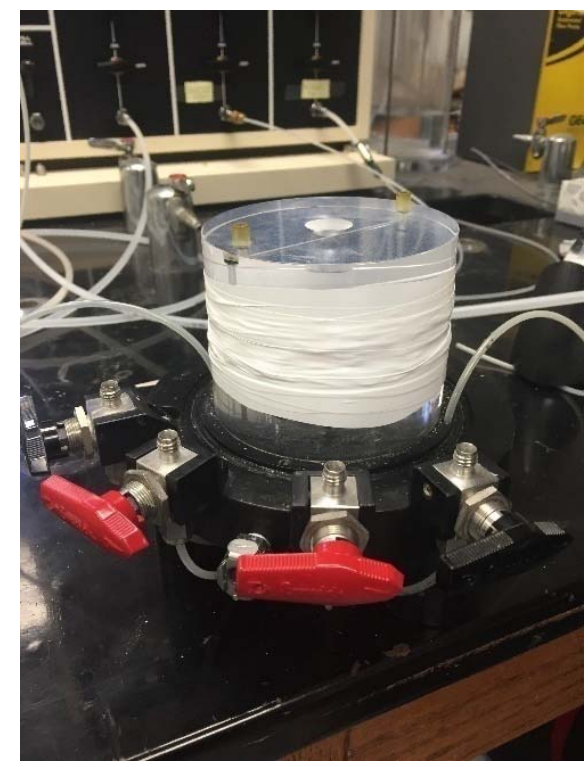

Figure 4-7. GCL specimen wrapped by Teflon tape 
At the final step, the GCL specimens were wrapped by latex membrane. to seal the membrane to the top cap and the base, a pair of O-ring was placed around the specimen. The physical properties of GCL specimens are summarized in Table 4-3 and Table 4-4.

Table 4-3. The physical parameters of calcium based GCL specimens

\begin{tabular}{cccc}
\hline $\begin{array}{c}\text { Column } \\
\text { Component }\end{array}$ & $100 \%$ Ca-bentonite & $\begin{array}{c}90 \% \text { Ca-bentonite }+ \\
10 \% \text { HDTMA- } \\
\text { bentonite }\end{array}$ & $\begin{array}{c}80 \% \text { Ca-bentonite }+ \\
\text { 20\% HDTMA- } \\
\text { bentonite }\end{array}$ \\
\hline $\begin{array}{c}\text { Diameter }(\mathrm{mm}) \\
\text { Height }(\mathrm{mm})\end{array}$ & 101.6 & 101.6 & 101.6 \\
$\begin{array}{c}\text { Specific gravity } \\
\text { of soil filling } \\
\left(\mathrm{G}_{\mathrm{s}}\right)\end{array}$ & 2.8 & 8 & 7.9 \\
$\begin{array}{c}\text { Porosity } \\
\text { Pore volume } \\
\left(\mathrm{cm}^{3}\right)\end{array}$ & 0.64 & 2.53 & 2.44 \\
\hline
\end{tabular}

Table 4-4. The physical parameters of sodium based GCL specimens

\begin{tabular}{cccc}
\hline $\begin{array}{c}\text { Column } \\
\text { Component }\end{array}$ & $100 \%$ Na-bentonite & $\begin{array}{c}90 \% \text { Na-bentonite }+ \\
10 \% \text { HDTMA- } \\
\text { bentonite }\end{array}$ & $\begin{array}{c}80 \% \text { Na-bentonite }+ \\
\text { 20\% HDTMA- } \\
\text { bentonite }\end{array}$ \\
\hline $\begin{array}{c}\text { Diameter }(\mathrm{mm}) \\
\text { Height }(\mathrm{mm})\end{array}$ & 101.6 & 101.6 & 101.6 \\
$\begin{array}{c}\text { Specific gravity } \\
\text { of soil filling } \\
\left(\mathrm{G}_{\mathrm{s}}\right)\end{array}$ & 7.5 & 7.7 & 7.8 \\
$\begin{array}{c}\text { Porosity } \\
\text { Pore volume }\end{array}$ & 0.68 & 2.54 & 2.45 \\
$\left(\mathrm{~cm}^{3}\right)$ & 37 & 0.67 & 0.64 \\
\hline
\end{tabular}




\subsubsection{Permeant liquids}

Anhydrous benzene with purity of $99.8 \%$ was diluted by deionized water to reach to the target concentration for this study, which was 300 to $400 \mu \mathrm{g} / \mathrm{mL}$. To achieve the desired concentration, 0.3 to $0.4 \mathrm{~g}$ of liquid benzene was extracted by a $10 \mu \mathrm{L}$ glass syringe (Hamilton Co.) from the source and placed into a flask (Fisher scientific Co.) with the capacity of 2 L. one liter of deionized water was added to the flask and stirred in an Ultrasonic Bath (VWR Co.) for 30 mins. The obtained stock solutions were stored at room temperature for less than 1 hour before the tests. Additionally, pure methanol (Carolina Biological Supply Co.) and unleaded gasoline (grade 87) were used as low polarity liquids for the permeability tests.

\subsubsection{Swell index test of GCL soil components}

Previous studies indicated that the permeability of GCL is typically related to the swelling tendency of the filling soil in the permeant liquid (Jo et al. 2001). The swell index tests were conducted to evaluate the swelling tendency of studied soils, following the ASTM standard D5890-11.Initially, the studied soils were oven dried at $90{ }^{\circ} \mathrm{C}$ for 24 . Next, the soils were sieved through the No. 100 sieve (Phanikumar and Shankar 2016). 2 $\mathrm{g}$ of sieved dry soil grains was then added to a $100 \mathrm{~mL}$ graduated glass cylinder filled with $90 \mathrm{~mL}$ of one of the selected liquids (DI water, methanol, gasoline, sodium chloride $(\mathrm{NaCl})$ solution, and basic/acidic solutions). Additional liquid was then added to the cylinder until the $100 \mathrm{~mL}$ mark was reached. $\mathrm{NaCl}$ solutions with ionic concentrations of

$0.01 \mathrm{M}, 0.1 \mathrm{M}$, and $1 \mathrm{M}$ were prepared and used for the swelling tests. the volume of suspended soil was measured for the first 24 hours. 


\subsubsection{Permeability test}

To investigate the impact of the polarity of the fluids on the permeability of organobentonite amended GCLs, 16 GCL specimens were constructed following the method described in 4.2.1. 6 GCL specimens were filled with Ca-bentonite, Na-bentonite, 10\% HDTMA-bentonite $+90 \%$ Ca-bentonite, $10 \%$ HDTMA-bentonite $+90 \%$ Nabentonite, 20\% HDTMA-bentonite $+80 \%$ Ca-bentonite, and 20\% HDTMA-bentonite + Na-bentonite. and three permeant liquids with high polarity (water), intermediate polarity (methanol) and low polarity (gasoline) were used. Additionally, 10 Na-bentonite GCL specimens with different percentage of HDTMA-bentonite and PM-199 were constructed to examine the effect of organobentonite amendments. The physical properties of GCL specimens are summarized in Table 4-5.

Table 4-5. Physical properties of GCL specimens for permeability study

\begin{tabular}{|c|c|c|c|}
\hline GCL specimen & $\begin{array}{c}\text { Water content } \\
(\%)\end{array}$ & $\begin{array}{l}\text { Average dry density } \\
\left(\mathrm{g} / \mathrm{cm}^{3}\right)\end{array}$ & $\begin{array}{l}\text { Mass per unit area } \\
\left(\mathrm{g} / \mathrm{cm}^{2}\right)\end{array}$ \\
\hline Ca-Bentonite & $8 \%$ & 1.26 & 0.95 \\
\hline Na-Bentonite & $8 \%$ & 1.10 & 0.83 \\
\hline $\begin{array}{c}\text { 10\% HDTMA-Bentonite }+ \\
90 \% \text { Ca-Bentonite }\end{array}$ & $10 \%$ & 0.93 & 0.75 \\
\hline $\begin{array}{c}20 \% \text { HDTMA-Bentonite }+ \\
80 \% \text { Ca-Bentonite }\end{array}$ & $9 \%$ & 1.00 & 0.77 \\
\hline $\begin{array}{c}\text { 10\% HDTMA-Bentonite + } \\
90 \% \text { Na-Bentonite }\end{array}$ & $10 \%$ & 1.03 & 0.80 \\
\hline $\begin{array}{c}20 \% \text { HDTMA-Bentonite }+ \\
80 \% \text { Na-Bentonite }\end{array}$ & $9 \%$ & 1.26 & 0.90 \\
\hline $\begin{array}{c}30 \% \text { HDTMA-Bentonite }+ \\
70 \% \text { Na-Bentonite }\end{array}$ & $9 \%$ & 1.05 & 0.89 \\
\hline $\begin{array}{c}50 \% \text { HDTMA-Bentonite }+ \\
50 \% \text { Na-Bentonite }\end{array}$ & $10 \%$ & 1.11 & 0.84 \\
\hline $\begin{array}{c}\text { 70\% HDTMA-Bentonite }+ \\
30 \% \text { Na-Bentonite }\end{array}$ & $10 \%$ & 1.00 & 0.75 \\
\hline $\begin{array}{c}10 \% \text { PM- } 199+90 \% \mathrm{Na}- \\
\text { Bentonite }\end{array}$ & $9 \%$ & 1.18 & 0.83 \\
\hline $\begin{array}{c}20 \% \text { PM- } 199+80 \% \mathrm{Na}- \\
\text { Bentonite }\end{array}$ & $9 \%$ & 1.15 & 0.84 \\
\hline $\begin{array}{c}30 \% \text { PM- } 199+70 \% \mathrm{Na}- \\
\text { Bentonite }\end{array}$ & $10 \%$ & 1.12 & 0.81 \\
\hline
\end{tabular}




\begin{tabular}{cccc}
\hline $\begin{array}{c}50 \% \text { PM-199+50\% Na- } \\
\text { Bentonite }\end{array}$ & $8 \%$ & 1.06 & 0.77 \\
$70 \%$ PM-199+30\% Na- & $9 \%$ & 1.08 & 0.79 \\
Bentonite & $8 \%$ & 1.15 & 0.98 \\
HDTMA-Bentonite & $8 \%$ & 1.09 & 0.95 \\
PM-199 & & \\
\hline
\end{tabular}

The permeability of studied GCLs were carried out in a flexible wall permeameter following ASTM D6766. The conductivity (k) of permeant liquids based on the falling head test method can be measured as follow:

$k_{t}=\frac{a L}{A t} \ln \left(\frac{h_{1}}{h_{2}}\right)$

where $k_{t}$ is hydraulic conductivity $(\mathrm{m} / \mathrm{s}), a$ is cross-sectional area of the reservoir containing the influent liquid $\left(\mathrm{m}^{2}\right), L$ is length of the specimen $(\mathrm{m}), A$ is cross-sectional area of the specimen $\left(\mathrm{m}^{2}\right), h_{1}$ is the head loss (m) across the specimen at time $t_{1}(\mathrm{~s}), h_{2}$ is the head loss (m) across the specimen at time $t_{2}(\mathrm{~s})$, and $t$ is the elapsed time (s) between determination of $h_{1}$ and $h_{2}$.

Also, the intrinsic permeability was calculated for each GCL specimen. The intrinsic permeability is independent of the fluid properties and represents the pore distributions and connectivity in the porous media. The intrinsic permeability is defined as:

$k_{i}=\frac{\mu k_{t}}{g}$

where $k_{i}$ is intrinsic permeability $\left(\mathrm{m}^{2}\right), \mu$ is kinematic viscosity of the permeant fluid $\left(\mathrm{m}^{2} / \mathrm{s}\right), k_{t}$ is hydraulic conductivity $(\mathrm{m} / \mathrm{s})$, and $g$ is the gravitational acceleration $\left(\mathrm{m} / \mathrm{s}^{2}\right)$.

After the assembly of the GCL specimens, de-aired water was flushed through the specimens under a relatively high hydraulic gradient (100) to flush two pore volumes of water in a short period of time. A relatively lower hydraulic gradient (25) was applied to 
the GCL specimens when permeated with organic liquids (methanol and gasoline). This was similar to the procedure by Ruhl and Daniel (1997). The GCL specimens were saturated for 4 days until the flow reached steady state. For each specimen, the confining pressure (cell pressure) was kept constant at $34.47 \mathrm{kPa}$ during entire test. The steady state flow was at $1.1 \pm 0.2 \mathrm{~mL} /$ hour and $0.9 \pm 0.2 \mathrm{~mL} /$ hour for Na-bentonite and Ca-bentonite based GCL specimens, respectively.

\subsubsection{Breakthrough test}

Breakthrough test was conducted to evaluate organic contaminant transport through the compacted soils, certain volume of the contaminant solution was introduced to each soil column with known soil constituents. Effluent was collected and analyzed for the concentration of the contaminant remained in the flow. Finally, the breakthrough curve was obtained by plotting the concentration of contaminant (or the relative concentration, the ratio of the effluent concentration to the source concentration) in the effluent versus time. Also, the collected pore volumes of effluent samples were recorded during the sampling. In this study, the mass transport of benzene through the GCL specimens with/without sorptive amendments (HDTMA-bentonite) was recorded during the breakthrough test. As explained in permeability test, the GCL specimens were flushed with de-aired water prior to the breakthrough test. The benzene solution with initial concentration of 300 to $400 \mu \mathrm{g} / \mathrm{ml}$ was fed to the GCL specimens using a bladder accumulator. The pulse-type contaminant injection method was selected as one pore volume of benzene solution was injected into the each GCL specimen, followed by the de-aired water until the test was completed. The breakthrough tests were terminated after the concentration of benzene in effluent was lower than the detection limit. For all 
specimens, the flow rate of benzene solutions was monitored during the breakthrough test. The effluent samples were collected in $10 \mathrm{~mL}$ conical centrifuge tubes (CORING Co.) and filtered through $0.2 \mu \mathrm{m}$ syringe filters (Acrodisc Co.). The liquid-liquid extraction was performed to extract the dissolved benzene from the filtered solution. Dichloromethane (DCM) was choose as the extraction liquid and it was mixed with the filtered solution in using a separatory funnel at a ratio of $10: 1(\mathrm{v} / \mathrm{v})$. Then the separatory funnel was shaken gently and left at rest until the two separate phases were observed. The DCM liquids were analyzed in Gas Chromatography equipped with Flame Ionization Detector (Clarus 480, Perkin Elmer Co.). As explained in chapter 3, the retardation factor $R_{d}$ of contaminant transport under low-flow rate condition was estimated as (Valocchi 1985):

$R_{d}=\frac{\sum\left(C / C_{0}\right) P V \Delta P V}{\sum\left(C / C_{0}\right) \Delta P V}-0.5 P V_{0}$

where $R_{d}$ is the dimensionless retardation factor, $C_{0}(\mu \mathrm{g} / \mathrm{mL})$ and $\mathrm{C}(\mu \mathrm{g} / \mathrm{mL})$ are the initial and equilibrium concentrations of naphthalene in aqueous phase, respectively; PV $(\mathrm{mL})$ is the corresponding pore volume to each measured concentration, $\Delta \mathrm{PV}(\mathrm{mL})$ is the differential pore volume between each sampling step, and $\mathrm{PV}_{0}(\mathrm{~mL})$ is the initial injected pore volume of the solution into the soil column.

In addition, the diffusion coefficient and the retardation factor were estimated by the numerical and analytical solutions. Assuming the steady state flow and equilibrium sorption, the contaminant transport through the porous media can be described by a onedimensional advection-dispersion-retardation equation (equation 1-3). To determine the soil parameter including retardation factor and diffusion coefficient, an implicit finite 
difference scheme was employed to fit the laboratory data. as following:

$$
C_{j}^{k+1}=C_{j}^{k}+\left(\frac{D \cdot \Delta t}{R_{d} \cdot \Delta x^{2}}\right)\left(C_{j-1}^{k}-2 C_{j}^{k}+C_{j+1}^{k}\right)-\left(\frac{v \cdot \Delta t}{2 \cdot R_{d} \cdot \Delta x}\right)\left(C_{j+1}^{k}-C_{j-1}^{k}\right)
$$

where $\mathrm{k}$ corresponds to the distance dimension, $\mathrm{j}$ corresponds to the time dimension, $\mathrm{C}$ is the concentration of the effluent in time $\mathrm{j}$ and location of $\mathrm{k}(\mu \mathrm{g} / \mathrm{mL}), \mathrm{D}$ is the diffusion coefficient $\left(\mathrm{cm}^{2} / \mathrm{s}\right), \mathrm{R}_{\mathrm{d}}$ is the retardation factor, $\Delta \mathrm{t}$ is the time step (s), and $\Delta \mathrm{x}$ is the distance step (cm). Two criteria have to be met to assure the convergence of the solution.

$$
\left\{\begin{array}{l}
\text { 1. }\left(\frac{D \cdot \Delta t}{R_{d} \cdot \Delta x^{2}}\right) \leq 0.5 \\
2 \cdot\left(\frac{v \cdot \Delta t}{R_{d} \cdot \Delta x}\right)^{2} \leq\left(\frac{2 \cdot D \cdot \Delta t}{R_{d} \cdot \Delta x^{2}}\right)
\end{array}\right.
$$

The convergence criteria was met by setting the time step to 0.1 and the distance step to 0.1. Two parameters were determined by finding the best fit: (1) the retardation factor $\left(R_{d}\right)$, and (2) the diffusion coefficient (D). An initial value for D was assumed based on the common range of $\mathrm{D}$ reported in previous studies $\left(\sim 10^{-6} \mathrm{~cm}^{2} / \mathrm{s}\right)$ and the best fitted curve was attained by changing $\mathrm{D}$ and $\mathrm{R}_{\mathrm{d}}$, simultaneously.

In addition, the laboratory results were compared with an analytical solution to equation 1-3 considering the pulse-type injection method (Genuchten et al. 2013). The pulse-type injection can be defined as:

$$
g(t)=\left\{\begin{array}{lr}
C_{0} & 0<t \leq t_{0} \\
0 & t>t_{0}
\end{array}\right.
$$

And the solution to equation 1-3 can be obtained as follow:

$$
C(x, t)=\left\{\begin{array}{lr}
C_{i}+\left(C_{0}-C_{i}\right) A(x, t) & 0<t \leq t_{0} \\
C_{i}+\left(C_{0}-C_{i}\right) A(x, t)-C_{0} A\left(x, t-t_{0}\right) & t>t_{0}
\end{array}\right.
$$


where,

$$
\begin{aligned}
A(x, t)=\frac{1}{2} \operatorname{erf} c & {\left[\frac{R_{d} x-v t}{\sqrt{4 D R_{d} t}}\right]+\sqrt{\frac{v^{2} t}{\pi D R_{d}}} \exp \left[\frac{\left(R_{d} x-v t\right)^{2}}{4 D R_{d} t}\right] } \\
& -\frac{1}{2}\left(1+\frac{v x}{D}+\frac{v^{2} t}{D R_{d}}\right) \exp \left(\frac{v x}{D}\right) \operatorname{erf} c\left[\frac{R_{d} x+v t}{\sqrt{4 D R_{d} t}}\right]
\end{aligned}
$$

where $\mathrm{C}(\mathrm{x}, \mathrm{t})$ is the solute concentration $(\mu \mathrm{g} / \mathrm{mL}), \mathrm{C}_{0}$ is the initial concentration of injected pulse $(\mu \mathrm{g} / \mathrm{mL}), \quad C_{i}$ is the initial concentration of studied semi-infinite domain $(\mu \mathrm{g} / \mathrm{mL}), \mathrm{v}$ is the longitudinal fluid flow velocity $(\mathrm{cm} / \mathrm{s}), \mathrm{t}$ is the time of breakthrough $(\mathrm{s})$, and $\mathrm{D}$ is longitudinal diffusion coefficient $\left(\mathrm{cm}^{2} / \mathrm{s}\right)$. Likewise, both $\mathrm{R}_{\mathrm{d}}$ and $\mathrm{D}$ were changed simultaneously to find the best curve fitting in this solution.

\subsection{Result and discussion}

\subsubsection{Swelling index}

The results of swell index test are shown in Figure 4-8. It can be noticed that the unmodified bentonites, especially Na-bentonite, exhibit a significant swelling in water because of strong hydration of inorganic cations in the interlayer. When sodium or calcium bentonites are dry, the interlayer spacing are typically $9 \sim 10 \AA$ as the cations formed surface complex on the sillica sheets. However, the bonding between the inorganic cations and montmorillonite sheets are very week and can be easily interrupted by polar fluids such as water (Oweis and Khera 1998). The water molecules would form hydration shells around the $\mathrm{Na}^{+}$and $\mathrm{Ca}^{2+}$ cations and prop open the interlayer spacing (from $14 \AA \sim 16 \AA$ ) (Ayral-Cinar et al. 2016; Doh and Cho 1998). Additionally, the hydration of $\mathrm{Na}^{+}$in water is the highest because it has a strong dipole polarity, 1.854 (Lo 
and Yang 2001). Consequently, the volume of particle aggregates increases as the hydration prevails in the interlayer of the bentonites.

In comparison, the swelling index of HDTMA-bentonite and PM-199 in water are significantly lower $(5 \mathrm{~mL} / 2 \mathrm{~g})$. Because the naturally occurring interlayer cations $\left(\mathrm{Na}^{+}\right.$or $\left.\mathrm{Ca}^{2+}\right)$ of bentonite were replaced by quaternary ammonium cations, the surfactant-coated surfaces of modified bentonite became hydrophobic. The cation hydration was no longer the prevailing mechanism of organobentonite swelling in water. The swelling of Nabentonite and HDTMA-bentonite admixture or Na-bentonite and PM-199 admixture decreased slightly from $24 \mathrm{~mL} / 2 \mathrm{~g}$ for $100 \%$ Na-bentonite to $21 \mathrm{~mL} / 2 \mathrm{~g}$ for $80 \% \mathrm{Na}$ bentonite $+20 \%$ HDTMA-bentonite, and $22 \mathrm{~mL} / 2 \mathrm{~g}$ for $80 \%$ Na-bentonite $+20 \% \mathrm{Pm}$ 199.

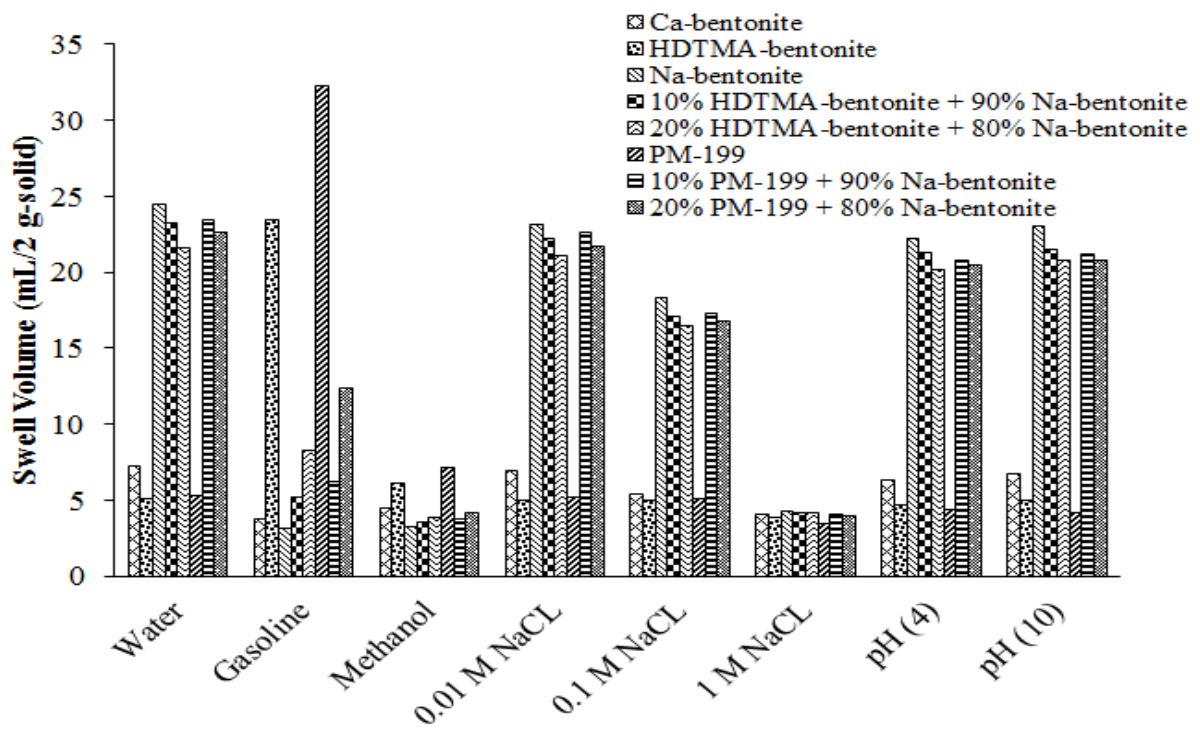

Figure 4-8. Swell index result for studied soil matrixes

The swelling of Na-bentonite in gasoline and methanol were inherently low (3.2 and 3.3, respectively). Similarly, Ca-bentonite swelled much less in gasoline and methanol as well 
(3.8 and 4.5, respectively). This because the dominant constituents of the gasoline or methanol such as normal alkanes, benzene, and p-xylene have symmetric molecular structures which result in the dipole polarity of zero or near zero (Lo and Yang 2001). Because of this reason, the adsorption of gasoline or methanol molecules by the interlayer of $\mathrm{Na}^{+}$or $\mathrm{Ca}^{2+}$ bentonites was minimum and the interlayer swelling of the two were inhibited. The low swelling capacity of the unmodified bentonite can also be interpreted from the dielectric constant of the solution (ع).Graber and Mingelgrin (1994) explained that the swelling of bentonite decreases steadily when the dielectric constant of the solution decreases. They indicated that the maximum volumetric swelling of bentonite was in the water as it has the highest value of dielectric constant $(\varepsilon=80.20)$.

In contrast, HDTMA-bentonite and PM-199 had significant swelling in gasoline, Figure 4-9. The swelling indices of HDTMA-bentonite and PM-199 in gasoline were 23.5 and 32.2, respectively. Also, a slight swelling of HDTMA-bentonite and PM-199 in methanol were observed (6.1 and 7.2, respectively). Previous studies suggested that the swelling tendency of organobentonite in organic liquid is related to the TOC of the liquid (Benson et al. 2015). Typically, the TOC of gasoline and methanol are higher than $10000 \mathrm{ppm}$ (Lo and Yang 2001). Because of the hydrophobic interactions between the intercalated surfactants and the non-polar solvent molecules, the modified clay minerals show higher tendency to adsorb organic liquids. Additionally, PM-199 exhibited higher swelling capacity in gasoline/methanol compared to the HDTMA-bentonite. This was due to the fact that PM-199 had a double chain quaternary ammonium cation while HDTMAbentonite was modified by a single chain quaternary ammonium cation. 


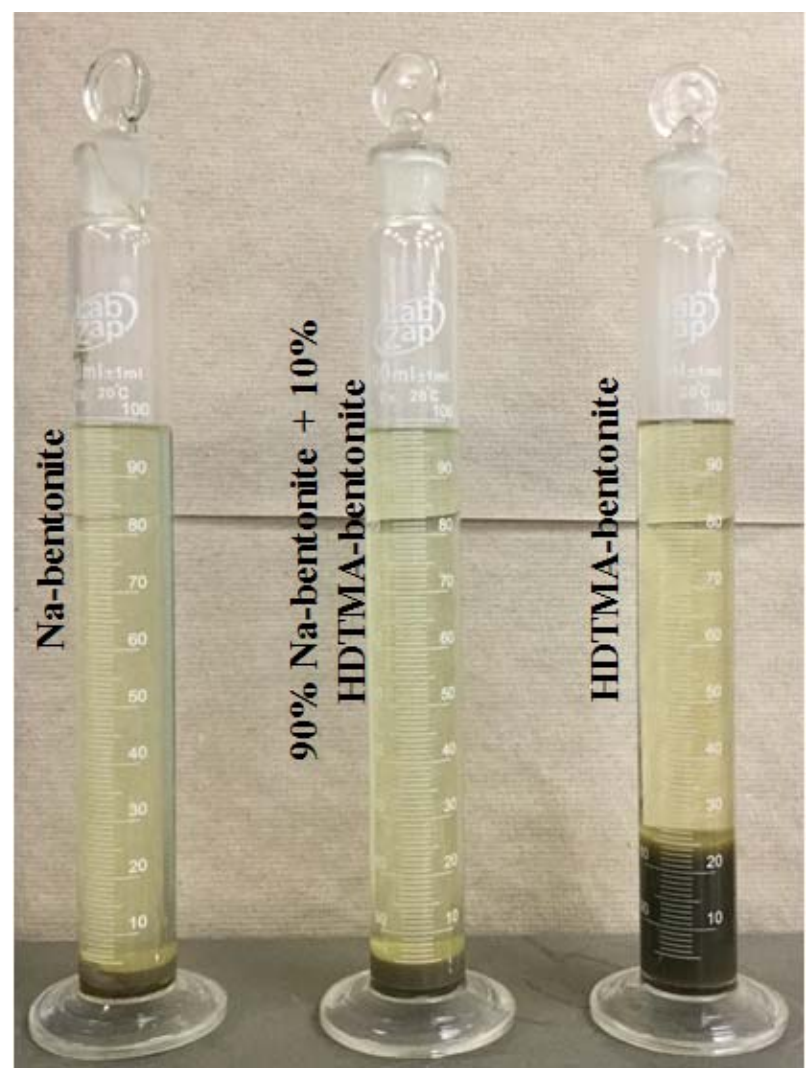

\section{Figure 4-9. Swell index experiment for three studied soil specimens in gasoline}

The results of swelling tests indicated that the organoclays and unmodified clays may exhibit very different swelling tendency in different liquids. The swelling tendency of unmodified bentonite increased when the polarity of the solution increased while organobentonites exhibited a lower swelling capacity when the polarity of solution increased. Notably, the organobentonites had increased swelling when the soaked in gasoline, which indicated both had a higher compatibility with gasoline, or other petroleum products.

The lower ionic concentration of 0.01 and $0.1 \mathrm{M}$ of $\mathrm{NaCl}$ had limited impact on the swelling index of $\mathrm{Na}$ and Ca-bentonites. However, the swelling of Na-bentonite decreased to $4.3 \mathrm{~mL} / 2 \mathrm{~g}$ at very high ionic strength (1M) (Figure 4-10). This was because the free energy gradient that induced by the elevated ionic concentration in the bulk 
solution dragged the water out of the interlayer of $\mathrm{Na}$ and Ca-bentonites (McBride 1994; Sposito 1981). Because of the same reason, it was observed that the permeability of GCL increases significantly when the ionic concentration of the fluid is very high (Jo et al. 2001). PM-199 and HDTMA-Bentonite had limited and consistent swelling in the $\mathrm{NaCl}$ solution with varying ionic strength. It can be concluded that although the organobentonites swell inherently less in aqueous solution, they are also less susceptible to the ionic concentration. The low percentage of organobentonites (10\% and $20 \%)$ in the admixture with Na-bentonite did not affect the overall swelling tendency of Na-bentonite.

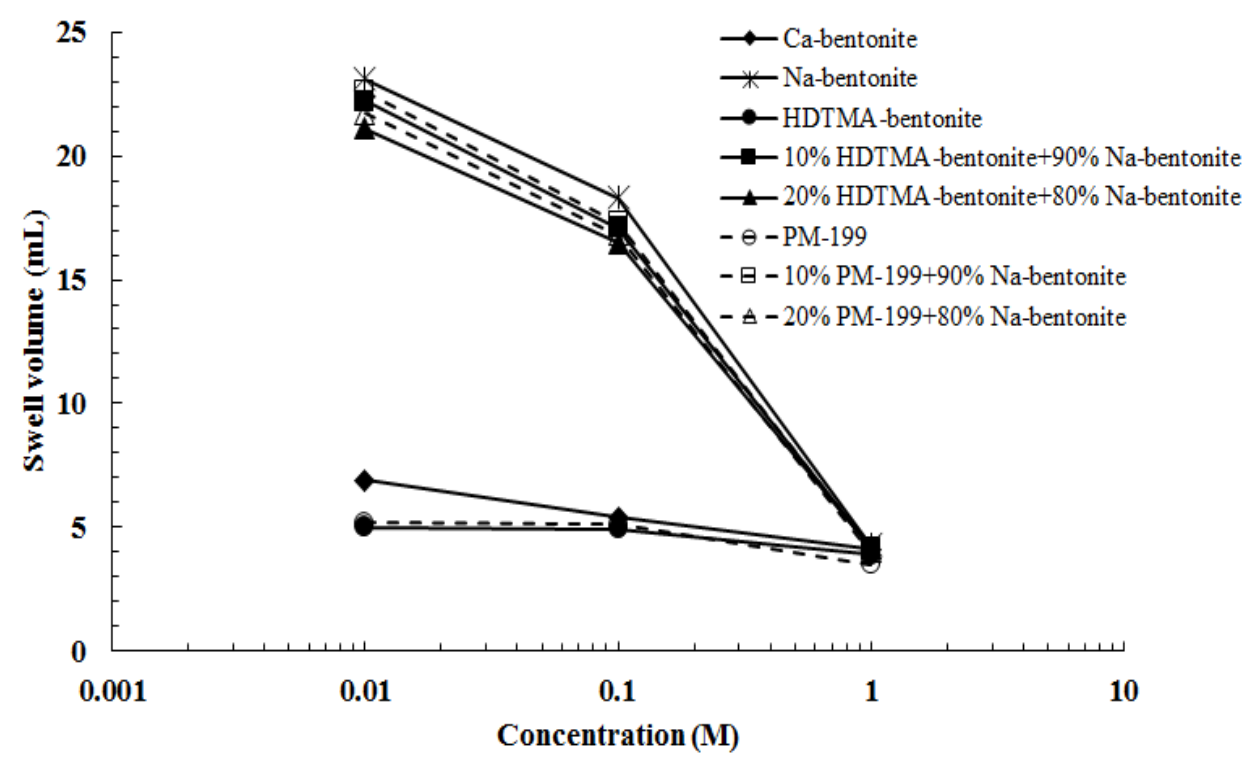

\section{Figure 4-10. The effect of ionic concentration on the swelling tendency of the proposed soil combinations}

In addition, the effect of $\mathrm{pH}$ on the swelling tendency of the soils were examined and results are presented in Figure 4-11. It was observed that the $\mathrm{pH}$ had limited effect on the swelling tendency of the all soils (in the range of 4-10). The observation in this study was similar to the results of a sedimentation experiment of sodium bentonite in the $\mathrm{HCl}$ and $\mathrm{NaOH}$ solutions (Shackelford (1994). However, previous studies have also indicated that 
the swelling of Na-bentonite can be significantly affected when the $\mathrm{pH}$ level of the solution is greater than 12 or less than 3 (Jo et al. 2001).The effect of $\mathrm{pH}$ on the swelling volume of the Na-bentonite in combination with different percentage of HDTMAbentonite and PM-199 in presented in Figure 4-12. Organobentonites have a limited swelling capacity in aqueous solutions with different $\mathrm{pH}$ level (4,7, and 10). Thus, the small dosage of organobentonites (10\% and $20 \%$ ) mixed with Na-bentonite did not affect the overall swelling tendency of Na-bentonite (Figure 4-12).

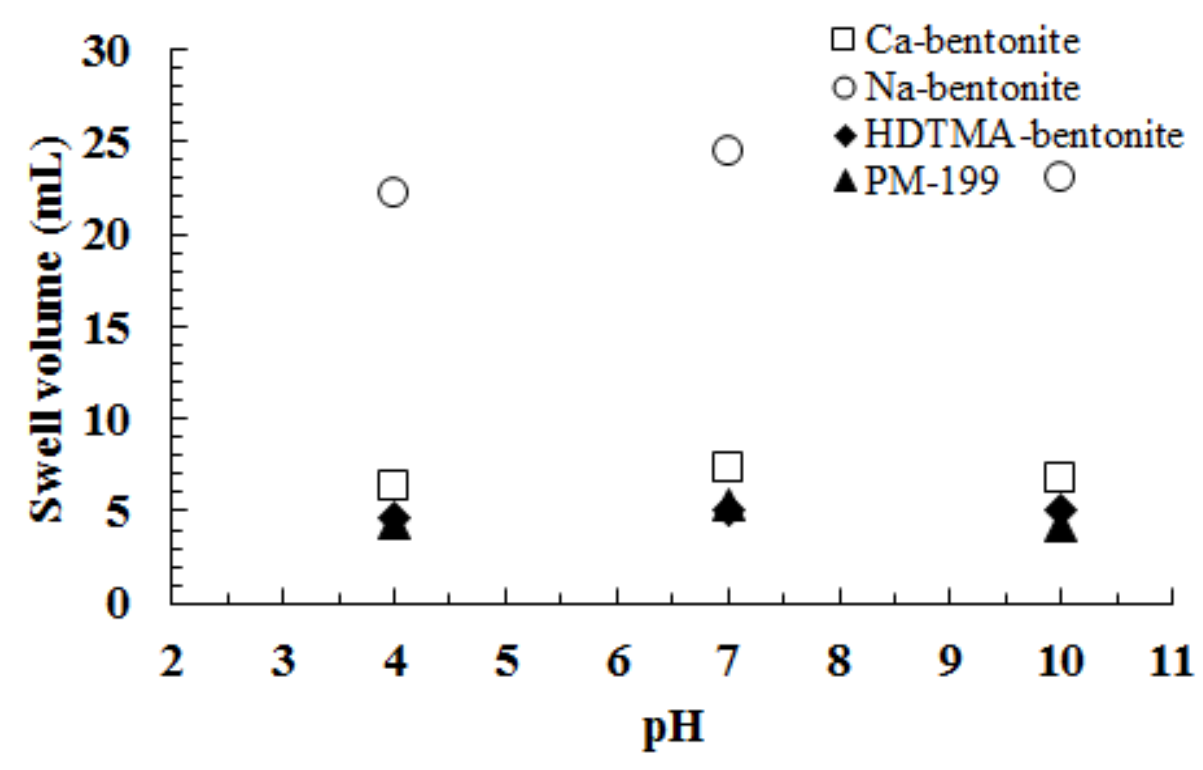

Figure 4-11. Effect of $\mathrm{pH}$ on the swelling of studied sorbents 


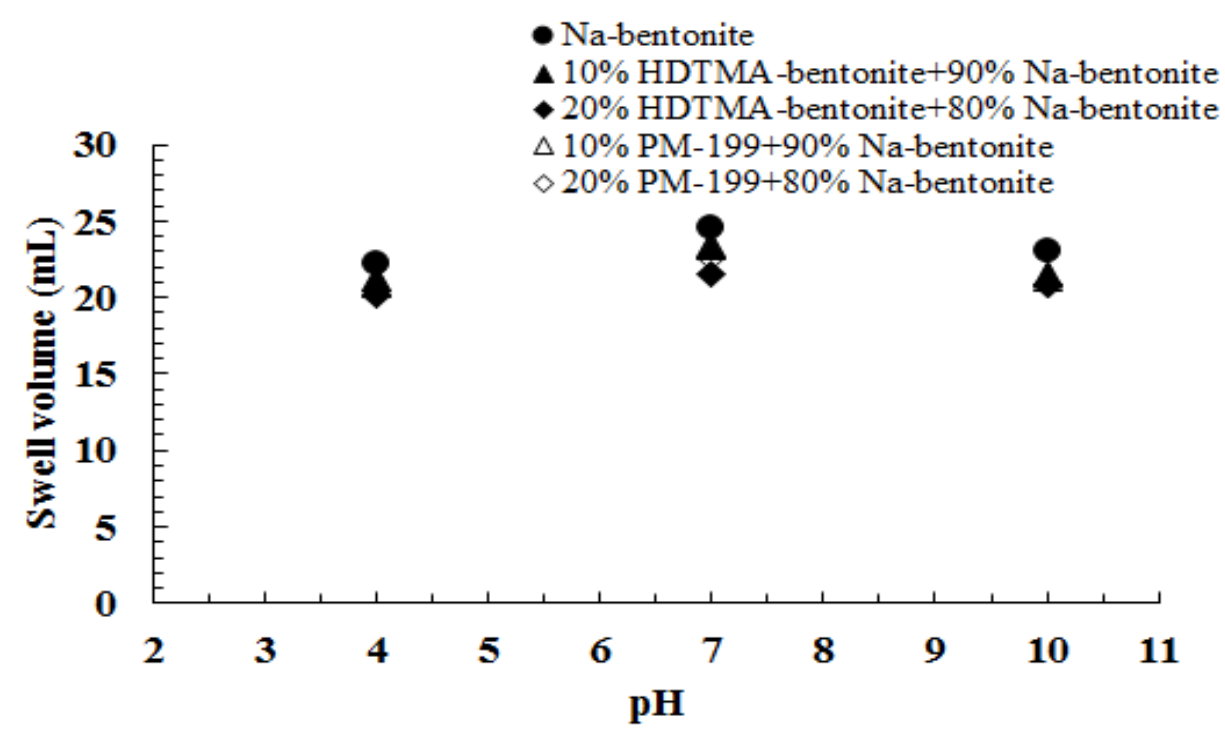

Figure 4-12. Effect of $\mathrm{pH}$ on the swelling volume of the Na-bentonite mixture with PM-199 and HDTMA-bentonite

Although the free-swelling tests directly compared the stability of suspended particles in aqueous phase, soil swelling in GCL could be under a partially saturated, confined environment. During the permeability and breakthrough tests, the thickness of dry and hydrated GCL specimens were measured to yield better insights into the swelling of soils confined between geotextiles. The GCL specimens were subjected to the isotropic confining stress of $34.47 \mathrm{kPa}$ during the entire experiment and no additional overburden stress were applied to the GCLs. The initial thickness $\left(\mathrm{H}_{\mathrm{i}}\right)$ and the final thickness $\left(\mathrm{H}_{\mathrm{f}}\right)$ of GCL specimens were measured before and after the tests. the ratio of $\mathrm{H}_{\mathrm{f}}$ to $\mathrm{H}_{\mathrm{i}}$ was determined as the swelling ratio of the GCL specimen (Lorenzetti et al. 2005). The measured swelling ratio of the five studied specimens are summarized in Table 4-6.

\section{Table 4-6. Swelling ratio of studied GCL specimens}

\begin{tabular}{cc} 
GCL specimen components & Swelling ratio \\
\hline Ca-bentonite & 1.25 \\
$10 \%$ HDTMA-bentonite $+90 \%$ Ca-bentonite & 1.21 \\
$20 \%$ HDTMA-bentonite $+80 \%$ Ca-bentonite & 1.19 \\
Na-bentonite & 2.05 \\
$10 \%$ HDTMA-bentonite $+90 \%$ Na-bentonite & 2.00
\end{tabular}


It was observed that GCL specimens exhibited considerable swelling in vertical direction ranging from $20 \sim 30 \%$ for calcium amended GCLs and around $100 \%$ for sodium bentonite amended samples. It was believed that the excessive swelling of several GCL specimens occurred because the geotextiles of GCL specimens were not stitched together. In general, it is expected that the swelling tendency of GCL specimens decreases when the percentage of organoclays increases. However, no significant differences were detected between the swelling ratio of calcium/sodium bentonite amended GCLs and HDTMA-Bentonite amended GCLs due to the small fraction of HDTMA-bentonite in the filling matrix (maximum $20 \%$ by weight).

\subsubsection{Permeability test}

The fluid conductivities (k) and intrinsic permeability of constructed GCL specimens to different liquids are summarized in Table 4-7.

Table 4-7. Average conductivity of studied GCL specimens permeated by different liquids

\begin{tabular}{|c|c|c|c|}
\hline GCL component & Permeant Liquid & $\mathbf{k}(\mathbf{m} / \mathbf{s})$ & Intrinsic permeability $\left(\mathrm{m}^{2}\right)$ \\
\hline \multirow[b]{2}{*}{ Ca-bentonite } & water & $3.0 \times 10^{-10}$ & $2.16 \times 10^{-17}$ \\
\hline & $\begin{array}{c}\text { benzene solution }\left(C_{0}=300\right. \\
\text { to } 400 \mu \mathrm{g} / \mathrm{mL})\end{array}$ & $3.1 \times 10^{-10}$ & $2.23 \times 10^{-17}$ \\
\hline \multirow{3}{*}{$\begin{array}{l}10 \% \text { HDTMA- } \\
\text { bentonite }+90 \% \mathrm{Ca}- \\
\text { bentonite }\end{array}$} & water & $4.6 \times 10^{-10}$ & $4.5 \times 10^{-17}$ \\
\hline & benzene solution $\left(\mathrm{C}_{0}=300\right.$ & $3.5 \times 10^{-10}$ & $3.42 \times 10^{-17}$ \\
\hline & methanol & $2.75 \times 10^{-8}$ & $2.1 \times 10^{-15}$ \\
\hline \multirow{3}{*}{$\begin{array}{c}20 \% \text { HDTMA- } \\
\text { bentonite }+80 \% \mathrm{Ca}- \\
\text { bentonite }\end{array}$} & water & $8.6 \times 10^{-10}$ & $7.82 \times 10^{-17}$ \\
\hline & benzene solution $\left(\mathrm{C}_{0}=300\right.$ & $8.1 \times 10^{-10}$ & $7.37 \times 10^{-17}$ \\
\hline & methanol & $7.7 \times 10^{-8}$ & $5.49 \times 10^{-15}$ \\
\hline \multirow{3}{*}{ Na-bentonite } & water & $1.7 \times 10^{-11}$ & $1.49 \times 10^{-18}$ \\
\hline & benzene solution $\left(\mathrm{C}_{0}=300\right.$ & $1.8 \times 10^{-11}$ & $1.48 \times 10^{-18}$ \\
\hline & methanol & $5.4 \times 10^{-8}$ & $3.5 \times 10^{-15}$ \\
\hline
\end{tabular}




\begin{tabular}{|c|c|c|c|}
\hline & gasoline & $7.2 \times 10^{-7}$ & $4.27 \times 10^{-14}$ \\
\hline \multirow{4}{*}{$\begin{array}{l}10 \% \text { HDTMA- } \\
\text { bentonite }+90 \% \text { Na- } \\
\text { bentonite }\end{array}$} & water & $2.8 \times 10^{-11}$ & $2.47 \times 10^{-18}$ \\
\hline & $\begin{array}{c}\text { benzene solution }\left(\mathrm{C}_{0}=300\right. \\
\text { to } 400 \mu \mathrm{g} / \mathrm{mL})\end{array}$ & $2.73 \times 10^{-11}$ & $2.41 \times 10^{-18}$ \\
\hline & methanol & $2.62 \times 10^{-8}$ & $1.81 \times 10^{-15}$ \\
\hline & gasoline & $2.72 \times 10^{-7}$ & $1.72 \times 10^{-14}$ \\
\hline \multirow{4}{*}{$\begin{array}{l}20 \% \text { HDTMA- } \\
\text { bentonite }+80 \% \text { Na- } \\
\text { bentonite }\end{array}$} & water & $5.7 \times 10^{-11}$ & $4.11 \times 10^{-18}$ \\
\hline & $\begin{array}{c}\text { benzene solution }\left(\mathrm{C}_{0}=300\right. \\
\text { to } 400 \mu \mathrm{g} / \mathrm{mL})\end{array}$ & $5.62 \times 10^{-11}$ & $4.05 \times 10^{-18}$ \\
\hline & methanol & $1.52 \times 10^{-8}$ & $8.6 \times 10^{-16}$ \\
\hline & gasoline & $4.12 \times 10^{-8}$ & $2.13 \times 10^{-15}$ \\
\hline \multirow{3}{*}{ HDTMA-bentonite } & water & $4.5 \times 10^{-8}$ & $3.56 \times 10^{-15}$ \\
\hline & methanol & $6.7 \times 10^{-9}$ & $4.15 \times 10^{-16}$ \\
\hline & gasoline & $1.5 \times 10^{-10}$ & $8.5 \times 10^{-18}$ \\
\hline
\end{tabular}

The hydraulic conductivity of Ca-bentonite and Na-bentonite GCLs were measured as 3.0 $\times 10^{-10}$ and $1.7 \times 10^{-11} \mathrm{~m} / \mathrm{s}$, respectively. The hydration of inorganic cations $\left(\mathrm{Na}^{+}\right.$or $\left.\mathrm{Ca}^{2+}\right)$ leads to the interlayer expansion of the bentonite particle aggregates and consequently, the expansion of the bulk volume. Since bentonite soil filling in GCL was confined between two layers of geotextile, the volume expansion of soil filling was inhibited and instead, the bentonite ended up with a lower pore volume and decreased size of mesopores. This process controls the permeability of water in the GCL as hydrated GCL tend to have much lower hydraulic conductivity. Mesri and Olson (1971) demonstrated that the higher plasticity of clayey soils is related to their higher swelling and lower hydraulic conductivity. They explained that the clay, especially colloidal particles typically have thicker double layer which resulted in stronger interactions with water molecules. Benson et al. (1994) suggested that the hydraulic conductivity of the geo-materials decreases when the plasticity index or swelling potential increases. The dissolved organics had no or low impact (e.g. 5\% of difference) on the hydraulic conductivity of the Ca-bentonite and Na-bentonite GCLs. 
Previous study indicated that the hydraulic conductivity of calcium or sodium bentonite GCL increases as the mass ratio of organoclay additives increases (Lorenzetti et al. 2005). The increased hydraulic conductivity is attributed to the hydrophobic characteristics of organoclays surfaces, which tends to impose decreased drag forces on water in the pore space. As a result, the hydraulic conductivity of Na-bentonite GCL specimen with $20 \%$ of HDTMA-bentonite was reported to be $5.7 \times 10^{-11} \mathrm{~m} / \mathrm{s}$, approximately three times higher than the hydraulic conductivity of $100 \%$ Na-bentonite GCL. The same trend was observed for the Ca-bentonite based GCLs. The hydraulic conductivity of Ca-bentonite GCL was measured as $3.0 \times 10^{-10} \mathrm{~m} / \mathrm{s}$ and it increased to 8.6 $\times 10^{-10} \mathrm{~m} / \mathrm{s}$ by adding $20 \%$ HDTMA-bentonite to the Ca-bentonite.

The interaction between sodium or calcium bentonite and low polarity liquids are very limited as the inorganic cations cannot be solvated or hydrated by the larger, non-polar organic molecules. Consequently, the swelling of Na-bentonite and Ca-bentonite were inhibited in the low polarity fluids like gasoline or methanol. The permeability of methanol and gasoline were at $5.4 \times 10^{-8} \mathrm{~m} / \mathrm{s}$ and $7.2 \times 10^{-7} \mathrm{~m} / \mathrm{s}$ (almost 3 orders of magnitude higher water) in the Na-bentonite GCL, respectively.

The correlations of the permeability (to water and gasoline) of GCL specimens and the mass percentages of PM-199/HDTMA-bentonite amendments are illustrated in Figure 4-13. The obtained results for the GCL specimens with HDTMA-bentonite amendment suggest that the GCL soil should have at least 43\% HDTMA-bentonite in order to obtain a low permeability $\left(1 \times 10^{-9} \mathrm{~m} / \mathrm{s}\right)$ to gasoline and water at the same time. However, the acquired results for GCL specimens with PM-199 amendments suggest that 28\% PM-199 amendment in Na-bentonite GCLs can provide a permeability of $6 \times 10^{-10} \mathrm{~m} / \mathrm{s}$ for 
gasoline and water at the same time. Moon et al. (2007) evaluated the permeability of a compacted HDTMA-bentonite specimen to gasoline. They suggested that a compacted specimen consisted of $100 \%$ HDTMA-bentonite could provide the permeability to gasoline as low as $2.53 \times 10^{-10} \mathrm{~m} / \mathrm{s}$. in another study, Yang and Lo (2004) investigated the permeability of a compacted organoclay (BB-40) specimen to gasoline. Their result suggested that the organoclay compacted specimen could reach to a permeability as low as $6 \times 10^{-11} \mathrm{~m} / \mathrm{s}$ for gasoline. The obtained results in this study suggested that a GCL specimen with 100\% HDTMA-bentonite/PM-199 could provide such a low permeability to gasoline that was reported for compacted organoclay specimen. However, it can be concluded that PM-199 is more efficient amendment for the GCL specimen compared to HDTMA-bentonite. Because a lower percentage (10 20\%) of PM-199 not only maintained a low permeability of GCL to water (less than $10^{-10} \mathrm{~m} / \mathrm{s}$ ) but also decreased the permeability of GCL to gasoline by approximately two orders of magnitude $\left(10^{-6} \mathrm{~m} / \mathrm{s}\right.$ to $\left.10^{-8} \mathrm{~m} / \mathrm{s}\right)$. 


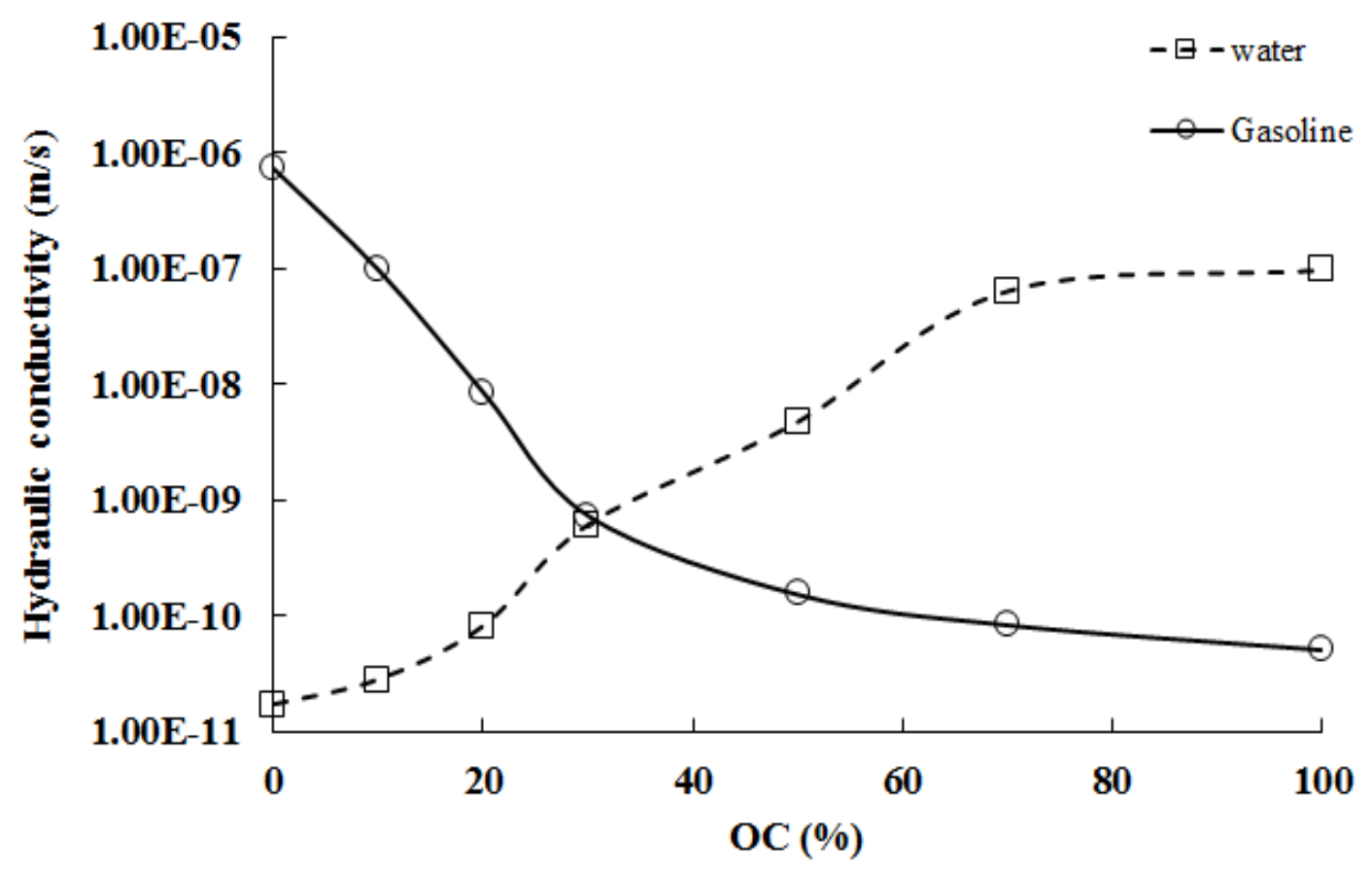

(a)

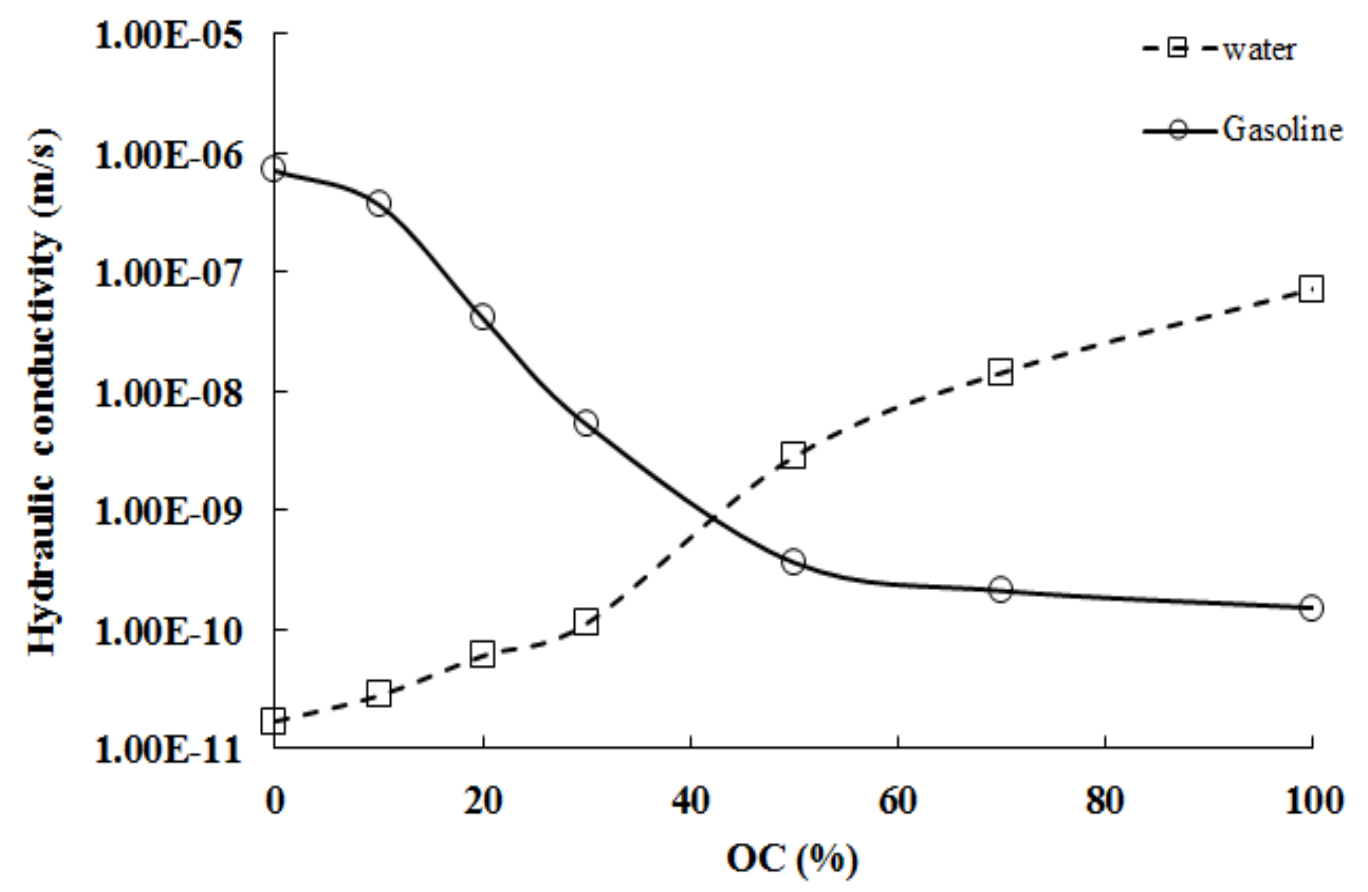

(b)

Figure 4-13. Permeability of Na-bentonite GCL specimens with different percentages of (a) PM-199 (b) HDTMA-bentonite permeated by water and gasoline 
Previous studies indicated that increasing the confining stress in the permeameter would decrease the void ratio of GCL soil, which typically leads to lower hydraulic conductivities (Shackelford et al. 2000; Shan and Daniel 1991).The effect of confining stress on the hydraulic conductivity of Na-bentonite GCL and GCL with $10 \%$ and $20 \%$ HDTMA-bentonite amendment is presented in Figure 4-14. The fluid confining pressure applied to the GCL specimens were $34.47,68.94,137.89,206.84$, and $275.79 \mathrm{kPa}$. It was observed that the hydraulic conductivity of Na-bentonite GCL and GCL with $10 \%$ HDTMA-bentonite $+90 \%$ Na-bentonite decreased as the confining stress increased from 5 to $20 \mathrm{kPa}$.

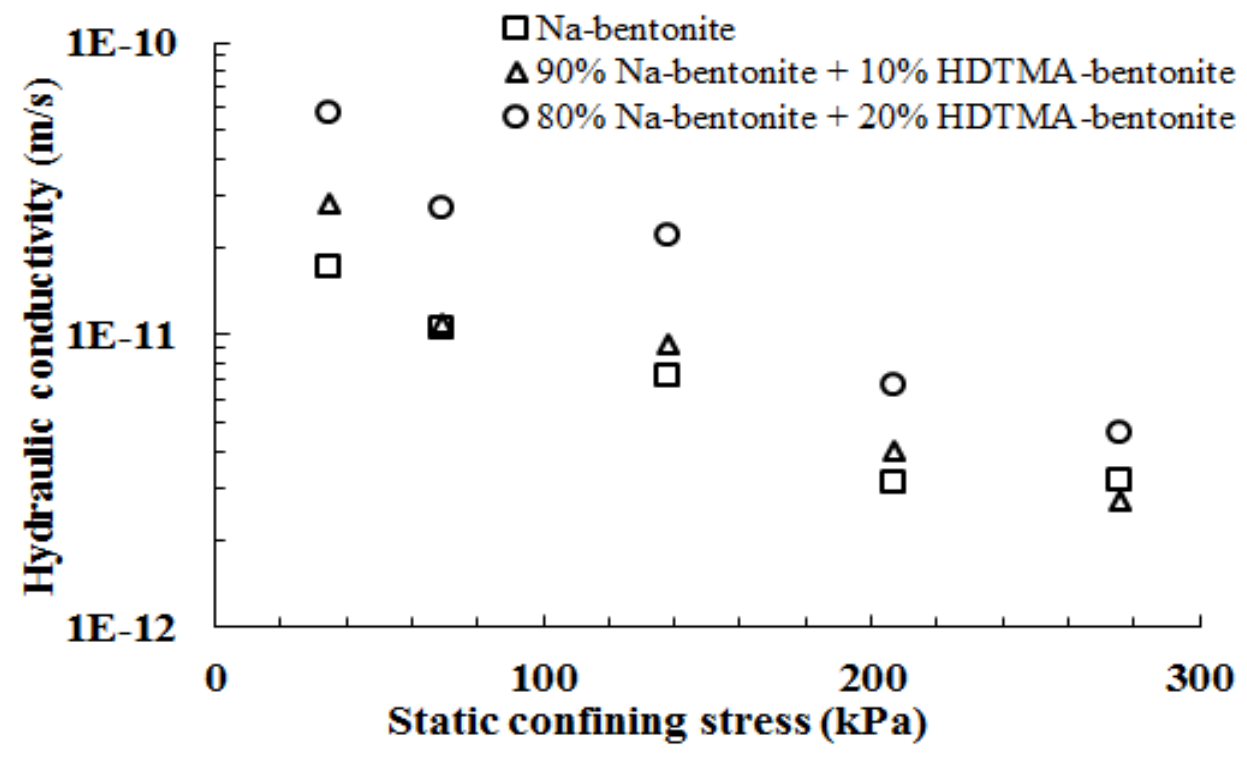

\section{Figure 4-14. Effect of confining stress on the hydraulic conductivity of Na-amended GCLs}

The quantity of solution that permeates through a certain area of the liner system (GCL) during a certain period of time under a specific hydraulic gradient is defined as permittivity. The permittivity is determined as the ratio of the permeability to the thickness of the GCL specimen: 
$\psi=\frac{k}{t}$

where $\psi$ is permittivity $(1 / \mathrm{s}), k$ is the permeability of GCL specimen $(\mathrm{cm} / \mathrm{s})$, and $t$ is the thickness of the GCL specimen $(\mathrm{cm})$.

The average permittivity of the studied GCL specimens permeated by water and benzene solution are summarized in Table 4-8. It was observed that the permittivity of Nabentonite/Ca-bentonite based GCLs are comparable with the permittivity of conventional compacted clays $\left(1.6 \times 10^{-9} \mathrm{~s}^{-1}\right)$.

Table 4-8. The average permittivity of GCL specimens

\begin{tabular}{|c|c|c|c|c|}
\hline GCL component & Permeant liquid & Permeability $(\mathrm{m} / \mathrm{s})$ & Thickness $(\mathrm{cm})$ & Permittivity $(1 / \mathrm{s})$ \\
\hline \multirow[b]{2}{*}{ Ca-bentonite } & water & $3.0 \times 10^{-10}$ & \multirow[b]{2}{*}{0.8} & $3.75 \times 10^{-8}$ \\
\hline & benzene solution & $3.1 \times 10^{-10}$ & & $3.875 \times 10^{-8}$ \\
\hline \multirow{2}{*}{$\begin{array}{c}10 \% \text { HDTMA- } \\
\text { bentonite }+90 \% \\
\text { Ca-bentonite }\end{array}$} & water & $4.6 \times 10^{-10}$ & \multirow[b]{2}{*}{1.2} & $3.83 \times 10^{-8}$ \\
\hline & benzene solution & $3.5 \times 10^{-10}$ & & $2.91 \times 10^{-8}$ \\
\hline \multirow{2}{*}{$\begin{array}{c}20 \% \text { HDTMA- } \\
\text { bentonite }+80 \% \\
\text { Ca-bentonite } \\
\end{array}$} & water & $8.6 \times 10^{-10}$ & \multirow[b]{2}{*}{1.3} & $6.61 \times 10^{-8}$ \\
\hline & benzene solution & $8.1 \times 10^{-10}$ & & $6.23 \times 10^{-8}$ \\
\hline Na-bentonite & $\begin{array}{c}\text { water } \\
\text { benzene solution }\end{array}$ & $\begin{array}{l}1.7 \times 10^{-11} \\
1.8 \times 10^{-11}\end{array}$ & 0.75 & $\begin{array}{l}2.26 \times 10^{-9} \\
2.4 \times 10^{-9}\end{array}$ \\
\hline \multirow{2}{*}{$\begin{array}{c}10 \% \text { HDTMA- } \\
\text { bentonite }+90 \% \\
\text { Na-bentonite }\end{array}$} & water & $2.8 \times 10^{-11}$ & \multirow[b]{2}{*}{0.77} & $3.63 \times 10^{-9}$ \\
\hline & benzene solution & $2.73 \times 10^{-11}$ & & $3.54 \times 10^{-9}$ \\
\hline \multirow{2}{*}{$\begin{array}{c}20 \% \text { HDTMA- } \\
\text { bentonite }+80 \% \\
\text { Na-bentonite }\end{array}$} & water & $5.7 \times 10^{-11}$ & \multirow[b]{2}{*}{0.78} & $7.3 \times 10^{-9}$ \\
\hline & benzene solution & $5.62 \times 10^{-11}$ & & $7.2 \times 10^{-9}$ \\
\hline
\end{tabular}

Based on the measured fluid conductivities, it was estimated that the advective breakthrough in the Ca-bentonite GCL, GCL with 10\% HDTMA-bentonite $+90 \%$ Cabentonite, and GCL with 20\% HDTMA-bentonite $+80 \%$ Ca-bentonite would require 308,297 , and 185 days (thickness divided by conductivity) under a hydraulic gradient of 1. However, the advective breakthrough time for the fluid flow to transport along Nabentonite GCL and GCL with 10\% HDTMA-bentonite $+90 \%$ Na-bentonite would 
require 4823 and 3392 days under a gradient of 1. Furthermore, around 7233 days is needed for the advection of the solution through a compacted clay layer.

The advection of benzene solution through GCL specimens were monitored during the breakthrough test and the calculated fluid conductivities as a function of time were shown in Figure 4-15. Also, the acquired data for hydraulic conductivity was used to determine the average seepage velocity of the contaminant flow. The measured average seepage velocities during the breakthrough of the benzene solution are illustrated in Figure 4-16.

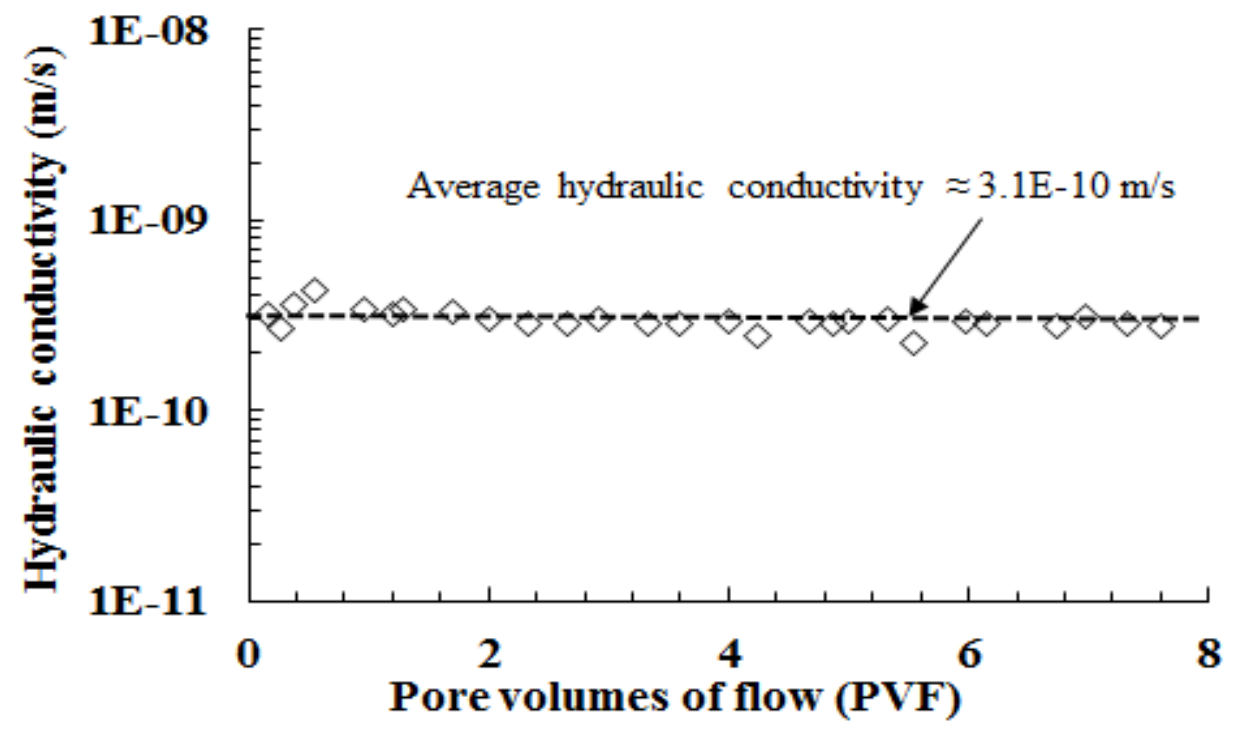

(a) 


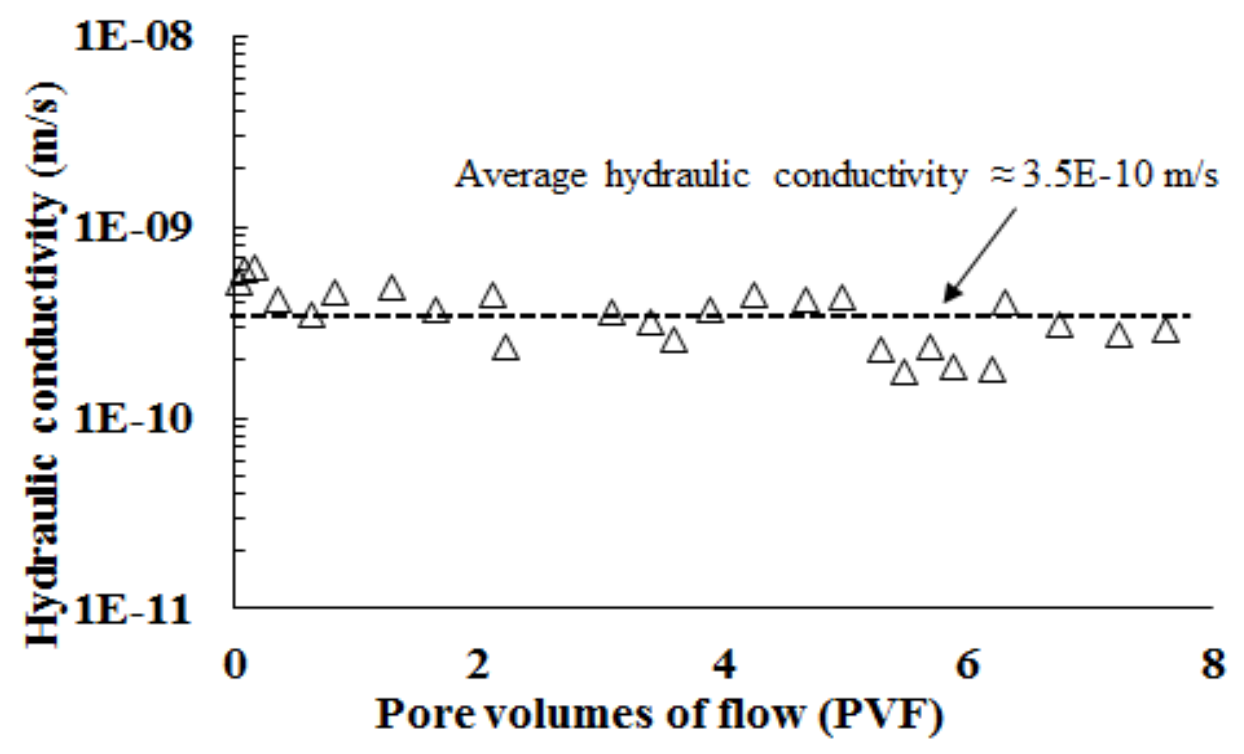

(b)

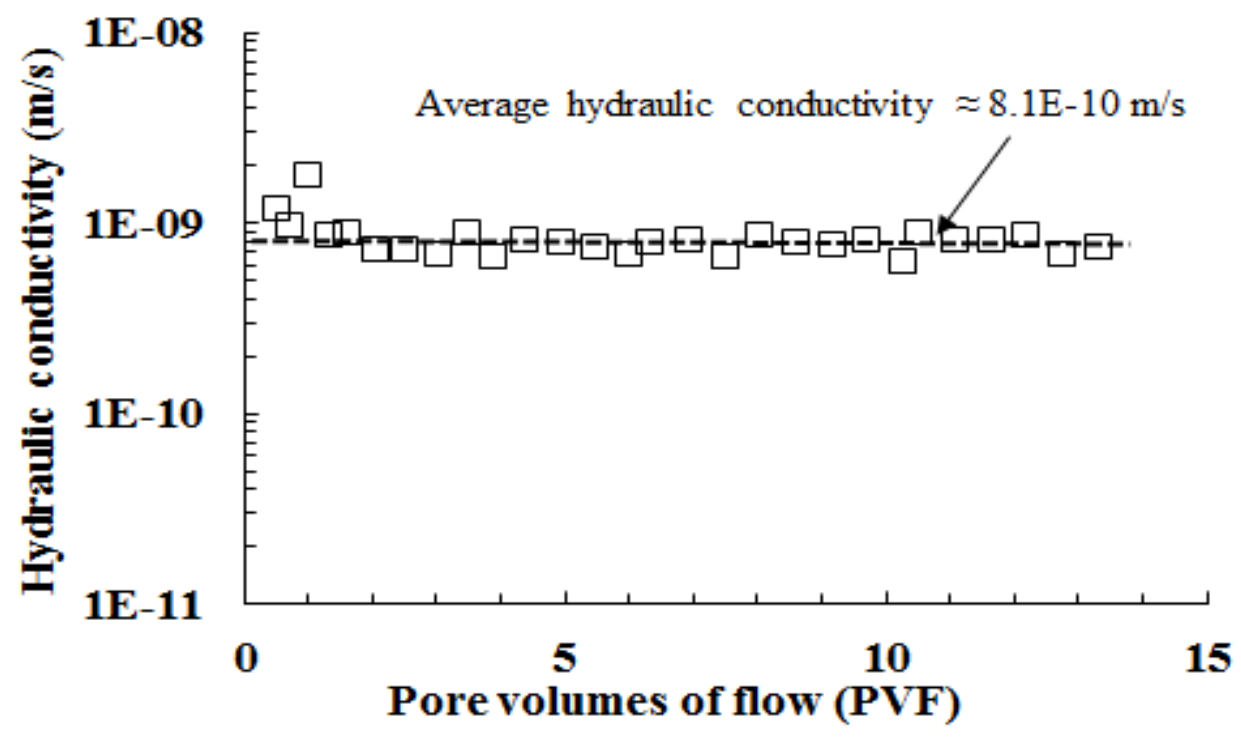

(c) 


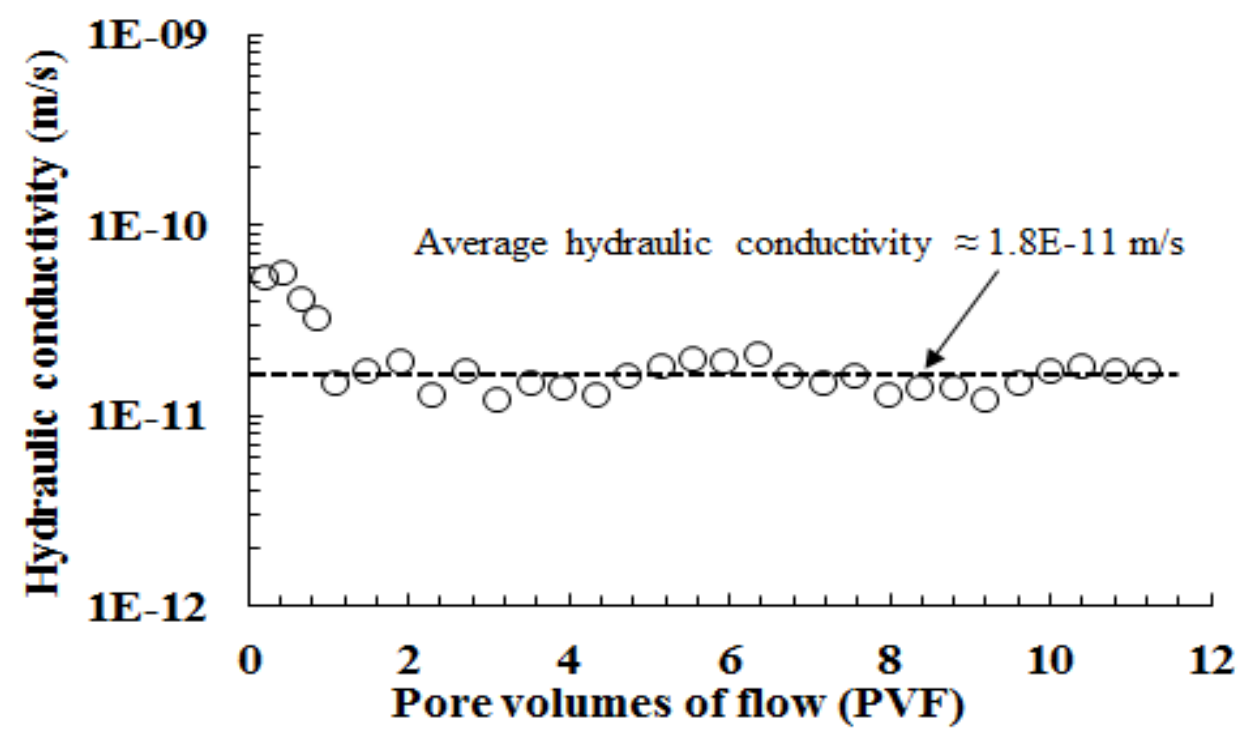

(d)

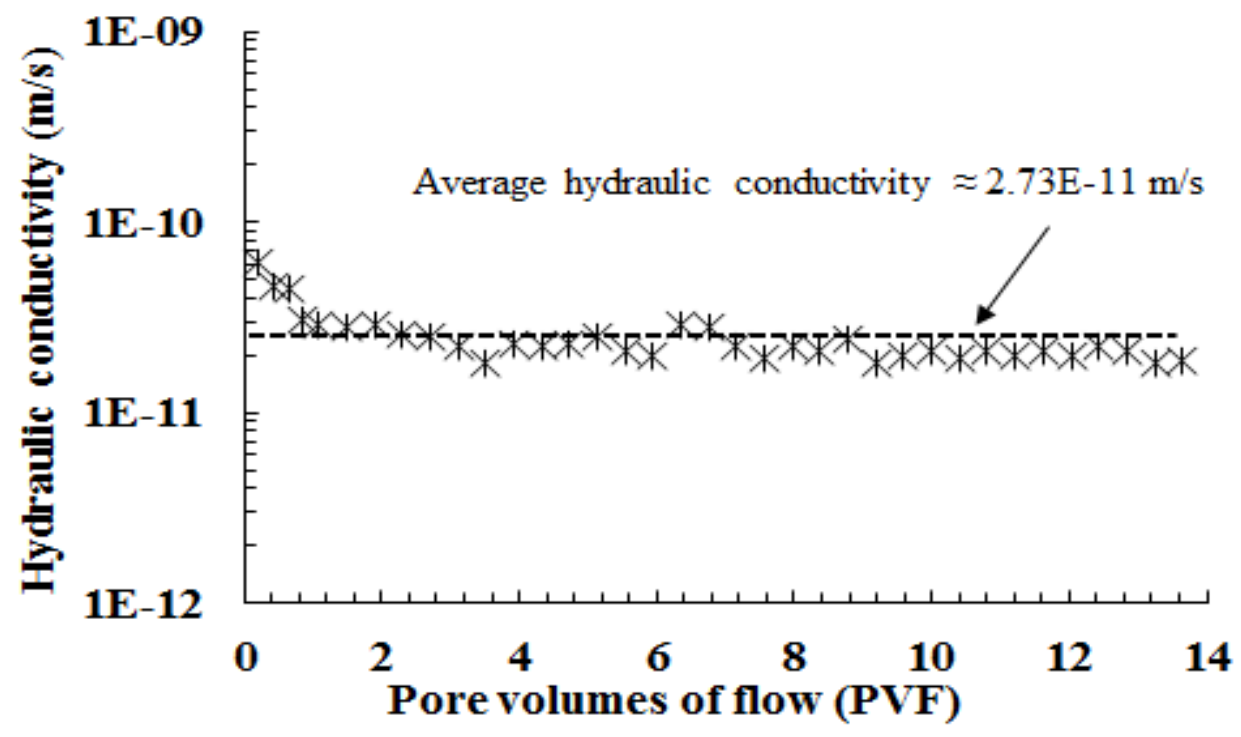

(e) 


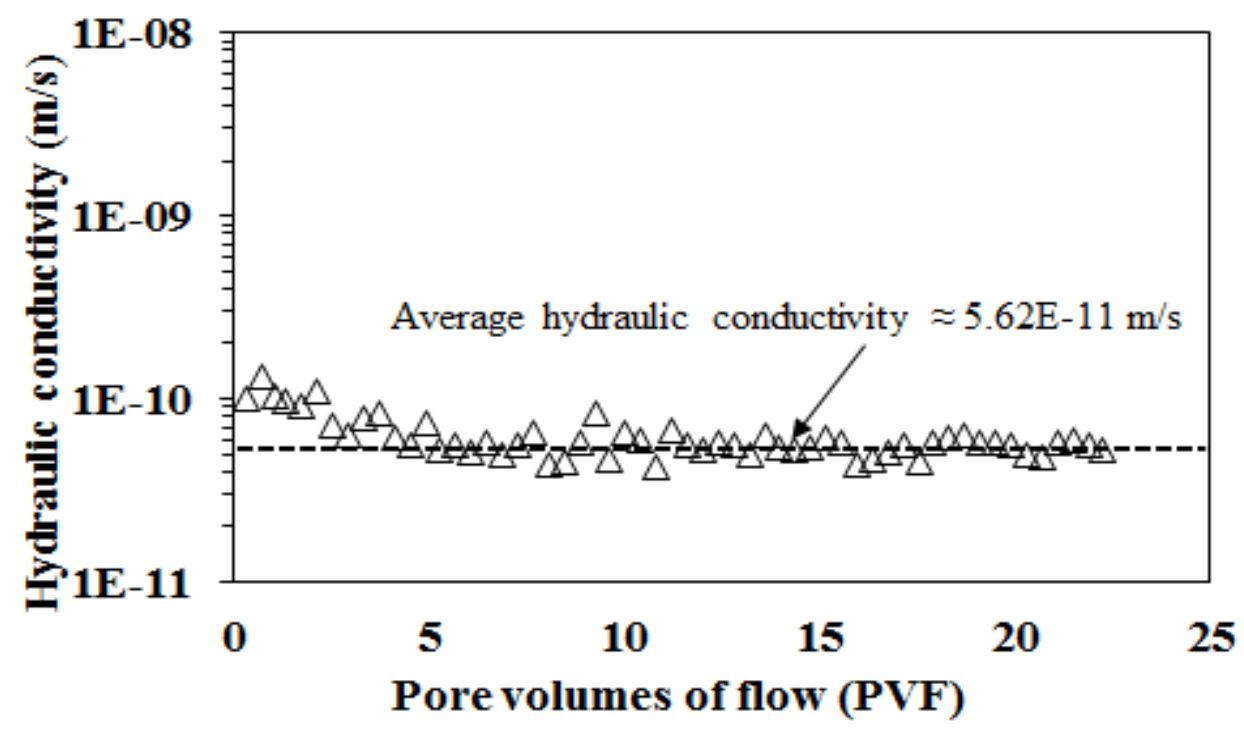

(f)

Figure 4-15. Measured hydraulic conductivity during breakthrough test for GCL with (a) Ca-bentonite (b) $10 \%$ HDTMA-bentonite + $90 \%$ Ca-bentonite (c) $20 \%$ HDTMA-bentonite + 80\% Ca-bentonite (d) Na-bentonite (e) 10\% HDTMAbentonite + $90 \%$ Na-bentonite (f) $20 \%$ HDTMA-bentonite + $80 \%$ Na-bentonite

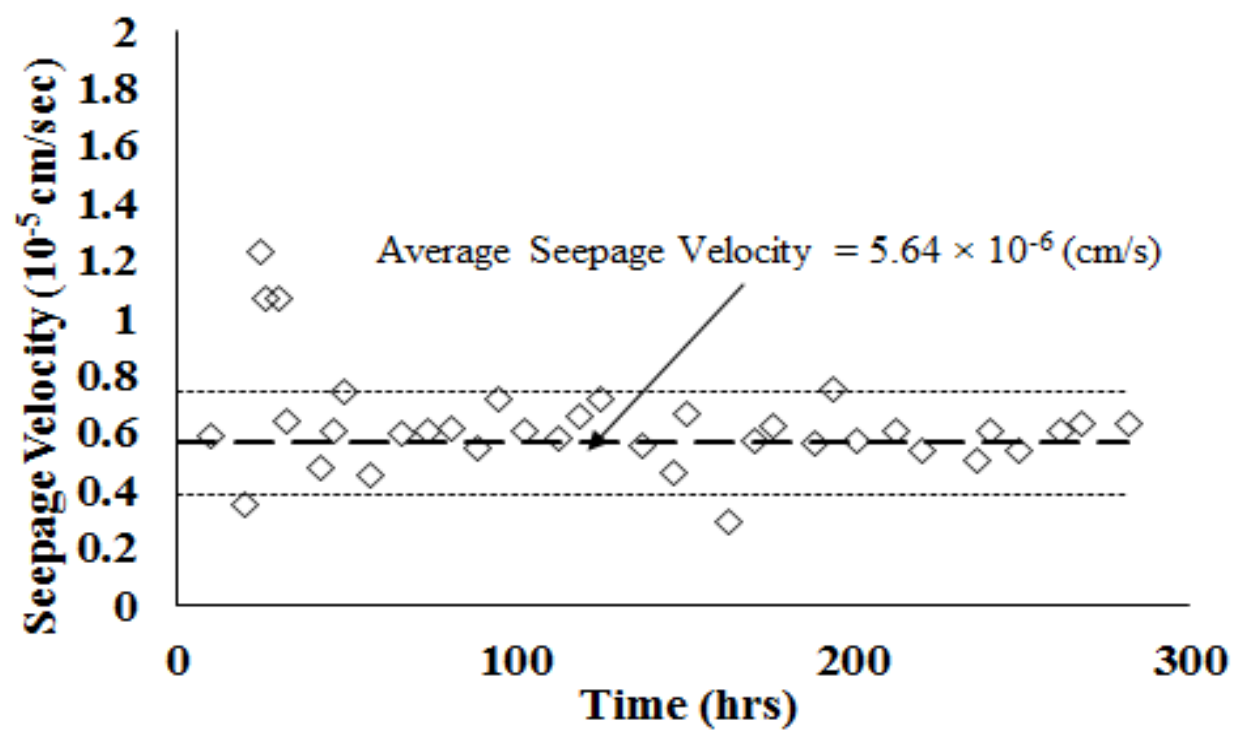

(a) 


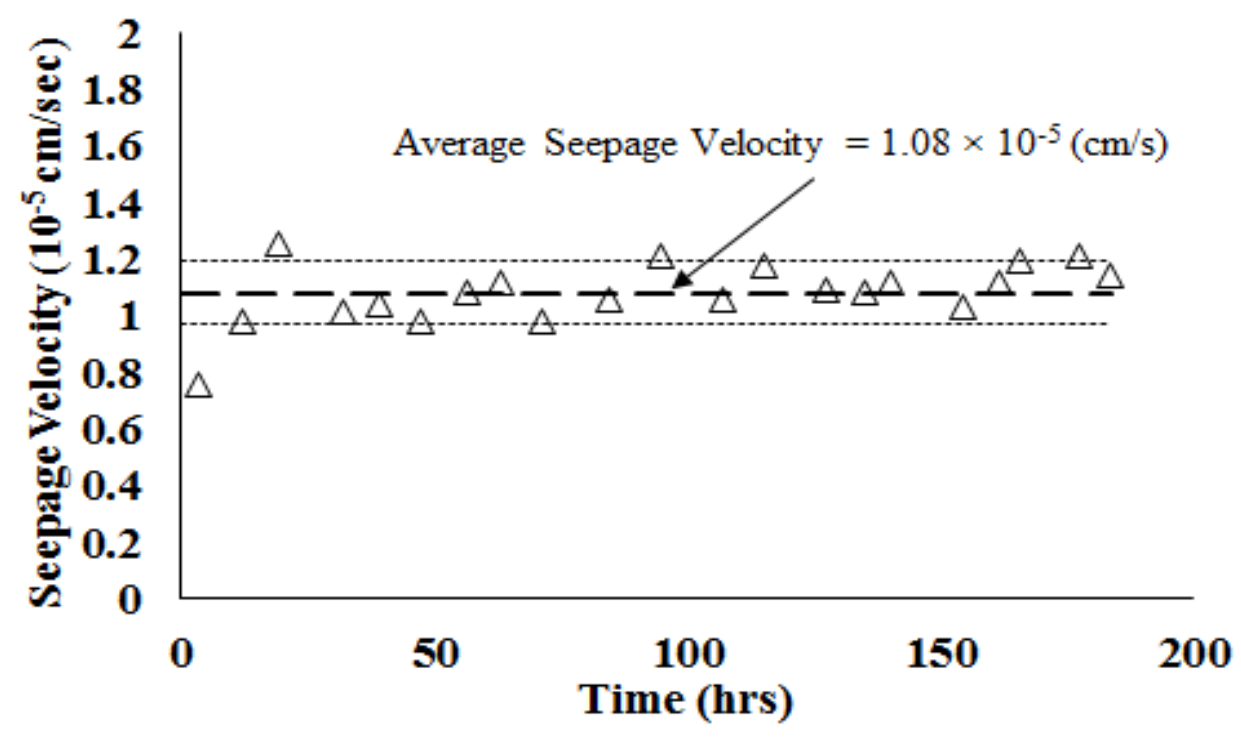

(b)

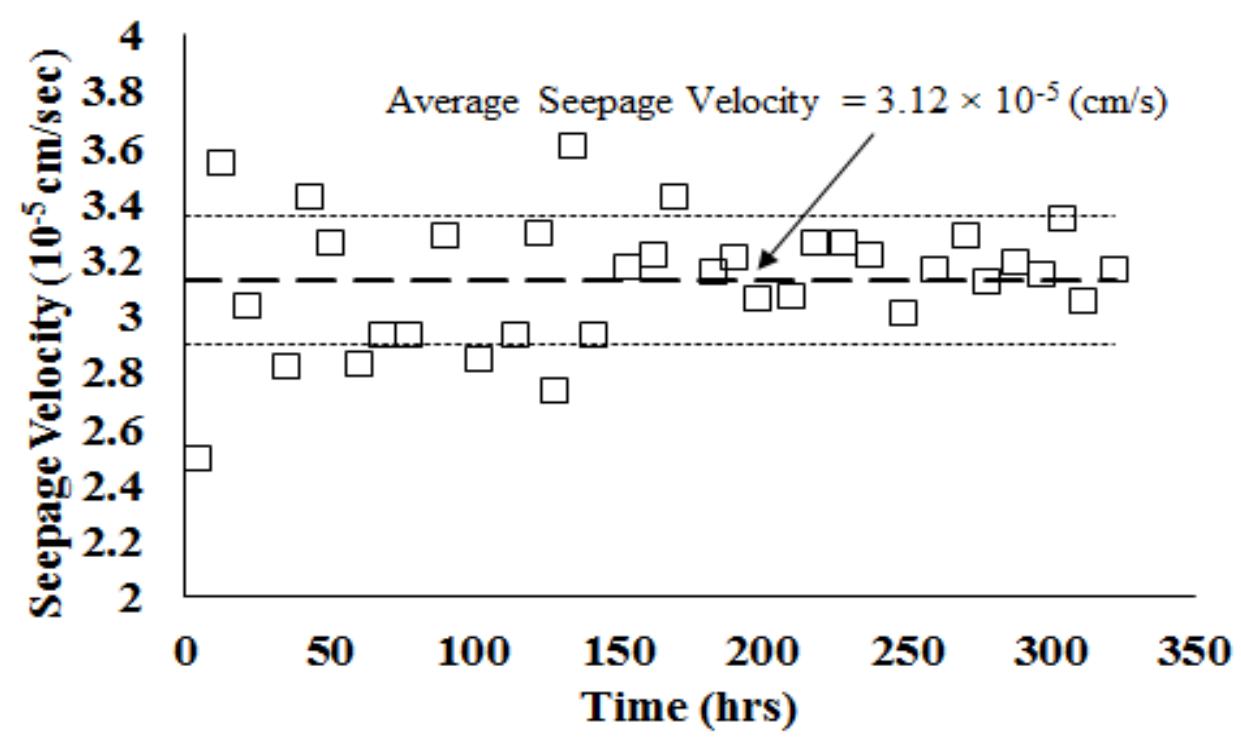

(c) 


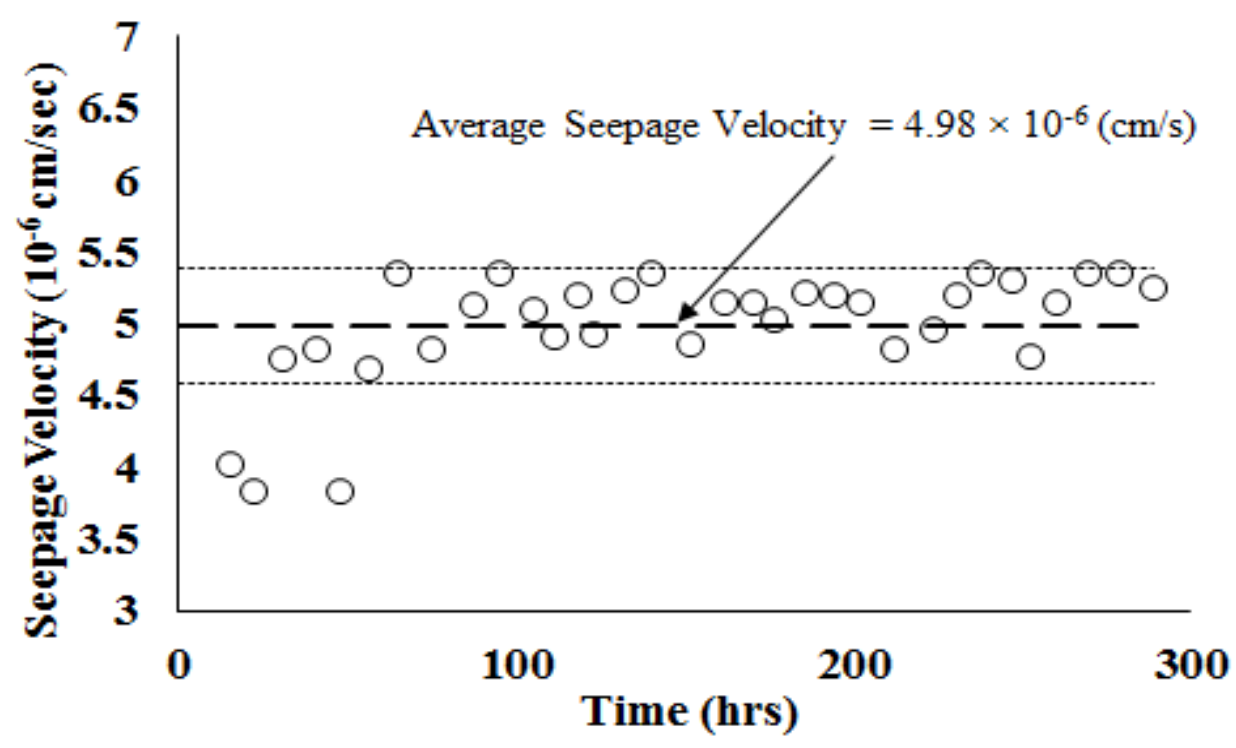

(d)

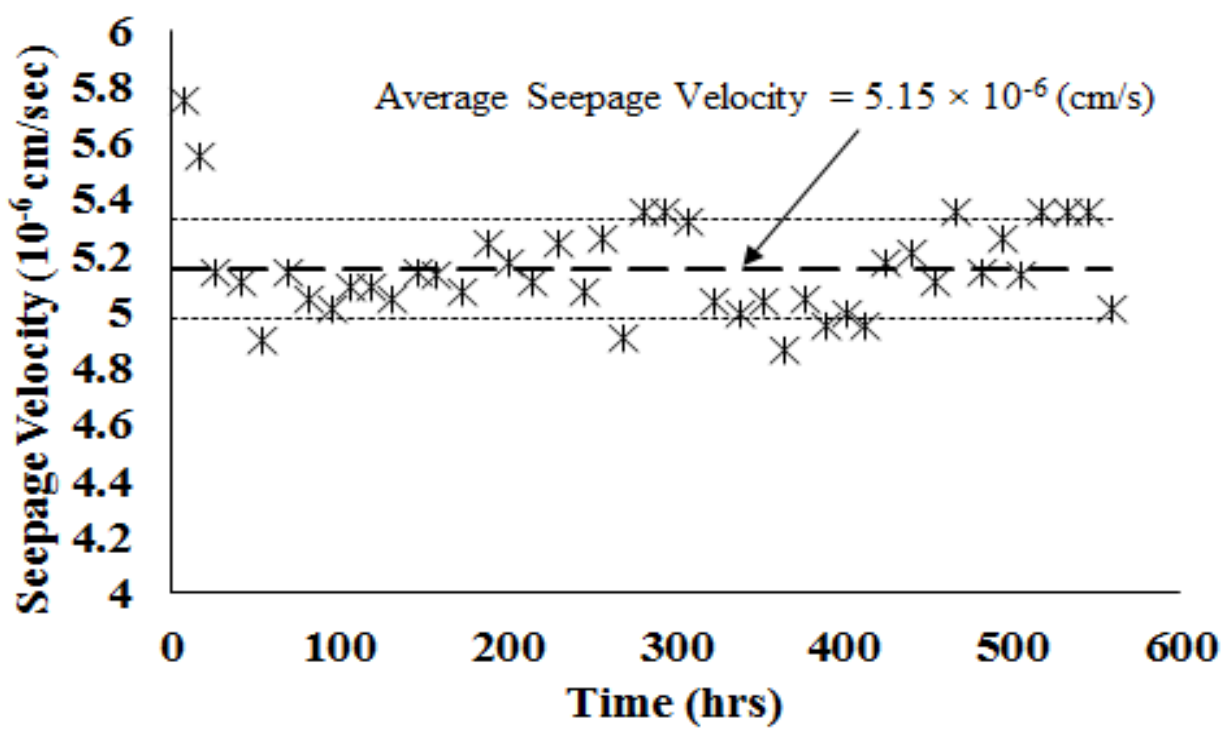

(e) 


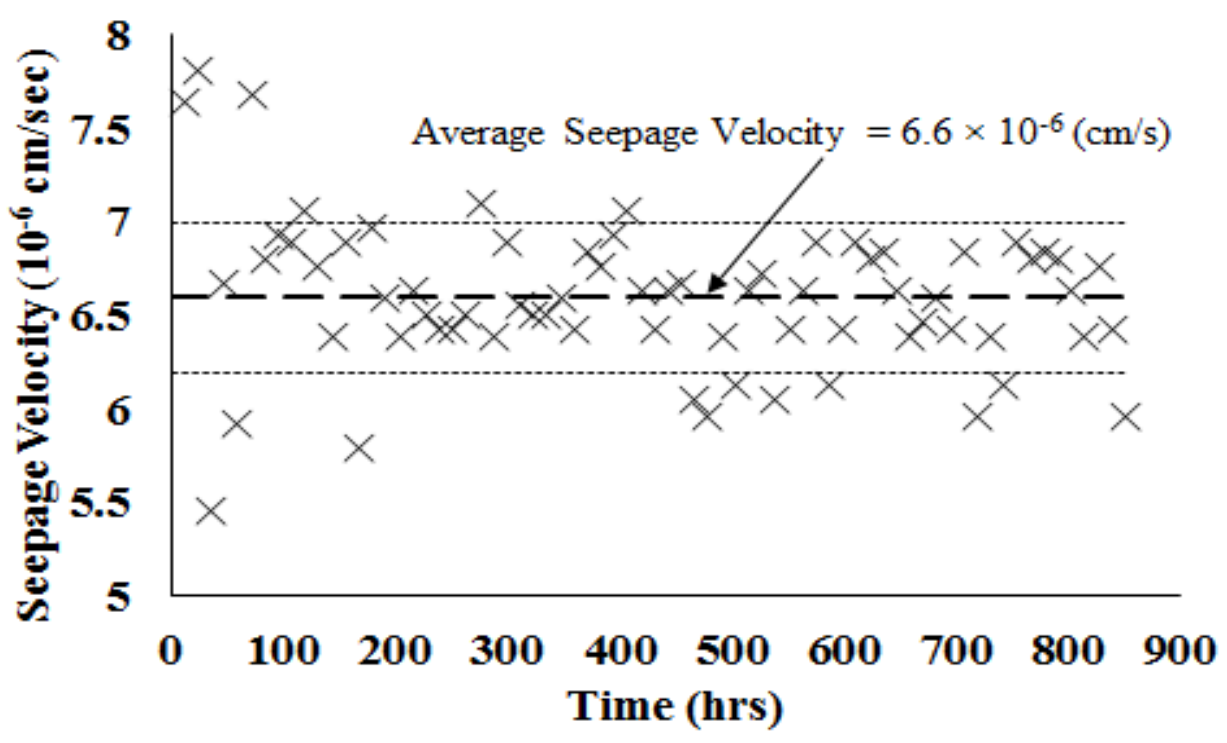

(f)

Figure 4-16. Average seepage velocity of GCLs with (a) Ca-bentonite (b) $\mathbf{1 0 \%}$ HDTMA-bentonite + 90\% Ca-bentonite (c) $20 \%$ HDTMA-bentonite $+80 \%$ Cabentonite (d) Na-bentonite amended GCL (e) 10\% HDTMA-bentonite $+90 \%$ Nabentonite (f) $20 \%$ HDTMA-bentonite $+80 \%$ Na-bentonite

\subsubsection{Breakthrough test}

Two series of breakthrough tests on the Ca-bentonite based and Na-bentonite based GCL specimens were conducted to examine the mass transport of benzene through the GCL when subjected to sorption and retardation. The acquired breakthrough curves for both types of GCL specimens are presented in Figure 4-17. 


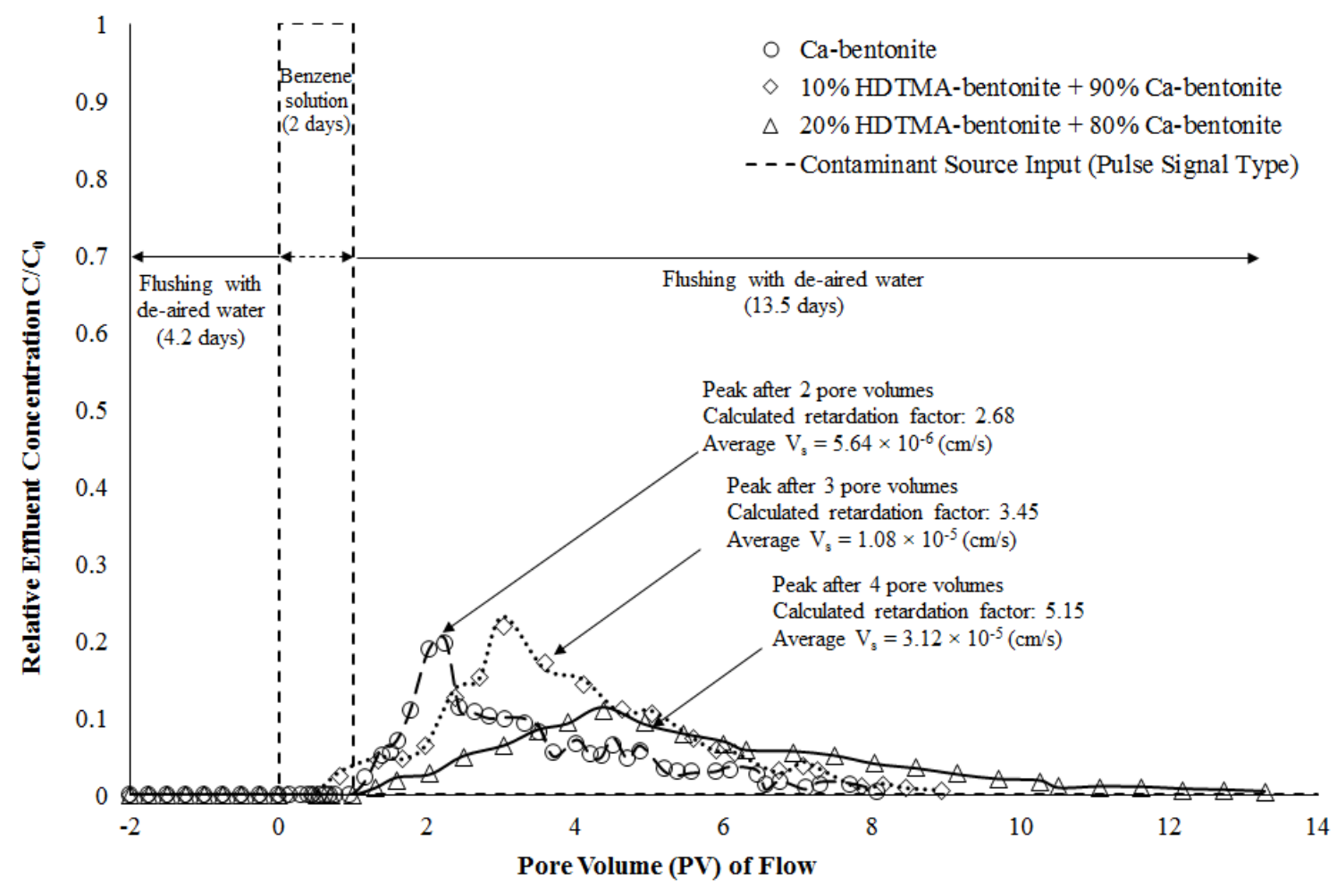

(a)

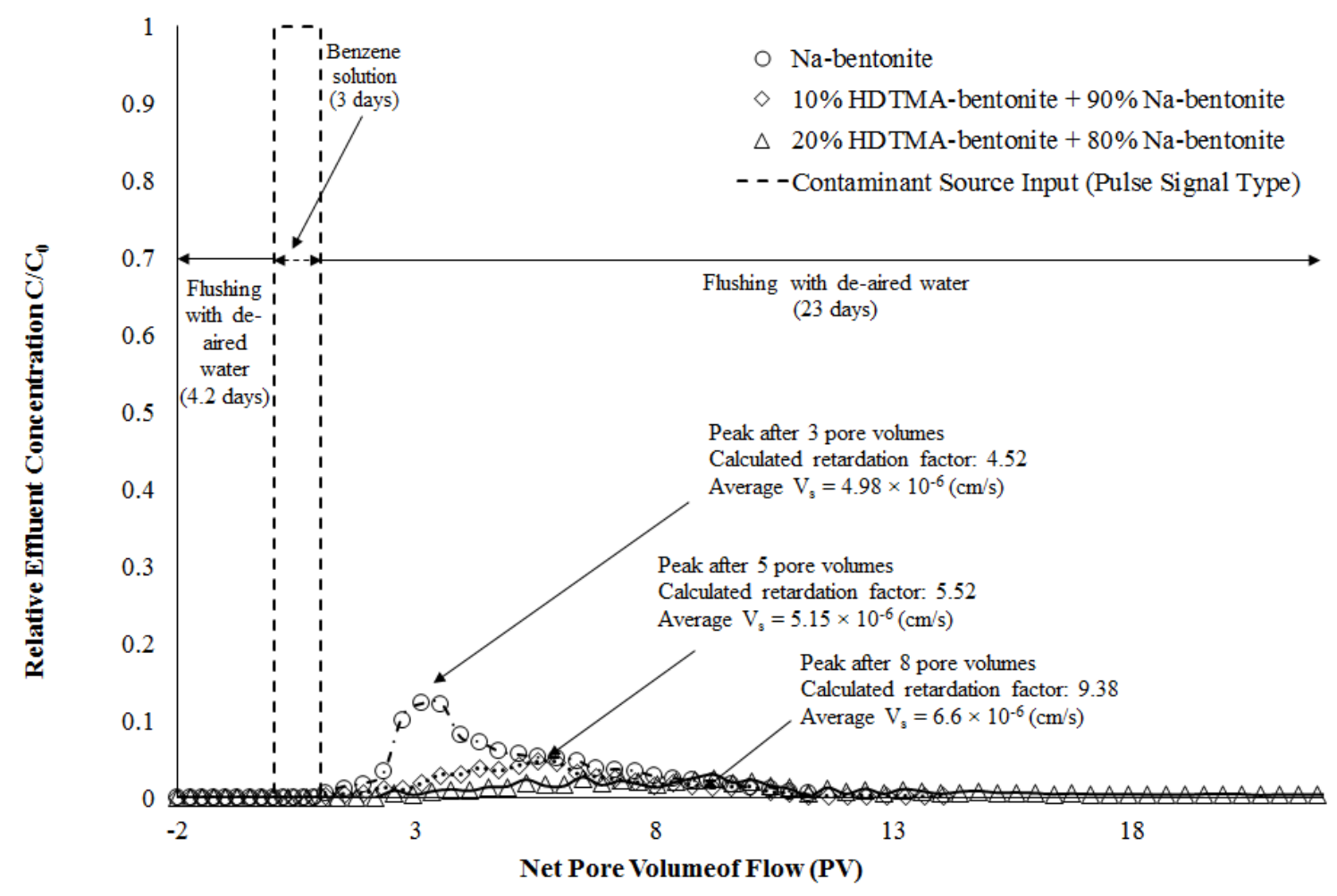

(b) 
Figure 4-17. Benzene breakthrough curves through (a) Ca-bentonite based (b) Nabentonite based GCL specimens without/with HDTMA-bentonite

The breakthrough experiments typically lasted more than 2 weeks ( $~ 8$ to 13 pore volumes) for the Ca-bentonite based GCL specimens while it took more than 3 weeks ( $\sim 13$ to 15 pore volumes) for the Na-bentonite based GCL specimens. The sampling was continued until the concentration of benzene in the effluent was below the detection limit of GC equipment.

The seepage velocity of benzene solution permeating Na-bentonite and Ca-bentonite GCL specimens were measured as $4.98 \times 10^{-6}$ and $5.64 \times 10^{-6} \mathrm{~m} / \mathrm{s}$ which were at the same range. However, the seepage velocity of GCL specimen with 20\% HDTMA-bentonite + $80 \%$ Na-bentonite to benzene solution remained at the range of $6.6 \times 10^{-6} \mathrm{~m} / \mathrm{s}$ and addition of $20 \%$ HDTMA-bentonite did not change the seepage velocity of Na-bentonite amended GCL significantly. As mentioned previously, it is because of strong hydration of Na-bentonite with polar liquids with resulted in such low permeability. In contrast, the seepage velocity of GCL specimen with 20\% HDTMA-bentonite $+80 \%$ Ca-bentonite to benzene solution was measured as $3.12 \times 10^{-6} \mathrm{~m} / \mathrm{s}$ which was about one order of magnitude higher than the he seepage velocity of Ca-bentonite GCL specimen. The peak of mass flux in Na-bentonite GCL occurred at approximately 3 pore volumes, one pore volume later when compared to Ca-bentonite GCL. This happened because of lower hydraulic conductivity of Na-bentonite compared to Ca-bentonite and longer advective breakthrough of benzene solution in Na-bentonite GCL.

The required time for breakthrough, or retarded transport of benzene in Na-bentonite GCL with $10 \%$ of HDTMA-bentonite was significantly longer than what required for Na- 
bentonite GCL. However, this difference was not observed between GCLs with Cabentonite GCL and Ca-bentonite + 10\% HDTMA-bentonite.

In the HDTMA-bentonite amended GCL specimens, organic contaminants are absorbed by the HDTMA-bentonite and the absorbed mass of contaminants releases with a lower rate of mass per unit time (quantified by the mass flux). The peak corresponding to the maximum relative concentration of effluent in Ca-bentonite based GCL specimens with $0 \%, 10 \%$, and $20 \%$ of HDTMA-bentonite were detected after approximately 2,3 , and 4 pore volumes, respectively. In comparison, the peak corresponding to the maximum relative concentration of effluent in Na-bentonite based GCL specimens with $0 \%, 10 \%$, and $20 \%$ of HDTMA-bentonite were detected after 3,5 , and 8 pore volumes, respectively. The decreased peak concentration was accompanied with the possible breakthrough within the first pore volume due to the diffusion of contaminant molecules (Shackelford 1994).

It was observed that $10 \%$ of HDTMA-bentonite amendments in Ca-bentonite GCL did not make a notable difference in reducing the mass flux of benzene. This could be the result of (1) lower dosage of HDTMA-bentonite (2) the diffusive transport of benzene through the shorter path ( $8 \sim 10 \mathrm{~mm}$, compared with $2 \sim 3 \mathrm{ft}$ of compacted clays) overcame the retardation mechanism. In contrast, the $20 \%$ of HDTMA-bentonite amendments in Ca-bentonite GCL caused the delayed occurrence of the max mass flux of benzene (two pore volumes compared to Ca-bentonite GCL) and also decreased the magnitude of the relative concentration at peak. The peak mass flux of benzene through Ca-bentonite GCL was decreased by 5 times when 10\% HDTMA-bentonite was added and further decreased to 10 times when $20 \%$ of HDTMA-bentonite amendments were added. 


\section{Interpretation of the breakthrough test results}

Initially, the retardation factor of benzene transport through the GCL specimens was determined using the first-moment equation. However, it yielded underestimated retardation factors as less than $100 \%$ of the introduced mass of benzene was collected in the effluent. Consequently, both numerical and analytical solution was employed to estimate the retardation factor and diffusion coefficient of the benzene transport in GCL specimens (Figure 4-18).
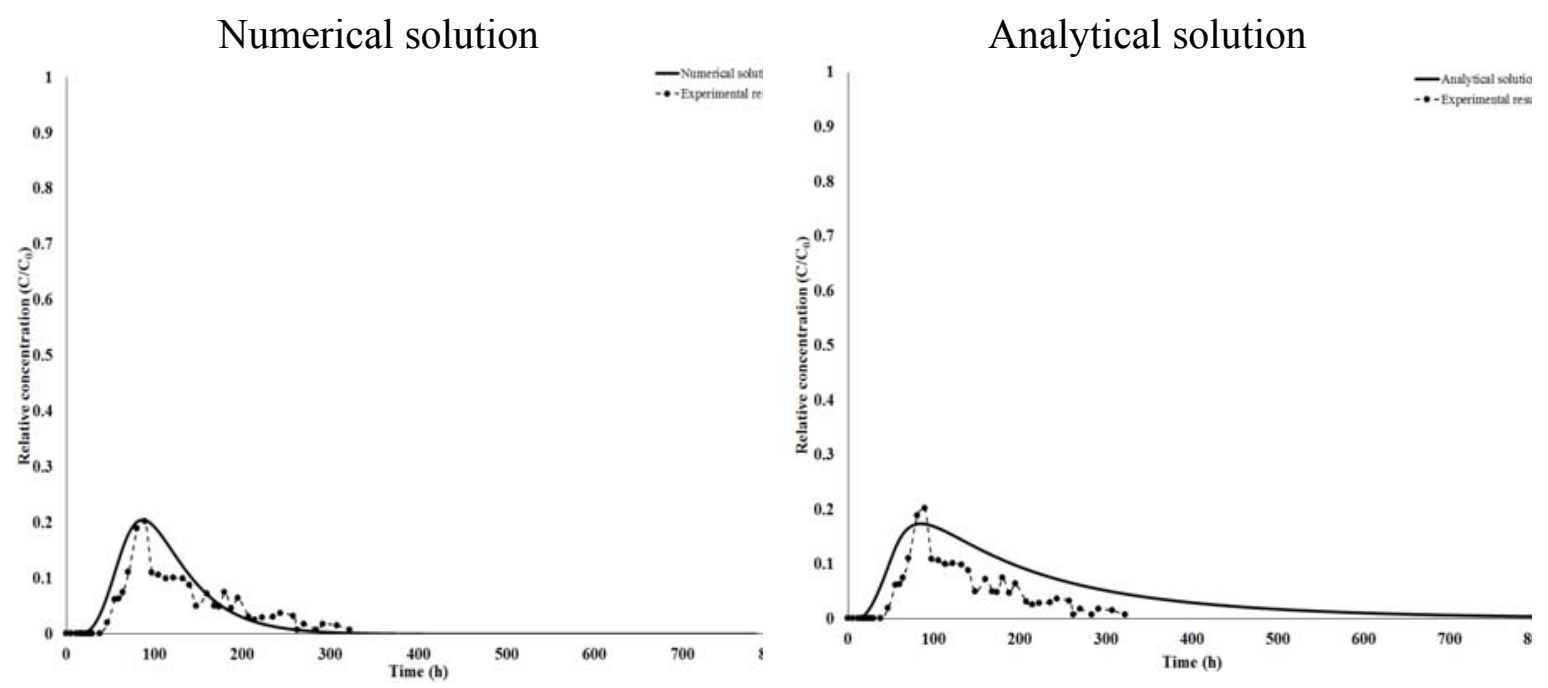

(a)
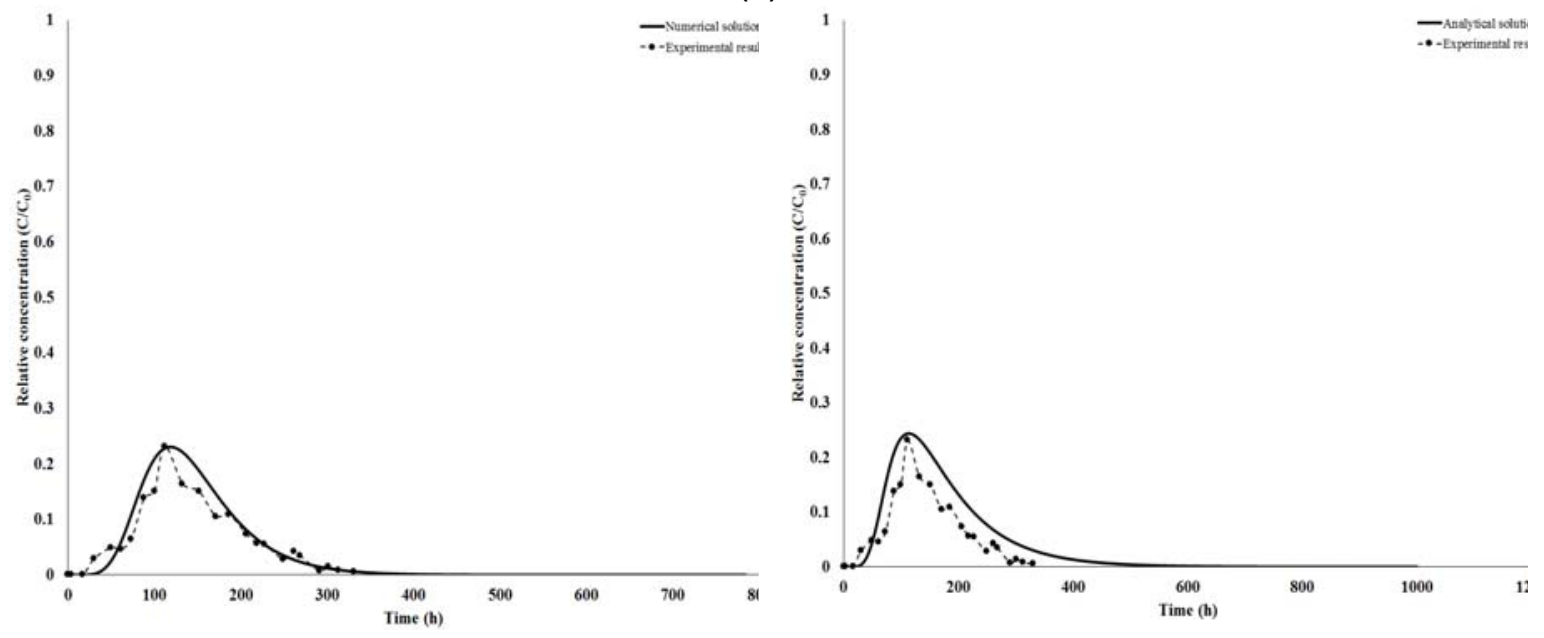

(b) 

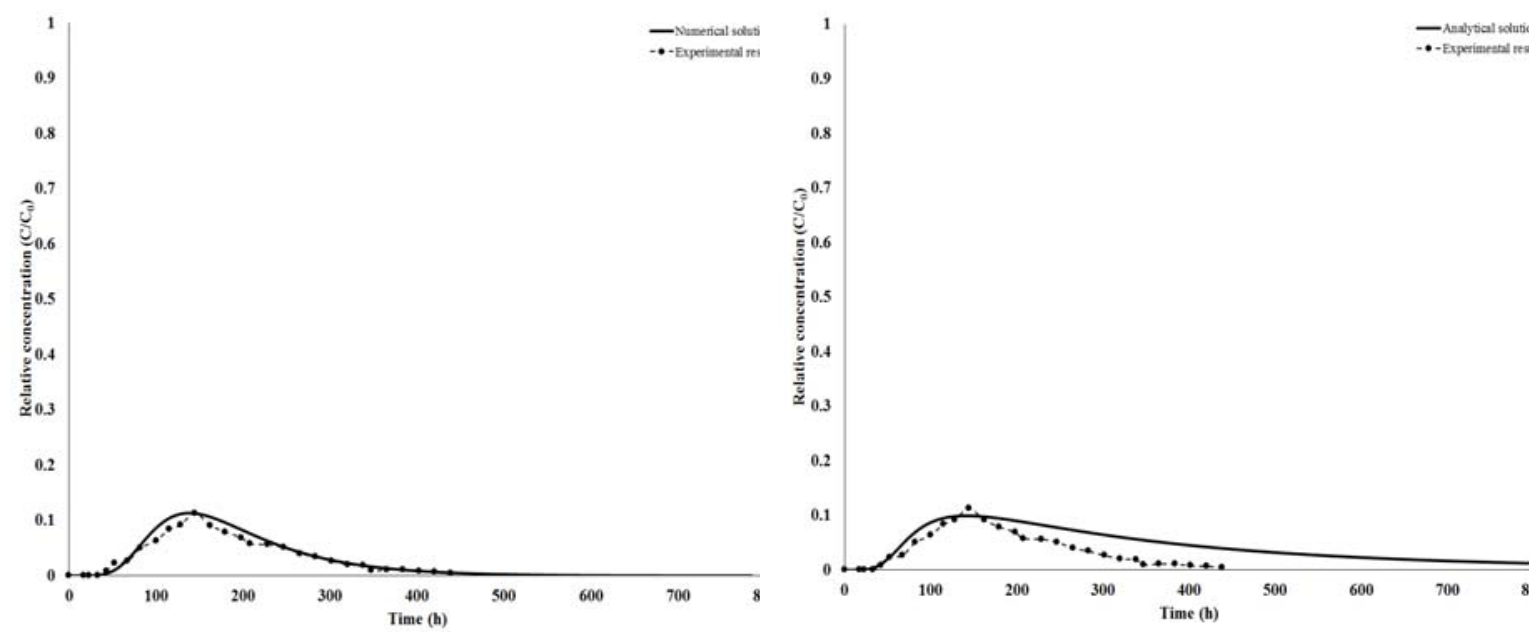

(c)
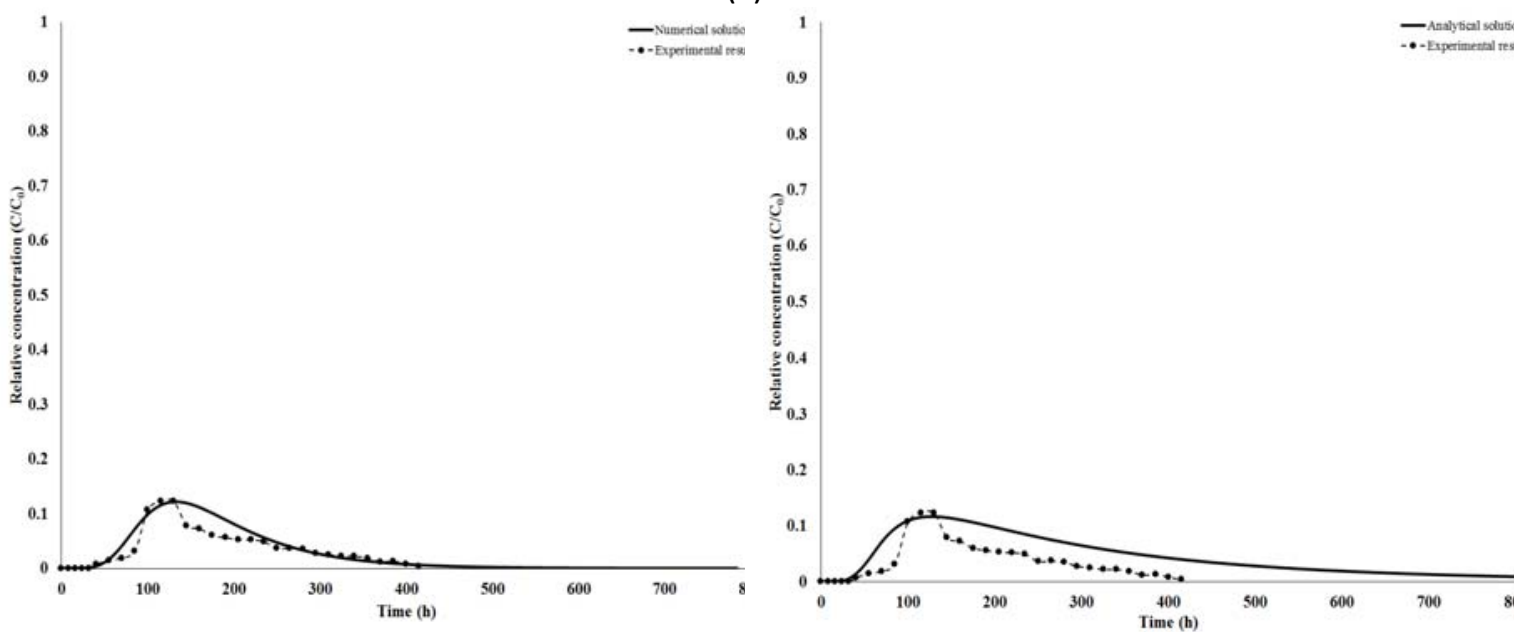

(d)
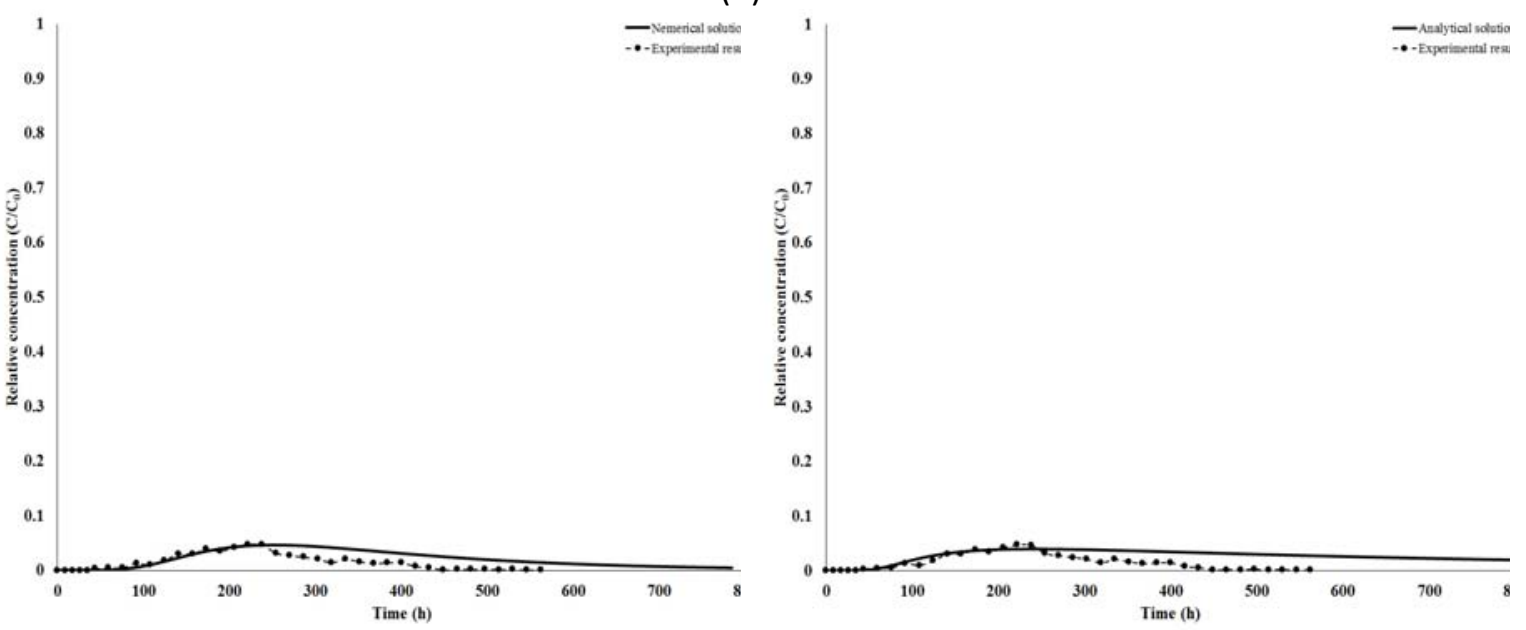

(e) 

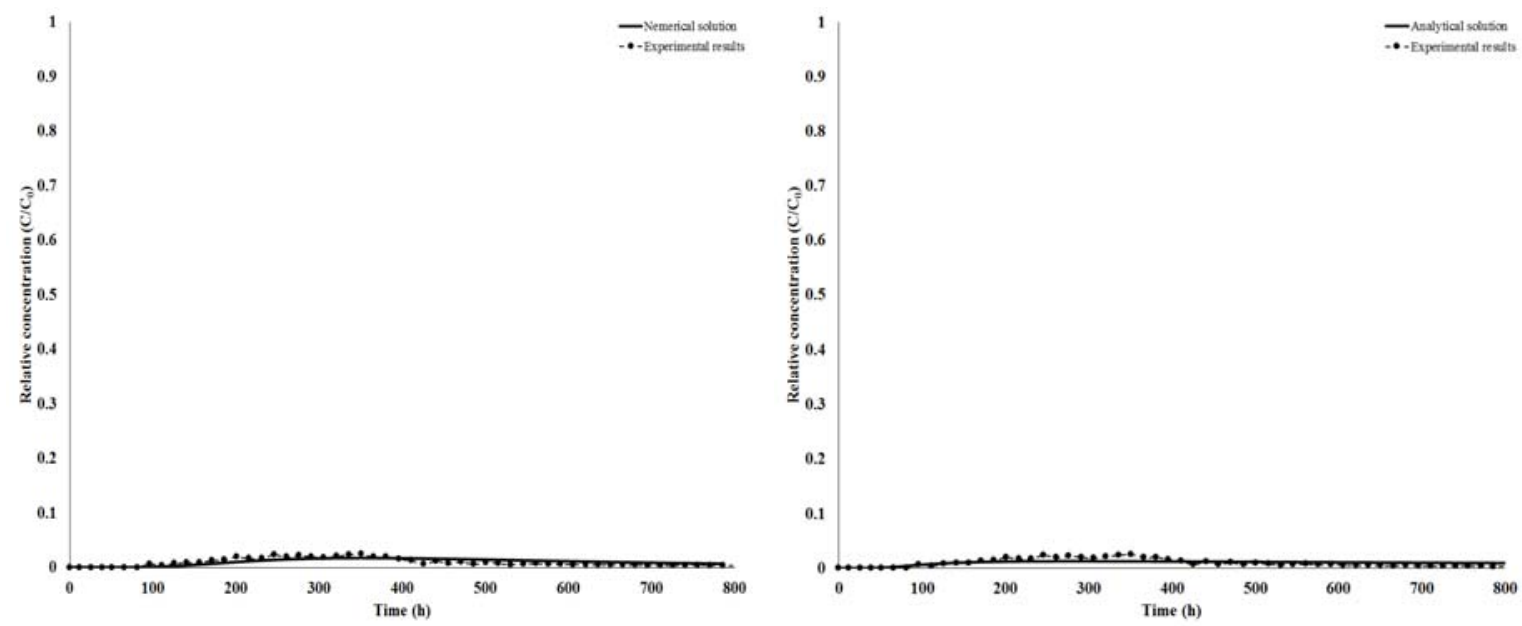

(f)

Figure 4-18. Fitted curve applying numerical and analytical solution for (a) Cabentonite GCL (b) Ca-bentonite GCL with 10\% HDTMA-bentonite amendment (c) Ca-bentonite GCL with $20 \%$ HDTMA-bentonite amendment (d) Na-bentonite GCL (e) Na-bentonite GCL with $10 \%$ HDTMA-bentonite amendment (f) Na-bentonite GCL with $20 \%$ HDTMA-bentonite amendment

The retardation factors and diffusion coefficients for all breakthrough tests were obtained and compared with the calculated retardation factors from the first-moment equation (Table 4-9).

Table 4-9. Retardation factor and diffusion coefficients for six GCL specimens obtained from analytical and numerical methods and the first-moment equation

\begin{tabular}{cccccc}
\hline \multirow{2}{*}{$\begin{array}{c}\text { GCL } \\
\text { component }\end{array}$} & $\begin{array}{c}\text { first-moment } \\
\text { analysis }\end{array}$ & \multicolumn{2}{c}{ Numerical solution } & \multicolumn{2}{c}{ Analytical solution } \\
\cline { 2 - 6 } $\begin{array}{c}\text { Retardation } \\
\text { factor }\end{array}$ & $\begin{array}{c}\text { Retardation } \\
\text { factor }\end{array}$ & $\begin{array}{c}\text { Diffusion } \\
\text { coefficient } \\
\left(\mathrm{cm}^{2} / \mathrm{s}\right)\end{array}$ & $\begin{array}{c}\text { Retardation } \\
\text { factor }\end{array}$ & $\begin{array}{c}\text { Diffusion } \\
\text { coefficient } \\
\left(\mathrm{cm}^{2} / \mathrm{s}\right)\end{array}$ \\
\hline $\begin{array}{c}\text { Ca-bentonite } \\
90 \% \text { Ca- } \\
\text { bentonite }+\end{array}$ & 2.68 & 6.9 & $1.8 \times 10^{-6}$ & 5 & $7.1 \times 10^{-6}$ \\
$10 \%$ & & & & & \\
$\begin{array}{c}\text { HDTMA- } \\
\text { bentonite }\end{array}$ & 3.45 & 14 & $2.0 \times 10^{-6}$ & 9 & $1.5 \times 10^{-6}$ \\
$\begin{array}{c}80 \% \text { Ca- } \\
\text { bentonite }+\end{array}$ & & & & & \\
$20 \%$ & 5.15 & 68 & $5.8 \times 10^{-6}$ & 52 & $4.6 \times 10^{-6}$ \\
$\begin{array}{c}\text { HDTMA- } \\
\text { bentonite }\end{array}$ & & & & & \\
Na-bentonite & 4.52 & 10 & $1.5 \times 10^{-6}$ & 7 & $6.3 \times 10^{-6}$ \\
$90 \%$ Na- & 5.52 & 26 & $2.0 \times 10^{-6}$ & 20 & $7.0 \times 10^{-6}$
\end{tabular}




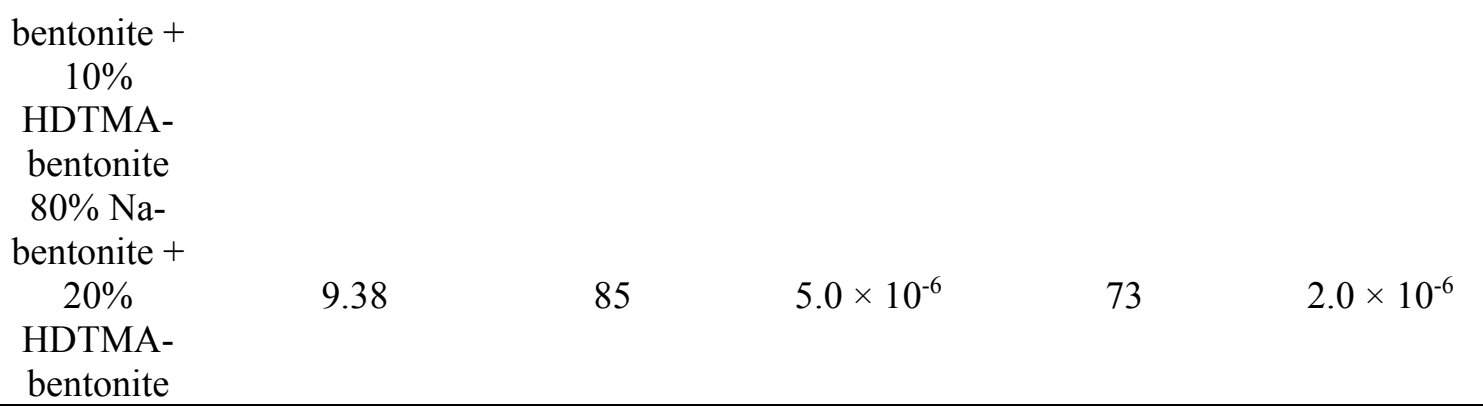

The calculated retardation factors from numerical and analytical solutions suggested that these two methods result in results within a same range. the mathematical models resulted in retardation factors of (5 to 7) and (7 to 10) for Ca-bentonite and Na-bentonite GCLs, respectively. For unmodified bentonites, the calculated retardation factors from mathematical modeling were reletively close to the acquired results from the first moment analysis. The retardation factors calculated from the first moment analysis were 2.68, and 4.52 for Ca-bentonite and Na-bentonite GCL specimens, respectively. However, the mathematical modeling resulted in significantly higher retardation factors compared to the first moment analysis method as the percentages of HDTMA-benotnite increased in the GCL soil. It was observed that the retardation factors obtained from the first moment analysis method increased linearly by increasing the percentage of HDTMA-bentonite. In contrast, the obtainde results from mathematical solutions showed a significant sharp increase in retardation factor by increasing the percent of HDTMAbentonite in the GCL soil.

The higher retardation factors indicated lower mass flux of benzene throught the GCLs and longer time of benzene breakthrough. Specifically, the peak mass flux of benzene was at $0.007 \mathrm{mg} / \mathrm{cm}^{2} \times$ day in Ca-bentonite GCL and it decreased by almost half to the $0.004 \mathrm{mg} / \mathrm{cm}^{2} \times$ day for Ca-bentonite GCL with 20\% HDTMA-bentonite amendment. For 
Na-bentonite GCL, the peak mass flux of benzene was approximately $0.005 \mathrm{mg} / \mathrm{cm}^{2} \times$ day and it decreased to the $0.002 \mathrm{mg} / \mathrm{cm}^{2} \times$ day in Na-bentonite GCL amended with $20 \%$ HDTMA-bentonite. Also, the average mass flux of benzene at source for Ca-bentonite based GCL specimens was at the range of $0.1658 \mathrm{mg} / \mathrm{cm}^{2} \times$ day while it decreased to $0.1132 \mathrm{mg} / \mathrm{cm}^{2} \times$ day for the Na-bentonite based GCL specimens. Therefore, it is recommended to employ either numerical or analytical solution to measure the retardation factor when $100 \%$ of mass does not retrived in effluent.

\subsection{Conclusion}

In this chapter, the swelling capacity of studied soils including Ca-bentonite, Nabentonite, HDTMA-bentonite, PM-199, and soil admixtures including 10\%/20\% HDTMA-bentonite, and 10\%/20\% PM-199 with Na-bentonite exposed to different solutions were evaluated. It was observed that Ca-bentonite and Na-bentonite had higher swelling capacity in water due to strong hydration of $\mathrm{Ca}^{2+}$ and $\mathrm{Na}^{+}$. However, their swelling capacity decreased drastically in low polarity liquids (gasoline and methanol) because of symmetric molecular structure of low polarity liquids which resulted in the dipole polarity of zero or near zero and lower adsorption of their molecules by $\mathrm{Ca}$ bentonite and Na-bentonite. In contrast, organobentonites exhibited higher swelling tendency in low polarity liquids because the intercalated surfactants increased the organophilicity/hydrophobicity of the organobentonite followed by higher adsorption of low polarity compounds. Because of the mentioned reason, the swelling capacity of the soil admixtures in gasoline increased as the percentage of organobentonite increased while the reverse trend was detected for the swelling tendency of soil admixtures in 
water. In addition, the effect of ionic strength on the swelling capacity of the studied soils were evaluated. It was observed that the swelling capacity of the organobentonites did not change as a function of ionic strength and they did not exhibit a notable swelling in the solutions with different ionic strength. In contrast, bentonite soils showed a significant swelling capacity in solution with low ionic concentration $(0.01 \mathrm{M} \mathrm{NaCl})$. However, the swelling tendency of bentonite soils decreased by increasing the concentration of ionic solution because the higher ionic concentration dragged water molecules out of bentonite interlayers and resulted in lower swelling capacity. Additionally, the effect of basic and acidic solution was investigated on the swelling capacity of the studied soils. It was observed that basic and acidic solution $(4<\mathrm{pH}<10)$ did not affect the swelling capacity of studied soils. However, it is expected that the swelling tendency of the bentonites decrease in strong acidic and basic solutions.

Also, the hydraulic performance of GCL with organobentonite amendment for different fluids were evaluated. It was observed that the permeability of bentonite GCL specimens to water was $3.0 \times 10^{-10}$ for Ca-bentonite and $1.7 \times 10^{-11} \mathrm{~m} / \mathrm{s}$ for Na-bentonite. The hydration of inorganic cations resulted in the interlayer expansion due to the adsorption of water molecules by inorganic cations. Consequently, the bentonite ended up with a lower pore volume and decreased size of meso-pores which resulted in lower permeability of bentonite GCL specimens to water. However, Na-bentonite and Cabentonite had limited interaction with low polarity liquids (gasoline and methanol) and the inorganic cations could not hydrate by the larger, non-polar organic molecules. Consequently, the permeability of the Na-bentonite GCL specimens to gasoline and methanol increased to $7.2 \times 10^{-7} \mathrm{~m} / \mathrm{s}$ and $5.4 \times 10^{-8} \mathrm{~m} / \mathrm{s}$, respectively. In contrast, 
HDTMA-bentonite exhibited low permeability to low polarity liquids. The low permeability of HDTMA-bentonite to gasoline and methanol is attributed to the inherited organophilic characteristics of organobentonites. As a result, the organobentonites have higher solvation in low polarity liquids. The higher adsorption of large molecules of methanol and gasoline by the intercalated surfactant in the interlayer of organobentonites results in the interlayer expansion of organobentonites. Consequently, the organobentonites molecules swell and fill the available pores in the structure of GCL specimens. As a result, the permeability of GCL specimen with 100\% HDTMA-bentonite was as low as $1.5 \times 10^{-10} \mathrm{~m} / \mathrm{s}$. Based on the mentioned reason, the permeability of GCL specimens to low polarity liquids decreased by increasing the percentage of HDTMAbentonite in the GCL soil. In conclusion, the permeability of Na-bentonite GCL specimen with $20 \%$ of HDTMA-bentonite was measured as $4.12 \times 10^{-8} \mathrm{~m} / \mathrm{s}$ which was lower than the permeability of Na-bentonite GCL specimen to gasoline.

In addition, the permeability of Na-bentonite based GCL specimens with different percentage of HDTMA-bentonite/PM-199 to both polar (water) and non-polar (gasoline) liquids was measured. It was found that the minimum permeability of $1 \times 10^{-9} \mathrm{~m} / \mathrm{s}$ for gasoline and water could be achieved for Na-bentonite GCL with HDTMA-bentonite amendment by using 43\% HDTMA-bentonite in the GCL soil. While, it was observed that only 28\% PM-199 amendment in Na-bentonite GCLs can provide an approximate permeability of $6 \times 10^{-10} \mathrm{~m} / \mathrm{s}$ to gasoline and water. Other studies reported that the permeability of compacted organobentonite specimens to gasoline was in order of $10^{-10}$ $\mathrm{m} / \mathrm{s}$. The same range of permeability to gasoline and water was achieved by adding $28 \%$ PM-199 amendment to the Na-bentonite GCL specimen. For this reason, it was 
concluded that PM-199 could serve more efficiently than HDTMA-bentonite as an amendment to Na-bentonite GCLs because it could provide a lower permeability for both polar and non-polar liquids.

Moreover, the effect of confining stress on the hydraulic conductivity of three GCL specimens including Na-bentonite, 10\% HDTMA-bentonite $+90 \%$ Na-bentonite, and $20 \%$ HDTMA-bentonite $+80 \%$ Na-bentonite was investigated. It was observed that the hydraulic conductivity of GCL specimens decreased when the confining stress increased from $34.47 \mathrm{kPa}$ to $275.79 \mathrm{kPa}$. This phenomenon happened because the void ratio in GCL specimens decreased by increasing the confining stress.

Only slight increases in retardation of benzene through GCL specimens with 10\%/20\% of HDTMA-bentonite amendment was observed, due to the lower fraction of HDTMAbentonite and their relatively lower sorption capacity for benzene. However, Na-bentonite GCL specimens exhibited relatively higher retardation factor compared to Ca-bentonite based GCL specimens. The reason could be because of lower permeability of Nabentonite GCL specimens to benzene solution which increased the interaction time between HDTMA-bentonite and benzene solution. The average effluent mass flux of benzene at peak started from $0.007 \mathrm{mg} / \mathrm{cm}^{2} \times$ day for Ca-bentonite GCL and decreased by half to the $0.004 \mathrm{mg} / \mathrm{cm}^{2} \times$ day for Ca-bentonite GCL with $20 \%$ HDTMA-bentonite. However, the average effluent mass flux of benzene at peak started from $0.005 \mathrm{mg} / \mathrm{cm}^{2} \times$ day for Na-bentonite GCL and decreased to the $0.002 \mathrm{mg} / \mathrm{cm}^{2} \times$ day for Nabentonite GCL with 20\% HDTMA-bentonite. The breakthrough of benzene lasted 13 and 23 days in Ca-bentonite and Na-bentonite GCL specimens with HDTMA-bentonite amendment, respectively. It suggested that $100 \%$ of benzene mass breakthrough would 
take much longer time in HDTMA-bentonite amended GCLs. In addition, a numerical model and analytical solution were employed to calculate the retardation factor and diffusion coefficient corresponding to $100 \%$ of benzene mass breakthrough. The analytical solution revealed that the corresponding retardation factors to $100 \%$ mass of benzene were much higher compared to the experimental results, especially for GCL specimens with higher percentage of HDTMA-bentonite. However, the obtained results from numerical modeling approach were slightly higher than those from the analytical solution. The mentioned difference was anticipated because of the discretization error in the numerical modeling procedure. The obtained diffusion coefficient from both procedures were in good agreement with previous studies. Overall, this study suggests that using HDTMA-bentonite or other organically modified clay amendments may enhance the attenuation of organic compounds but also decrease the permeability of low polarity fluids in GCL. 


\section{CHAPTER FIVE NON-EQUILIBRIUM SORPTION AND RETARDATION OF ORGANIC CONTAMINANTS IN PERMEABLE REACTIVE BARRIERS (PRBs) AMENDED WITH ORGANOCLAYS}

\subsection{Introduction}

Permeable reactive barriers (PRB) is an in-situ technology that is mostly used in fast flow rate conditions such as groundwater to remediate the contaminants carried by the flow using reactive barrier components. PRBs consist of a permeable vertical curtain of reactive materials which is constructed perpendicular to the groundwater flow. When the contaminant plume flows through the PRB under the natural hydraulic gradient, the reactive materials interact with the plume and retard the mass transport of the contaminant and immobilize the contaminants or transform them to the non-toxic compounds (Carey et al. 2002; Powell et al. 1998; Skinner and Schutte 2006). A schematic illustration of PRB system is shown in Figure 5-1.

In addition, it is possible to employ the PRB system in horizontal orientated filter layer to control the downward migration of contaminants (Technologies 2017). In most cases, groundwater flow pass through the PRB system naturally under the existing hydraulic gradient. However, sheet piles or low permeability slurry walls may be required in other cases to conduct the groundwater flow toward the PRBs. PRBs can be constructed in a 
single layer, in combination with low permeability barriers (e.g. sheet pile), or in a series to remediate individual contaminants.

A summary of different common treatment media that have been considered for PRB application are listed in Table 5-1.

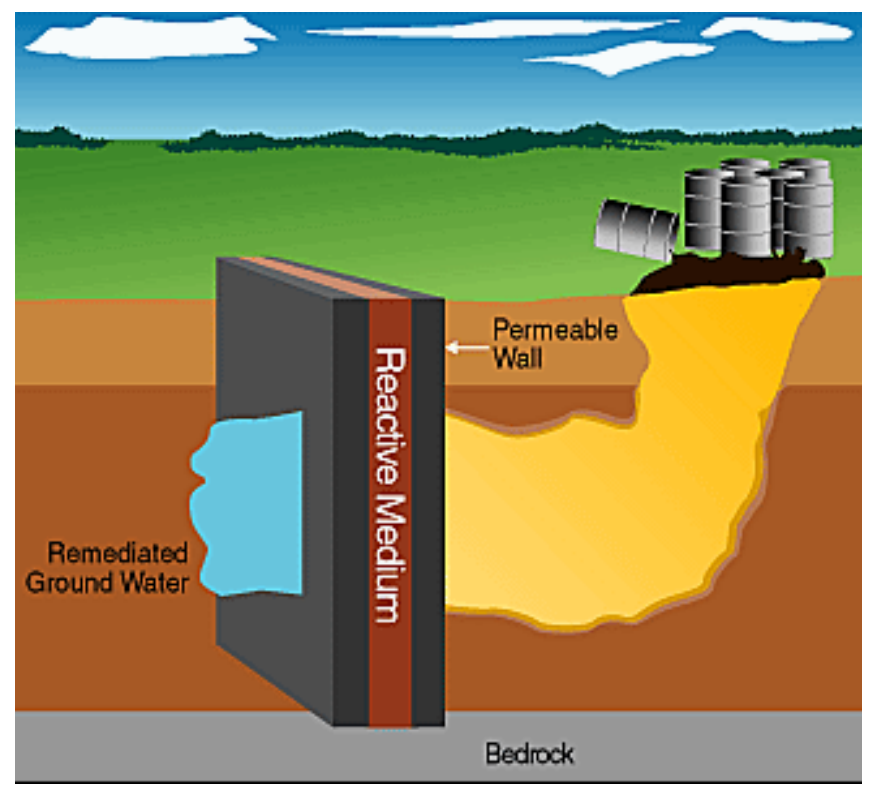

Figure 5-1. Schematic figure of PRB system (DOE-sites 1999)

Table 5-1. Common treatment medium and targeted contaminants in PRBs

Common treatment medium

zero valent iron

limestone

precipitation agents (gypsum,

hydroxyapatite)

sorptive agents ( $\mathrm{Fe}$ hydroxide, granular

activated carbon, zeolites, organoclay,

coal)

\section{Targeted contaminants}

Halocarbons, reducible metals

Metals, acid waters

\section{Metals}

Metals (such as $\mathrm{Ni}, \mathrm{Pb}, \mathrm{Cd}, \mathrm{Cr}, \mathrm{Hg}$ ) and organics (such as benzene, toluene, ethylbenzene, xylene, nitrobenzene, 


\begin{tabular}{cc}
\hline & dichloroethane, trichloroethane, \\
reducing agents (organic compost, & perchloroethylene, petroleum hydrocarbons \\
dithionite, hydrogen sulfide) & Reducible metals, Trichloroethylene \\
metal couples & halocarbons \\
biologic electron acceptors (oxygen \\
release compound -oxygen source, \\
nitrate)
\end{tabular}

To attain an efficient PRB in the field, three major factors must be taken into considerations. First, the required time for a desired cleanup should be less than the detention time of the flow in the PRB system. In the case that the reaction rate is slow, partial interaction between reactive material and contaminants could happen. The second requirement is to employ economical efficient materials as reactive components as in some scenarios, the replacement or regeneration of the materials must be affordable. Most importantly, it is required that the reactive components do not cause contamination to the groundwater themselves.

In addition, a detailed site characterization and site assessment must be conducted prior to the installment of barrier system to ensure the efficiency of the PRB system in removing the contaminants in the groundwater flow. Typically, the geological and hydrogeological information, the existing contaminants, and the geochemistry are evaluated before the implementation (Gavaskar et al. 2000). The advantages and disadvantages of PRB system 
has been summarized in Table 5-2 (Carey et al. 2002; Henderson and Demond 2007;

Powell et al. 1998; Puls 2006).

Table 5-2. Advantages and disadvantages of PRB system (Obiri-Nyarko et al. 2014)

\begin{tabular}{|c|c|}
\hline Advantages & Disadvantages \\
\hline $\begin{array}{l}\text { Relatively cheap passive technology, low } \\
\text { maintenance cost, and negligible cost for } \\
\text { disposal of treated contaminants }\end{array}$ & $\begin{array}{l}\text { Only the contaminants passing through } \\
\text { PRBs can be treated }\end{array}$ \\
\hline Applicable for multi contaminates & $\begin{array}{l}\text { Detail site characterization and site } \\
\text { assessment is required prior to the barrier } \\
\text { installation }\end{array}$ \\
\hline $\begin{array}{l}\text { Able to remediate a wide range of } \\
\text { contaminants }\end{array}$ & $\begin{array}{l}\text { Efficient for the plumes no deeper than } 20 \\
\mathrm{~m} \text { beneath ground surface }\end{array}$ \\
\hline $\begin{array}{l}\text { The contaminated site can be running while } \\
\text { the remediation is ongoing }\end{array}$ & $\begin{array}{l}\text { Lack of data regarding the longevity of the } \\
\text { PRBs }\end{array}$ \\
\hline $\begin{array}{l}\text { No surface contamination causing from } \\
\text { PRBs }\end{array}$ & $\begin{array}{c}\text { Possible difficulties in construction and } \\
\text { performance }\end{array}$ \\
\hline $\begin{array}{l}\text { Occasional monitoring to assure the } \\
\text { functionality of the system }\end{array}$ & $\begin{array}{c}\text { Possibility of reactive material replacement } \\
\text { in long term }\end{array}$ \\
\hline $\begin{array}{c}\text { No groundwater loss during the treatment } \\
\text { process }\end{array}$ & $\begin{array}{l}\text { Require monitoring especially in the case } \\
\text { of persistent contaminants or low } \\
\text { groundwater flow }\end{array}$ \\
\hline
\end{tabular}

The selection of suitable reactive component for PRB depends on the type of target contaminants in groundwater flow. The treatment mechanism can be based on organic, inorganic, or combined reaction scheme. A multiple phase contaminants can be remediated by employing a single or combined treatment procedure, or using single/multi-media. Particularly, some hydrocarbons and certain heavy metals can be treated through the sorption mechanism using fine-grained soils. The possible treatment mechanisms include chemical precipitation mechanism, Oxidation-reduction mechanism, zero-valent metal reaction, and sorption reaction which are explained in following paragraphs. 
In chemical precipitation mechanism, slightly soluble compounds that contain ions are used to interact and precipitate the dissolved inorganic species like heavy metals and result in an insoluble salt such as sulfate, or carbonate metal salts containing the contaminants. Oxidation-reduction mechanism which also is known as "redox" attenuate the dissolved inorganic contaminants through the precipitation process by changing the valance state of contaminants during the redox process. In zero-valent metal reaction, metal provide the electron for reduction of chlorocarbons by removing the chlorine from the structure of chlorocarbons and releasing it to the solution as a combination of chloride and ferrous iron $\left(\mathrm{Fe}^{2+}\right)$.

The sorption reaction can be categorized in three groups including hydrophobic, hydrophilic, and ion exchange type. Many different materials have been used to sorb the organic and inorganic compounds from arouse phase. The sorption media are suitable for PRB application because the equilibrium sorption process occurs in a short amount of time. However, the sorption materials have a specific sorption capacity. The breakthrough of contaminants starts as soon as the sorption materials reach to their maximum capacity. In conclusion, an additional means is required in conjunction with sorptive material which remove or replenish the sorption medium.

The sorption reaction has been studied well for the strong organic sorbents which have very low water solubility, strongly hydrophobic, and highly stable for biodegradation. These compounds transfer from the water phase to the available organic carbon in the solid phase geo-materials through the partitioning process. Consequently, it can be concluded that the contaminants carried by groundwater flow can be removed efficiently from the aquifer system by increasing the organic carbon content of aquifer materials. 
However, the sorption capacity of the selected materials is one of the most important characteristics which needs to be considered before selecting the treatment materials. The organically modification of sorptive materials can increase their sorption capacity and makes them favorable sorptive material for different scenarios.

Most commonly, zero-valent iron (ZVI), natural zeolites, activated carbon (AC), lime and other alkaline materials, apatite, transformed red mud (TRM), oxide, and sodium dithionite have been employed as the reactive component of PRB system (Liao et al. 2010; Nakagawa et al. 2003; Peric et al. 2004; Simon and Meggyes 2000; Triay et al. 1989). Among the possible options for PRB reactive materials, organoclays have gained more attention because of their higher sorption capacity to the common groundwater contaminants such as aromatic hydrocarbons (Guerin et al. 2002; Lee et al. 2012). In addition, organoclays demonstrated that they uptake contaminants from groundwater through the sorption process. As mentioned previously, the equilibrium sorption process occurs in a fast rate which makes it a favorable mechanism for the fast flow rate systems such as PRBs. The sorption mechanism can be used in aquifers with low organic carbon by utilizing organoclay complex as reactive material for PRBs. In this case, the organoclay can make a mineral complex with aquifer minerals which increase the sorption capacity of the minerals. Various surfactant can be utilized to create the organo complex with aquifer solid minerals. However, the interaction time between organoclays and dissolved contaminant should be enough to let the organo complex adsorb the contaminants. Otherwise, the non-equilibrium sorption mechanism would be dominant and the introduced contaminants would be attenuated partially. Lee et al. (2012) investigated the feasibility of using organoclays to remove PAHs from groundwater flow. 
They suggested that organoclays can be employed efficiently for fast flow rate systems. They observed that organoclays blocked the advective transport of non-aqueous-phase liquid (NAPL) while they allowed the water with dissolved PAHs to pass through the PRB system and sorbed the dissolved PAHs.

In a fast flow rate permeable systems, the level of interaction between groundwater contaminants and PRB materials is typically relied on both the sorptivity of the PRB materials and the contact time between the contaminants and PRB materials (Carey et al. 2002; Chen et al. 2011; Henderson and Demond 2007; Puls 2006; Wilkin and Puls 2003).A non-equilibrium condition often exists in such a scenario, even if the sorption of organics onto organoclays are relatively fast (Chapter 2). Consequently, kinetic study is required to understand the sorption capacity of the system at non-equilibrium condition. The scope of this study is to investigate the potentials of using organobentonites as reactive amendment in PRB materials and also provides quantitative results to aid design and possible implementation of such applications Two sets of soil columns with of $10 \%$ of organobentonites (HDTMA-bentonite and PM-199) with different hydraulic conductivities (ranging from $10^{-4}$ to $10^{-7} \mathrm{~m} / \mathrm{s}$ ) were prepared and the impact of or seepage velocity on the sorption and retardation of the organic contaminants were examined. In addition, a model was established to relate the non-equilibrium partitioning coefficients and retardation factors as a function of time.

\subsection{Materials and methods}

Six different soils (low plasticity silty clay, HDTMA-bentonite, ASTM 20-30, coarse sand, fine sand, and PM-199 powder) were used to prepare the binary soil admixtures for 
this study. Coarse sand and medium sand were classified as SP (poorly graded sand) according to ASTM D422 and their grain size distribution curves are illustrated in Figure 5-2. The physical properties of the ASTM 20-30, coarse and fine sand are summarized in Table 5-3.

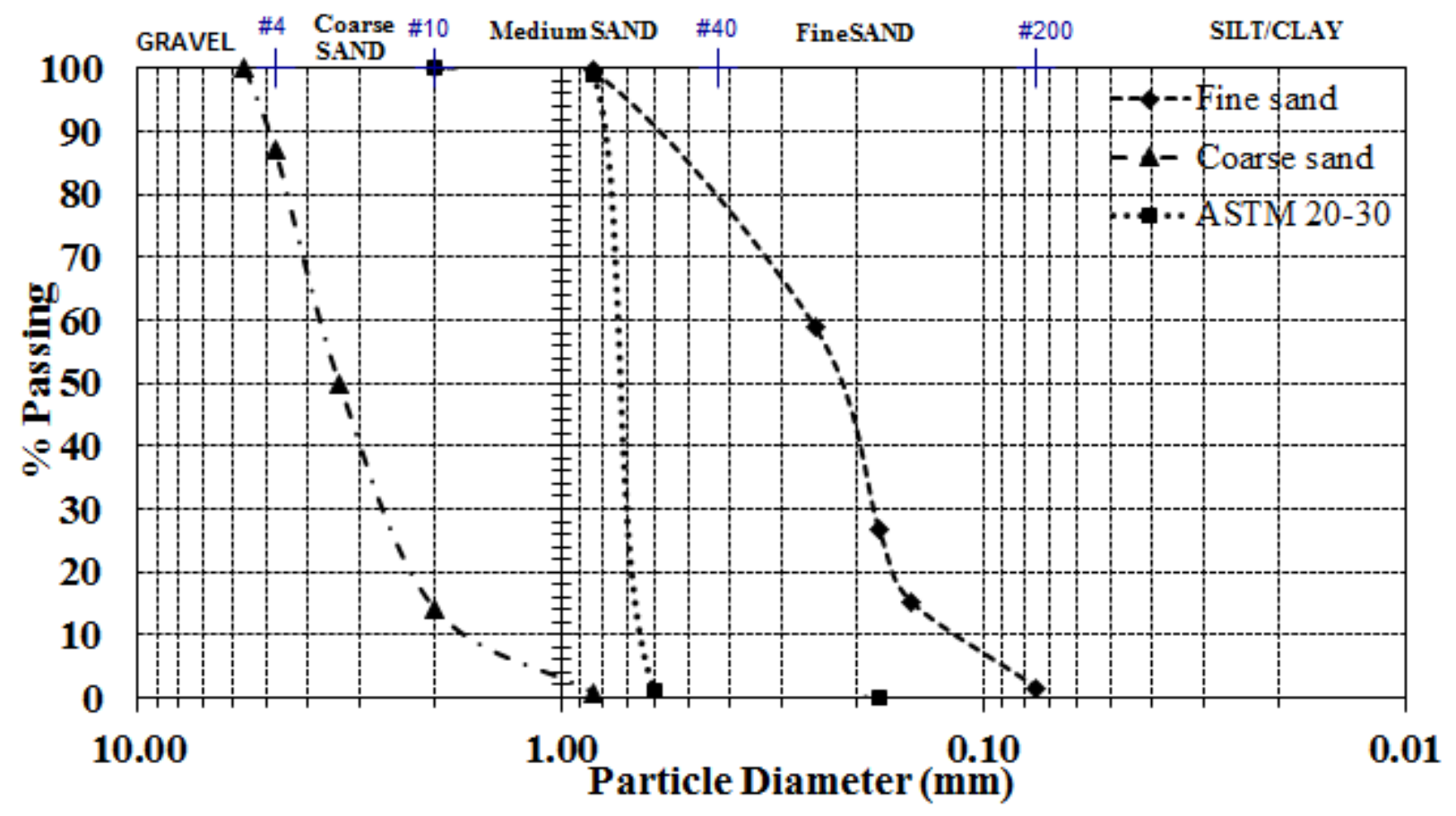

Figure 5-2. grain size distribution curve for coarse and fine sand

Table 5-3. physical properties of the coarse and fine sand

\begin{tabular}{cccc}
\hline Properties & Coarse sand & Fine sand & ASTM 20-30 \\
\hline $\mathrm{C}_{\mathrm{c}}$ & 1.14 & 1.06 & 1.15 \\
$\mathrm{C}_{\mathrm{u}}$ & 2.2 & 2 & 1 \\
Type of gradation & Poorly graded & Poorly graded & Poorly graded \\
Specific gravity & 2.67 & 2.65 & 2.65 \\
Total organic carbon $(\%)$ & $<1$ & $<1$ & $<1$ \\
\hline
\end{tabular}


For this study, pure benzene was dissolved in deionized water to prepare the permeant stock solution with approximate concentration of $100 \mu \mathrm{g} / \mathrm{mL}$ following the procedure explained in chapter 2 . The stock solutions were stored at room temperature for less than 1 hour before the tests.

\subsubsection{Column preparation}

To study the effect of seepage velocity on the contaminant sorption and transport mechanisms, two sets of soil columns were designed. The first set of tests were performed in 4 packed columns with 10\% HDTMA-bentonite and $90 \%$ of (1) coarse sand, (2) ASTM 20-30 sand, (3) silty clay, and (4) silty clay (slightly compacted). The second set of tests were performed in 3 packed columns with 10\% PM-199 (powder) and 90\% of (1) ASTM 20-30 sand, (2) fine sand, and (3) silty clay (loose). The percentages of organoclays were kept constant at low ratio of $10 \%$ (by weight) because the high sorption capacity of the studied organoclays could yield low effluent concentration that can't be easily tested in GC. The physical properties of the soil columns are summarized in Table 5-4.

Table 5-4. Properties of packed columns

\begin{tabular}{|c|c|c|c|c|c|c|}
\hline Column NO. & Soil component & Soil mass (g) & $\begin{array}{l}\text { Specific } \\
\text { gravity }\end{array}$ & $\begin{array}{l}\text { Pore volume } \\
\quad(\mathrm{mL})\end{array}$ & $\begin{array}{l}\text { Dry density } \\
\left(\mathrm{g} / \mathrm{cm}^{3}\right)\end{array}$ & Porosity \\
\hline Column 1 & $\begin{array}{c}10 \% \\
\text { HDTMA }+90 \% \\
\text { coarse sand }\end{array}$ & 110 & 2.53 & 44 & 1.49 & 0.6 \\
\hline Column 2 & $\begin{array}{c}10 \% \\
\text { HDTMA }+90 \% \\
\text { ASTM } 20-30 \text { sand }\end{array}$ & 110 & 2.58 & 30 & 1.02 & 0.52 \\
\hline Column 3 & $\begin{array}{c}10 \% \\
\text { HDTMA+90\% }\end{array}$ & 75 & 2.53 & 30 & 1.02 & 0.42 \\
\hline
\end{tabular}




\begin{tabular}{|c|c|c|c|c|c|c|}
\hline & silty clay & & & & & \\
\hline Column 4 & $\begin{array}{c}10 \% \\
\text { HDTMA }+90 \% \\
\text { silty clay (slightly } \\
\text { compacted) }\end{array}$ & 90 & 2.53 & 38 & 1.22 & 0.41 \\
\hline Column 5 & $\begin{array}{c}\text { 10\% PM-199 } \\
\text { (POWDER)+90\% } \\
\text { ASTM 20-30 sand }\end{array}$ & 110 & 2.58 & 31 & 1.49 & 0.6 \\
\hline Column 6 & $\begin{array}{c}\text { 10\% PM-199 } \\
\text { (POWDER)+90\% } \\
\text { Fine sand }\end{array}$ & 110 & 2.58 & 31 & 1.49 & 0.42 \\
\hline Column 7 & $\begin{array}{c}10 \% \text { PM-199 } \\
\text { (POWDER) }+90 \% \\
\text { silty clay }\end{array}$ & 75 & 2.53 & 44 & 1.02 & 0.4 \\
\hline
\end{tabular}

Cylindrical glass columns with length of $15 \mathrm{~cm}$ and diameter of $2.5 \mathrm{~cm}$ with Teflon coded caps (Kimble Chase Co.) were used for the column studies. Columns were first cleaned with methanol and deionized water. Teflon tubing was used in this experiment for inlet and outlet flow lines to minimize the sorption of benzene to the wall of tubing.

\subsubsection{Hydraulic conductivity test}

The hydraulic conductivity of seven soil columns were measured using constant head method following ASTM D 2434. The prepared columns were fixed on a stand and connected to the water reservoir. To saturate and squeeze the trapped air pockets out of the columns, the water was flushed through the columns from bottom to top until the stable water head at water reservoir and steady state at effluent was achieved. The effluent was collected in a container. Meanwhile the required time to collect the effluent 
and the water head were recorded for each column. The hydraulic conductivity was measured using equation 5-1:

$k=\frac{Q L}{A t h}$

where $\mathrm{k}$ is the hydraulic conductivity $(\mathrm{cm} / \mathrm{s}), \mathrm{Q}$ is the quantity of water discharge $\left(\mathrm{cm}^{3}\right)$, $\mathrm{L}$ is the length of column $(\mathrm{cm}), \mathrm{A}$ is the cross-section area of column $\left(\mathrm{cm}^{2}\right), \mathrm{t}$ is the total time for water discharge (s), and $\mathrm{h}$ is the water head difference.

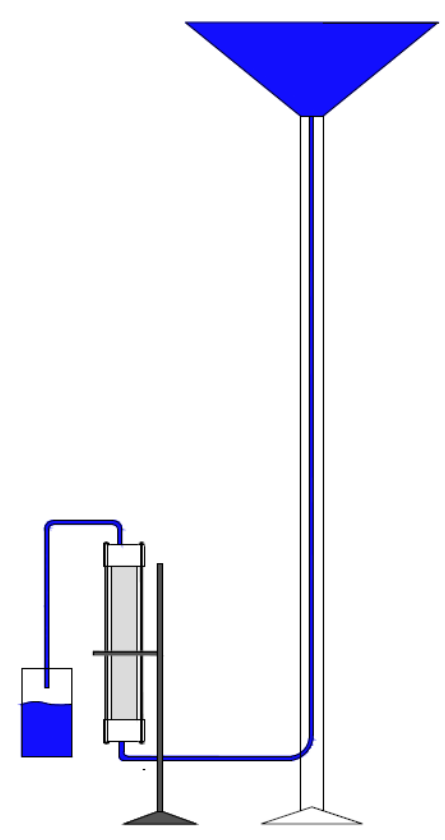

Figure 5-3. Hydraulic conductivity test setup with constant head

\subsubsection{Breakthrough test}

The breakthrough tests were carried out to obtain the retardation capacity of each binary soil admixture in the seven packed columns. This part of experiment was designed to evaluate the sorptivity of benzene by the organoclay amendments when given a fast seepage velocity and possibly, a non-equilibrium sorption scenario in PRBs. 
The pre-saturated columns from the hydraulic conductivity experiment were used for the breakthrough study. A bladder accumulator with viton membrane was used to feed the benzene solution into the soil columns. For this reason, pressure control panel was used to inject the solution. Initially, bladder accumulator was filled with benzene solution and 1 pore volume of pulse-type contaminant solution was injected to the soil columns. Then, the flow was switched to the deionized water. Following the test procedure explained in chapter 4, The effluent samples were collected and analyzed for the concentration of benzene. The columns were flushed with deaired water until the concentration of benzene in effluent was reached below the detection limit. The breakthrough curve for benzene solution was obtained by measuring the concentration of benzene in the effluent. The schematic setup of breakthrough experiment is presented in Figure 5-4. 


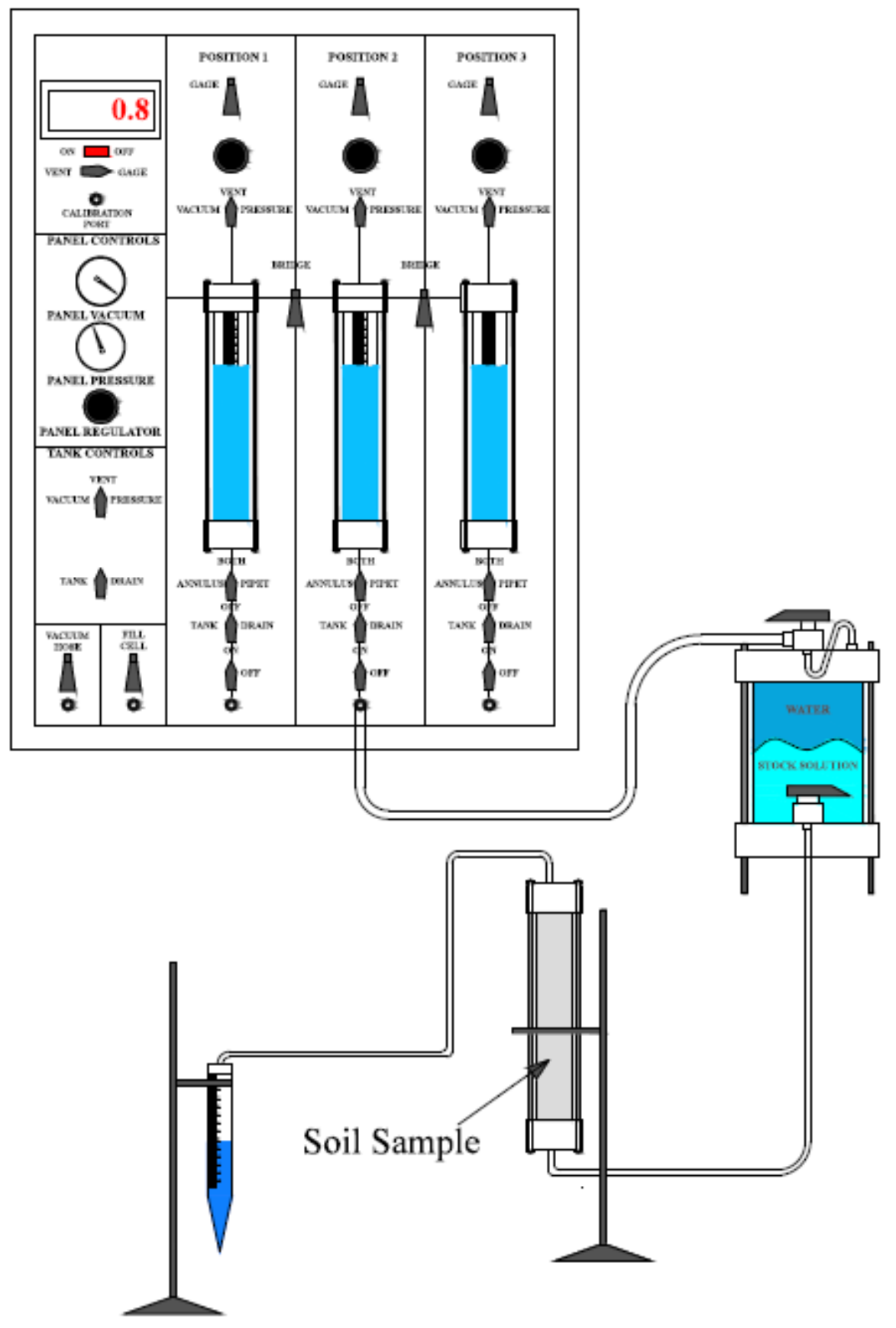

Figure 5-4. Schematic setup of breakthrough test

To analyze the breakthrough test results, the non-equilibrium partitioning coefficient of benzene was estimated from the kinetic study (chapter 2). Also, the numerical and analytical solutions were obtained to estimate the contaminant transport parameters 
following the same procedure explained in chapter 4. The obtained results from mathematical modeling was compared with the non-equilibrium partitioning coefficient of benzene to verify the accuracy of models.

\subsection{Result and discussion}

\subsubsection{Hydraulic conductivity test}

The hydraulic conductivity $(\mathrm{k})$ and corresponding seepage velocities $\left(\mathrm{v}_{\mathrm{s}}\right)$ for seven studied columns were measured and the obtained results are summarized in Table 5-5.

Table 5-5. The measured hydraulic conductivity

\begin{tabular}{cccc}
\hline Column components & Void ratio (e) & $\mathbf{V}_{\mathbf{s}}(\mathbf{m} / \mathbf{s})$ & $\mathbf{k ~ ( m / s )}$ \\
\hline Column 1 & 1.5 & $1.36 \times 10^{-3}$ & $1.33 \times 10^{-4}$ \\
Column 2 & 1.08 & $2.83 \times 10^{-4}$ & $4.61 \times 10^{-5}$ \\
Column 3 & 0.72 & $3.29 \times 10^{-5}$ & $2.25 \times 10^{-6}$ \\
Column 4 & 0.69 & $3.17 \times 10^{-6}$ & $4.07 \times 10^{-7}$ \\
Column 5 & 1.5 & $1.15 \times 10^{-3}$ & $1.12 \times 10^{-4}$ \\
Column 6 & 0.72 & $4.13 \times 10^{-4}$ & $2.83 \times 10^{-5}$ \\
Column 7 & 0.66 & $1.77 \times 10^{-5}$ & $3.32 \times 10^{-6}$ \\
\hline
\end{tabular}

The hydraulic conductivity of soil columns with HDTMA-bentonite amendment was at $1.33 \times 10^{-4} \mathrm{~m} / \mathrm{s}$ for column 1 and decreased to $4.07 \times 10^{-7} \mathrm{~m} / \mathrm{s}$ for slightly compacted soil column 4. The same trend was observed regarding the hydraulic conductivity of soil columns with PM-199 amendment. The hydraulic conductivity of column 5 was measured as $1.12 \times 10^{-4} \mathrm{~m} / \mathrm{s}$ while it decreased to $3.32 \times 10^{-6} \mathrm{~m} / \mathrm{s}$ for column 7 . It was observed that the hydraulic conductivity of soil columns were function of void ratio. 
Taylor (1948) suggested an equation for coefficient of permeability which considered the properties of both soil medium and permeant fluid, equation 5-2.

$k=C D_{s}{ }^{2} \frac{\mu}{\gamma} \frac{e^{3}}{(1+e)} S^{3}$

where $\mathrm{C}$ is the shape factor, $D_{s}$ is the effective particle diameter, $\mathrm{e}$ is the void ratio, $\mu$ is the viscosity of the permeant fluid, $\gamma$ is the unit weight of the soil, and $\mathrm{S}$ is the degree of saturation. It was observed that the void ratio of packed columns with HDTMA-bentonite amendment started from 1.5 for the column with highest flow rate (column 1) and decreased to 0.69 for the column with lowest flow rate (column 4). Consequently, the hydraulic conductivity in HDTMA-bentonite amended columns started at higher end for column 1 as $1.33 \times 10^{-4} \mathrm{~m} / \mathrm{s}$ and decreased to $4.07 \times 10^{-7} \mathrm{~m} / \mathrm{s}$ for column 4 at the lowest end. Likewise, the void ratio of packed columns with PM-199 amendment started from 1.5 for the column with highest flow rate (column 5) and decreased to 0.66 for the column with lowest flow rate (column 7). As a result, the hydraulic conductivity in PM199 amended columns started at higher end for column 5 as $1.12 \times 10^{-4} \mathrm{~m} / \mathrm{s}$ and decreased to $3.32 \times 10^{-6} \mathrm{~m} / \mathrm{s}$ for column 7 at the lowest end.

In this study, the obtained results suggested that the void ratio decreased by decreasing the particle size of soil column constituent. As it was anticipated, the hydraulic conductivity of soil columns decreased by mean particle sizes.

\subsubsection{Breakthrough test}

The breakthrough time increased as the coarse particle fraction decreased in the soil columns. For columns 1, 2, 5, and 6 the tests typically lasted about 20 to 30 minutes (for 25 to 30 pore volumes). However, columns 3, 4, and 7 lasted more than 2 weeks (for 20 
to 25 pore volumes). The seepage velocity started from $1.3 \times 10^{-3} \mathrm{~m} /$ in soil columns $\mathrm{s}$ filled with admixture of HDTMA-bentonite and coarse sand and it decreased to $3.17 \times$ $10^{-6} \mathrm{~m} / \mathrm{s}$ for soil column with HDTMA-bentonite and silty clay. Similar trend was observed as the seepage velocity in PM-199 ASTM with 20-30 sand was measured at $1.15 \times 10^{-3} \mathrm{~m} / \mathrm{s}$ and it decreased to $1.77 \times 10^{-5} \mathrm{~m} / \mathrm{s}$ in PM199 and silty clay. The peak of mass flux in both columns of HDTMA-bentonite + coarse sand and PM-199 + ASTM 2030 sand appeared after 3 pore volumes. However, the peak of mass flux in HDTMAbentonite + silty clay occurred 2 pore volumes earlier than PM-199 + silty clay. This was explained as a result of higher sorption capacity of PM-199 compared to HDTMAbentonite. The obtained breakthrough curve for columns with $10 \%$ organoclay amendments are illustrated in Figure 5-5.

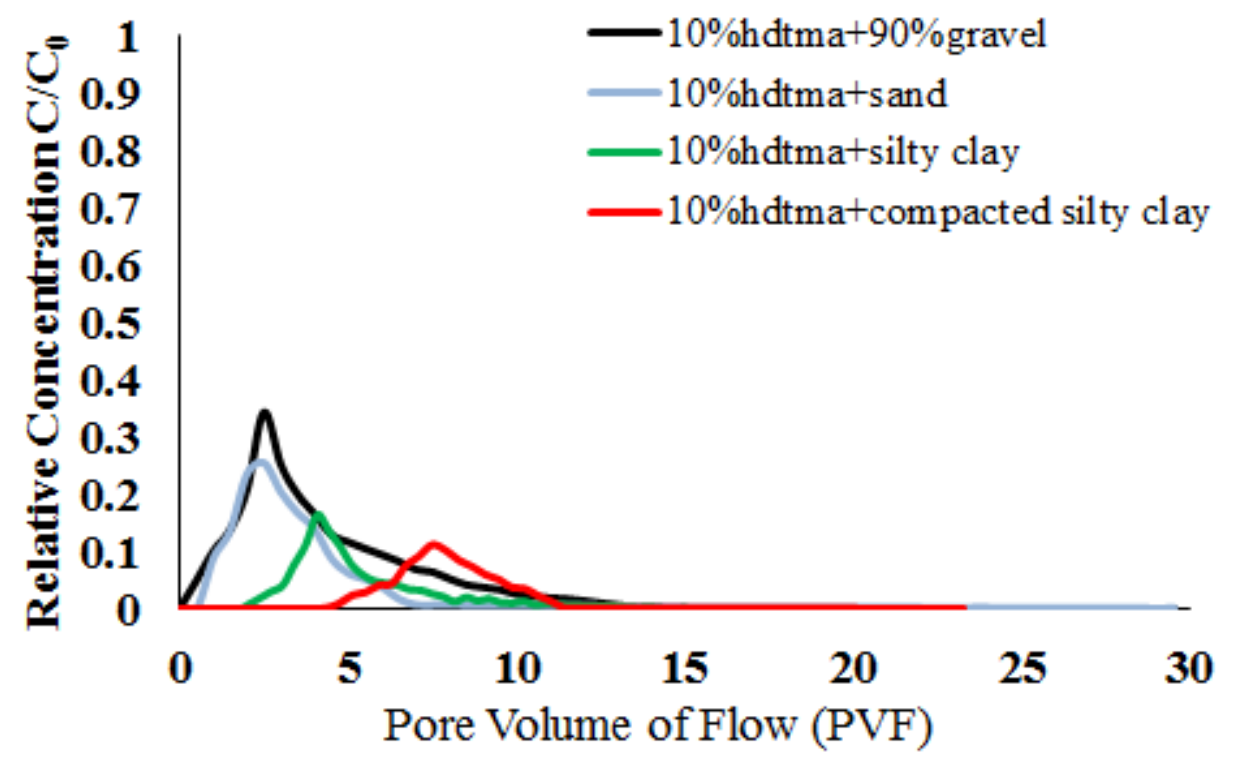

(a) 


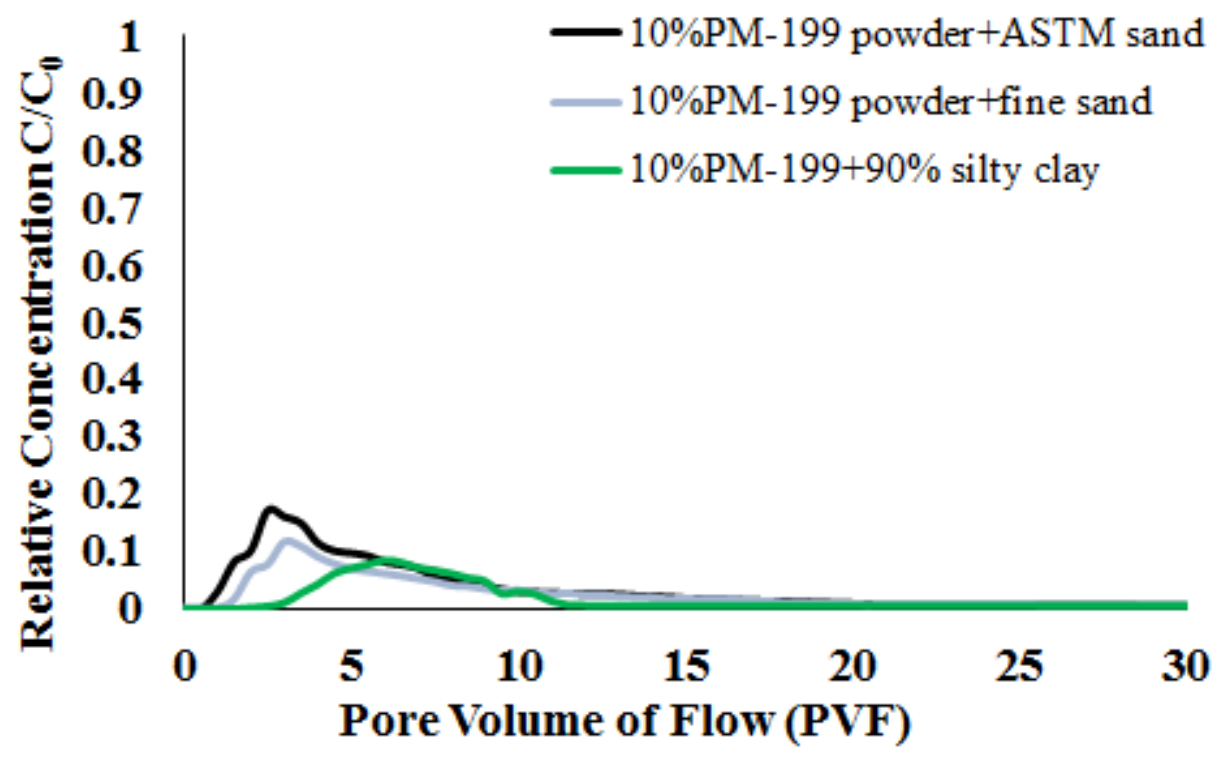

(b)

Figure 5-5. Breakthrough curve of benzene transport in column with (a) $10 \%$ HDTMA-bentonite amendment (b) 10\% PM-199 amendment

The delayed arrival and decrement of the peak mass flux was attributed to the sorption of benzene by the soils. A retardation factor is typically used to describe such a hindered transport of organic contaminant. Most commonly, the retardation factor is determined by the sorptivity of the soil sorbent $\left(R=1+\frac{\rho}{n} k_{d}\right)$ and the partitioning coefficient $\mathrm{K}_{\mathrm{d}}$ in this equation indicates the affinity of contaminant sorbate towards soil sorbent. However, the partitioning coefficient $\mathrm{K}_{\mathrm{d}}$ is typically determined by batch sorption tests and it represents a distribution of contaminants between soil sorbent and aqueous phase under the equilibrium condition. In the PRBs, because the breakthrough time of contaminant through the reactive materials could be less than the time required for equilibrium sorption, the equation tends to yield overestimated $\mathrm{K}_{\mathrm{d}}$ and consequently, overestimated 
retardation factor. It is necessary to investigate the non-equilibrium sorption and the resultant retardation factor given the fast flow situation.

Table 5-6. Required time for seepage of benzene solution through the soil columns

\begin{tabular}{ccc}
\hline Column components & $\mathbf{V}_{\mathbf{s}}(\mathbf{m} / \mathbf{s})$ & Time (min) \\
\hline 10\% HDTMA + 90\% coarse sand & $1.36 \times 10^{-3}$ & 1.83 \\
$10 \%$ HDTMA + 90\% ASTM 20-30 sand & $2.83 \times 10^{-4}$ & 8.81 \\
10\% HDTMA + 90\% silty clay & $3.29 \times 10^{-5}$ & 75.93 \\
10\% HDTMA + 90\% silty clay (slightly & $3.17 \times 10^{-6}$ & 786.88 \\
compacted) & & \\
10\% PM-199 (POWDER) + 90\% ASTM & $1.15 \times 10^{-3}$ & 2.16 \\
20-30 sand & & 6.05 \\
10\% PM-199 (POWDER) + 90\% Fine & $4.13 \times 10^{-4}$ & 14.08 \\
\hline
\end{tabular}

Initially, breakthrough time of contaminant flow in each column was calculated based on the seepage velocity (Table 5-6):

$t=\frac{L}{V_{s}}$

Where $\mathrm{t}$ is the breakthrough time (s), $\mathrm{L}$ is the length of the column $(\mathrm{cm})$, and $\mathrm{V}_{\mathrm{s}}$ is the seepage velocity $(\mathrm{cm} / \mathrm{s})$. The obtained breakthrough time was then used to estimate the non-equilibrium partitioning coefficient through the aqueous concentration of benzene from the kinetic study (chapter 2).

$C_{t}=C_{e}+\left[C_{0}-C_{e}\right] \exp \left[-\left(\frac{\varepsilon C_{0}}{C_{e}}\right) t\right]$

For kinetic study, the concentration of dissolved benzene in the solution as a function of time $\left(\mathrm{C}_{\mathrm{t}}\right)$ was recorded. In addition, the initial concentration of the benzene in the solution was measured as $\left(\mathrm{C}_{0}\right)$. Also, the equilibrium concentration of benzene in the 
solution was measured as $\left(\mathrm{C}_{\mathrm{e}}\right)$. An initial value for the mass transfer coefficient $(\varepsilon)$ was chosen and the resultant curve from equation 5-4 was plotted. The value of $\varepsilon$ was altered to fit a curve to the experimental results. Consequently, the suitable value of $\varepsilon$ was found and the concentration of benzene as a function of time was calculated by using equation 5-4. the partitioning coefficient of HDTMA-bentonite as a function of time was calculated by dividing the absorbed mass of benzene to the solid phase over the remained concentration of benzene in the solution for each time step. The calculated partitioning coefficient of HDTMA-bentonite for benzene as a function of time is presented in Figure $5-6$.

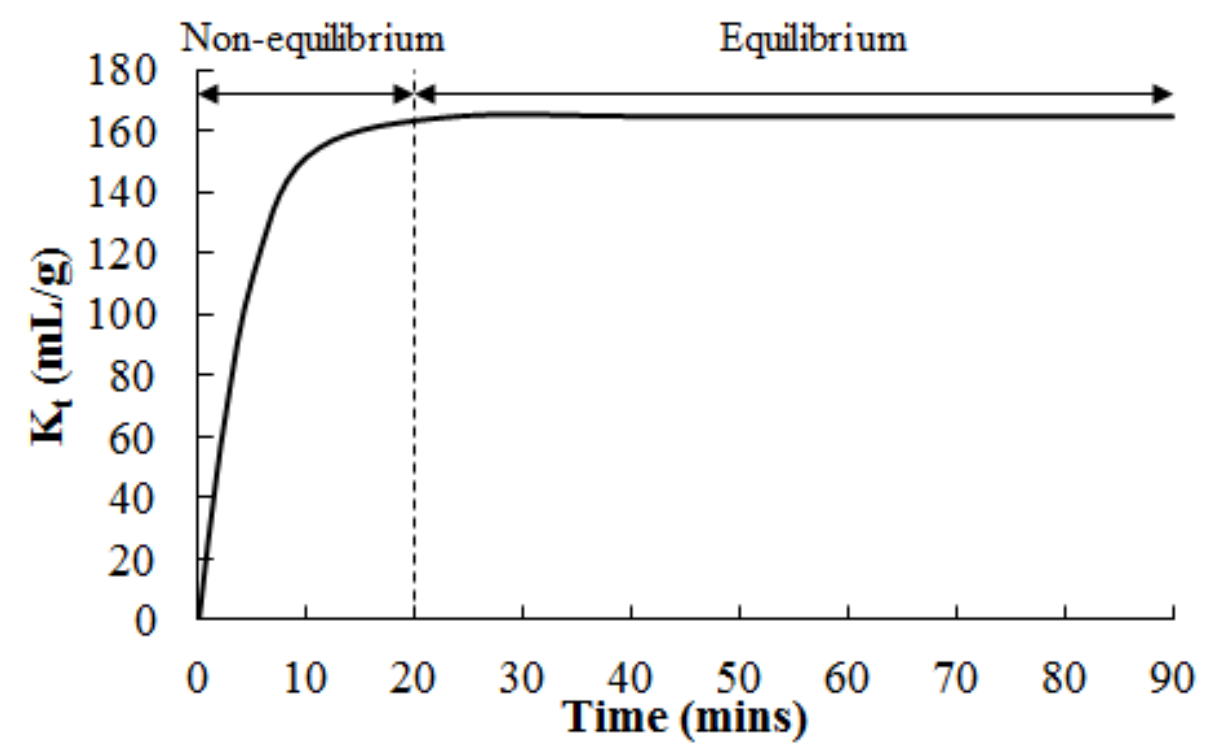

Figure 5-6. partitioning coefficient of HDTMA-bentonite for benzene as a function of time

Based on the results in Figure $\mathrm{x}$, it can be concluded that approximately 20 minutes is needed for the equilibrium sorption of benzene onto HDTMA-bentonite. Consequently, the partitioning coefficient obtained from equilibrium batch sorption test is not valid anymore for non-equilibrium sorption condition with the breakthrough time less than 20 mins. Specifically, out of the 7 packed columns, the benzene transport and retardation in 
5 columns (column 1,2,5,6,7, Table 5-7) must be considered as non-equilibrium sorption case.

Table 5-7. Non-equilibrium partitioning coefficient of HDTMA-bentonite for benzene

\begin{tabular}{|c|c|c|c|c|}
\hline \multirow{2}{*}{$\begin{array}{l}\text { Column } \\
\text { number }\end{array}$} & \multirow{2}{*}{ Column components } & \multirow{2}{*}{$\begin{array}{l}\text { Breakthrough } \\
\text { Time (min) }\end{array}$} & \multicolumn{2}{|c|}{$\mathrm{K}(\mathrm{mL} / \mathrm{g})$} \\
\hline & & & $\mathbf{K}_{\mathbf{t}}$ & $\mathbf{K}_{\mathbf{d}}$ \\
\hline 1 & $10 \%$ HDTMA $+90 \%$ coarse sand & 1.83 & 13 & --- \\
\hline 2 & 10\% HDTMA + 90\% ASTM 20-30 sand & 8.81 & 110 & --- \\
\hline 3 & 10\% HDTMA + 90\% silty clay & 75.93 & --- & 149.59 \\
\hline 4 & $\begin{array}{c}10 \% \text { HDTMA }+90 \% \text { silty clay (slightly } \\
\text { compacted) }\end{array}$ & 786.88 & --- & 149.59 \\
\hline 5 & $\begin{array}{l}\text { 10\% PM-199 (powder) + 90\% ASTM 20- } \\
30 \text { sand }\end{array}$ & 2.16 & & A. \\
\hline 6 & 10\% PM-199 (powder) + 90\% Fine sand & 6.05 & & A. \\
\hline 7 & $10 \%$ PM-199 (powder) $+90 \%$ silty clay & 14.08 & & A. \\
\hline
\end{tabular}

The calculation to determine the overall sorptivity and retardation factor of the soil admixture is illustrated below:

Considering negligible sorptivity of coarse sand, the overall distribution coefficient $\left(\mathrm{K}_{\mathrm{a}}\right)$ can be calculated as:

$K_{a}=\frac{\sum_{i=1}^{n} K_{i} W_{i}}{W_{i}}$

where $K_{i}$ is the partitioning coefficient of each sorbent (at equilibrium or nonequilibrium condition), and $W_{i}$ is the mass percentage of each sorbent in the column soil. 
Following the mentioned procedure, the distribution coefficients was measured for studied columns. Then, the retardation factor was calculated using equation 5-6.

$$
R=1+\frac{\rho}{n} K
$$

the $\mathrm{K}$ value used for column 1 and 2 were the non-equilibrium distribution coefficients that was measured through the kinetic study while the retardation factor for column 3, and 4 were measured using the equilibrium distribution coefficients $\left(\mathrm{K}_{\mathrm{d}}\right)$. The calculated partitioning coefficient and retardation factors for the studied columns are summarized in Table 5-8.

Analytical solution was employed to calculate the retardation factor corresponding to $100 \%$ mass of benzene in effluent, Figure 5-7. The acquired results are summarized in Table 5-8.

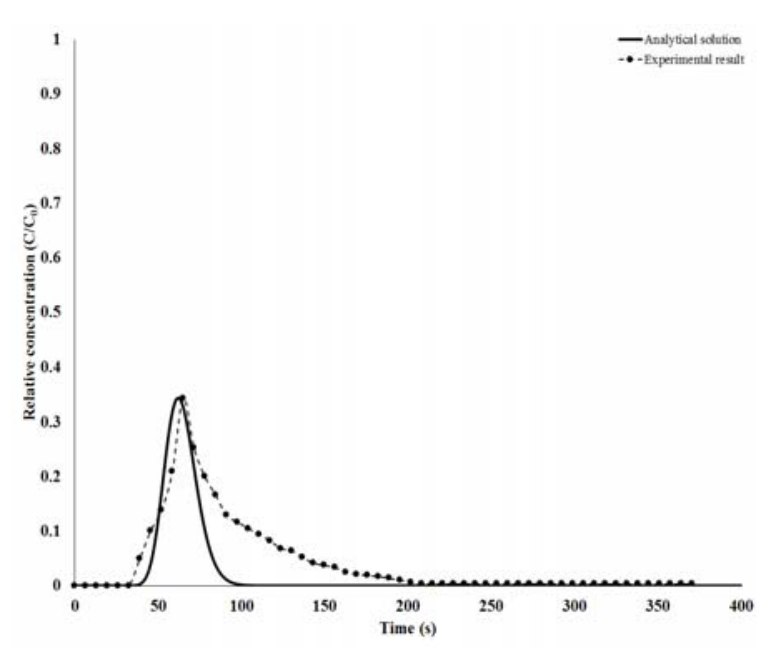

(a)

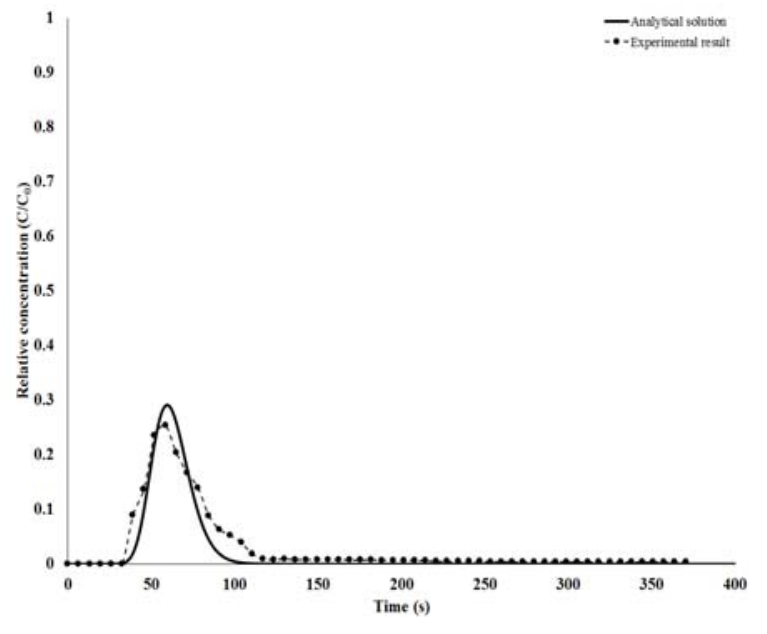

(b) 


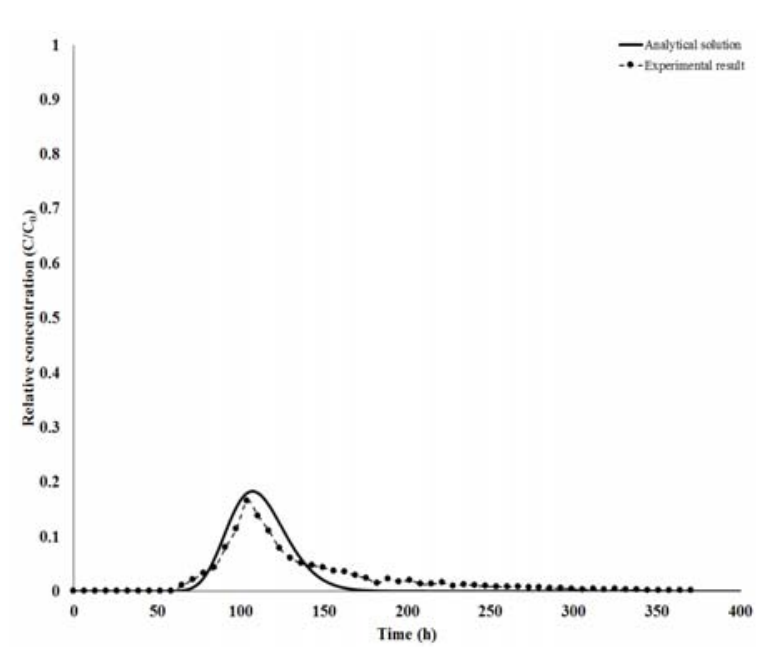

(c)

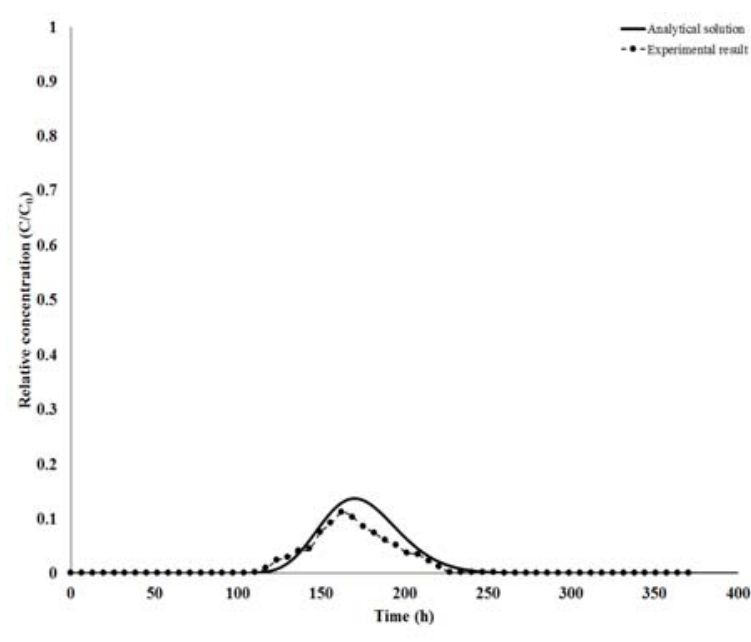

(d)

Figure 5-7. Fitted curve applying analytical solution for column (a) 1 (b) 2 (c) 3 (d) 4

Table 5-8. Retardation factor and diffusion coefficients for seven soil columns obtained from analytical and numerical methods and the first-moment equation

\begin{tabular}{ccccc}
\hline & \multicolumn{2}{c}{ Calculated from kinetic study } & \multicolumn{2}{c}{$\begin{array}{c}\text { Experimental results fitted } \\
\text { by analytical solution }\end{array}$} \\
\cline { 2 - 5 } Column number & $\mathrm{K}(\mathrm{mL} / \mathrm{g})$ & $\begin{array}{c}\text { Retardation } \\
\text { factor }\end{array}$ & $\begin{array}{c}\text { Retardation } \\
\text { factor }\end{array}$ & $\begin{array}{c}\text { Diffusion } \\
\text { coefficient } \\
\left(\mathrm{cm}^{2} / \mathrm{s}\right)\end{array}$ \\
\hline 1 & 1.3 & 4.23 & 4 & $2.4 \times 10^{-6}$ \\
2 & 11.0 & 22.57 & 19.2 & $1.2 \times 10^{-6}$ \\
3 & 14.59 & 37.33 & 41.1 & $6.2 \times 10^{-6}$ \\
4 & 14.59 & 45.51 & 58.6 & $1.8 \times 10^{-6}$ \\
\hline
\end{tabular}

The retardation factor calculated from the non-equilibrium partitioning coefficient and estimated from analytical solution was 4.23 , and 4 for soil columns 1 , respectively. Also, the retardation factor for column 2 was obtained from the non-equilibrium partitioning coefficient and the analytical solution as 22.57 , and 19.2 , respectively. The retardation factor obtained from analytical solution and kinetic study showed only a 5\% difference in column 1 whereas in column 2 there was a 15\% difference. These results suggested that the kinetic study was a suitable method to calculate the non-equilibrium partitioning coefficient and yield a reasonable retardation factor for non-equilibrium condition. 
Additionally, the estimated diffusion coefficient for all columns were at the range of $10^{-6}$ $\mathrm{cm}^{2} / \mathrm{s}$ which were at an acceptable range compared to previous studies.

5.3.3 Effect of seepage velocity on the retrieved percentage of benzene mass in effluent

The retrieved percentage of benzene mass was defined as equation 5-7.

$R_{\text {mass }}=\frac{M_{\text {out }}}{M_{\text {in }}} \times 100$

where $\mathrm{R}_{\text {mass }}$ is the retrieved percentage of benzene mass (\%), $\mathrm{M}_{\text {in }}$ is the initial mass of benzene which was introduced to the packed column ( $\mu \mathrm{g})$, and Mout is the mass of benzene which was collected in effluent $(\mu \mathrm{g})$. By using the mass balance analysis, Rmass were measured as $80 \%, 71 \%, 45 \%$, and $31 \%$ for column 1 to 4 , respectively. $R_{\text {mass }}$ is plotted versus the seepage velocity in Figure 5-8.

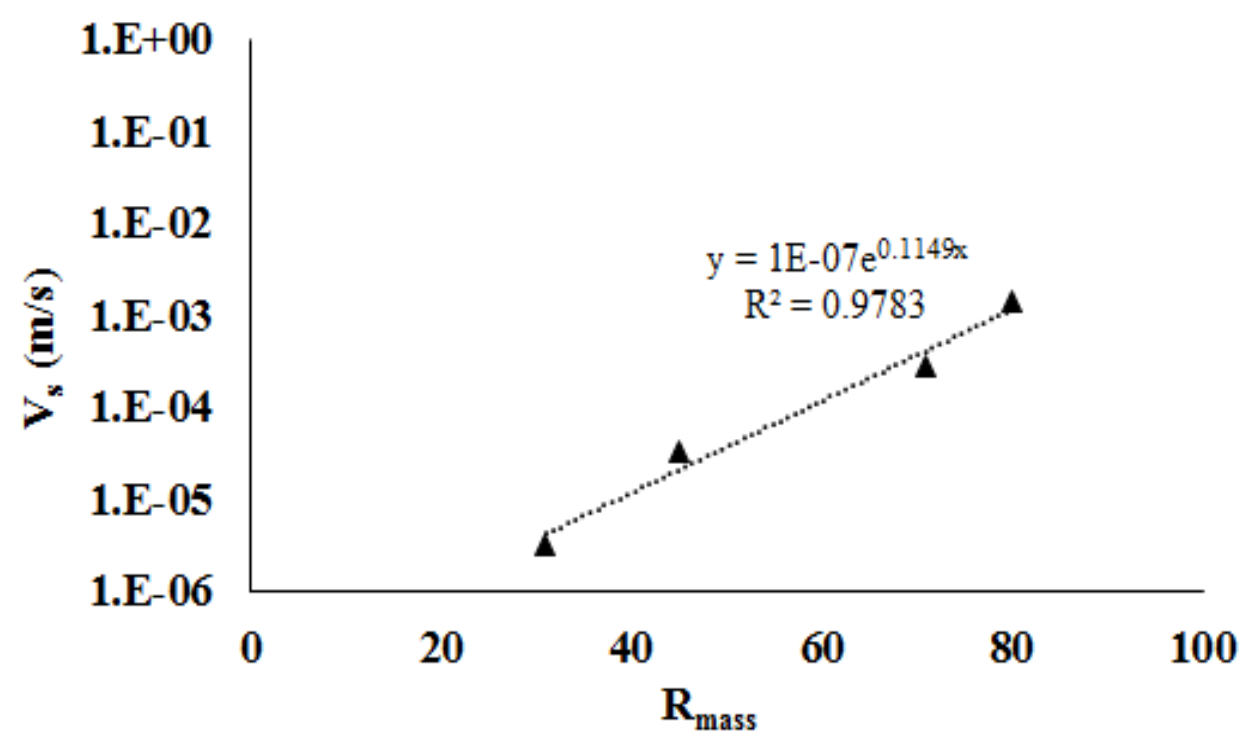

Figure 5-8. $\mathbf{R}_{\text {mass }}$ versus seepage velocity 
It was observed that $\mathrm{R}_{\text {mass }}$ decreased exponentially from $80 \%$ for column 1 with seepage velocity of $1.36 \times 10^{-3} \mathrm{~m} / \mathrm{s}$ to $31 \%$ for column 4 with seepage velocity of $3.17 \times 10^{-6} \mathrm{~m} / \mathrm{s}$. The $R_{\text {mass }}$ in column 1, and 2 were measured as $80 \%$ and $71 \%$ respectively, which had higher seepage velocity compared to column 3 , and 4 . However, $\mathrm{R}_{\text {mass }}$ decreased to $45 \%$ and $31 \%$ for column 3 , and 4 respectively. It suggested that the sorbed mass of benzene by HDTMA-bentonite needed longer breakthrough time by decreasing the permeability of the system. The acquired results suggested that the HDTMA-bentonite amended PRBs could have promising performance as permeable reactive barriers. Because they have a reasonable range of permeability between $4.07 \times 10^{-7} \mathrm{~m} / \mathrm{s}$ to $1.33 \times 10^{-4} \mathrm{~m} / \mathrm{s}$ as a permeable barrier. In addition, it was observed that the dissolved organic contaminants (benzene) required a long breakthrough time ( $\sim 787 \mathrm{~min})$ with a significantly low mass flux in column with lowest seepage velocity (column 4).

\subsection{Conclusion}

In this chapter, the transport of benzene through the fast flow rate columns at different seepage velocity was investigated. It was observed that the permeability of the packed columns decreased as the void ratio decreased. This happened because the soil grains with finer particle size occupied the pores within the soil structure and reduced the advective transport of the fluid (water) through the packed column. In addition, the barrier performance of HDTMA-bentonite and PM-199 as reactive amendment to the PRBs were explored. It was observed that the breakthrough of benzene in PM-199 amended soil columns occurred 3 pore volumes later than the HDTMA-bentonite amended columns. Also, the mass flux of benzene through the PM-199 amended 
columns was much lower than the HDTMA-bentonite amended columns. This happened because of higher affinity of benzene to PM-199 compared to HDTMA-bentonite.

It was noticed that the non-equilibrium condition was dominant in columns with high rate of seepage velocity $\left(1.36 \times 10^{-3}\right.$ to $\left.2.83 \times 10^{-4} \mathrm{~m} / \mathrm{s}\right)$. For this condition, the retardation factor was obtained from two approaches (1) kinetic study; (2) analytical solution. The results of retardation factor for non-equilibrium condition showed a good agreement between the calculated results from kinetic study and estimated result from analytical solution. This result suggested that the non-equilibrium partitioning coefficient measured from kinetic study can be employed to calculate a reliable retardation factor in nonequilibrium condition. Also, the acquired results suggested to employ the analytical solution to estimate the retardation factor for equilibrium condition.

Moreover, it was observed that the $\mathrm{R}_{\text {mass }}$ decreased by decreasing the seepage velocity of the soil column which assured the promising performance of HDTMA-amendment as reactive material in PRBs. Because not only they provide the required range of permeability for permeable barriers, but also, they decrease the mass flux of benzene which resulted in longer required breakthrough time. The overall results in this chapter suggest that HDTMA-bentonite or other organophilic clays are efficient reactive materials for PRB barriers to uptake the dissolved aromatic hydrocarbons from groundwater flow. 


\section{CHAPTER SIX SUMMARY, CONCLUSIONS, AND RECOMMENDATIONS}

Earthen barriers such as CCLs and GCLs have been employed in geotechnical practices to provide a low permeability hydraulic barrier since long time ago. These types of barriers exhibited satisfactory performance for many applications such as landfills. The performance of low permeability barriers is based on the swelling potential of their component, which is mostly Na-bentonite, in contact with polar fluids such as water. However, the acceptable range of conductivity cannot be achieved by traditional earthen barriers when they are permeated by non-polar fluids such as gasoline. This phenomenon occurs due to the incompatibility of earthen barrier constituent with non-polar compounds. Also, the traditional earthen barriers are not able to retard the contaminant transport due to their negligible reactivity with organic compounds. As a result, the application of low permeability barriers was limited to polar and non-contaminated flows. In this study, the performance of traditional earthen barriers as a hydraulic and chemical barrier was enhanced by introducing an organically modified amendment (HDTMAbentonite) to traditional earthen barrier's components.

This research studied the geotechnical behavior and field performance of an engineered organobentonite (HDTMA-bentonite) as an amendment for sorptive soil barriers. The HDTMA-bentonite was synthesized under a controlled laboratory condition and the sorptivity of HDTMA-bentonite in along with other sorbents including a commercially 
available partitioning clay (PM-199), Ca-bentonite, and Na-bentonite were investigated as a function of: sorbate properties (organic carbon content, surfactant type, grain size); sorbate properties (chlorination, aromatic ring) and the aqueous environment (temperature, co-solvent). To quantify the sorptivity of the studied sorbents, a series of equilibrium batch sorption test were conducted. The obtained results were analyzed and summarized in Table 6-1.

Table 6-1. Results for equilibrium batch sorption study

\begin{tabular}{|c|c|c|c|c|}
\hline $\begin{array}{l}\text { Studied } \\
\text { sorbents }\end{array}$ & $\begin{array}{l}\text { Studied } \\
\text { Sorbate }\end{array}$ & $\begin{array}{l}\text { Solvent } \\
\text { solution }\end{array}$ & $\begin{array}{c}\text { Function of } \\
\text { Sorbate/sorbent/ } \\
\text { aqueous } \\
\text { environment }\end{array}$ & Results \\
\hline $\begin{array}{c}\text { PM-199, } \\
\text { HDTMA- } \\
\text { bentonite, } \\
\text { Na- } \\
\text { bentonite, } \\
\mathrm{Ca}- \\
\text { bentonite }\end{array}$ & benzene & DI water & TOC & $\begin{array}{l}\text { The natural or intercalated } \\
\text { organic carbons on the surface or } \\
\text { interlayer of unmodified } \\
\text { soil/organobentonite increase the } \\
\text { organophilicity of the sorbents. } \\
\text { As a result, } \\
\text { the sorptivity increased by } \\
\text { increasing the organic carbon } \\
\text { content. Organobentonites } \\
\text { exhibited much higher sorptivity } \\
\text { to organic contaminants } \\
\text { compared to unmodified soils. }\end{array}$ \\
\hline $\begin{array}{l}\text { PM-199, } \\
\text { HDTMA- } \\
\text { bentonite }\end{array}$ & Benzene & $\begin{array}{c}30 \% \\
\text { acetone + } \\
70 \% \text { DI } \\
\text { water }\end{array}$ & Surfactant type & $\begin{array}{l}\text { Sorptivity of PM-199 is higher } \\
\text { than HDTMA-bentonite. The } \\
\text { intercalated surfactant in PM- } \\
199 \text { is a double chain surfactant. } \\
\text { Consequently, PM-199 has } \\
\text { higher aliphatic carbon compare } \\
\text { to the HDTMA-bentonite which } \\
\text { has a single chain intercalated } \\
\text { surfactant }\end{array}$ \\
\hline $\begin{array}{l}\text { PM-199 } \\
\text { (powder), }\end{array}$ & Benzene & DI water & Particle size & No significant differences were \\
\hline
\end{tabular}




\begin{tabular}{|c|c|c|c|c|}
\hline $\begin{array}{l}\text { PM-199 } \\
\text { (granular) }\end{array}$ & & & & observed \\
\hline $\begin{array}{l}\text { HDTMA- } \\
\text { bentonite }\end{array}$ & $\begin{array}{c}\text { Benzene, } \\
\text { 1,2,4- } \\
\text { trichlorob } \\
\text { enzene, } \\
\text { HCB }\end{array}$ & acetone & chlorination & $\begin{array}{l}\text { The solubility of organic } \\
\text { compounds decreased by } \\
\text { increasing the chlorinated } \\
\text { positions on the aromatic ring. } \\
\text { As a result, organophilicity of } \\
\text { the organic contaminants } \\
\text { increased as chlorination } \\
\text { increased. The affinity of } \\
\text { organic contaminants toward the } \\
\text { organic phase of sorbents } \\
\text { increased which resulted in } \\
\text { higher partitioning to HDTMA- } \\
\text { bentonite (hexachlorobenzene }>1 \text {, } \\
2,4 \text {-trichlorobenzene } \\
>\text { benzene). }\end{array}$ \\
\hline $\begin{array}{l}\text { HDTMA- } \\
\text { bentonite }\end{array}$ & $\begin{array}{l}\text { Benzene, } \\
\text { naphthale } \\
\text { ne, } \\
\text { phenanth } \\
\text { rene }\end{array}$ & acetone & aromatic ring & $\begin{array}{l}\text { The solubility of organic } \\
\text { compounds decreased by } \\
\text { increasing the aromatic ring. As } \\
\text { a result, organophilicity of the } \\
\text { organic contaminants increased } \\
\text { as the number of aromatic rings } \\
\text { increased. The affinity of } \\
\text { organic contaminants toward the } \\
\text { organic phase of sorbents } \\
\text { increased which resulted in } \\
\text { higher partitioning to HDTMA- } \\
\text { bentonite } \\
\text { (phenanthrene }>\text { naphthalene }>\text { ben } \\
\text { zene) }\end{array}$ \\
\hline \multirow[t]{2}{*}{$\begin{array}{l}\text { HDTMA- } \\
\text { bentonite }\end{array}$} & benzene & $\begin{array}{c}\text { DI water, } \\
\text { acetone, } \\
30 \% \\
\text { acetone }+ \\
70 \% \text { water }\end{array}$ & \multirow[t]{2}{*}{ Co-solvent } & \multirow{2}{*}{$\begin{array}{l}\text { The sorption capacity decreased } \\
\text { as the co-solvent percentage } \\
\text { increased. Cosolvency of co- } \\
\text { solvent increased the solubility } \\
\text { and decreased the sorption } \\
\text { capacity of hydrophobic organic } \\
\text { contaminants. }\end{array}$} \\
\hline & $\begin{array}{c}\text { naphthale } \\
\text { ne }\end{array}$ & $\begin{array}{c}\text { acetone, } \\
30 \% \\
\text { acetone }+ \\
70 \% \text { water }\end{array}$ & & \\
\hline
\end{tabular}




\begin{tabular}{|c|c|c|c|c|}
\hline $\begin{array}{c}\text { HDTMA- } \\
\text { bentonite }\end{array}$ & benzene & DI water & $\begin{array}{c}\text { Temperature }(10, \\
\left.25,40,60^{\circ} \mathrm{C}\right)\end{array}$ & $\begin{array}{c}\text { The sorptivity of HDTMA- } \\
\text { bentonite to }\end{array}$ \\
\hline
\end{tabular}

The hydraulic performance, and transport of naphthalene as a representative of NAPL was studied through the compacted soil column which consisted of 5\% HDTMAbentonite and $95 \%$ silty clay. The obtained results showed that a small percentage of HDTMA-bentonite $(<10 \%)$ does not affect the swelling tendency of the silty clay in water while it leads to significant swelling of the HDTMA-bentonite amended silty clay in gasoline. The significant swelling of HDTMA-bentonite in gasoline can be explained as the high interaction of organophilic surfactants in the HDTMA bentonite and nonpolar liquid. On the other hand, a small percentage of HDTMA-bentonite $(<10 \%)$ amendment in compacted silty clay slightly increased the permeability of column to water while it decreased the permeability of column to gasoline significantly. In addition, it was observed that only 5\% HDTMA bentonite amendment enhanced the retardation capacity of the system while it had no significant effect on the permeability of the compacted silty clay. The obtained results suggested that a small percentage of HDTMAbentonite can reduce the mass flux of contaminant by $90 \%$ which suggested that HDTMA-bentonite has a promising performance as reactive material for Compacted liner barrier for organic and/or low polarity fluids.

Additionally, the feasibility of using HDTMA-bentonite as a reactive amendment for GCL liners were investigated. The swelling behavior of Na-bentonite as the major component of GCL, CA-bentonite, HDTMA-bentonite, PM-199, soil admixtures including 10\%/20\% HDTMA-bentonite + Na-bentonite, and 10\%/20\% PM-199 + Nabentonite were studied as a function of: polarity, ion strength, acidic/basic environment. 
It was observed that Na-bentonite had the maximum swelling in water due to the strong hydration of $\mathrm{Na}^{+}$with polar liquids. In addition, Ca-bentonite exhibited a medium swelling in contact with water due to weaker hydration of $\mathrm{Ca}^{2+}$ compared to $\mathrm{Na}^{+}$with polar liquids. In contrast, it was observed that organobentonites did not show any significant swelling in polar liquid (water) due to their hydrophobic characteristics. Consequently, the swelling of soil admixtures decreased by increasing the percentage of organobentonite.

Unmodified bentonite showed a negligible swelling tendency in low polarity liquids such as methanol and gasoline (Gheibi et al. 2016). The acquired result suggested that $\mathrm{Ca}^{2+}$ and $\mathrm{Na}^{+}$did not hydrate in low polarity liquids due to the incompatibility of unmodified bentonites with low polarity liquids. In contrast, organobentonites swelled significantly as the polarity of the liquid decreased (Khabiri et al. 2016). Consequently, the swelling of soil admixtures increased by increasing the percentage of organobentonite.

It was also observed that the solution with low ionic concentration $(0.01 \mathrm{M} \mathrm{NaCl})$ and $\mathrm{pH}$ level in the range of 4 to 10 did not affect the swelling tendency of studied soils and soil admixtures. However, the swelling tendency of unmodified bentonites decreased drastically by increasing the concentration of ionic strength due to the drag force of ions which pull the water molecules out of clay interlayer.

The study on the permeability of GCLs revealed that Na-bentonite GCLs demonstrated lower permeability to polar liquids compared to Ca-bentonite GCLs. Also, the permeability of GCL specimens to polar liquids increased slightly by increasing the percentage of HDTMA-bentonite in the GCL soil. However, the obtained results suggested that the permeability of Na-bentonite and Ca-bentonite increased significantly 
when permeated by low polarity liquids such as methanol and gasoline. It was because of the chemical incompatibility of unmodified bentonites with low polarity liquids. In contrast, the chemical compatibility of GCL soils with low polarity liquids enhanced by increasing the percentage of HDTMA-bentonite to the GCL soils.

The permeability of Na-bentonite GCL with different percentage of PM-199 and HDTMA-bentonite to polar (water) and non-polar (gasoline) liquids were also studied (Gheibi and Bagheripour 2010; Gheibi and Bagheripour 2011; Gheibi and Bagheripour 2011; Gheibi et al. 2011). It was observed that the minimum permeability of the GCL when is permeated by both liquids can be obtained by adding $28 \%$ of PM-199 to the Nabentonite GCL soil. Also, the permeability of the GCL specimens decreased by increasing the confining stress due to confinement of existing pores within GCL soil.

The transport of benzene as a representative of BTEX through the GCL specimens which consisted of $(0,10,20 \%)$ HDTMA-bentonite + Na-bentonite and $(0,10,20 \%)$ HDTMAbentonite + Ca-bentonite were also studied. The column tests were performed to obtain the breakthrough curve for benzene transport. It was observed that $20 \%$ HDTMAbentonite amended GCL decreased the mass flux of benzene by half compared to unmodified GCL specimens while its effect on the permeability of the unmodified GCL specomens was insignificant (Gheibi and Gassman 2014; Gheibi and Gassman 2014; Gheibi et al. 2014). Due to the retardation mechanism, $100 \%$ of introduced mass was not received in effluent and a long breakthrough time was required for the sorbed benzene (Gheibi and Gassman 2015). As a result, an analytical and numerical approach was employed to estimate the retardation factor and diffusion coefficient of benzene transport through the column because the retardation factor obtained from the experimental data 
did not account for $100 \%$ of benzene mass. The acquired results suggested that Nabentonite with a small percentage of HDTMA-bentonite $(20 \%)$ can enhance the retardation factor and chemical compatibility of the GCL liners under a low advective flow condition.

Finally, two soil columns with of $10 \%$ of organobentonites (HDTMA-bentonite and PM199) with different seepage velocities were prepared to investigate the potentials of using organobentonites as reactive amendment in PRB materials. The results of permeability experiments suggested that the seepage velocity decreased by decreasing the void ratio. This happened because the soil grains with finer particle size occupied the pores within the soil structure and reduced the advective transport of the fluid (water) through the packed column. Also, the peak mass flux of benzene through the PM-199 amended columns was much lower than the HDTMA-bentonite amended columns. It was observed that the partitioning of benzene onto HDTMA-bentonite in columns with fast seepage velocity did not reach equilibrium condition (Gheibi and Gassman 2016; Gheibi et al. 2017). To obtain the transport parameters of benzene under non-equilibrium condition, two approaches including kinetic study and analytical solutions were employed. The results of retardation factor for non-equilibrium condition showed a good agreement between the calculated results from kinetic study and estimated result from analytical solution (Niaki and Jahani 2012; Niaki and Jahani 2013). This result suggested that the non-equilibrium partitioning coefficient measured from kinetic study can be employed to calculate a reliable retardation factor in non-equilibrium condition. In addition, the obtained results suggested that the retardation capacity of the PRBs increased by decreasing the seepage velocity. The overall results suggested that HDTMA-bentonite 
can serve as an efficient reactive material in PRBs which not only increased the retardation capacity of the fast flow rate columns, but also did not affect the seepage velocity of the system with fast seepage velocity.

This obtained results from this study showed the promising application of organoclays as an amendment for CCL and GCL barriers (Ebrahimi et al. 2017; Ebrahimi et al. 2016; Ebrahimi et al. 2016; Mirbagheri et al. 2014). Also, it was concluded that organoclays are sufficient sorbents to uptake the dissolved contaminants in the fast flow rate barriers such as PRBs. There are several areas or directions of future study, which we could further enhance the work presented in this dissertation.

1. Feasibility of using organoclays as a sorbent of common runoff contaminants for permeable pavement (PP) systems.

2. Feasibility of using organoclays as a sorbent of common runoff contaminants for permeable pavement (PP) systems.

3. Feasibility of using organoclays as a sorbent of common runoff contaminants for permeable pavement (PP) systems.

4. Feasibility of using organoclays as a sorbent of common runoff contaminants for permeable pavement (PP) systems. 


\section{REFERENCES}

Acar, Y. B., and Haider, L. (1990). "Transport of Low-Concentration Contaminants in Saturated Earthen Barriers." J Geotech Eng-Asce, 116(7), 1031-1052.

Ahn, H. S., and Jo, H. Y. (2009). "Influence of exchangeable cations on hydraulic conductivity of compacted bentonite." Appl Clay Sci, 44(1-2), 144-150.

Alexandre, M., and Dubois, P. (2000). "Polymer-layered silicate nanocomposites: preparation, properties and uses of a new class of materials." Mat Sci Eng R, 28(12), 1-63.

ASTMD854-14 (2014). "Standard Test Methods for Specific Gravity of Soil Solids by Water Pycnometer."ASTM International, West Conshohocken, PA.

ASTMD4318-10e1 (2010). "Standard Test Methods for Liquid Limit, Plastic Limit, and Plasticity Index of Soils." ASTM D4318-10e1West Conshohocken, PA.

ASTMD6913-04 (2009). "Standard Test Methods for Particle-Size Distribution (Gradation) of Soils Using Sieve Analysis."ASTM International, West Conshohocken, PA.

ASTMD7348-13 (2013). "Standard Test Methods for Loss on Ignition (LOI) of Solid Combustion Residues."ASTM International, West Conshohocken, PA.

Australia., U. o. N. (2012). "Georemediation." <http://www.newcastle.edu.au/researchcentre $/ \mathrm{cgmm} / \mathrm{research} /$ georemediation.html $>$.

Ayral-Cinar, D., Otero-Diaz, M., and Demond, A. H. (2016). "A mechanism of basal spacing reduction in sodium smectitic clay materials in contact with DNAPL wastes." Chemosphere, 159, 577-583.

Bagchi, A. (2004). Design of landfills and integrated solid waste management., John Wiley and Sons Inc., New Jersey.

Bartelt-Hunt, S. L., Burns, S. E., and Smith, J. A. (2003). "Nonionic organic solute sorption onto two organobentonites as a function of organic-carbon content." Journal of Colloid and Interface Science, 266(2), 251-258.

Bate, B. (2010). "Engineering behavior of fine-grained soils modified with a controlled organic phase." Ph.D. Dissertation, Georgia Institute of Technology.

Bate, B., Zhao, Q., and Burns, S. E. (2014). "Impact of Organic Coatings on Frictional Strength of Organically Modified Clay." J Geotech Geoenviron, 140(1), 228-236.

Benson, C. H., Ho Young, J., and Musso, T. (2015). "Hydraulic Conductivity of Organoclay and Organoclay-Sand Mixtures to Fuels and Organic Liquids." $J$ Geotech Geoenviron, 141(2), 04014094 (04014011 pp.).

Benson, C. H., Zhai, H., and Wang, X. (1994). "Estimating Hydraulic Conductivity of Compacted Clay Liners." Journal of Geotechnical Engineering, 120(2), 366-387.

Bouazza, A. "Performance of geosynthetic clay liners." Proc., Proceedings of the First ANZ Conference on Environmental Geotechnics, 307-313. 
Bouazza, A. (2002). "Geosynthetic clay liners." Geotextiles and Geomembranes, 20, 317.

Bouazza, A. (2002). "Geosynthetic clay liners." Geotextiles and Geomembranes, 20(1), 3-17.

Bowders, J. J., and Daniel, D. E. (1987). "Hydraulic Conductivity of Compacted Clay to Dilute Organic-Chemicals." J Geotech Eng-Asce, 113(12), 1432-1448.

Bowman, R. B. (1999). "pilot-scale testing of a surfactant-modified zeolite PRB." EPA Ground Water Currents, 3-4.

Boyd, S. A., Mortland, M. M., and Chiou, C. T. (1988). "Sorption Characteristics of Organic-Compounds on Hexadecyltrimethylammonium-Smectite." Soil Sci Soc Am J, 52(3), 652-657.

Boyd, S. A., Mortland, M. M., and Chiou, C. T. (1988). "Sorption Characteristics of Organic Compounds on Hexadecyltrimethylammoniun-Smectite." Soil Science Society American Journal, 652-657.

Boynton, S. S., and Daniel, D. E. (1985). "Hydraulic Conductivity Tests on Compacted Clay." J Geotech Eng-Asce, 111(4), 465-478.

Bradshaw, S. L., Benson, C. H., and Rauen, T. L. (2016). "Hydraulic Conductivity of Geosynthetic Clay Liners to Recirculated Municipal Solid Waste Leachates." $J$ Geotech Geoenviron, 142(2).

Bright, M. I., Thornton, S. F., Lerner, D. N., and Tellam, J. H. (2000). "Attenuation of landfill leachate by clay liner materials in laboratory columns, 1. Experimental procedures and behaviour of organic contaminants." Waste Manage Res, 18(3), 198-214.

Broderick, G. P., and Daniel, D. E. (1990). "Stabilizing Compacted Clay against Chemical Attack." J Geotech Eng-Asce, 116(10), 1549-1567.

Brown, K. W., Green, J. W., and Thomas, J. C. "The influence of selected organic liquids on the permeability of clay liners." Proc., 9th Annu. Res. Symp. on Land Disposal of Hazardous Waste,.

Brown, K. W., Thomas, J. C., and Green, J. W. "Permeability of compacted soils to solvents mixtures and petroleum products." Proc., 10th Annu. Res. Symp. on Land Disposal of Hazardous Waste.

Brown, M. J., and Burris, D. R. (1996). "Enhanced Organic Contaminant Sorption on Soil Treated with Cationic Surfactants." Ground Water, 34(4), 734-744.

Burns, S. E., Bartelt-Hunt, S. L., Smith, J. A., and Redding, A. Z. (2006). "Coupled mechanical and chemical behavior of bentonite engineered with a controlled organic phase." J Geotech Geoenviron, 132(11), 1404-1412.

Caenn, R., Darley, H. C. H., and Gray, G. R. (2011). Composition and Properties of Drilling Fluids and Completion Fluids, Gulf Professional Publishing.

Carey, M. A., Fretwell, B. A., Mosley, N. G., and Smith, J. W. N. (2002). "Guidance on the Use of Permeable Reactive Barriers for Remediating Contaminated Groundwater.", National Groundwater and Contaminated Land Centre. UK Environment Agency, Bristol, 140.

CETCO (2014). "BENTOMAT 200R." $<$ http://www.cetco.com/DesktopModules/Bring2mind/DMX/Download.aspx?Co mmand $=$ Core Download\&PortalId $=0 \&$ EntryId $=167>$. 
Changchaivong, S., and Khaodhiar, S. (2009). "Adsorption of naphthalene and phenanthrene on dodecylpyridinium-modified bentonite." Appl Clay Sci, 43(3-4), 317-321.

Chapuis, R. P. (1990). "Sand-Bentonite Liners - Predicting Permeability from Laboratory Tests." Canadian Geotechnical Journal, 27(1), 47-57.

Chen, G., Qiao, M. Q., Zhang, H. Y., and Zhu, H. L. (2005). "Sorption and transport of naphthalene and phenanthrene in silica sand in the presence of rhamnolipid biosurfactant." Separ Sci Technol, 40(12), 2411-2425.

Chen, Y., Li, J., Lei, C., and Shim, H. (2011). "Interactions Between BTEX, TPH, and TCE During Their bio-removal from the Artificially Contaminated Water." BIONATURE 2011: The Second International Conference on Bioenvironment, Biodiversity and Renewable Energies.

Chiou, C. T. (1998). "Soil sorption of organic pollutants and pesticides." Encyclopedia of environmental analysis and remediation, Wiley, New York, 4517-4554.

Chiou, C. T., McGroddy, S. E., and Kile, D. E. (1998). "Partition characteristics of polycyclic aromatic hydrocarbons on soils and sediments." Environmental Science \& Technology, 32(2), 264-269.

Chiou, C. T., Peters, L. J., and Freed, V. H. (1979). "A physical concept of soil-water equilibria for nonionic organic compounds." Science, 206(4420), 831-832.

Chiou, C. T., Porter, P. E., and Schmedding, D. W. (1983). "Partition Equilibria of NonIonic Organic-Compounds between Soil Organic-Matter and Water." Environmental Science \& Technology, 17(4), 227-231.

Chiou, C. T., Schmedding, D. W., and Manes, M. (1982). "Partitioning of OrganicCompounds in Octanol-Water Systems." Environmental Science \& Technology, 16(1), 4-10.

Crocker, F. H., Guerin, W. F., and Boyd, S. A. (1995). "Bioavailability of naphthalene sorbed to cationic surfactant-modified smectite clay." Environ Sci Technol, 29(12), 2953-2958.

Crooks, V. E., and Quigley, R. M. (1984). "Saline Leachate Migration through Clay - a Comparative Laboratory and Field Investigation." Canadian Geotechnical Journal, 21(2), 349-362.

D422, A. (2012). "Standard Test Method for Particle-Size Analysis of Soils."

D854, A. (2012). "Standard Test Methods for Specific Gravity of Soil Solids by Water Pycnometer."

D2434, A. (2014). "Standard Test Method for Permeability of Granular Soils (Constant Head) ".

D4318-05, A. (2010). "Standard Test Method for Liquid Limit, Plastic Limit, and Plasticity Index of Soils."

D4546, A. (2014). "Standard Test Methods for One-Dimensional Swell or Collapse of Soils."

D5084, A. (2016). "Standard Test Methods for Measurement of Hydraulic Conductivity of Saturated Porous Materials Using a Flexible Wall Permeameter."

D5890-11, A. (2013). "Standard Test Methods for Swell Index of Clay Mineral Component of Geosynthetic Clay Liners."

D5891, A. (2010). "Standard Test Method for Fluid Loss of Clay Component of Geosynthetic Clay Liners." 
D5993, A. (2010). "Standard Test Method for Measuring Mass Per Unit of Geosynthetic Clay Liners."

D6243, A. (2010). "Standard Test Method for Determining the Internal and Interface Shear Strength of Geosynthetic Clay Liner by the Direct Shear Method."

D6496, A. (2010). "Standard Test Method for Determining Average Bonding Peel Strength Between Top and Bottom Layers of Needle-Punched Geosynthetic Clay Liners."

D6766, A. (2010). "Standard Test Method for Evaluation of Hydraulic Properties of Geosynthetic Clay Liners Permeated with Potentially Incompatible Aqueous Solutions."

D6768, A. (2010). "Standard Test Method for Tensile Strength of Geosynthetic Clay Liners."

Daniel, D., Shan, H., and Anderson, J. "Effects of partial wetting on the performance of the bentonite component of a geosynthetic clay liner." Proc., Geosynthetics '93 Conference, 1483-1496.

Daniel, D. E. (1993). Geotechnical Practice for Waste Disposal, Chapman \& Hall, London.

Daniel, D. E., and Benson, C. H. (1990). "Water-Content Density Criteria for Compacted Soil Liners." J Geotech Eng-Asce, 116(12), 1811-1830.

de Paiva, L. B., Morales, A. R., and Diaz, F. R. V. (2008). "Organoclays: Properties, preparation and applications." Appl Clay Sci, 42(1-2), 8-24.

Di Cesare, D., and Smith, J. A. (1994). "Surfactant Effects on Desorption Rate of Nonionic Organic Compounds from Soils to Water." 134, 1-29.

DOE-sites (1999). "Gasoline Ground on pump and treat." $<$ http://infohouse.p2ric.org/ref/14/13983.htm>.

Doh, J. G., and Cho, I. (1998). "Synthesis and properties of polystyrene organoammonium montmorillonite hybrid." Polym Bull, 41(5), 511-518.

Ebrahimi, M., Gerber, E. L., and Rockaway, T. D. (2017). "Temporal performance assessment of wastewater treatment plants by using multivariate statistical analysis." J Environ Manage, 193, 234-246.

Ebrahimi, M., Kazemi, H., Ehtashemi, M., and Rockaway, T. D. (2016). "Assessment of groundwater quantity and quality and saltwater intrusion in the Damghan basin, Iran." Chem Erde-Geochem, 76(2), 227-241.

Ebrahimi, M., Kazemi, H., Mirbagheri, S. A., and Rockaway, T. D. (2016). "An optimized biological approach for treatment of petroleum refinery wastewater." $J$ Environ Chem Eng, 4(3), 3401-3408.

Egloffstein, T. A. (2001). "Natural bentonites - influence of the ion exchange and partial desiccation on permeability and self-healing capacity of bentonites used in GCLs." Geotextiles and Geomembranes, 19(7), 427-444.

Esfandiari, A., Nazokdast, H., Rashidi, A. S., and Yazdanshenas, M. E. (2008). "Reviewe of Polymer-Organoclay Nanocomposites." Journal of Applied science, 8(3).

Fernandez, F., and Quigley, R. M. (1985). "Hydraulic Conductivity of Natural Clays Permeated with Simple Liquid Hydrocarbons." Canadian Geotechnical Journal, 22(2), 205-214.

Francisca, F. M., and Glatstein, D. A. (2010). "Long term hydraulic conductivity of compacted soils permeated with landfill leachate." Appl Clay Sci, 49(3), 187-193. 
Freeze, R. A., and Cherry, J. A. (1979). Groundwater, Englewood Cliffs, N.J. : PrenticeHall.

Fu, J. K., and Luthy, R. G. (1986). "Effect of Organic-Solvent on Sorption of Aromatic Solutes onto Soils." J Environ Eng-Asce, 112(2), 346-366.

Gates, W. P., Bouazza, A., and Churchman, G. J. (2009). "Bentonite Clay Keeps Pollutants at Bay." Elements, 5(2), 105-110.

Gates, W. P., Nefiodovas, A., and Peter, P. (2004). "Permeability of an organo-modified bentonite to ethanol-water solutions." Clay Clay Miner, 52(2), 192-203.

Gavaskar, A., Gupta, N., Sass, B., Janosy, R., and Hicks, J. (2000). "Design Guidance for Application of Permeable Reactive Barriers for Groundwater Remediation." Air Force Research Laboratory, Tyndall Air Force Base, Florida, Columbus, OH, 157.

Ghavami, M., Javadi, S., and Zhao, Q. (2016). "Laboratory Characterization of the Saturated Conductivities of Compacted Clay-Organobentonite Mixtures." 458467.

Gheibi, E., and Bagheripour, M. H. "Evaluation of the equivalent number of cycles in liquefaction potential study using energy approach." Proc., 4th International Conference on Geotechnical Engineering and soil Mechanics.

Gheibi, E., and Bagheripour, M. H. "Alterations of equivalent number of cycles in depth of soil profile." Proc., 6th International Conference of Seismology and Earthquake Engineering (SEE6).

Gheibi, E., and Bagheripour, M. H. (2011). "Effect of Parameters on Equivalent Number of Cycles Using Nonlinear Seismic Site Response Analysis." Advanced Materials Research, 255-260, 2365-2369.

Gheibi, E., Bagheripour, M. H., and Gheibi, A. "Soil liquefaction potential assessment using nonlinear site response analysis." Proc., 6th International Conference of Seismology and Earthquake Engineering (SEE6).

Gheibi, E., and Gassman, S. L. "Back analysis of prehistoric earthquake accelerations at the Hollywood site in the South Carolina Coastal Plain." Proc., Proc., 86th annual meeting of the Eastern Section of the Seismological Society of America, Seismological Society of America.

Gheibi, E., and Gassman, S. L. "Reassessment of prehistoric earthquake accelerations at Sampit and Gapway sites in the South Carolina Coastal Plain." Proc., 10NCEE.

Gheibi, E., and Gassman, S. L. (2015). "Magnitudes of Prehistoric Earthquakes at the Hollywood, South Carolina, Site." 1246-1256.

Gheibi, E., and Gassman, S. L. (2016). "Application of GMPEs to estimate the minimum magnitude and peak ground acceleration of prehistoric earthquakes at Hollywood, SC." Eng Geol, 214, 60-66.

Gheibi, E., Gassman, S. L., Hasek, M., and Talwani, P. (2017). "Assessment of paleoseismic shaking that caused sand blow at Fort Dorchester, SC." Bulletin of Earthquake Engineering.

Gheibi, E., Gassman, S. L., and Tavakoli, A. "Using regression model to predict cyclic resistance ratio at South Carolina Coastal Plain (SCCP)." Proc., 22nd Annual Southeast SAS Users Group Conference (SESUG 2014).

Gheibi, E., Sasanakul, I., Sanin, M., and Puebla, H. (2016). "Effect of temperatures on the dynamic properties of asphaltic core for an earth dam." Geo-Chicago 2016. 
Giannelis, E. P., Krishnamoorti, R., and Manias, E. (1999). "Polymer-silicate nanocomposites: Model systems for confined polymers and polymer brushes." Adv Polym Sci, 138, 107-147.

Graber, E. R., and Mingelgrin, U. (1994). "Clay swelling and regular solution theory." Environ Sci Technol, 28(13), 2360-2365.

Guerin, T. F., Horner, S., McGovern, T., and Davey, B. (2002). "An application of permeable reactive barrier technology to petroleum hydrocarbon contaminated groundwater." Water Res, 36(1), 15-24.

He, H. P., Galy, J., and Gerard, J. F. (2005). "Molecular simulation of the interlayer structure and the mobility of alkyl chains in $\operatorname{HDTMA}(+) /$ montmorillonite hybrids." J Phys Chem B, 109(27), 13301-13306.

Headley, J. V., Boldt-Leppin, B. E. J., Haug, M. D., and Peng, J. M. (2001). "Determination of diffusion and adsorption coefficients for volatile organics in an organophilic clay-sand-bentonite liner." Canadian Geotechnical Journal, 38(4), 809-817.

Henderson, A. D., and Demond, A. H. (2007). "Long-term performance of zero-valent iron permeable reactive barriers: A critical review." Environ Eng Sci, 24(4), 401423.

Ho, Y. S. (2006). "Isotherms for the sorption of lead onto peat: Comparison of linear and non-linear methods." Pol J Environ Stud, 15(1), 81-86.

Javadi, S., Ghavami, M., Zhao, Q., and Bate, B. (2016). "Advection and retardation of non-polar contaminants in compacted clay barrier material with organoclay amendment." Appl Clay Sci.

Jaynes, W. F., and Boyd, S. A. (1990). "Trimethylphenylammonium-Smectite as an Effective Adsorbent of Water-Soluble Aromatic-Hydrocarbons." J Air Waste Manage, 40(12), 1649-1653.

Jaynes, W. F., and Boyd, S. A. (1991). "Clay Mineral Type and Organic-Compound Sorption by Hexadecyltrimethlyammonium-Exchanged Clays." Soil Sci Soc Am J, 55(1), 43-48.

Jo, H. Y., Katsumi, T., Benson, C. H., and Edil, T. B. (2001). "Hydraulic conductivity and swelling of nonprehydrated GCLs permeated with single-species salt solutions." J Geotech Geoenviron, 127(7), 557-567.

Kalkan, E. (2006). "Utilization of red mud as a stabilization material for the preparation of clay liners." Eng Geol, 87(3-4), 220-229.

Kalkan, E., and Akbulut, S. (2004). "The positive effects of silica fume on the permeability, swelling pressure and compressive strength of natural clay liners." Eng Geol, 73(1-2), 145-156.

Kandhal, P. S., and Parker, F. (1998). Aggregate tests related to asphalt concrete performance in pavements, Transportation Research Board.

Khabiri, M. M., Khishdari, A., and Gheibi, E. (2016). "Effect of tyre powder penetration on stress and stability of the road embankments." Road Materials and Pavement Design, 18(4), 966-979.

Komine, H. (2010). "Predicting hydraulic conductivity of sand-bentonite mixture backfill before and after swelling deformation for underground disposal of radioactive wastes." Eng Geol, 114(3-4), 123-134. 
Lagaly, G. (1986). "Interaction of alkylamines with different types of layered compounds." Solid State Ionics, 22(1), 43-51.

LaGrega, M. D., Buckingham, P. L., and Evans, J. C. (1994). Hazardous Waste Management, McGraw-Hill, New York.

Lai, K. C. K., and Lo, I. M. C. (2006). "Removals of Chlorinated Aliphatic Hydrocarbons by Fe0: Full-scale PRB vs Column Study." 9-34.

Lai, K. C. K., Lo, I. M. C., and Kjeldsen, P. (2006). "Hydraulic Studies of Zero-Valent Iron in Permeable Reactive Barriers Using Tracer Experiment." 309-335.

Lake, C. B., and Rowe, R. K. (2004). "Volatile organic compound diffusion and sorption coefficients for a needle-punched GCL." Geosynth Int, 11(4), 257-272.

Lan, T., Kaviratna, P. D., and Pinnavaia, T. J. (1995). "Mechanism of Clay Tactoid Exfoliation in Epoxy-Clay Nanocomposites." Chem Mater, 7(11), 2144-2150.

Larsen, T., Christensen, T. H., and Brusseau, M. (1992). "Predicting Nonequilibrium Transport of Naphthalene through Aquifer Materials Using Batch Determined Sorption Parameters." Chemosphere, 24(2), 141-153.

Lee, J. F., Crum, J. R., and Boyd, S. A. (1989). "Enhanced retention of organic contaminants by soils exchanged with organic cations." Environmental Science \& Technology, 23(11), 1365-1372.

Lee, S., Ören, A. H., Benson, C. H., and Dovantzis, K. (2012). "Organoclays as Variably Permeable Reactive Barrier Media to Manage NAPLs in Ground Water." $J$ Geotech Geoenviron, 138(2), 115-127.

Lee, S. M., and Tiwari, D. (2012). "Organo and inorgano-organo-modified clays in the remediation of aqueous solutions: An overview." Appl Clay Sci, 59-60, 84-102.

Li, J., Smith, J. A., and Winquist, A. S. (1996). "Permeability of earthen liners containing organobentonite to water and two organic liquids." Environmental Science \& Technology, 30(10), 3089-3093.

Li, Z. H., Alessi, D., Zhang, P. F., and Bowman, R. S. (2002). "Organo-illite as a low permeability sorbent to retard migration of anionic contaminants." J Environ EngAsce, 128(7), 583-587.

Liao, D. X., Zheng, W., Li, X. M., Yang, Q., Yue, X., Guo, L., and Zeng, G. M. (2010). "Removal of lead(II) from aqueous solutions using carbonate hydroxyapatite extracted from eggshell waste." Journal of Hazardous Materials, 177(1-3), 126130.

Liu, K. H., Enfield, C. G., and Mravik, S. C. (1991). "Evaluation of sorption odels in the simulation of naphthalene transport through saturated soils." U.S. Environmental Protection Agency, Washington, D.C.

Lo, I. M., and Yang, X. (2001). "Laboratory investigation of the migration of hydrocarbons in organobentonite." Environ Sci Technol, 35(3), 620-625.

Lo, I. M. C. (2001). "Organoclay with soil-bentonite admixture as waste containment barriers." J Environ Eng-Asce, 127(8), 756-759.

Lo, I. M. C., and Liljestrand, H. M. (1996). "Laboratory sorption and hydraulic conductivity tests: Evaluation of modified-clay materials." Waste Manage Res, 14(3), 297-310.

Lo, I. M. C., and Mak, R. K. M. (1998). "Transport of phenolic compounds through a compacted organoclay liner." Water Science and Technology, 38(2), 143-150. 
Lo, I. M. C., Mak, R. K. M., and Lee, S. C. H. (1997). "Modified clays for waste containment and pollutant attenuation." J Environ Eng-Asce, 123(1), 25-32.

Lo, I. M. C., and Yang, X. Y. (2001). "Use of organoclay as secondary containment for gasoline storage tanks." J Environ Eng-Asce, 127(2), 154-161.

Lorenzetti, R., Bartelt-Hunt, S., Burns, S., and Smith, J (2005). "Hydraulic Conductivities and Effective Diffusion Coefficients of Geosynthetic Clay Liners with Organobentonite Amendments." Geotextiles and Geomembranes, 23, 385-400.

Lorenzetti, R. J., Bartelt-Hunt, S. L., Burns, S. E., and Smith, J. A. (2005). "Hydraulic conductivities and effective diffusion coefficients of geosynthetic clay liners with organobentonite amendments." Geotextiles and Geomembranes, 23(5), 385-400.

Ma, J., Nossa, C. W., and Alvarez, P. J. (2015). "Groundwater ecosystem resilience to organic contaminations: microbial and geochemical dynamics throughout the 5year life cycle of a surrogate ethanol blend fuel plume." Water Res, 80, 119-129.

McBride, M. B. (1994). Environmental Chemistry of Soils, Oxford University Press.

Mesri, G., and Olson, R. (1971). "Mechanisms controlling the permeability of clays." Clay Clay Miner, 18, 151-158.

Mirbagheri, S. A., Ebrahimi, M., and Mohammadi, M. (2014). "Optimization method for the treatment of Tehran petroleum refinery wastewater using activated sludge contact stabilization process." Desalin Water Treat, 52(1-3), 156-163.

Mirmohamadsadeghi, S., Kaghazchi, T., Soleimani, M., and Asasian, N. (2012). "An efficient method for clay modification and its application for phenol removal from wastewater." Appl Clay Sci, 59-60, 8-12.

Montgomery, D., Sollars, C., Perry, R., Tarling, S., Barnes, P., and Henderson, E. (1991). "Treatment of organic-contaminated industrial wastes using cement-based stabilization/solidification-II. Microstructural analysis of the organophilic clay as a pre-solidification adsorbent." Waste Manage Res, 9(2), 113-125.

Moon, C. H., Lee, J. Y., Oh, B. T., and Choi, S. I. (2007). "Organically modified lowgrade kaolin as a secondary containment material for underground storage tanks." Environ Geochem Hlth, 29(4), 271-280.

Mortland, M. M., Shaobai, S., and Boyd, S. A. (1986). "Clay-Organic Complexes as Adsorbents for Phenol and Chlorophenols." Clay Clay Miner, 34(5), 581-585.

Musso, T. B., Roehl, K. E., Pettinari, G., and Valles, J. M. (2010). "Assessment of smectite-rich claystones from Northpatagonia for their use as liner materials in landfills." Appl Clay Sci, 48(3), 438-445.

Musy, G. (2008). "Leak detection methods for underground storage tanks." $<$ http://www.processonline.com.au/content/materials-handlinglogistics/article/leak-detection-methods-for-underground-storage-tanks$1227374745>$.

Nakagawa, K., Mukai, S. R., Suzuki, T., and Tamon, H. (2003). "Gas adsorption on activated carbons from PET mixtures with a metal salt." Carbon, 41(4), 823-831.

Nathalie Touze-Foltz, H. Z., Robert M Koerner (2012). "Special issue on GCLs." Geotextiles and Geomembranes, 33, P1.

Niaki, S. T. A., and Jahani, P. "Economic Design of MEWMA VSSI Control Charts for Multiattribute Processes." Proc., ICORES, 93-99.

Niaki, S. T. A., and Jahani, P. (2013). "The economic design of multivariate binomial EWMA VSSI control charts." J Appl Stat, 40(6), 1301-1318. 
Nzengung, V. A., NkediKizza, P., Jessup, R. E., and Voudrias, E. A. (1997). "Organic cosolvent effects on sorption kinetics of hydrophobic organic chemicals by organoclays." Environmental Science \& Technology, 31(5), 1470-1475.

Nzengung, V. A., Voudrias, E. A., Nkedi-Kizza, P., Wampler, J. M., and Weaver, C. E. (1996). "Organic Cosolvent Effects on Sorption Equilibrium of Hydrophobic Organic Chemicals by Organoclays." Environmental Science \& Technology, 30(1), 89-96.

Obiri-Nyarko, F., Grajales-Mesa, S. J., and Malina, G. (2014). "An overview of permeable reactive barriers for in situ sustainable groundwater remediation." Chemosphere, 111, 243-259.

Owabor, C. N., Ogbeide, S. E., and Susu, A. A. (2010). "Estimation of transport and degradation parameters for naphthalene and anthracene: influence of mass transfer on kinetics." Environ Monit Assess, 169(1-4), 607-617.

Oweis, I. S., and Khera, R. P. (1998). Geotechnology of waste management, PWS Publishers Co., Boston.

Palmer, B. G., Edil, T. B., and Benson, C. H. (2000). "Liners for waste containment constructed with class F and C fly ashes." J Hazard Mater, 76(2-3), 193-216.

Park, Y., Ayoko, G. A., and Frost, R. L. (2011). "Characterisation of organoclays and adsorption of p-nitrophenol: Environmental application." Journal of Colloid and Interface Science, 360(2), 440-456.

Peric, J., Trgo, M., and Vukojevic Medvidovic, N. (2004). "Removal of zinc, copper and lead by natural zeolite-a comparison of adsorption isotherms." Water Res, 38(7), 1893-1899.

Petrov, R. J., Rowe, R. K., and Quigley, R. M. (1997). "Comparison of laboratorymeasured GCL hydraulic conductivity based on three permeameter types." Geotech Test J, 20(1), 49-62.

Petrov, R. J., Rowe, R. K., and Quigley, R. M. (1997). "Selected factors influencing GCL hydraulic conductivity." J Geotech Geoenviron, 123(8), 683-695.

Phanikumar, B. R., and Shankar, M. U. (2016). "Studies on Hydraulic Conductivity of Fly Ash-Stabilised Expansive Clay Liners." Geotech Geol Eng, 34(2), 449-462.

Pickens, J. F., and Lennox, W. C. (1976). "Numerical-Simulation of Waste Movement in Steady Groundwater Flow Systems." Water Resour Res, 12(2), 171-180.

Powell, R. M., Blowes, D. W., Gillham, R. W., Schultz, D., Sivavec, T., Puls, R. W., Vogan, J. L., Powell, P. D., and Landis, R. (1998). "Permeable Reactive Barrier Technologies for Contaminant Remediation." U. S. Environmental Protection Agency, Washington, DC, 51.

Prasad, B., Sangeeta, K., and Tewary, B. K. (2012). "Fly Ash Zeolite as Permeable Reactive Barrier for Prevention of Groundwater Contamination Due to Coal Ash Disposal." Asian J Chem, 24(3), 1045-1050.

Puls, R. W. (2006). "Long-Term Performance of Permeable Reactive Barriers: Lessons Learned on Design, Contaminant Treatment, Longevity, Performance Monitoring and Cost - an Overview." 69, 221-229.

Qu, X., Liu, P., and Zhu, D. (2008). "Enhanced sorption of polycyclic aromatic hydrocarbons to tetra-alkyl ammonium modified smectites via cation-pi interactions." Environ Sci Technol, 42(4), 1109-1116. 
Rad, N. S., Jacobson, B. D., and Bachus, R. C. "Compatibility of Geosynthetic Clay Liners with Organic and Inorganic Permeants." Proc., In PROCEEDINGS OF THE INTERNATIONAL CONFERENCE ON GEOTEXTILES GEOMEMBRANES AND RELATED PRODUCTS.

Rao, P. S., Hornsby, A. G., Kilcrease, D. P., and Nkedi-Kizza, P. J. (1985). "Sorption and transport of toxic organic substances in mixed_solvent systems: Model development and preliminary evaluation." J. Environ. Qual., 14, 367-383.

Rao, P. S. C., Lee, L. S., and Pinal, R. (1990). "Cosolvency and Sorption of Hydrophobic Organic-Chemicals." Environmental Science \& Technology, 24(5), 647-654.

Redding, A. Z., Burns, S. E., Upson, R. T., and Anderson, E. F. (2002). "Organoclay sorption of benzene as a function of total organic carbon content." Journal of Colloid and Interface Science, 250(1), 261-264.

Richards, S., and Bouazza, A. (2007). "Phenol adsorption in organo-modified basaltic clay and bentonite." Appl Clay Sci, 37(1-2), 133-142.

Rodriguez-Cruz, M. S., Sanchez-Martin, M. J., Andrades, M. S., and Sanchez-Camazano, M. (2007). "Modification of clay barriers with a cationic surfactant to improve the retention of pesticides in soils." J Hazard Mater, 139(2), 363-372.

Rowe, R. K., Lake, C. B., and Petrov, R. J. (2000). "Apparatus and procedures for assessing inorganic diffusion coefficients for geosynthetic clay liners." Geotech Test J, 23(2), 206-214.

Rowe, R. K., Mukunoki, T., and Sangam, H. P. (2005). "Benzene, Toluene, Ethylbenzene,m\&p-Xylene,o-Xylene Diffusion and Sorption for a Geosynthetic Clay Liner at Two Temperatures." J Geotech Geoenviron, 131(10), 1211-1221.

Rowe, R. K., Quigley, R. M., Brachman, R. W., Booker, J. R., and Brachman, R. (2004). Barrier Systems for Waste Disposal Facilities, Taylor \& Francis Books Ltd (E \& FN Spon), London.

Ruhl, J. L., and Daniel, D. E. (1997). "Geosynthetic clay liners permeated with chemical solutions and leachates." J Geotech Geoenviron, 123(4), 369-381.

Sadeghi Ghari, H., and Shakouri, Z. (2016). "Testing and evaluation of microstructure of organoclay in chlorosulfunated polyethylene nanocomposites by emphasis on solvent transport properties." Journal of Vinyl and Additive Technology, n/a-n/a.

Santamarina, J., Klein, K., Wang, Y., and Prencke, E. (2002). "Specific surface: determination and relevance." Canadian Geotechnical Journal, 39(1), 233-241.

Santamarina, J. C., Klein, K. A., Wang, Y. H., and Prencke, E. (2002). "Specific surface: determination and relevance." Can Geotech J, 39(1), 233-241.

Sarkar, B., Xi, Y., Megharaj, M., Krishnamurti, G. S. R., Bowman, M., Rose, H., and Naidu, R. (2012). "Bioreactive Organoclay: A New Technology for Environmental Remediation." Critical Reviews in Environmental Science and Technology, 42(5), 435-488.

Schumacher, B. A. (2002). "METHODS FOR THE DETERMINATION OF TOTAL ORGANIC CARBON (TOC) IN SOILS AND SEDIMENTS ", Ecological Risk Assessment Support Center, Office of Research and Development.

Shackelford, C. D. (1994). "Critical concepts for column testing." Journal of Geotechnical Engineering, 120(10).

Shackelford, C. D. (1994). "Critical Concepts for Column Testing." J Geotech Eng-Asce, 120(10), 1804-1828. 
Shackelford, C. D. (1994). "Waste-soil interactions that alter hydraulic conductivity." Hydraulic conductivity and waste contaminant transport in soil, D. E. Daniel, and S. J. Trautwein, eds., ASTM, West Conshohocken, Pa., 111-168.

Shackelford, C. D. (1995). "Analytical models for cumulative mass column testing." In Geoenvironment 2000 Characterization, Containment, Remediation, and Performance in Environmental Geotechnics., ASCE, 355-372.

Shackelford, C. D., Benson, C. H., Katsumi, T., Edil, T. B., and Lin, L. (2000). "Evaluating the hydraulic conductivity of GCLs permeated with non-standard liquids." Geotextiles and Geomembranes, 18(2-4), 133-161.

Shackelford, C. D., and Daniel, D. E. (1991). "Diffusion in Saturated Soil. II: Results for Compacted Clay." Journal of Geotechnical Engineering, 117(3), 485-506.

Shackelford, C. D., and Redmond, P. L. (1995). "Solute Breakthrough Curves for Processed Kaolin at Low Flow Rates." Journal of Geotechnical Engineering, 121(1), 17-32.

Shan, S., and Daniel, D. E. "Results of laboratory tests on a geotextile/bentonite liner material." Proc., Geosynthetics Conference, 517-535.

Sharma, H. D., and Reddy, K. R. (2004). Geoenvironmental Engineering: Site Remediation, Waste Containment, and Emerging Waste Management Technologies.

Simon, F., and Meggyes, T. (2000). "Removal of organic and inorganic pollutants from groundwater using permeable reactive barriers Part 1. Treatment processes for pollutants." Land Contamination \& Reclamation, 8(3), 103-117.

Skinner, S. J. W., and Schutte, C. F. (2006). "The feasibility of a permeable reactive barrier to treat acidic sulphate- and nitrate-contaminated groundwater." Water Sa, 32(2), 129-135.

Slade, P. G., and Gates, W. P. (2004). "The swelling of HDTMA smectites as influenced by their preparation and layer charges." Appl Clay Sci, 25(1-2), 93-101.

Smith, J. A., Bartelt-Hunt, S. L., and Burns, S. E. (2003). "Sorption and permeability of gasoline hydrocarbons in organobentonite porous media." J Hazard Mater, 96(1), 91-97.

Smith, J. A., and Jaffe, P. R. (1994). "Adsorptive Selectivity of Organic-Cation-Modified Bentonite for Nonionic Organic Contaminants." Water Air Soil Poll, 72(1-4), 205211

Smith, J. A., Jaffe, P. R., and Chiou, C. T. (1990). "Effect of ten quaternary ammonium cations on tetrachloromethane sorption to clay from water." Environmental Science \& Technology, 24(8), 1167-1172.

Smith, J. A., Witkowski, P. J., and Chiou, C. T. (1988). "Partition of Nonionic OrganicCompounds in Aquatic Systems." Rev Environ Contam T, 103, 127-151.

Soule, N. M., and Burns, S. E. (2001). "Effects of organic cation structure on behavior of organobentonites." J Geotech Geoenviron, 127(4), 363-370.

Sposito, G. (1981). The thermodynamics of soil solutions, Oxford University Press.

Sreedharan, V., and Sivapullaiah, P. V. (2014). "Swell Behavior of Organo Clay and Organo Clay-Bentonite Mixtures." 1940-1950.

Standards, U. S. D. o. C. N. B. o. (1981). "standard x-ray diffraction powder patterns." U. S. Department of Commerce/National Bureau of Standards, Washington, DC. 
Suga, M., Asahina, S., Sakuda, Y., Kazumori, H., Nishiyama, H., Nokuo, T., Alfredsson, V., Kjellman, T., Stevens, S. M., Cho, H. S., Cho, M., Han, L., Che, S. N., Anderson, M. W., Schuth, F., Deng, H. X., Yaghi, O. M., Liu, Z., Jeong, H. Y., Stein, A., Sakamoto, K., Ryoo, R., and Terasaki, O. (2014). "Recent progress in scanning electron microscopy for the characterization of fine structural details of nano materials." Prog Solid State Ch, 42(1-2), 1-21.

Sun, D. a., Cui, H., and Sun, W. (2009). "Swelling of compacted sand-bentonite mixtures." Appl Clay Sci, 43(3-4), 485-492.

Suzuki, M. (1990). Adoption Engineering, KODANSHA LTD., Tokyo ELSEVIER SCIENCE PUBLISHERS B.V., Amsterdam.

Taylor, D. W. (1948). Fundamental of Soil Mechanics, Wiley, New York.

Technologies, A. o. B. C. (2017). "Assessment of Barrier Containment Technologies ", $<$ https://cluin.org/download/contaminantfocus/dnapl/Treatment_Technologies/Contai>.

Thierrin, J., Davis, G. B., and Barber, C. (1995). "A Ground-Water Tracer Test with Deuterated Compounds for Monitoring In Situ Biodegradation and Retardation of Aromatic Hydrocarbons." Ground Water, 33(3), 469-475.

Touze-Foltz, N., Zanzinger, H., and Koerner, R. M. (2012). "Special issue on GCLs." Geotextiles and Geomembranes, 33, P1-P1.

Triay, I. R., Meijer, A., Cisneros, M. R., Miller, G. G., Mitchell, A. J., Ott, M. A., Hobart, D. E., Palmer, P. D., Perrin, R. E., and Aguilar, R. D. "Sorption of Americium in Tuff and Pure Minerals Using Synthetic and Natural Ground waters." Proc., 2nd International Conference on Chemistry and Migration Behavior of Actinides and Fission Products in the Geosphere, 13.

Upson, R. T., and Burns, S. E. (2006). "Sorption of nitroaromatic compounds to synthesized organoclays." J Colloid Interface Sci, 297(1), 70-76.

USDOT (2015). "Beyond traffic: US DOT's 30 year framework for the future.", $<$ http://www.dot.gov/BeyondTraffic $\% 3 \mathrm{E} .>$.

Valocchi, A. J. (1985). "Validity of the Local Equilibrium Assumption for Modeling Sorbing Solute Transport through Homogeneous Soils." Water Resour Res, 21(6), 808-820.

Varank, G., Demir, A., Yetilmezsoy, K., Bilgili, M. S., Top, S., and Sekman, E. (2011). "Estimation of transport parameters of phenolic compounds and inorganic contaminants through composite landfill liners using one-dimensional mass transport model." Waste Manage, 31(11), 2263-2274.

Vidic, R. D., and Pohland, F. G. (1996). "Treatment walls." groundwater remediation technologies analysis center, Pittsburgh, PA.

Wagner, J., Chen, H., Brownawell, B. J., and Westall, J. C. (1994). "Use of Cationic Surfactants to Modify Soil Surfaces to Promote Sorption and Retard Migration of Hydrophobic Organic-Compounds." Environmental Science \& Technology, 28(2), 231-237.

Webb, P. A. (2003). "Introduction to Chemical Adsorption Analytical Techniques and their Applications to Catalysis." MIC Technical Publications.

Widomski, M. K., Stepniewski, W., Horn, R., Bieganowski, A., Gazda, L., Franus, M., and Pawlowska, M. (2015). "Shrink-swell potential, hydraulic conductivity and 
geotechnical properties of clay materials for landfill liner construction." Int Agrophys, 29(3), 365-375.

Wiles, M. C., Huebner, H. J., McDonald, T. J., Donnelly, K. C., and Phillips, T. D. (2005). "Matrix-immobilized organoclay for the sorption of polycyclic aromatic hydrocarbons and pentachlorophenol from groundwater." Chemosphere, 59(10), $1455-1464$.

Wilkin, R. T., and Puls, R. W. (2003). "Capstone Report on the Application, Monitoring, and Performance of Permeable Reactive Barriers for Ground-Water Remediation: Volume 1 Performance Evaluations at Two Sites.", U.S. Environmental Protection Agency, National Risk Management Research Laboratory, Cincinnati, $\mathrm{OH}, 135$.

Wiśniewska, M., and Stępniewski, W. (2007). The influence of lime, water-glass and clay addition of sealing properties of waste rock from Bogdanka, Francis and Taylor Group, London.

Wolfe, T. A., Demirel, T., and Baumann, E. R. (1986). "Adsorption of Organic Pollutants on Montmorillonite Treated with Amines." $J$ Water Pollut Con F, 58(1), 68-76.

Xue, W., He, H., Zhu, J., and Yuan, P. (2007). "FTIR investigation of CTAB-Almontmorillonite complexes." Spectrochim Acta A Mol Biomol Spectrosc, 67(3-4), 1030-1036.

Yang, X. Y., and Lo, I. M. C. (2004). "Flow of gasoline through composite liners." $J$ Environ Eng-Asce, 130(8), 886-890.

Ye, W. M., Zheng, Z. J., Chen, B., Chen, Y. G., Cui, Y. J., and Wang, J. (2014). "Effects of $\mathrm{pH}$ and temperature on the swelling pressure and hydraulic conductivity of compacted GMZ01 bentonite." Appl Clay Sci, 101, 192-198.

Younus, M. M., and Sreedeep, S. (2012). "Reevaluation and Modification of PlasticityBased Criterion for Assessing the Suitability of Material as Compacted Landfill Liners." J Mater Civil Eng, 24(11), 1396-1402.

Zhao, Q., and Burns, S. E. (2012). "Molecular dynamics simulation of secondary sorption behavior of montmorillonite modified by single chain quaternary ammonium cations." Environ Sci Technol, 46(7), 3999-4007.

Zhao, Q., Choo, H., Bhatt, A., Burns, S. E., and Bate, B. (2016). "Review of the fundamental geochemical and physical behaviors of organoclays in barrier applications."

Appl

Clay

Sci. 


\section{CURRICULUM VITAE}

\section{Sadra Javadi}

Civil and Environmental Engineering

University of Louisville

University of Louisville

W.S. Speed Room 100

Louisville, KY, 40292

Phone: (502) 852- 7956

Email: rfsj_ce@yahoo.com

\section{EDUCATION}

- Ph.D. Civil Engineering - Geotechnical, University of Louisville, Louisville, KY (GPA: 4.0/4.0)

Dissertation Title: Interaction between organic contaminant and organic surfactant with modified bentonite

- M.Sc. Geotechnical Engineering, K.N.Toosi University of Technology, Tehran, Iran (GPA: 4.0/4.0)

Thesis Title: Experimental investigation on uplift behavior of belled pile supported on Geocell reinforced-soil

- B.Sc. Civil and Environmental Engineering, University of Tabriz, Tabriz, Iran

\section{EMPLOYMENT}

- $\quad$ Ph.D. researcher (2013-Current), University of Louisville, Louisville, Kentucky.

$>$ Led the Ph.D. Geomechanics Laboratory research group under the supervision of Dr. Zhao

$>$ Trained fellow students on the knowledge and operation of Gas Chromatography (GC). The GC was new equipment within the geotechnical engineering laboratory.

$>$ Mastered the knowledge of contaminant attenuation mechanisms in liner and barrier systems (CCL, GCL, and PRB)

$>$ Modeled the organic contaminant transport through landfill systems using GEO-STUDIO

- Teaching Assistant (2014-Current), University of Louisville, Louisville, Kentucky.

$>$ Geomechanics - University of Louisville (Instructed by: Dr. Qian Zhao)

$>$ Environmental Geotechnics - University of Louisville (Instructed by: Dr. Qian Zhao)

$>$ Foundation Engineering - University of Louisville (Instructed by: Dr. Thomas Rockaway)

$>$ Structural Analysis - University of Louisville (Instructed by: Dr. Zhihui Sun)

$>$ Mechanics 1: Statics - University of Louisville (Instructed by: Dr. Mark French and Dr. Qian Zhao)

- Senior Geotechnical Engineer (2010-2012), GRANTEEN Consultant and Corporation Company, Tehran, Iran.

$>$ Led multi-disciplinary teams of individuals investigating geotechnical integrity of client sites

$>$ Supervised field exploration including CPT and SPT, soil sampling, and in situ testing

$>$ Conducted geotechnical laboratory analyses and interpreted results for meaningful recommendations

$>$ Prepared geotechnical reports, sharing key recommendations with clients for an estimated cost savings of approximately $\$ 10,000$ to $\$ 15,000$ per site

$>\quad$ Visited 5 to 8 sites per week, maintaining a highly productive schedule across GRANTEEN's various clients

$>$ Traveled to other cities to cover the requests from non-local clients

$>$ Performed geotechnical analyses such as bearing capacity, slope stability, lateral earth pressures, pile design, etc.

$>$ Supervised field operations including soil stabilization, foundation construction and cut-and-fill operations

$>$ Worked to find practical and economical solutions for site specific geotechnical conditions

$>$ Performed stabilization operation using nail-anchorage and soldier pile systems for

$>$ Worked on many high profile projects including the Atlas Mall Project, a colossal excavation project in Iran which required a 120 -foot-deep excavation over a 2.5 -acre site

- Geotechnical Engineer (2009-2012), Soil Mechanics Industries (SMI), Tehran, Iran.

$>$ Performed field soil sampling. Worked with the drillers to modify procedures to improve the reliability and quality of testing data

$>$ Prepared geotechnical reports and client recommendation to optimize site development

$>$ Performed geotechnical laboratory tests including consolidation, triaxial, atterberg limits, etc.

- Teaching Assistant (2009-2011), K. N. University of Technology, Tehran, Iran. 
> Advanced Engineering Mathematics - K. N. Toosi University of Technology (Instructed by: Dr. Naser Maghaddas Tafreshi)

$>$ Foundation Engineering - K. N. Toosi University of Technology (Instructed by: Dr. Naser Maghaddas Tafreshi)

- Internship (Summer 2008), Sazehaye Pol CO., Tehran, Iran.

$>$ Controlled the structural drawings based on the original design, and developed at least $15 \%$ of accuracy

$>$ Estimated the required steel for different projects under the supervision of senior structural engineer

$>$ Collected and consolidated daily reports from different construction teams working in other cities

\section{Computer Skills}

$>$ Revit $>>$ AUTOCAD $>>$ ABAQUS $>>$ MATLAB

$>$ Microsoft Office Suite (Access, Excel, FrontPage, PowerPoint, Visio, Word)

\section{PROFESSIONAL ACTIVITIES}

- $\quad$ Student Member of American Society of Civil Engineering (ASCE)

- Student Member of Computational Geotechnics, Geo-Institute of ASCE

- Reviewer of "Journal of Environmental Chemical Engineering," 2015- present

- $\quad$ Registered in Civil Engineer committee of Sharif University of Tehran, Iran, 2009- present

\section{HONORS AND AWARDS}

- $\quad$ Nominated for outstanding Ph.D. student- University of Louisville - $(2015$ - 2016)

- $\quad$ Selected Ph.D. student - Department of Civil \& Environmental Engineering - University of Louisville - (2015 2016)

- The Geosynthetic Institute Fellowship - Geosynthetics Institute - (2015 - 2016)

- $\quad$ Graduate Student Council Scholarship - University of Louisville - Spring 2014

- $\quad$ Grosscurth Scholarship - University of Louisville - $(2013-2015)$

\section{ADDITIONAL RESEARCH PROJECTS}

- Investigation on interlocking effect on bending plate

- $\quad$ Numerical modeling of Escherichia Coli (E.Coli) propagation in soil

- Numerical modeling of Geogrid-reinforced rail tracks

- $\quad$ Physical modeling of pile-soil-pile interaction

\section{PUBLICATIONS}

- Javadi, S., Abonoori, A.(2011). "Numerical and analytical solutions of partial differential equations." In the Persian language. BOOK ISBN No. 978-964-04-7735-9.

- Javadi, S., Shabanzad, H.(2011). "Principals of Geosynthetics Engineering.”'In the Persian language. BOOK ISBN No. 978-964-04-7736-6.

- Sadra Javadi, Seyed Naser Moghaddas Tafreshi "Laboratory investigation of the uplift behavior of belled piles in reinforced sand." 3rd International Conference on New Developments in Soil Mechanics and Geotechnical Engineering, 28-30 June 2012, Near East University, Nicosia, North Cyprus.

- Boudaghpour, S., Javadi, S., Ebrahimi, M., “Application of Prefabricated Materials in Building Construction on the basis of Green Construction Approaches in order to Improve Construction Safety and Decrease Adverse Environmental Effects." Accepted for oral presentation at 2nd National Congress on Building Safety (Design, Building, Operation), Iran, November 2010

- $\quad$ Boudaghpour, S., Javadi, S., Ebrahimi, M., “Air Pollution Forecasting of Tehran's District 12 by Using Artificial Intelligence Neural Network Software". Accepted for oral presentation at 6th National Congress on Civil Engineering, Iran, April 2011.

- Moghaddas Tafreshi, S., Javadi, S., \& Dawson, A. R. (2014, June). Influence of geocell reinforcement on the uplift response of belled piles. Acta Geotechnica, Volume 9 (Issue3), 513-528.

- Javadi, S., Abdollahian, S., Ghavami, M., Rockaway, T., Zhao, Q., (2016) "Effectiveness of heavy metal removal in Urban Permeable Pavement Systems." Accepted for publication and presentation in ASCE, GEO-CHICAGO August $14-182016$.

- $\quad$ Ghavami, M., Javadi, S., Zhao, Q., (2016) "Laboratory Characterization of Saturated Conductivities of Compacted Clay- Organobentonite mixtures." Accepted for publication and presentation in ASCE, GEO-CHICAGO August $14-182016$.

- Javadi, S., Ghavami, M., Zhao, Q., Bate. B, S., (2016) "Advection and Retardation of non-polar contaminants in Compacted Clay Barrier material with Organoclay amendment," under review in Journal of Applied Clay Science.

- Javadi, S., Ghavami, M., Zhao, Q., (2017) "Sorption and transport of benzene through reactive geosynthetic clay liner (GCL)." Submitted to ASCE, Geotechnical Frontiers March 12 - 152017.

- Shang, H., Javadi, S., Zhao, Q., (2017) "Organic surfactant modified zeolite as permeable reactive barrier component-a laboratory study." Submitted to ASCE, Geotechnical Frontiers March 12 - 152017. 
- Ghavami, M., Zhao, Q., Jangam, J. S. D., Jasinski, J. B, Saraei, N., Javadi, S., (2016) "Change of Organobentonite Interlayer Microstructure Induced by Sorption of Aromatic Hydrocarbon and Petroleum Hydrocarbons - A Combined Study of Laboratory Characterization and Molecular Dynamics Simulations", under review in Journal of Langmuir.

- $\quad$ Ghasemzade, H., Abdollahian, S., Shabanzad, H., Javadi, S., (2016) "Experimental investigation on the effect of added fractions of favorable minerals on the transport of E. coli in saturated porous media", under review in Journal of Contaminant Hydrology.

- Ghavami, M., Mohd Nayan, K., A., Kadir, M., I., Javadi, S., (2016) "Determination of Allowable Bearing Capacity of Shallow Foundation Using a Modified Hyperbolic Stress-Strain Model," under review in European Journal of Environmental and Civil Engineering. 